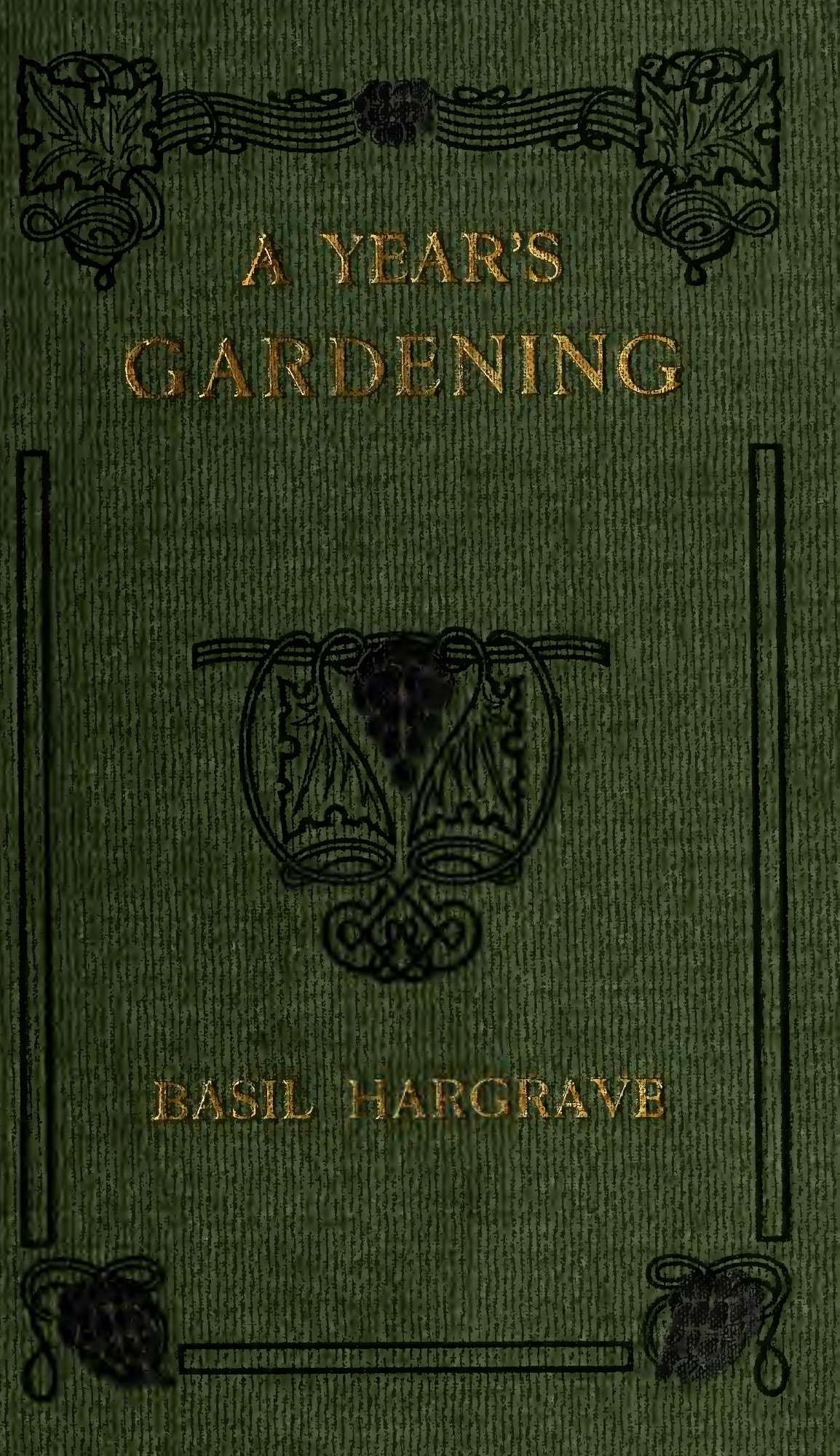




$$
\delta
$$





$$
\text { El- }
$$





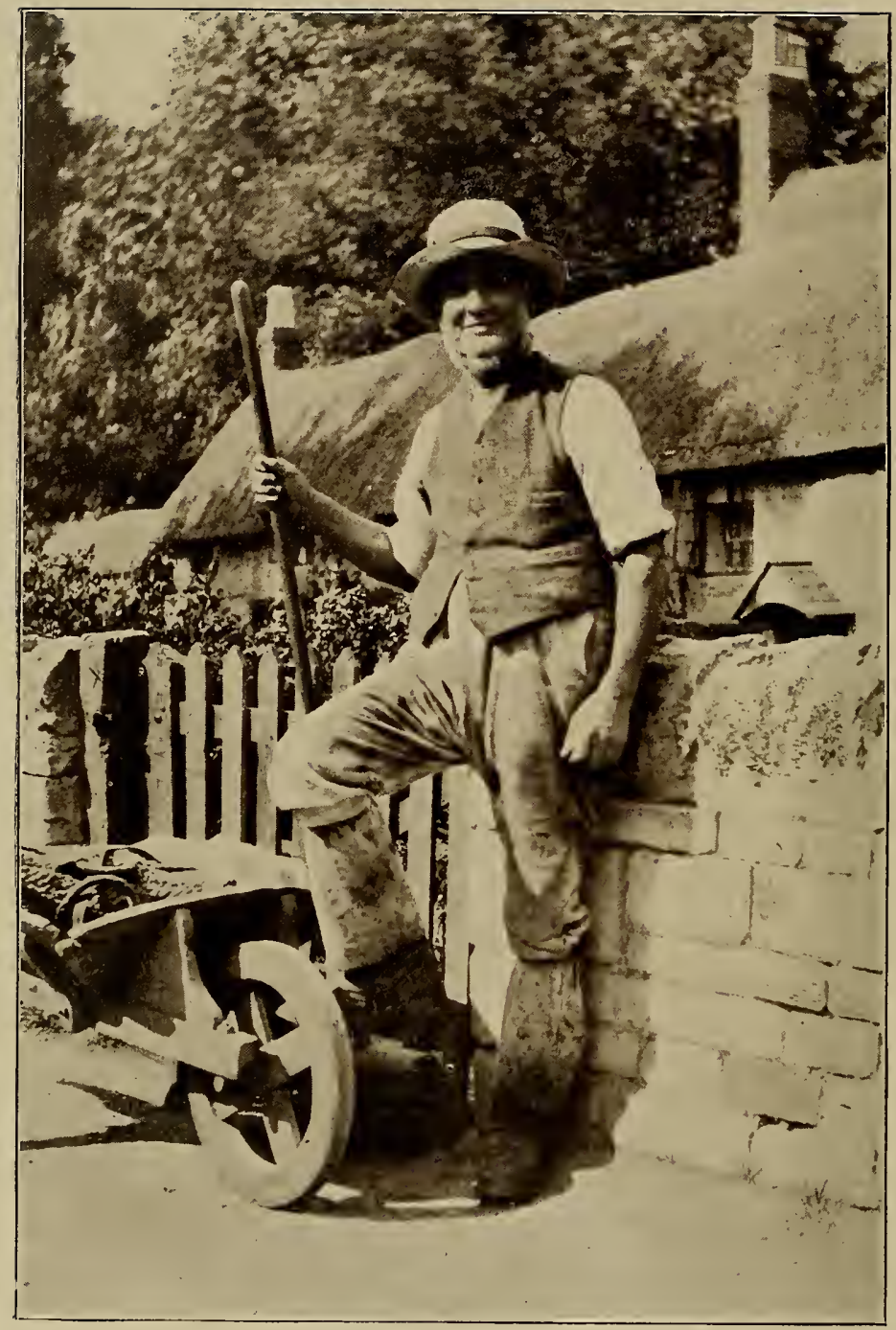

THE JOBBING GARDENER. 


\section{A \\ YEAR'S GARDENING}

BY

BASIL HARGRAVE

FULLY ILLUSTRATED

NEW YORK : CHARLES SCRIBNER'S SONS LONDON : T. WERNER LAURIE 


$$
5^{8 x^{5^{3}}}+x^{30}
$$

19ong 


\section{CONTENTS}

A Calendar giving a Series of Jobs for Each Day in THE YEAR.

Alpine, Rock and Wall Gardens . . . . . 107

The Wild Garden and the Spring GaRden . . . 112

Gardening in Window-boxes, Ornamental Pots, Tubs AND BOWLS $\quad . \quad$. $\quad . \quad$. $\quad . \quad$. 116

LaWNS : Their Making, MaINTAINING AND Renovation • i2I

Fruit Trees: Their Planting, Training, Pruning and RENOVATION $. \quad . \quad$. $\quad . \quad$.

Bush Fruit : Gooseberries, Currants and Raspberries • I 36

Fruit Destroyers and Garden Pests . . . . 140

The Vegetable Garden Month by Month . • . 147

An Alphabetical and Descriptive List of Flowers, with HiNTS ON THEIR Cultivation . . . . . 173

INIEX . $\quad . \quad$. $\quad . \quad$. . . . . 267 



\section{LIST OF ILLUSTRATIONS}

The JobBing GaRdener

Frontispiece FERNS IN A COPPICE RIDE . . . . . T Tace page 8 OUR WeEk-end Cottage-As We Found It . . " 20 OUR WeEk-end Cottage-Two Years Later. . " 20

A GaRden in THE MAKING - PERgola AND SPRING GARDEN (FIRST STAGE) . . . . . . .

A Garden in the MAKING - Pergola and Spring GARDEN TWO YeARS LATER . . . . " " MidSUMMER IN THE GARDEN . . . . . OUR Week-end Cottage-The Path to the FrontDOOR

Our Week-end Cottage-The Porch at the SideDOOR

OUR WEEK-END COTTAGE-A BORDER OF HOLLyHOCKS OUR Week-end Cottage-Entrance to the Pergola In a Country Garden-The Bridge, With Glimpse OF HERBACEOUS BORDER SHRUBS AT WisLey . 58

IN THE WILD GARDEN-A ROSE LEFT TO ITS OWN SWEET WILL

In a Country Garden-A Glimpse of Stream, BeechTREES AND DRIVE

Steps to the Rock GaRden-"Sicily in England". In the Rock Garden-Double White ARabis NATURE'S GARDEN-WILD ROSES . IN THE WILD GARDEN-WISLEY A COTTAGER'S GARDEN In a COUntry GaRden - Massed Rhododendrons BACKED BY YeW AND WEEPING ASH 


\section{LIST OF ILLUSTRATIONS}

IN A COUNTRY GaRDEN-Herbaceous BORDER AND

RHODODENDRON BED SLOPING TO STREAM .

To face page 126

A Water-Side Path

An Avenue of Pines

A Water-lily PoOL

When MEN Built Stately Houses

I 36

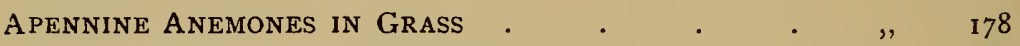

White Campanula (Persicifolia grandiflora) . . " " 186

A GOOD BEGINNING - SPRING BORDER AND ROCK

GARDEN • •

In a Country Garden-Grass Path bordered by DELPHINIUMS

In a Country Garden-A Wild Border of FoXgloves

IN THE WILD GARDEN-A TYPICAL VIEW

146

160

172

In a Suburban Garden-Madonna Lilies

In a Suburban Garden-Euphrosyne Rose over ARBOUR .

186

in a Country Garden-Tree Lupin Grown from SEED

In a Suburban Garden-Bush of White Michaelmas DAISIES

In a Suburban Garden-A Fine Clump of Iris .

PeEONy (Carnea Elegans Triumphans)-PINK PETAlS AND SUlPHUR-COLOURED CENTRES

SPIRAEA (S. Thunbergi)-SPRING-FLOWERING : CRIMSON

A Wild Patch of Garden - Canterbury Bells, Campanulas and Sweet-Williams .

In a Suburban Garden-A Wild Corner-Poppies.

Clipped Yews at leven's Hall.

A WoOdland Bog GaRden 


\section{A CALENDAR}

\section{GIVING A SERIES OF JOBS FOR EACH}

\section{DAY IN THE YEAR}

\section{JANUARY I}

Greenhouse and Frames.-Wash roof and sides of the house to remove accumulated soot and dirt; see that the coverings for lights are in proper condition.

Vegetable and Fruit Garden.-Walk round the garden and consider what are the best arrangements for the coming year. Look over seeds in hand and make a list of what must be ordered.

Flower Garden.-Take a general survey, bearing in mind last year's effect, and decide if any alterations are required in shape and size of flower-beds, paths, etc.

\section{JANUARY 2}

Greenhouse and Frames.-Re-arrange plants in house if necessary. Bulbs for early flowering should be placed in a warm and sheltered position. Sow Kidney Beans in 4 -in. pots in a hot-bed made as if for Cucumbers.

Vegetable and Fruit Garden.--Look through tools and decide what must be replaced or repaired. Look through seed potatoes and other roots.

Flower Garden.-Examine the lawns and see if anything has been neglected in the autumn renovation.

\section{JANUARY 3}

Greenhouse and Frames.-Clear up all litter on floor and shelves of house and remove dead leaves from plants. Sow Early Horn Carrots in a hot-bed. 


\section{A YEAR'S GARDENING}

Vegetable and Fruit Garden.-Look through pea-sticks and stakes and decide what further supply will be needed.

Flower Garden.-Gently stir with a small fork the surface of the beds stocked with herbaceous plants.

\section{JANUARY 4}

Greenhouse and Frames.-Look to the heap of compost for spring potting and see that it is thoroughly dry. Sow Radishes for succession in frame.

Vegetable and Fruit Garden.-Collect and burn all refuse and rubbish, storing the ashes in a dry place for future use.

Flower Garden.-If any beds intended for bedding-out plants have not been manured they should be done now.

\section{JANUARY 5}

Greenhouse and Frames.-Wash and dry pots which will be required, and prepare stakes, labels, etc. Sow Early Peas in 4-in. pots placed in a frame.

Vegetable and Fruit Garden.-If any ground still needs trenching and manuring start to-day.

Flower Garden.--Plant Crocuses and any other hardy bulbs to succeed those planted in the autumn.

\section{JANUARY 6}

Greenhouse and Frames.-Prepare hot-beds for forcing Sea-kale.

Vegetable and Fruit Garden.-Continue digging and preparing ground.

Flower Garden.-Where autumn-planted bulbs are beginning to show, protect them from frost with light litter.

\section{JANUARY 7}

Greenhouse and Frames.-Look over all the plants in house and exterminate vermin of any kind. Beware of mildew-free ventilation is the remedy. 


\section{A CALENDAR}

Vegetable and Fruit Garden.-Prepare a piece of ground for sowing Parsnips.

Flower Garden.-Look to the paths and decide whether the gravel must be renewed or turned, and act accordingly.

\section{JANUARY 8}

Greenhouse and Frames.-Look through Azaleas and advance them by greater heat, if required. Plant Potatoes in frame for an early crop.

Vegetable and Fruit Garden.-In a warm dry soil make first sowing of Early Long-pod Broad Beans.

Flower Garden.-Continue the repair of gravel paths.

\section{JANUARY 9}

Greenhouse and Frames.-Look through Cinerarias; if large plants are required, transplant into larger pots and pinch off tops to produce bushy heads.

Vegetable and Fruit Garden.-Put a fresh top-dressing of halfrotted manure on Asparagus bed.

Flower Garden.-Prune Honeysuckle and cut out old and decayed branches from Lilac bushes, but do not interfere with last year's shoots.

\section{JANUARY ro}

Greenhouse and Frames.-Sow seeds of tuberous Begonias, Fuchsias and Pelargoniums. Sow Cucumber seeds in hot-bed for bearing in three months' time.

Vegetable and Fruit Garden.-Make a small sowing of Early Peas in a favourable spot.

Flower Garden.-Nail and train creepers to wall and fences where they require it.

\section{JANUARY II}

Greenhouse and Frames.-Sow seeds of Gloxinias for flowering the same season, and proceed with potting off singly all cuttings of Geraniums, Verbenas, etc., now in store-pots. 


\section{A YEAR'S GARDENING}

Vegetable and Fruit Garden.-Look through early-grown Broccoli and take up any that is nearly fit for use, storing it in a shed so as to preserve from frost.

Flower Garden.-Look to the Rock Garden and make any structural repairs that may be desirable.

\section{JANUARY I2}

Greenhouse and Frames.-Sow seeds of Tomatoes for producing plants for fruiting indoors, and plant Sea-kale in hot-bed already prepared.

Vegetable and Fruit Garden.-If weather and soil be favourable, sow, in a warm border, a little of an early variety of Carrot and Turnip seed.

Flower Garden.-Look over carefully the individual plants in the Rock Garden and divide or re-arrange them in more suitable positions where required.

\section{JANUARY I3}

Greenhouse and Frames.-Look through Calceolarias and prick off those sown for late autumn blooming. Sow Cos Lettuce in hotbed.

Vegetable and Fruit Garden.-If the weather continues open, risk sowing a few Onions and Radishes for salads; also a little Parsley.

Flower Garden.-Plant groups of Primroses, Polyanthus and Daisies to fill up vacant spaces on rough banks or in the wild garden.

\section{JANUARY I4}

Greenhouse and Frames. - Shift into larger pots those Calceolaria seedlings which are sufficiently advanced. Take cuttings of pot Chrysanthemums.

Vegetable and Fruit Garden.-Unless there is an appearance of immediate frost, make small sowings of Lettuce and Endive in a warm border, covering with a hand-light or some litter.

Flower Garden.-Plant early flowering Gladioli and German Irises in suitable groups. 


\section{A CALENDAR}

\section{JANUARY I5}

Greenhouse and Frames.-Start a few Strawberry plants in pots in a cool corner of the house. Make a sowing of Broad Beans in the frame for an early crop.

Vegetable and Fruit Garden. - Examine full-grown plants of Endive and protect them with slates or tiles, further covering them with litter to blanch them.

Flower Garden.-Plant hardy creepers wherever they may be desirable.

\section{JANUARY I6}

Greenhouse and Frames.-Sow Cucumber seeds in the house in a temperature of $65^{\circ}$ to $70^{\circ}$. Introduce a few stools of Rhubarb under the staging of the house for forcing.

Vegetable and Fruit Garden.--Gather up dead leaves, remove stumps of Cabbage, etc., and hoe up weeds among the growing crops.

Flower Garden.-If top-dressing of lawns has not already been done, do it to-day.

\section{JANUARY I7}

Greenhouse and Frames.-Sow seeds of Antirrhinum, Verbena and Petunia for planting out later. Uncover bulbs which have been stored and are beginning to show active growth.

Vegetable and Fruit Garden.-Earth up any Celery which requires it.

Flower Garden.-Give some attention to shrubberies by seeing that the ground is in good condition. If the soil be poor, apply a light dressing of manure and gently fork in with it the fallen leaves, but do not disturb the roots of the bushes. Deep digging is injurious.

\section{JANUARY I8}

Greenhouse and Frames.-Sow seeds of Cyclamen, Carnation and Canna. Sow small salad (Mustard and Cress) round the edges of Carrots and Potatoes, or in a separate small frame. 


\section{A YEAR'S GARDENING}

Vegetable and Fruit Garden.-Cover Sea-kale and Early Rhubarb with pots and further protect them with soil and leaves for blanching.

Flower Garden.-Continue work in shrubbery and be sure that the fallen leaves are used as suggested in yesterday's directions; there is no better fertilizer than leaf manure.

\section{JANUARY I9}

Greenhouse and Frames.-Look through Pelargoniums and shift into larger pots those which are strongly rooted. Stop some of the plants required for succession and thin out weak shoots.

Vegetable and Fruit Garden.--If there are any young Peas coming up which were sown in October, give a mulching to protect the roots and cover them with light litter.

Flower Garden.-Look to any newly-planted shrubs and see that their roots are protected from frost by manure or litter, if this has not already been done.

\section{JANUARY 20}

Greenhouse and Frames.-If greenhouse mosses, such as Selaginellas, are grown, they may now be propagated by planting shoots half an inch apart in pans filled with compost of sandy loam and leaf mould. See that hot-beds are retaining proper heat; if not, put a lining of manure against the sides.

Vegetable and Fruit Garden.--Sow two or three rows of Spinach between the rows of Peas and Beans.

Flower Garden.-Look to the hedges-whether they are privet or thorn-and clear the bottom of all weeds and rubbish, pruning and trimming them where necessary.

\section{JANUARY 2I}

Greenhouse and Frames.-Protect the expanding buds of Camellias; give a dose of tepid manure water and syringe the plants with warm water. Sow Lettuce and Endive seed in a hot-bed.

Vegetable and Fruit Garden.-Lift and divide Mint, re-planting it in fresh bed. 


\section{A CALENDAR}

Flower Garden.-If increase of flowering trees and shrubs be required, make use of any prunings from shrubberies and hedges, if the weather be favourable, by planting them in a reserve piece of ground. By the spring many of them will have taken root and become strong plants by the autumn.

\section{JANUARY 22}

Greenhouse and Frames.-Cut back old Fuchsias so as to induce them to shoot anew preparatory to re-potting. If space has not been found for Strawberry-plants in the house they may be put into pots and placed in a frame.

Vegetable and Fruit Garden.-Attend to Strawberry bed. Gently loosen the earth between the plants with a small fork and mulch plentifully with long litter.

Flower Garden.-Examine the plants in the herbaceous border and divide, where desirable, such hardy perennials as Michaelmas Daisies, Phloxes, Lupins, Sunflowers, Pyrethrums, etc.

\section{JANUARY 23}

Greenhouse and Frames.--Strike cuttings of any bedding plants which may be suitable for the purpose, giving gentle bottom heat in a moist atmosphere.

Vegetable and Fruit Garden.-Prune the hardier kind of fruit trees if the weather is open and free from severe frost.

Flower Garden.-Prepare beds for planting Ranunculus and Poppy Anemones by deep digging and working in cow-dung or wellrotted other manure.

\section{JANUARY 24}

Greenhouse and Frames.-Pot crowns of Lily of the Valley where they will have sufficient heat, in order that they may bloom in six or seven weeks' time.

Vegetable and Fruit Garden.-Continue yesterday's pruning operations.

Flower Garden.-Continue yesterday's operations and plant tubers of Ranunculus, placing them claw-side downwards about 2 inches deep and 4 inches apart. 


\section{A YEAR'S GARDENING}

\section{JANUARY 25}

Greenhouse and Frames. - Prepare hot-bed for forcing Asparagus.

Vegetable and Fruit Garden.-Mulch the ground around Gooseberry and Currant bushes with half-rotten manure.

Flower Garden.-Complete the last two days' work by planting Poppy Anemones about 2 inches deep and 6 inches apart.

\section{JANUARY 26}

Greenhouse and Frames.-Pot corms of Gladiolus in compost of sandy loam and cover with cocoa-nut fibre.

Vegetable and Fruit Garden.-Protect the buds of the Gooseberry and Currant bushes from the depredations of birds by winding black cotton among the branches of the bushes.

Flower Garden.-Look to the Carnations, and if they are beginning to make shoots, protect them from the attacks of birds by fixing a few sticks around them and by winding several strands of black cotton from stick to stick.

\section{JANUARY 27}

Greenhouse and Frames.-Sow Fern spores in seed-pans, covering with piece of glass shaded by paper, as they germinate more quickly in the dark.

Vegetable and Fruit Garden.-Make a fresh plantation of Raspberry canes.

Flower Garden.--Sow Sweet Peas in a warm border for early flowering.

\section{JANUARY 28}

Greenhouse and Frames.-Look through Ferns and pot any requiring it. Look to the Mushroom beds and see that they have sufficient covering to protect them from frost.

Vegetable and Fruit Garden.--Prune out-door Vines, unless already done, as if longer deferred the sap will have begun to rise and the wounds made by pruning will be likely to bleed.

Flower Garden.-Prepare beds for the main sowing of hardy annuals. 


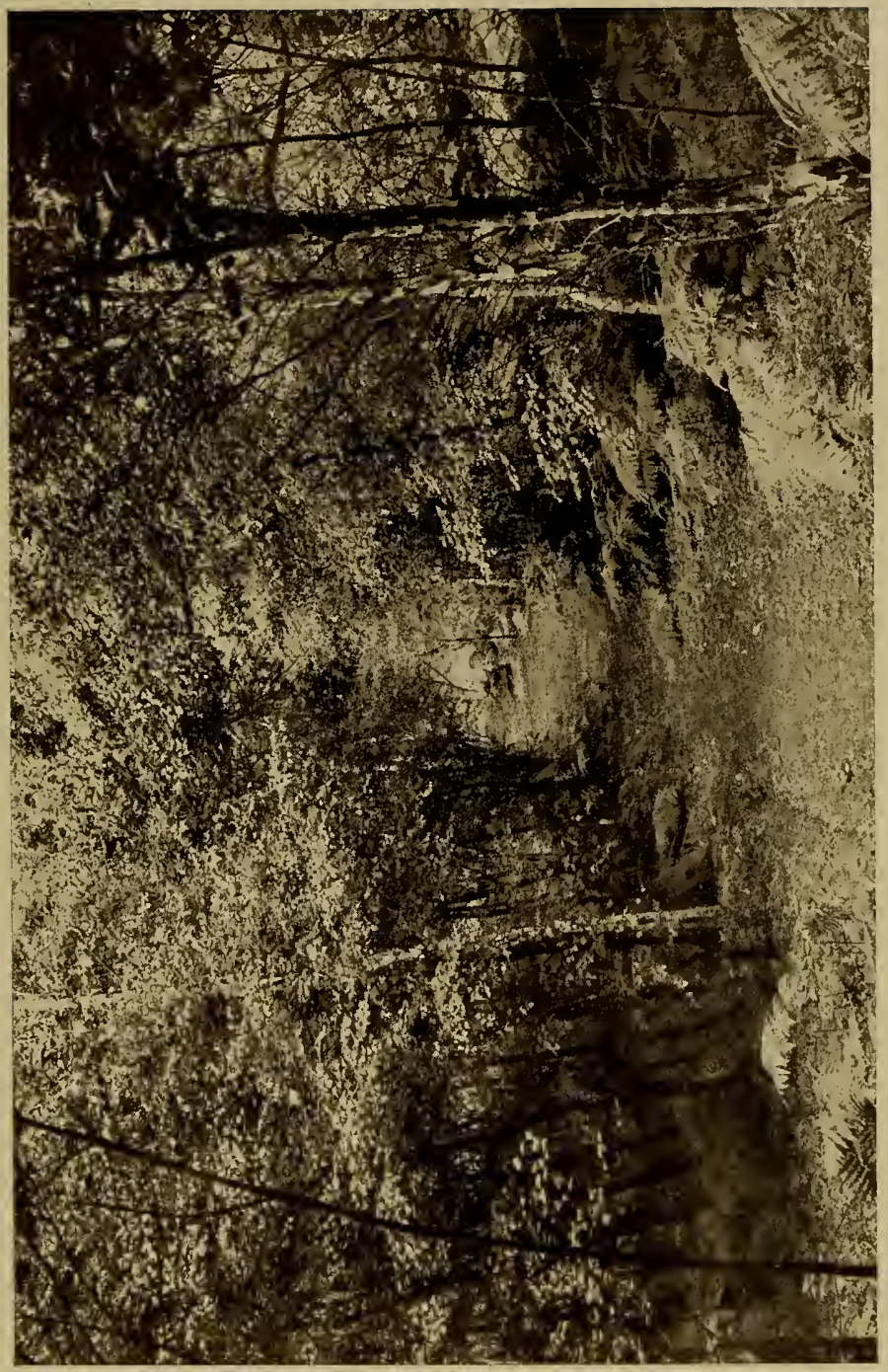





\section{A CALENDAR}

\section{JANUARY 29}

Greenhouse and Frames.-Prune Roses, cutting back shoots to the nearest dormant bud.

Vegetable and Fruit Garden.-Scions of Vines from yesterday's pruning should be put by the heels in a sheltered place for future grafting, if required.

Flower Garden.-Look to the Rose trees and prune back any which seem weakly.

\section{JANUARY 30}

Greenhouse and Frames.-Give a top-dressing of manure to all Roses planted indoors, either in tubs or beds, and see that the soil is previously well loosened.

Vegetable and Fruit Garden.-Decide if any old fruit trees are to be grafted in March, and if so, cut back their main branches to within 2 or 3 feet of their base.

Flower Garden.-Fork over gently the Rose beds, taking care not to injure the roots, and draw up the earth round the dwarf Tea Roses so as to protect the base of shoots.

\section{JANUARY 3I}

Greenhouse and Frames.-Sponge the leaves of all foliage plants with tepid water, to which may be added a little milk to give a glossy surface.

Vegetable and Fruit Garden.--Look through Cabbages, planting out any which are ready and filling up gaps in autumn planting.

Flower Garden.-Well manure the Rose beds.

\section{FEBRUARY I}

Greenhouse and Frames.-See that the roof of the house is clean -light, at this time of year, is of much value to the plants.

Vegetable and Fruit Garden.-Go over the garden and dig up any patch of unweeded ground before the weeds begin to flower, and thus make them useful for manure.

Flower Garden.-Plant and renovate edgings, such as Box, Thrift, London Pride, etc. 


\section{A YEAR'S GARDENING}

\section{FEBRUARY 2}

Greenhouse and Frames.-Look through the plants in the house and wash the leaves of those which need it.

Vegetable and Fruit Garden.-Plant Jerusalem Artichokes in any waste ground or corner of the garden which may be suitable for them.

Flower Garden.-Top-dress hardy Ferns with leaf-mould or welldecayed manure.

\section{FEBRUARY 3}

Greenhouse and Frames.-Make a careful inspection for green-fly, especially on Calceolaria and Cineraria.

Vegetable and Fruit Garden.-If the ground be dry enough, plant a few rows of Potatoes for an early crop.

Flower Garden.-Top-dress Ivy grown as edging with loam and well-rotted manure.

\section{FEBRUARY 4}

Greenhouse and Frames.-Look to the Strawberry plants. They should now be put near the glass and given as much air as possible.

Vegetable and Fruit Garden.-Prune nut bushes-such as Filberts and Cobnuts-cutting away shoots or branches that have borne catkins only.

Flower Garden.-Plant Herbaceous Phloxes, first digging soil two spits deep and putting in a layer of rotten manure between first and second spit.

\section{FEBRUARY 5}

Greenhouse and Frames.-Make a fresh potting of Strawberry plants for fruiting in April.

Vegetable and Fruit Garden.-If the pruning of fruit trees was not completed last month it should now be done without delay.

Flower Garden.--Attend to herbaceous borders, gently forking over the ground. Divide and re-arrange the plants where necessary. 


\section{A CALENDAR}

\section{FEBRUARY 6}

Greenhouse and Frames.-Look to the autumn-made cuttings and transplant them into the pots in which they are to flower.

Vegetable and Fruit Garden.-Look to the Peach, Apricot and Nectarine trees, and un-nail and prune them one by one.

Flower Garden.-Apply slaked lime to any vacant borders at the rate of a shovelful to the square yard. It will prove an excellent sweetener to the ground.

\section{FEBRUARY 7}

Greenhouse and Frames.-Make cuttings of all kinds of beddingout plants which it is desired to propagate.

Vegetable and Fruit Garden.-Continue yesterday's task.

Flower Garden.-Guard Crocuses, Tulips, Hyacinths, etc., from the attacks of mice, by plunging in the earth jars half filled with water to serve as traps; of sparrows, by spreading light netting; and of snails by laying down Cabbage leaves, which must be examined every night.

\section{FEBRUARY 8}

Greenhouse and Frames.-Look to the Chrysanthemum cuttings, as those which have made root should now be re-potted in light sandy soil.

Vegetable and Fruit Garden.-Mulch the whole of the borders in which fruit trees are growing; just round the stems of the trees is insufficient.

Flower Garden.-Sweep and roll turf and gravel to consolidate after frost.

\section{FEBRUARY 9}

Greenhouse and Frames. - Remove all dead wood from the climbers and train the new shoots into their proper places.

Vegetable and Fruit Garden.-If Raspberry canes have not already been pruned they should be done now.

Flower Garden.-Top-dress, turn, renew and re-lay the grass edgings of walks. 


\section{A YEAR'S GARDENING}

\section{FEBRUARY Io}

Greenhouse and Frames.--Remove any bulbs which have flowered to take their rest in a cold frame.

Vegetable and Fruit Garden.-If it is desired to make a new Strawberry bed, do it now.

Flower Garden.--Look to the lawn and repair any bare patches by means of turf or seed.

\section{FEBRUARY II}

Greenhouse and Frames.-Sow half-hardy annuals either in the house or a frame.

Vegetable and Fruit Garden.-Sow Broad Beans for early crops, choosing the driest and warmest situation.

Flower Garden.-Prune the hardier kind of Roses.

\section{FEBRUARY I2}

Greenhouse and Frames.-Continue the sowing of half-hardy annuals.

Vegetable and Fruit Garden.-Sow Early Peas for succession.

Flower Garden.-Give a plentiful top-dressing to Roses and plant hardier kinds, if this has not already been done.

\section{FEBRUARY I3}

Greenhouse and Frames.-Sow Nicotiana affinis, Verbena, Petunia and Lobelia, bearing in mind that a temperature of $65^{\circ}$ to $70^{\circ}$ is required for them.

Vegetable and Fruit Garden.--Look over Peas already coming up, and if in bad condition dig them in and sow again. Stick those that are doing well for further protection.

Flower Garden.-Look to evergreen and deciduous shrubs, cutting away any dead twigs or branches with a sharp knife. If it be necessary to use a saw, smooth down the cut afterwards with the knife. 


\section{A CALENDAR}

\section{FEBRUARY I4}

Greenhouse and Frames.-See that the Arum Lilies have a dose of liquid manure, and continue this for some time once or twice a week.

Vegetable and Fruit Garden.-Sow Parsnips in deeply-dug ground.

Flower Garden.-Plant Ivy where required, also such shrubs as Box, Cypress, Ribes, etc. The green-leaved Ivy will thrive in any aspect, but the variegated sort prefers a west or north aspect.

\section{FEBRUARY I5}

Greenhouse and Frames.-Sow seeds of Tomatoes in pans and apply water carefully day by day until the young plants appear.

Vegetable and Fruit Garden.-Sow Lettuce on a warm border and plant out from frames any that may be ready for removal.

Flower Garden.-Make a sowing of Sweet Peas for succession.

\section{FEBRUARY I6}

Greenhouse and Frames.-Thin and train the shoots of Pelargoniums. See that all forced and protected crops have sufficient air.

Vegetable and Fruit Garden.-Make fresh plantation of Rhubarb by dividing old stools, taking care to leave untouched enough for use during coming season.

Flower Garden.--Sow the hardier kind of annuals if the weather be suitable.

\section{FEBRUARY I7}

Greenhouse and Frames.-Stir the surface round such plants as Cauliflowers, Lettuces, etc., in frames, and dress the soil with soot and lime to destroy slugs.

Vegetable and Fruit Garden.-Make a new bed for Sea-kale in rows about $2 \mathrm{ft} .6 \mathrm{in}$. apart.

Flower Garden. - Look to the beds of hardy annuals and biennials sown last summer and weed them, if necessary, giving the young plants a mulching of light manure to protect them and to strengthen them for blooming later. 


\section{A YEAR'S GARDENING}

\section{FEBRUARY I8}

Greenhouse and Frames.-Nip off the buds of any forced Potatoes which are inclined to run too much to top growth.

Vegetable and Fruit Garden.-Give a thicker covering to Rhubarb and Sea-kale as they begin to push naturally.

Flower Garden.-Continue yesterday's task and take note which of the young plants require to be transferred to the flower-border, so as to seize the first favourable opportunity for transplanting them.

\section{FEBRUARY I9}

Greenhouse and Frames.- Re-pot Calceolarias and Cinerarias which are in frames and remove them to the greenhouse to flower.

Vegetable and Fruit Garden.-Sow Savoys on a mellow seed-bed and Turnips on a warm border.

Flower Garden.-Make a sowing of Anemones (they are easily raised from seed) in a rich, moist, light soil, covering the seed very lightly. Seed now sown should produce plants for blooming in September or October.

\section{FEBRUARY 20}

Greenhouse and Frames.-Place Dahlia roots in heat to excite growth for future cuttings. Sow Carrots for succession on a light hot-bed.

Vegetable and Fruit Garden.--Sow Broccoli on a sheltered border, and look to those which are already growing, seeing that they are well protected from frost. Cut any that may be ready.

Flower Garden.--Lift untidy edgings of Violas and unwieldy clumps of Pansies, dividing and re-planting them.

\section{FEBRUARY 2 I}

Greenhouse and Frames.-See that the heat of the Cucumber bed is not falling below $70^{\circ}$, and if necessary maintain temperature by applying a fresh lining.

Vegetable and Fruit Garden.-Give a dusting of lime between the rows of Cabbages to prevent the attacks of slugs. Fill up the rows where necessary. 


\section{A CALENDAR}

Flower Garden.-Divide and re-plant clumps of Polyanthus and Primrose.

\section{FEBRUARY 22}

Greenhouse and Frames.-Look to the setting of the Cucumbers, allowing not more than one or two to grow on a plant at the same time.

Vegetable and Fruit Garden.-If additional Fruit trees are required, sow seeds of Quince and Medlar in suitable positions, allowing the seeds to be $I$ inch deep in the soil and 6 inches apart.

Flower Garden.-Plant slips of Lavender in a sunny position.

\section{FEBRUARY 23}

Greenhouse and Frames.-Sow seeds of Ridge Cucumber, Capsicum and Vegetable Marrow in pots, and place in a frame.

Vegetable and Fruit Garden.-Mulberry trees may be propagated at this time. Insert a branch some 2 feet long in a shady border.

Flower Garden.-Plant Clematis, Jasmine, Honeysuckle, Virginia Creeper or Ampelopsis where they will be an improvement.

\section{FEBRUARY 24}

Greenhouse and Frames.-Sow seeds of Cauliflowers, Lettuce, Cabbage, Onions and Beet in a cold frame.

Vegetable and Fruit Garden.-Examine stocks of Fruit trees which are to be grafted this year, and if the sap is well risen make grafts at once.

Flower Garden.-Plant Periwinkle and St John's-wort on any ground rendered bare by the shade or drip from trees.

\section{FEBRUARY 25}

Greenhouse and Frames.-Put a few roots of Mint, Parsley, Horseradish and Chicory in pots and place in heat.

Vegetable and Fruit Garden.-Stocks for Apple, Pear, Plum and Cherry trees may be planted at this time of year. Lift the suckers from the old trees and re-plant them 2 feet apart, and they should be ready for grafting the following year. 


\section{A YEAR'S GARDENING}

Flower Garden.-Plant Hollyhocks, Sweet Williams, Canterbury Bells, Delphiniums and Peonies; the last in richly-manured ground, as they are gross feeders.

\section{FEBRUARY 26}

Greenhouse and Frames.-Sow Early Peas and French Beans in a frame for succession.

Vegetable and Fruit Garden.-Syringe Gooseberry and Currant bushes with a solution of lime and soot as an additional protection of the buds from the attacks of birds.

Flower Garden.--Plant Alpine Auricula, White Arabis and Purple Aubrietia in suitable positions in Rock Garden.

\section{FEBRUARY 27}

Greenhouse and Frames.-Sow Dahlia seeds in the house in a shallow box filled with light sandy loam, pressing it firm and covering the seeds thinly. Keep the seeds moist and shaded from the sun in a temperature of $55^{\circ}$ to $60^{\circ}$.

Vegetable and Fruit Garden.--Sow Onions and Leeks on a warm border and plant Garlick in rich soil 9 inches apart.

Flower Garden.-Do not neglect the rolling of the lawn; frequent cross-rolling with a light roller is most desirable after the winter's frosts.

\section{FEBRUARY 28}

Greenhouse and Frames.-Solomon's Seal (Polygonatum) well repays forcing and makes a decorative plant for the greenhouse. Lift a few roots from the open and re-plant in suitable pots.

Vegetable and Fruit Garden.-Sow Carrots (short-horn) on a sunny border; also Red-beet and Spinach-beet.

Flower Garden.--Roll the gravel paths; they generally need it about this time of year to consolidate them after the upheaval caused by frost.

\section{MARCH I}

Greenhouse and Frames.-Give a top-dressing of loam and decayed cow-manure to Auriculas and see that they have plenty of I6 


\section{A CALENDAR}

water, as they should now be throwing up their flower stems. Also sow seeds of Auricula and Polyanthus. Also sow a small quantity of Celery seed on a mild hot-bed, to be pricked out as soon as ready.

Vegetable and Fruit Garden.--Sow Peas for succession, allowing room for Cabbages and Potatoes between the rows.

Flower Garden.-Sow Sweet Peas for succession.

\section{MARCH 2}

Greenhouse and Frames.-Shift Azaleas and Camellias into larger pots if they have flowered or are forming new growth. Beans.

Vegetable and Fruit Garden.-Make a principal sowing of Broad

Flower Garden.-Stir the soil round the autumn-sown annuals and manure the beds that are to contain the bedding plants later.

\section{MARCH 3}

Greenhouse and Frames.-Proceed with the shifting of all plants requiring it.

Vegetable and Fruit Garden.--Sow Cabbage seed broadcast on a warm, sheltered bed; also Broccoli and Winter Greens of all sorts.

Flower Garden.--Plant out Gladiolus bulbs lifted last autumn. They should have a rich soil.

\section{MARCH 4}

Greenhouse and Frames.-If the greenhouse faces south, see that it is properly shaded from the mid-day sun. Plant Chicory in a hotbed, bearing in mind that it has to be blanched by excluding the light.

Vegetable and Fruit Garden.-Sow a small quantity of Carrot seed on ground that has been deeply dug in the autumn. Also sow Cardoon seed in a warm spot.

Flower Garden.--Look over the gravel paths to see if they need turning or re-gravelling, and start work on them if required. 


\section{A YEAR'S GARDENING}

\section{MARCH 5}

Greenhouse and Frames.-Make cuttings of Dahlias from stools which were placed in heat last month.

Vegetable and Fruit Garden.--Sow Onions and Leeks in rich, wellmanured soil.

Flower Garden.-Continue the work begun yesterday and finish by rolling the paths thoroughly.

\section{MARCH 6}

Greenhouse and Frames.-Prepare a slight hot-bed for forcing Asparagus and sow seeds of Vegetable Marrow in pots for the frame.

Vegetable and Fruit Garden.-Transplant from hand-lights and frames young plants of Cauliflower, Lettuce, etc.

Flower Garden.-Examine the lawn for weeds and moss and take measures to eradicate them. Moss is an unfailing sign of lack of drainage or poverty of soil.

\section{MARCH 7}

Greenhouse and Frames.-Sow seeds of Cucumber and Melon in pots, for placing in any hot-bed in which space can be found.

Vegetable and Fruit Garden.-Continue to plant out from the frames to-day and during any suitable weather.

Flower Garden.-Attend to Box edgings of beds and borders and re-plant where necessary.

\section{MARCH 8}

Greenhouse and Frames.-Make a new sowing, either in a frame or in the open, of Mustard and Cress, Radishes, etc.

Vegetable and Fruit Garden.--Sow all kinds of Lettuce seed in well-manured ground.

Flower Garden.-Finish off any pruning and training of climbers - such as Clematis, Jasmine, etc.-which may still remain to be done. 


\section{A CALENDAR}

\section{MARCH 9}

Greenhouse and Frames.-Make a first sowing, either in pans in the house or on a hot-bed, of some half-hardy annuals.

Vegetable and Fruit Garden.--Sow Spinach and Spinach-beet.

Flower Garden.-Fork over the flower beds so as to expose a new surface to the air.

\section{MARCH Io}

Greenhouse and Frames.-Sow seeds of Canna singly, in 2-in. pots filled with a compost of two parts loam and one part leaf mould. Soak the seeds previously for twenty-four hours in tepid water, file a notch in the shell to allow them to germinate more readily, and place them about half an inch deep in the soil.

Vegetable and Fruit Garden.-Make another plantation of Seakale; also make a small sowing.

Flower Garden.-See that all seed beds are protected from the attacks of birds.

\section{MARCH II}

Greenhouse and Frames.-Sow seeds of Chinese Primula (Primula Sinensis) in clean, well-drained pots filled with a compost of fibrous loam and leaf mould with a little silver sand. Cover seeds very thinly, place a piece of glass over each pot, and stand the pots in a temperature of $55^{\circ}$ to $60^{\circ}$.

Vegetable and Fruit Garden.-Complete yesterday's operations.

Flower Garden.--Support Hyacinths, Tulips, etc., with sticks as soon as they need them.

\section{MARCH I2}

Greenhouse and Frames.-Take cuttings of such Fuchsias as you wish to propagate.

Vegetable and Fruit Garden.--Sow the main crop of Parsnips in well-dug, friable soil. beds.

Flower Garden.-Give a liberal top-dressing to the Rhododendron 


\section{A YEAR'S GARDENING}

\section{MARCH I3}

Greenhouse and Frames.-Sow Celery on a hot-bed for an early supply.

Vegetable and Fruit Garden.-Uncover Globe Artichokes from protecting material. Prepare a bed for planting Artichoke suckers next month.

Flower Garden.-Finish all clearing and digging required in the shrubbery.

\section{MARCH I4}

Greenhouse and Frames.-Transfer Tomato seedlings to small pots and place them in frame for rooting before hardening and planting in the open.

Vegetable and Fruit Garden.--Finish yesterday's task and make a small sowing of Globe Artichoke seed.

Flower Garden.-Continue the work in the shrubbery and do all the staking and tying that may be necessary there.

\section{MARCH I5}

Greenhouse and Frames.- Sow Alpine Strawberry seeds in pans. Make a second sowing of Celery seed, to be pricked out as soon as possible.

Vegetable and Fruit Garden.-Plant out Beans raised in frames; earth up any that were sown early and are ready for it.

Flower Garden.-Mulch all recently-planted trees and shrubs.

\section{MARCH 16}

Greenhouse and Frames.-Prepare hot-bed for planting out Cucumber seedlings later on.

Vegetable and Fruit Garden.--Protect from frost any wall fruit blossoms which may be beginning to show; fern is sometimes used, or canvas.

Flower Garden.-Cut back Tea Roses. 


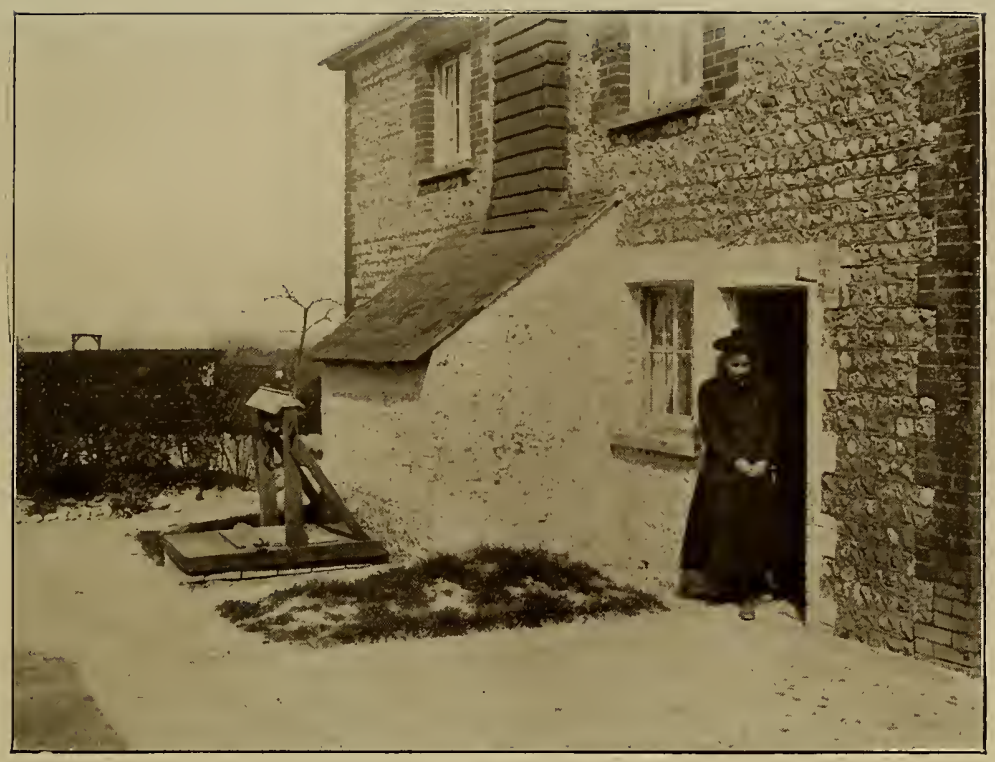

OUR WEEK-END COTTAGE.

As we found it.

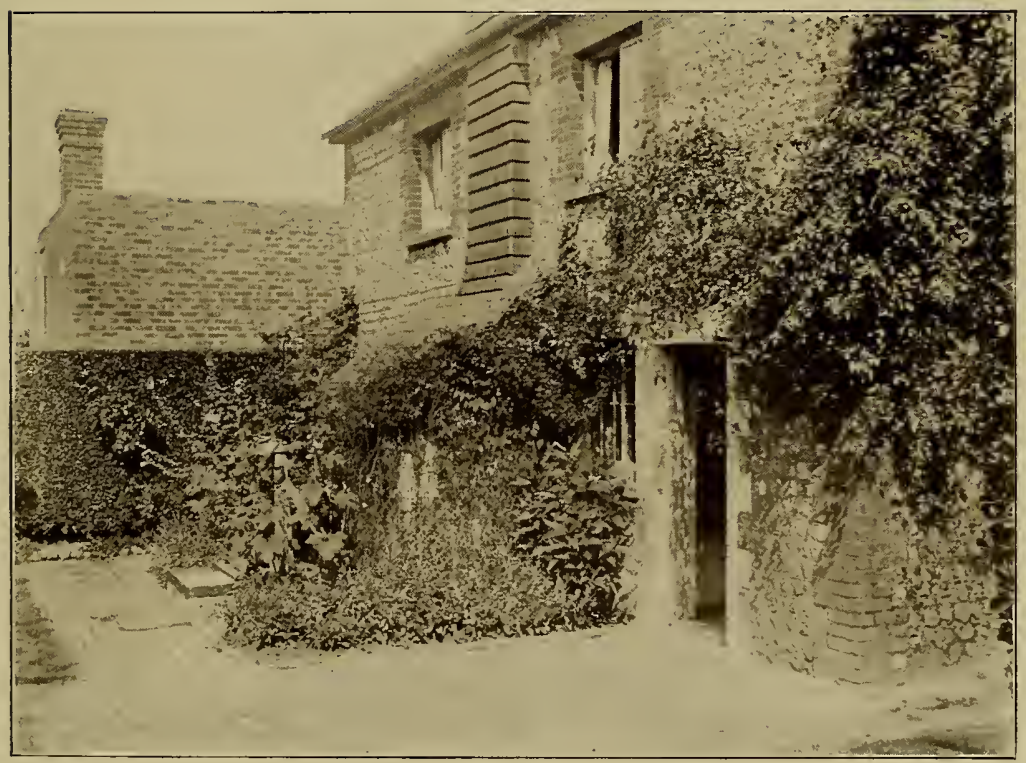

OUR WEEK-END COTTAGE.

Two years later. 



\section{A CALENDAR}

\section{MARCH I7}

Greenhouse and Frames.-Prick off into thumb-pots your Hollyhock, Verbena and Dianthus seedlings.

Vegetable and Fruit Garden.-Weed the Asparagus bed, and if very dry give it a good soaking.

Flower Garden.-Plant Roses now, but not later. Water copiously if dry.

\section{MARCH I8}

Greenhouse and Frames.-Sow seeds of Lobelia, Gaillardia, Nemesia, and African and French Marigold.

Vegetable and Fruit Garden.-Prepare bed for sowing Asparagus seed later. Plant Horseradish.

Flower Garden.-Plant Hollyhocks and Dwarf Stocks for bedding.

\section{MARCH I9}

Greenhouse and Frames.-Sow Coleus seed. Good plants may be raised at a temperature of $65^{\circ}$.

Vegetable and Fruit Garden.-Begin to plant Potatoes for the main crop.

Flower Garden.-Prepare the ground for the sowing of hardy annuals.

\section{MARCH 20}

Greenhouse and Frames.-Make use of any space in house or frames for forcing Strawberry plants.

Vegetable and Fruit Garden.-Continue the planting of Potatoes for the main crop and devote to it all time available until the work is finished.

Flower Garden.-Sow hardy annuals of the kind that require to be sown where they are to flower, such as Alyssum, Candytuft, Gypsophila, Larkspur, Lupins, Virginian Stock, etc., etc. 


\section{A YEAR'S GARDENING}

\section{MARCH 2 I}

Greenhouse and Frames.-Remove Chrysanthemums from the house into cold frames for hardening.

Vegetable and Fruit Garden.-Consider what herbs you have need of and sow, or divide up existing plants, accordingly. flower.

Flower Garden.-Sow all kinds of Poppies where they are to

\section{MARCH 22}

Greenhouse and Frames.-Re-pot Chrysanthemum seedlings in ordinary compost and keep them well watered, allowing them to grow naturally without any stopping process.

Vegetable and Fruit Garden.-Uncover Strawberry beds that have been protected; weed them and gently stir the soil round the plants.

Flower Garden.-Sow annuals that will bear transplanting, such as Annual Chrysanthemums, Clarkia, Convolvulus, Coreopsis, Cornflowers, etc., etc.

\section{MARCH 23}

Greenhouse and Frames.-Sow Asters in a compost of loam, leaf mould and sand, in shallow pans. Sprinkle the seed thinly and cover lightly, maintaining the temperature at $55^{\circ}$ to $60^{\circ}$.

Vegetable and Fruit Garden.-If all pruning and re-nailing of Fruit trees is finished, wash the trees, by means of a syringe, with a solution of sulphur and soot in tepid water, or with lime-wash, as a protection against insects.

Flower Garden.-Continue the sowing of annuals, such as Eschscholtzia, Godetia, Linum, Malope, Sweet Sultan, etc., etc.

\section{MARCH 24}

Greenhouse and Frames.-Prick out any half-hardy seedlings of annuals that are ready for hardening in a cold frame.

Vegetable and Fruit Garden.-Proceed with the grafting and budding of Fruit trees, if this has not already been done.

Flower Garden.-Continue the work of sowing annuals. 


\section{A CALENDAR}

\section{MARCH 25}

Greenhouse and Frames.--Sow New Zealand Spinach in moderate heat for hardening off and planting out by the end of May.

Vegetable and Fruit Garden.-Continue yesterday's operations. Flower Garden.-Plant out Violas and Pansies.

\section{MARCH 26}

Greenhouse and Frames.-Re-pot Orchids that are showing new growth and water liberally all plants that are growing actively.

Vegetable and Fruit Garden.-Spread fresh-slaked lime and rake it over the ground beneath the Gooseberry and Currant bushes. If this is done once or twice during the spring the attacks of caterpillars need not be feared.

Flower Garden.-Plant out any autumn-sown seedlings that may be ready.

\section{MARCH 27}

Greenhouse and Frames.-Pot down Vandas that have grown "leggy" and shade Odontoglossums, giving sufficient air while avoiding draughts.

Vegetable and Fruit Garden.-Dredge soot on the young buds of wall Fruit trees to prevent the mischief caused by birds. seed.

Flower Garden.-Make a sowing of Nasturtium and Tropæolum

\section{MARCH 28}

Greenhouse and Frames.-Re-pot any Palms that show a tendency to go brown at the tips, giving them a sweet, fresh compost.

Vegetable and Fruit Garden.-Sow French Beans of a dwarf variety in a sheltered border.

Flower Garden.-Plant out Pyrethrums in rich soil and in sunny position. 


\section{A YEAR'S GARDENING}

\section{MARCH 29}

Greenhouse and Frames.-Give a top-dressing of well-rotted manure to the foliage plants such as Palms, Aspidistras, etc.

Vegetable and Fruit Garden.-Strew soot round all plants that have been earthed up, as a protection from slugs and snails. Divide and re-plant Chives into fresh ground and plant Garlic.

Flower Garden.--Sow Ten-week Stocks on a sunny bed.

\section{MARCH 30}

Greenhouse and Frames.-Sow seeds of Balsams and Cockscombs in pans in a good heat, potting the seedlings later to form greenhouse plants.

Vegetable and Fruit Garden.-Sow Turnips and main crop of Brussels Sprouts.

Flower Garden.-Sow Mignonette where it is to flower, making the soil firm as for an onion bed.

\section{MARCH 3 I}

Greenhouse and Frames.--See that the Strawberry plants in bloom in house or frame have plenty of air and give them a little manure water.

Vegetable and Fruit Garden.-Tidy up the garden generally and roll the walks; make up any arrears of work.

Flower Garden.-Make up any arrears of sowing and sow again where failures have occurred.

\section{APRIL I}

Greenhouse and Frames.-Fumigate the greenhouse at night with tobacco smoke, as a protection against insects, particularly green-fly. All cracks and crevices giving admission to air must first be carefully closed up.

Vegetable and Fruit Garden.-If any pruning of Fruit trees is still required, do it at once.

Flower Garden.-Give a little time to any choice Tulips-see that they have protection from rain, frost and too much sun. 


\section{A CALENDAR}

\section{APRIL 2}

Greenhouse and Frames.-Well syringe the plants to remove dead insects.

Vegetable and Fruit Garden.-If Apricot, Nectarine and Peach trees are showing their bloom they should be carefully protected against frost. Make arrangements for doing so to-day.

Flower Garden.-Plant out biennials, such as Wallflowers, Stocks of various kinds, Hollyhocks, Campanulas, Sweet Williams, Foxgloves, etc., etc.

\section{APRIL 3}

Greenhouse and Frames.-Scrub all shelves and stages, and make the greenhouse as clean and tidy as possible.

Vegetable and Fruit Garden.-Examine Apricot, Peach and Nectarine trees for any withered branch, as all these trees may unexpectedly show a decayed limb, which should be immediately cut away as near the base as possible.

Flower Garden.-Continue the planting out of biennials.

\section{APRIL 4}

Greenhouse and Frames.-Look to the frames and see that they, too, are clean and sweet, and especially beware of woodlice.

Vegetable and Fruit Garden.-If the Strawberry beds were not uncovered last month, do not delay to uncover them now. Also clear away all weeds and nip off the runners.

Flower Garden.-Sow such hardy annuals as were not got in last month-Coreopsis, Mignonette and Sunflowers, for instance, which may be as well sown now as earlier.

\section{APRIL 5}

Greenhouse and Frames.-Make arrangements to shade plants in flower and those about to come into bloom.

Vegetable and Fruit Garden.-Give the Strawberry bed a spring dressing of half-rotted manure, soot and well-decayed leaves.

Flower Garden.-Sow Sweet Peas for succession. 


\section{A YEAR'S GARDENING}

\section{APRIL 6}

Greenhouse and Frames.-Sow double Zinnia seed in pots filled with leaf-mould compost mixed with sand, and keep them at a temperature of about $60^{\circ}$-not higher.

Vegetable and Fruit Garden.-Look over the outdoor Vine and remove useless shoots by rubbing them close to the stem with finger and thumb. Train those shoots which are retained, nailing them to the wall at proper distances apart.

Flower Garden.-Sow Nemesia, Convolvulus-major and Linumrubrum.

\section{APRIL 7}

Greenhouse and Frames.-Syringe Melon plants with water at a temperature a little higher than that of the bed in which they are growing. task.

Vegetable and Fruit Garden.-Continue and complete yesterday's

Flower Garden.-Sow Asters on a carefully-prepared bed, where they are to flower, thinning the seedlings when they are ready.

\section{APRIL 8}

Greenhouse and Frames.- See that the Cucumber plants have plenty of air in the daytime. Pinch off all shoots above the fruit and peg down the Vines.

Vegetable and Fruit Garden.-Sow Peas for succession.

Flower Garden.-Prune all Tea Roses and the allied kinds.

\section{APRIL 9}

Greenhouse and Frames.-Start some Cucumbers for succession, adding fresh soil and fresh lining to the bed, if required.

Vegetable and Fruit Garden.-Sow Onions for winter use and Cabbages for the autumn.

Flower Garden.-Continue yesterday's pruning and plant new trees in the place of any which may seem to be beyond their prime. 


\section{A CALENDAR}

\section{APRIL IO}

Greenhouse and Frames.-See that all such plants as Auriculas, Carnations and Pansies are getting sufficient air and water, and give them shade if the sun is hot.

Vegetable and Fruit Garden.-Plant suckers of Globe Artichokes in the bed prepared last month.

Flower Garden.- - Hoe the ground freely on the Rose beds, first scattering a good supply of soot. Water any Roses newly planted.

\section{APRIL II}

Greenhouse and Frames.-Begin to feed Sweet Peas in pots with manure water, so as to hasten their growth.

Vegetable and Fruit Garden.-Hoe over the beds wherever possible, so as to keep down the weeds and let in the sun, rain and air to the soil.

Flower Garden.-Plant out the Rose cuttings from the pots in greenhouse.

\section{APRIL I2}

Greenhouse and Frames.-Re-pot Ferns and Palms that need more room and see that they and all flowering plants are duly shaded.

Vegetable and Fruit Garden.-Go over the young crops, thinning and regulating them. Decide where protection must be continued and where removed. Water if necessary.

Flower Garden.-Well roll the gravel walks which were turned or re-gravelled last month.

\section{APRIL I3}

Greenhouse and Frames.-Sow Vegetable Marrow seeds in pots and bring them on in slight heat to plant out as soon as possible.

Vegetable and Fruit Garden.-Continue yesterday's work.

Flower Garden.-If the lawn has not been already mown this season do not postpone the work any longer. Use a sharp-bladed machine, set high, for the first mowing. 


\section{A YEAR'S GARDENING}

\section{APRIL I4}

Greenhouse and Frames.-Plant out Lettuces from frames.

Vegetable and Fruit Garden.-Sow Celery seed in a warm spot, on a bed of rotten manure. Prick out some of your Celery seedlings grown under cover into a similar bed, also in the open, but in a sheltered position.

Flower Garden.-Look to the Rhododendron bed and replace any plants that have passed their prime with new bushes, planting them in loose, peaty soil.

\section{APRIL I5}

Greenhouse and Frames.-Sow Endive in moderate heat and prick out the seedlings, when an inch high, into a bed of rich, light soil.

Vegetable and Fruit Garden.-Make another sowing of Brussels Sprouts for a late crop. Also sow Leeks, if the previous sowing has been inadequate.

Flower Garden.--Look around and see if any plants are needing the support of stakes, either by reason of the March winds or from their recent increase in growth.

\section{APRIL I6}

Greenhouse and Frames.-Prick out Celery seedlings into a bed of rotten manure and cover with a frame.

Vegetable and Fruit Garden.-Sow Lettuce seed for succession and plant out from the frames all that are ready to be moved.

Flower Garden.-Look to the winter-flowering climbers; prune and train them where necessary.

\section{APRIL I7}

Greenhouse and Frames.-Make a second sowing of Balsamsin a frame, without artificial heat.

Vegetable and Fruit Garden.-Make a liberal sowing of Parsley and Radishes.

Flower Garden.-Trim all Ivy on walls, etc. 


\section{A CALENDAR}

\section{APRIL I8}

Greenhouse and Frames.-Sow seed of Marvel of Peru if not done last month, as it will now germinate in a cold frame, without artificial heat.

Vegetable and Fruit Garden.--Renew your bed of Mint, if desired, by pulling up young shoots and re-planting them 6 inches apart. Old plantations of Mint are apt to become wiry and leafless. Sage, Marjoram and Thyme may also be propagated now.

Flower Garden.-Grub up Daisies from the lawn; a daisy-fork is the best tool for the purpose, but an old knife or carving-fork will serve.

\section{APRIL I9}

Greenhouse and Frames.-Look to the Azaleas which have already bloomed and remove all the seed vessels. Also shift into new pots those plants which may have become pot-bound.

Vegetable and Fruit Garden.-Make preparations for forming an outdoor Mushroom bed.

Flower Garden.-Complete yesterday's work by thoroughly rolling the lawn.

\section{APRIL 20}

Greenhouse and Frames.-Plant out Calceolarias that have wintered in a cold frame.

Vegetable and Fruit Garden.-Continue yesterday's task in making a Mushroom bed and complete the work as soon as opportunity occurs.

Flower Garden.-Give a weak solution of manure water to Auriculas, and thin their trusses.

\section{APRIL 2I}

Greenhouse and Frames.-Sow in pots, in the cold frame just emptied, such seeds as China-Asters, Ten-Week Stocks, French and African Marigolds, etc.

Vegetable and Fruit Garden.--Sow Kidney Beans, if there be no appearance of frosty weather occurring.

Flower Garden.-Scatter lime or soot around the plants on the herbaceous border as a preventive against the ravages of slugs and snails. 


\section{A YEAR'S GARDENING}

\section{APRIL 22}

Greenhouse and Frames.-Sow Melons for a second crop, growing the seedlings in pots until they are about a foot high.

Vegetable and Fruit Garden.-Sow Broad Beans for succession. Also make a sowing of Beet.

Flower Garden.-Make a further sowing of Nasturtium and Tropæolum seed in case of failure of some of that previously sown.

\section{APRIL 23}

Greenhouse and Frames.-Cut back Marechal Niel Roses to about 3 or 4 feet from the base, so that they may make new shoots.

Vegetable and Fruit Garden.--Sow the main crop of Carrots.

Flower Garden.-Sow any half-hardy annuals that have hitherto been omitted.

\section{APRIL 24}

Greenhouse and Frames.-Look over all Roses for mildew, and where it is found, dust with flowers of sulphur.

Vegetable and Fruit Garden.-Plant out Cauliflowers, as they are ready, at every favourable opportunity. Make a fresh sowing to-day.

Flower Garden.--Sow Ricinus (Castor-oil Plant) on a bed which has been thoroughly enriched with well-rotted manure.

\section{APRIL 25}

Greenhouse and Frames.-Prick off Aster seedlings that have attained the third leaf into suitable pans or pots to await single potting later on. Also make a fresh sowing.

Vegetable and Fruit Garden.-Sow Cardoons on well-manured ground, in rows 3 or 4 feet apart, and in groups of seed about I8 inches distant from each other.

Flower Garden.-See to the staking of the Sweet Peas; it is important that the tendrils, while still small, are provided with something on which to twine. 


\section{A CALENDAR}

\section{APRIL 26}

Greenhouse and Frames.-Sow Carnation seed in well-drained pots in a frame, transplanting the seedlings as soon as they can be handled for hardening in a cool pit.

Vegetable and Fruit Garden.--Sow Turnips for succession; also the long-standing variety of Spinach.

Flower Garden.-Examine the Dahlia roots and plant out those that are ready.

\section{APRIL 27}

Greenhouse and Frames.-Give the Dahlia seedlings plenty of water at this time and see that they are free from green-fly. Also pot up those which are ready.

Vegetable and Fruit Garden.-Stick any Early Peas which may be sufficiently advanced.

Flower Garden.-Sow Hollyhock seed in the reserve garden.

\section{APRIL 28}

Greenhouse and Frames.-Pot up the Petunia seedlings intended for bedding later on.

Vegetable and Fruit Garden.-Protect Early Potatoes by drawing the earth lightly over them with the hoe.

Flower Garden.-Top-dress the Pansy seedlings with well-rotted manure and plant out any that are sufficiently advanced.

\section{APRIL 29}

Greenhouse and Frames.-Make a further sowing of Ten-Week Stocks, transferring the seedlings later on to a cold frame or spent hot-bed.

Vegetable and Fruit Garden.-Thin and plant out young seedlings.

Flower Garden.--Lift and divide the Polyanthuses, Primroses, Daisies, etc. 


\section{A YEAR'S GARDENING}

APRIL 30

Greenhouse and Frames.-Remove the Cyclamen plants which have been flowering during the winter to a moist pit, where they should be watered very sparely.

Vegetable and Fruit Garden.-Remove hand-glasses from Cauliflowers ; earth them up and give them some liquid manure.

Flower Garden.--Stake and peg down such plants as may require it.

\section{MAY I}

Greenhouse and Frames.--Start some Melons in a frame, choosing sturdy plants for the purpose.

Vegetable and Fruit Garden.-Look to the Cherry and Apple trees; disbud where necessary, stop all useless shoots, and see that those retained are properly regulated.

Flower Garden.-Sow Sweet Peas for succession.

\section{MAY 2}

Greenhouse and Frames.-Sow some seed of decorative Gourds under glass, with the view of planting out the seedlings later on in a prepared bed.

Vegetable and Fruit Garden.-Continue yesterday's work and extend it to the Pear and Plum trees.

Flower Garden.-Plant out seedlings as they may be readysuch as Hollyhocks, Gaillardia, Dianthus, Marigold, etc.

\section{MAY 3}

Greenhouse and Frames.-Plant out into a cold frame the earlyflowering Chrysanthemums which were struck last month. Also put Tomato plants into a cold irame (with the lights off) for hardening.

Vegetable and Fruit Garden.-Look to the Apricot, Nectarine and Peach trees, and disbud and train them where required.

Flower Garden.-Continue yesterday's task of planting seedlings. 


\section{A CALENDAR}

\section{MAY 4}

Greenhouse and Frames.-Look to the recently-made Chrysanthemum cuittngs and pot up those that are well rooted.

Vegetable and Fruit Garden.-Continue yesterday's work on the Apricot, Nectarine and Peach trees.

Flower Garden.-Sow Nemesia in the open border. Also make a sowing of various strains of Wallflowers in the reserve garden, in order that the plants may be well grown and hardened before winter.

\section{MAY 5}

Greenhouse and Frames.-Water the Hydrangeas which are beginning to show bloom with a weak solution of liquid manure, and continue this occasionally while the plants are in flower.

Vegetable and Fruit Garden.--Examine all the Fruit trees for any appearance of insects, and if the trees are infected syringe them with a decoction of quassia chips and soft soap (4 ounces of each to a gallon of water) or with soap-suds and tobacco water.

Flower Garden.-Begin to harden off from frames and greenhouse such seedlings as Antirrhinum, Phlox, Stocks, etc.

\section{MAY 6}

Greenhouse and Frames.-Take stock of the various cuttings, other than Chrysanthemum, that may be in progress and pot up those which are ready.

Vegetable and Fruit Garden.-Take a careful survey of the fruit forming on the trees and thin out where necessary.

Flower Garden.--Make a further sowing of annuals in the open border, both for transplanting and for flowering where sown.

\section{MAY 7}

Greenhouse and Frames.-Sow seeds of Primulas and Cinerarias in pots filled with good mould and keep them shaded from the sun. 


\section{A YEAR'S GARDENING}

Vegetable and Fruit Garden.-Dust the young shoots of the Gooseberry and Currant bushes, by means of a dredger, with a mixture of dry lime, soot and guano in equal parts, as a preventive of the attacks of caterpillars. Tobacco water and soap-suds is another specific.

Flower Garden.-Lift and store the spring flowering and other bulbs as (but not before) their leaves begin to decay.

\section{MAY 8}

Greenhouse and Frames.-As the sun's heat is now making fire heat almost unnecessary, make provision to benefit by this, admitting more air as soon as the temperature reaches $55^{\circ}$, but closing the greenhouse between four and five o'clock.

Vegetable and Fruit Garden.-Give a similar dredging to the young shoots of any Fruit trees showing the presence of green or black fly.

Flower Garden.-Devote to-day's and to-morrow's time in the garden to general tidying up-mowing the lawn, clipping the edges, weeding, etc., as the garden should now show a perfection of neatness.

\section{MAY 9}

Greenhouse and Frames.-Examine the Orchids carefully to see if thrips be present, and when found, dust with tobacco powder.

Vegetable and Fruit Garden.-A proper amount of moisture is imperative at this time of year for the production of a good crop on the Fruit trees and bushes. See, therefore, that they are watered, if dry, and mulch the roots with manure, cocoa-nut fibre or moss to prevent evaporation.

Flower Garden.-Continue yesterday's work.

\section{MAY ro}

Greenhouse and Frames.-Thin the Grape Vine, remembering that a small number of good bunches of fruit is more satisfactory than a large crop poorly developed.

Vegetable and Fruit Garden.-Water the Strawberry beds plentifully, if they are at all dry, and nip off the runners continually, except from those plants which are reserved for propagation. 


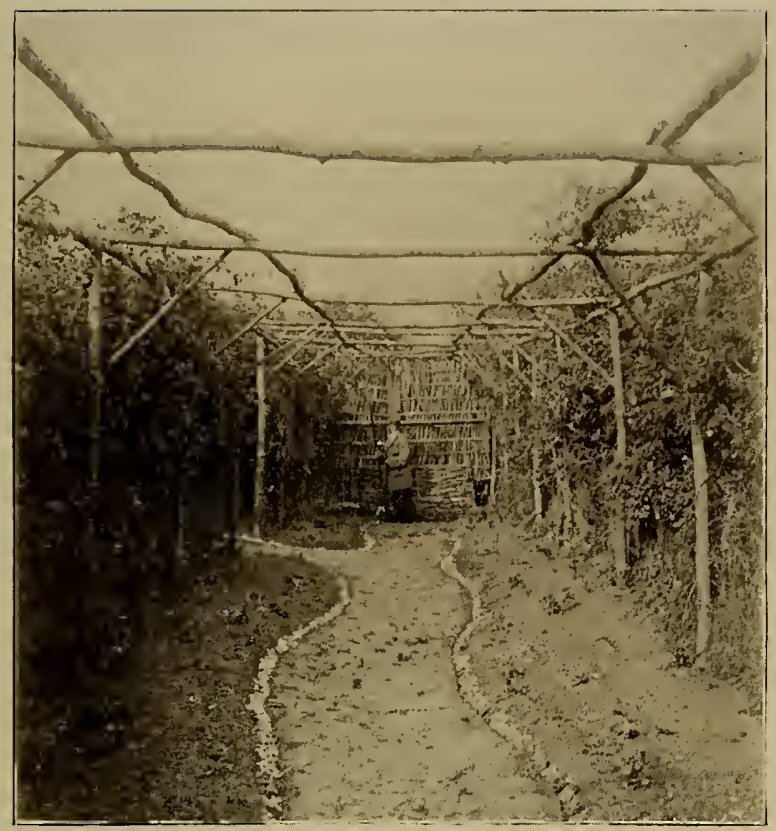

A GARDEN IN THE MAKING.

Pergola and Spring Garden (First stage).

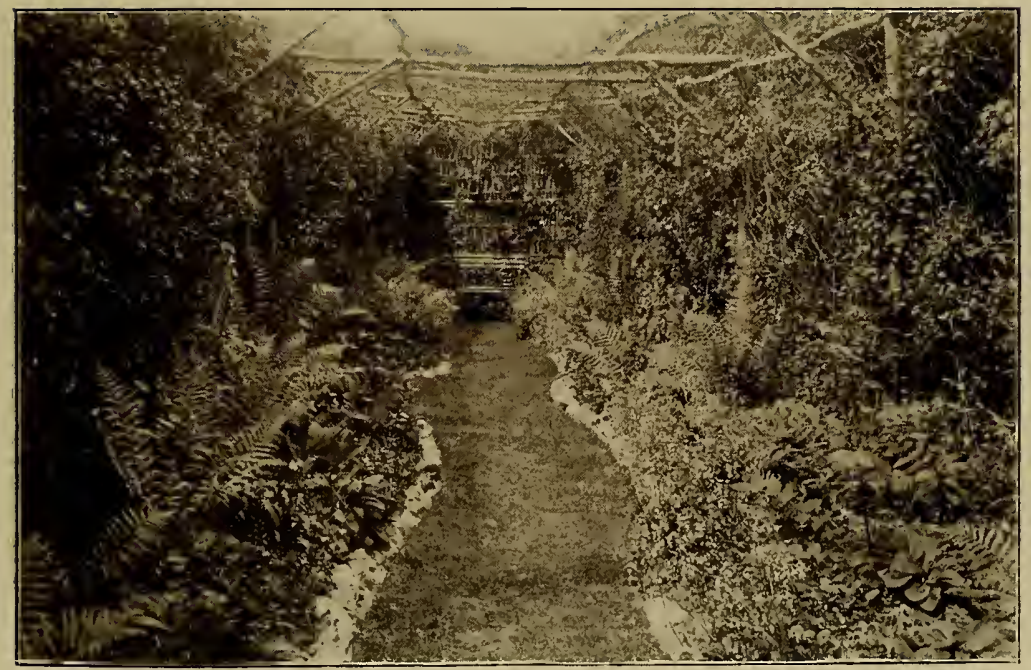

A GARDEN IN THE MAKING.

Pergola and Spring Garden two years later. 



\section{A CALENDAR}

Flower Garden.-Prepare a suitable bed for, and make a sowing of, perennial Delphiniums.

\section{MAY II}

Greenhouse and Frames.-Syringe the Roses to-day with a weak solution of insecticide, repeating the operation at intervals, as a means of warding off insect pests.

Vegetable and Fruit Garden.--Give a few doses of liquid manure at intervals to the Fruit bushes on which the fruit is beginning to set, so as to assist its development.

Flower Garden.-Give the Roses a watering of liquid manure and repeat the application two or three times at intervals of a few days. Look carefully for any curled leaves and promptly remove the grub which will be found therein.

\section{MAY I2}

Greenhouse and Frames.-Give a dusting of sulphur to any Roses which show a tendency to curled leaves, and water them freely with guano water.

Vegetable and Fruit Garden.-Thin out the Asparagus in the seed-bed and protect the bearing-bed with new-mown grass. Some Asparagus should now be ready; cut carefully those sticks which are ripe. Make a new sowing, if required.

Flower Garden.-Look to any choice Tulips which may be coming into bloom and shade them judiciously, watering round the beds to keep the plants cool and prolong their blooming.

\section{MAY I3}

Greenhouse and Frames.-Make some cuttings of Roses and put them into a very sandy soil, covering them with a bell-glass and sprinkling them every morning. For the cuttings select those shoots which have flowered.

Vegetable and Fruit Garden.-Sow Broad Beans for a late crop. Examine those in flower for black-fly and top them wherever the fly is present.

Flower Garden.- - If the planting of Violets was not done in the autumn, a bed of them may now be made. A shady situation and a well-manured soil should be chosen. 


\section{A YEAR'S GARDENING}

\section{MAY I4}

Greenhouse and Frames.-Prick out seedlings of half-hardy annuals into a slight hot-bed day by day as they become ready.

Vegetable and Fruit Garden.-Sow Kidney Beans of all sorts.

Flower Garden.-Sow Zinnias in the open border, choosing a southern aspect if possible.

\section{MAY I5}

Greenhouse and Frames.-Plant the off-sets taken from the Cucumbers into the frames emptied of the half-hardy annuals, or make a sowing of seed.

Vegetable and Fruit Garden.-Plant out Brussels Sprouts and Cabbages at every opportunity the weather permits. Make a sowing of small Cabbage.

Flower Garden.--Look to the hedges and trim and clip them where required.

\section{MAY 16}

Greenhouse and Frames.-Put out the bedding plants into a cold frame for gradual hardening preparatory for planting in the open, removing the frame-lights altogether.

Vegetable and Fruit Garden.-Thin out the main crop of Carrots and Parsnips and make a sowing for the main crop of Beet.

Flower Garden.-Make a special bed for the cultivation of fine specimens of Ten-Week Stocks, choosing a border which was well manured in the previous autumn, and where each seedling is to be planted take out a shovelful of earth and replace it with good potting compost.

\section{MAY I7}

Greenhouse and Frames.-Plant for summer flowering some tubers of Tuberoses in pots filled with a compost of good loam and coarse sand, plunging the pots into a hot-bed.

Vegetable and Fruit Garden.-Make a small sowing of Stumprooted Intermediate Carrots, to be pulled young.

Flower Garden.-Complete yesterday's work. 36 


\section{A CALENDAR}

\section{MAY I8}

Greenhouse and Frames.-Pinch back the undergrowth and peg down the stems of Cucumbers, and water them freely with tepid water.

Vegetable and Fruit Garden.-Plant out Cauliflowers as quickly as weather permits. Water them liberally in the absence of moist weather.

Flower Garden.-Prepare a piece of ground in a sunny border, which has been previously well manured, and sow seed of Tobacco plant (Nicotiana).

\section{MAY I9}

Greenhouse and Frames.-Plant out some of the Vegetable Marrow seedlings into a mild hot-bed, covering the plants with handlights.

Vegetable and Fruit Garden.-Make trenches for Celery, using plenty of manure. Put in the young plants 6 or 8 inches apart.

Flower Garden.-Plant out some of the young plants set on the ash-bed for hardening, such as Antirrhinums, Phlox, etc., etc.

\section{MAY 20}

Greenhouse and Frames.-Give a new lining to the frames in which the Early Carrots and Potatoes were grown, and utilize them for growing Tomatoes and Capsicums.

Vegetable and Fruit Garden.--Sow Lettuces for succession in the bed where they are to grow, and plant out, at first opportunity, any seedlings still on hand.

Flower Garden.-Continue yesterday's work.

\section{MAY $2 I$}

Greenhouse and Frames.--See to the re-potting of the Balsams, Celosias, Torenias, etc., in preparation for summer flowering in the greenhouse.

Vegetable and Fruit Garden.-Sow American Cress and other small salading, also Dandelion for winter and spring salad. 


\section{A YEAR'S GARDENING}

Flower Garden.-Sow hardy annuals on the patches of ground now occupied by bulbs which have finished flowering for the season, such as Snowdrops, Crocuses, etc., which are not to be lifted. By the time the annuals are up the foliage of the bulbs will have died down.

\section{MAY 22}

Greenhouse and Frames.-Look to the Fuchsias, Pelargoniums, etc., that are to be retained in the greenhouse for the summer and shift into larger pots any that may require it.

Vegetable and Fruit Garden.-Sow Onion seed thickly for salad onions. Also sow Radishes for succession.

Flower Garden.-Gently fork over the surface of the beds where it has become caked and hardened. See if plants set recently need watering.

\section{MAY 23}

Greenhouse and Frames.-See that the Heaths, Ferns and any other plants that seem to need more room are shifted accordingly.

Vegetable and Fruit Garden.-Sow Peas in trenches prepared (but without manure) as for Celery, only less deep. The trenches will act as draining receptacles for any rain which may fall and thus assist the growth of the Peas during a spell of dry weather.

Flower Garden.-Give a good soaking to all trees and shrubs planted this spring, unless in the unlikely event of having had much rain lately.

\section{MAY 24}

Greenhouse and Frames.-Remove from the greenhouse the Hyacinths, Tulips and other bulbs that have finished flowering for the season, putting the contents of each pot, soil and all, into the ground, so that the bulbs may renew their vigour while the leaves are fading.

Vegetable and Fruit Garden.-Plant a final small crop of Potatoes and earth up those that are sufficiently advanced.

Flower Garden.-Prune any overgrown Laurels and clip the Ivy. Make new planting of Ivy, if required. 


\section{A CALENDAR}

\section{MAY 25}

Greenhouse and Frames.-Look over the Azaleas as they cease to flower and pick off dead flowers and seed vessels. Re-pot them if young growth is beginning to show and give them an occasional watering with a weak solution of liquid manure.

Vegetable and Fruit Garden.-Sow Vegetable Marrow seeds on prepared bed where they are to grow, unless there are already at hand some strong young plants ready for planting.

Flower Garden.--Put in without delay any Dahlias still unplanted. Stake the Carnations.

\section{MAY 26}

Greenhouse and Frames.-Look to the Roses in pots; the Hybrid Perpetuals may probably be now benefited by being put out of doors, placed on a bed of ashes.

Vegetable and Fruit Garden.--Sow Spinach-beet. Plant out Leeks in well-dug ground.

Flower Garden.--Proceed to get in the bedding plants, unless the weather be particularly unfavourable.

\section{MAY 27}

Greenhouse and Frames.- Sow Cineraria seed in pots or pans and prick out the Cyclamen seedlings into pots.

Vegetable and Fruit Garden.-Thin out the Raspberry suckers, leaving only four or five strong shoots on each stool.

Flower Garden.-Continue yesterday's work of getting in the bedding plants and go on with it at every favourable opportunity.

\section{MAY 28}

Greenhouse and Frames.-Make a fresh sowing of Wallflower seed in pans and remove the Dahlia cuttings to a cold frame for hardening.

Vegetable and Fruit Garden.-It is not too late to divide some of the Rhubarb roots, if so desired. Plant out the divided roots about 4 feet apart and water thoroughly.

Flower Garden.-Plant out seedling Pansies for successionin a border with northern aspect if possible. Give them shade at mid-day if their position demands it, and water them in the evening. 


\section{A YEAR'S GARDENING}

\section{MAY 29}

Greenhouse and Frames.-Propagate from any special Chrysanthemums you may have on hand by making cuttings and inserting them round the edge of pots filled with sandy soil, placing them in a frame until rooted.

Vegetable and Fruit Garden.-Lay down fresh straw between and underneath the leaves of the Strawberry plants, so as to keep the fruit clean and expose it more fully to the sun.

Flower Garden.-Look to the Ranunculuses and press the soil closely round them; water them if dry. Perennials may still be propagated by division, if desired.

\section{MAY 30}

Greenhouse and Frames.-Plant out the young Celosias, Balsams, Cockscombs, etc., etc., in a hot-bed from which early vegetables have been removed, putting in a new surface soil and a new lining.

Vegetable and Fruit Garden.-Clear the Sea-kale of all litter used in forcing and gently fork up the ground between the rows.

Flower Garden.-See to the bulbs and tubers which are to be lifted and take them up as soon as their leaves are decayed.

\section{MAY 3I}

Greenhouse and Frames.-Tidy up the greenhouse generally; see that there is a proper supply of pegs, labels, etc.; turn over and mix the soil that is stored for potting.

Vegetable and Fruit Garden.-Clear away throughout the garden all manure and refuse which has been used for protection. Mix some with fresh stable manure to make hot-beds and throw the remainder into a heap to rot for compost.

Flower Garden.-Plant out another batch of the young plants set out for hardening, such as Balsams, Begonias, etc.

\section{JUNE I}

Greenhouse and Frames.-Sow Cineraria seeds for succession, and as soon as the seedlings are ready put them into a close frame, watering them gently night and morning. 


\section{A CALENDAR}

Vegetable and Fruit Garden.-Sow French Beans for succession.

Flower Garden.-Take a general survey of the bedding plants put out last month with a view to rectifying any mistakes made in arrangement or failure in individual plants.

\section{JUNE 2}

Greenhouse and Frames.-Pot up those Primula seedlings which are ready and make another sowing.

Vegetable and Fruit Garden.-Plant out Early Celery.

Flower Garden.-Continue to give attention to the bedding plants, stirring the soil, pegging down the Verbenas, Petunias, Ageratums, etc., and watering copiously, but not too frequently, as required.

\section{JUNE 3}

Greenhouse and Frames.--Sow seeds of Brompton Stocks in pans, placing them in slight heat until the seedlings are large enough to be hardened and planted out.

Vegetable and Fruit Garden.--Syringe the wall-fruit trees now and frequently, from day to day, to destroy red spider and aphis. Evening is the best time for the process.

Flower Garden.--Look over whatever surplus of bedding plants you have in hand and consider what use may be made of them for garden tubs and vases, hanging baskets, etc.

\section{JUNE 4}

Greenhouse and Frames.-Transfer the young Tobacco plants to a spare frame, where they may gradually harden for the open ground. They need plenty of moisture and a rich soil.

Vegetable and Fruit Garden.-Look to the Raspberry canes and remove all useless suckers as soon as they appear.

Flower Garden.-Continue yesterday's work by filling tubs, vases and baskets, bearing in mind that the latter should have some trailing plants. 


\section{A YEAR'S GARDENING}

\section{JUNE 5}

Greenhouse and Frames.-Sow seed of Primroses (white, blue, crimson, etc.) in pans, and harden off the seedlings in due course for filling up vacant spaces in the rock garden or where otherwise required.

Vegetable and Fruit Garden.-Give the Strawberry plants a liberal watering, if the weather be dry, and see that the maturing fruit is properly raised from the ground and well exposed to the ripening power of the sun. A few forked twigs or odd pieces of glass will be found useful for the purpose.

Flower Garden.-Collect the remainder of the bedding stock, re-pot where necessary, and arrange the plants in a cool and shady situation, ready for any unexpected demand. Keep the blooms pinched off.

\section{JUNE 6}

Greenhouse and Frames.-See that the greenhouse and all the frames and pits are receiving the full benefit of the sunshine and warm air, opening them early and giving shade where required. $\mathrm{Be}$ on the lookout for aphis, and sponge and cleanse any plants attacked, boldly removing any young shoots if necessary.

Vegetable and Fruit Garden.-Be on the watch to stop the needless shoots on Peach, Apricot and Nectarine trees, etc., and thin the fruit where necessary.

Flower Garden.-Give daily attention at this season of the year to the newly-planted beds, and remove, from time to time, the plants which have finished flowering. To-day remove the Wallflowers to reserve garden.

\section{JUNE 7}

Greenhouse and Frames.-Thin out the shoots of the Hydrangeas where they are crowded, if this has not already been done, putting in some of the cuttings for propagation.

Vegetable and Fruit Garden.-Give a thorough watering to the Peach, Apricot and Nectarine trees and other wall-fruit trees, unless the season be unusually wet, and keep a lookout for insect pests, dealing with them promptly when found.

Flower Garden.-Continue yesterday's work in the newly-planted beds and remove the Pansies which have ceased to bloom. 


\section{A CALENDAR}

\section{JUNE 8}

Greenhouse and Frames.-Pot up the Carnation cuttings and place them in a cold frame. Sow seed of Chinese Primulas.

Vegetable and Fruit Garden.-Keep all the wall-fruit trees well mulched, especially if the weather be dry, as a protection against excessive evaporation of moisture.

Flower Garden.-As a continuation of the two previous days' work remove the Anemones and other early flowering plants.

\section{JUNE 9}

Greenhouse and Frames.-Look to the Orchids and remove any flowers that may be appearing, lest they should retard the growth of the plants.

Vegetable and Fruit Garden.-Examine the Plum trees and remove all new wood not required for extending the size of the trees.

Flower Garden.-Attend to the Carnations, Pinks and Picotees, and thin out the shoots of those plants which are rampant in growth.

\section{JUNE Io}

Greenhouse and Frames.-Give a top-dressing of loam and decayed manure to the Liliums. Plant Calla Lilies in a trench having a layer of manure at the bottom.

Vegetable and Fruit Garden.-Continue yesterday's work on the Plum trees and keep a sharp lookout for the small fly which frequently attacks them, destroying it as soon as observed.

Flower Garden.-Continue the work on the Carnations, etc., carefully tying the remaining shoots to their stakes and binding the flower-pods where they are inclined to burst prematurely.

\section{JUNE II}

Greenhouse and Frames.-Make cuttings of such plants as Fuchsias, Heliotropes, Verbenas, etc.

Vegetable and Fruit Garden.-Look to the outdoor Grape-vine and thin out the young shoots, allowing only one shoot to remain at each joint. 


\section{A YEAR'S GARDENING}

Flower Garden.-Look to the Hollyhocks, Delphiniums and Phloxes, and thin out any crowded shoots so as to promote good bloom.

\section{JUNE I2}

Greenhouse and Frames.-Make a setting in pots of Strawberry runners for next season's forcing of Strawberry plants.

Vegetable and Fruit Garden.--See to the Fruit trees that were grafted in the spring and remove the ties which were used to keep the grafts in position.

Flower Garden.-Continue yesterday's work on the Hollyhocks, Delphiniums, etc., and stake and tie them carefully.

\section{JUNE I3}

Greenhouse and Frames.-Turn out of doors the pot Roses as they cease to bloom, putting them into a sunny spot and packing them in cocoa-nut fibre to retain moisture.

Vegetable and Fruit Garden.-To-day and to-morrow may well be devoted to the summer stopping of the Gooseberry and Red and White Currant bushes. While doing this, bear in mind the importance of a good-shaped bush, and leave only such young shoots as will assist in that object.

Flower Garden.-Attend to the Dahlias recently planted out, water them in the evening if dry, and give them a slight mulching at the roots.

\section{JUNE I4}

Greenhouse and Frames.-Sow Melon seed for a final crop. Make arrangements for the support of fruit which is heavy on existing Melon plants, by means of nets or pieces of board properly suspended.

Vegetable and Fruit Garden.--Continue and, if possible, complete yesterday's work.

Flower Garden.-Continue to give attention to the Dahlias, remove some of the shoots if growth is exuberant and stake and tie up carefully those retained. Be on the lookout for the attacks of slugs, and if any indication of them be found, encircle the plants with a deep ring of soot. 


\section{A CALENDAR}

\section{JUNE I5}

Greenhouse and Frames.-Sow Calceolaria seed and be prepared to give the seedlings an even temperature and early transplanting, with careful shading and watering.

Vegetable and Fruit Garden.-Sow the main crop of winter Turnips.

Flower Garden.-Mid-June is pre-eminently the time for Roses, and throughout the remainder of this month daily attention should be given to them. Make it to-day's work to look over a certain number of trees and destroy any maggot or green-fly which may be discovered.

\section{JUNE I6}

Greenhouse and Frames.-Move the Gloxinias which are showing signs of bloom into an airy and shady position. Look to the Camellias, and fumigate them if they are being attacked by thrips.

$V$ egetable and Fruit Garden.-Sow Endive seed, either broadcast or in shallow drills 4 to 6 inches apart.

Flower Garden.-Continue yesterday's work of searching for and destroying insect pests on the Roses.

\section{JUNE I7}

Greenhouse and Frames.-Give attention to Balsams, Cockscombs and other annuals grown to fill vacant places. Re-pot them and put them near the glass, giving them gentle bottom heat if their growth seems slow. Remove early buds to prevent premature flowering.

Vegetable and Fruit Garden.-Look to the Broad Beans again and nip off the tops of the plants, especially those which bear any sign of black-fly.

Flower Garden.-Continue to give attention to the Roses, and to-day, in particular, see that the Standards are effectually secured to their stakes.

\section{JUNE I8}

Greenhouse and Frames.-The Capsicums and Lilies should now be brought forward; re-pot them and plunge them into moderate heat. 


\section{A YEAR'S GARDENING}

Vegetable and Fruit Garden.-Thin out the Beetroot seedlings and hoe the ground between the rows.

Flower Garden.-Continue to keep a close watch on the Roses, and let to-day's especial work be the regulating and tying up of any weak-growing shoots.

\section{JUNE I9}

Greenhouse and Frames.-Look to the Cucumber plants and clear them of any dead leaves, stirring the soil and adding fresh earth, if needed.

Vegetable and Fruit Garden.-Look to the outdoor Cucumbers, and if they are running too freely nip off the ends of the main stems and thus induce them to break into side shoots.

Flower Garden.-In continuation of the work on the Roses make a careful survey and remove all fading flowers, cutting back the branches of the autumn-flowering kinds which have ceased to bloom.

\section{JUNE 20}

Greenhouse and Frames.-Both the Cucumber and Melon plants are liable to the attacks of insect pests at this season. Examine the plants carefully and take immediate steps to exterminate any insects that may be present.

Vegetable and Fruit Garden.-Look to the Asparagus bed to determine if cutting should not cease, bearing in mind that it is wise to leave a few heads uncut.

Flower Garden.- - Let attention be still given to the Roses, stirring the ground around them and giving them a plentiful supply of manure water.

\section{JUNE 2I}

Greenhouse and Frames.-Pinch back all useless shoots that may be appearing on the Melon plants and make a further planting of seedlings for succession.

Vegetable and Fruit Garden.-Continue to give attention to the Asparagus bed, and if cutting has now ceased, weed the bed carefully and thoroughly and sprinkle it all over with salt. 


\section{A CALENDAR}

Flower Garden.-Do not forget to keep a watch on the Rose beds, but also give some attention to-day to the Tulips, doing what is desirable in the way of shade and protection to prolong their bloom.

\section{JUNE 22}

Greenhouse and Frames.-Examine the seedlings which have been raised for winter blooming in the greenhouse-such as Cinerarias, etc., etc.- and pot up all those which are ready, keeping them in a cool frame, well shaded.

Vegetable and Fruit Garden.-Make a final sowing of French Beans for succession, if required.

Flower Garden.--Let to-day's time to the Roses be devoted to the training and tying of the new shoots of the climbers. As to the Tulips, look over the beds carefully and note the habit and character of the individual plants with the view of insuring still more effective planting next season.

\section{JUNE 23}

Greenhouse and Frames.-Make a final shift of Chrysanthemums into suitable pots and water them copiously-twice a day in hot weather is not too much.

Vegetable and Fruit Garden.-It is not too late to make another sowing of Runner Beans. If the weather be dry, water the drills before sowing, and let the seed be previously soaked in water for twelve hours or so.

Flower Garden.-Do not relax attention to the Roses-frequent syringing is beneficial and tobacco water is reckoned to be destructive to the green-fly. Lift those Tulips which have ceased to bloom and on which the foliage has turned yellow and put the bulbs to dry in the sun preparatory to storing.

\section{JUNE 24}

Greenhouse and Frames.-This is a good time for propagating the indoor Roses. Take cuttings of those which are best suited for the purpose.

Vegetable and Fruit Garden.-Make a final sowing of Broccoli seed for winter use. 


\section{A YEAR'S GARDENING}

Flower Garden.--Should you desire to try your hand at budding Roses, this is a good time to begin, if it be a showery day. Note that if the bark does not lift freely the operation had better be postponed for a few days.

\section{JUNE 25}

Greenhouse and Frames.-Begin the clearing of the greenhouse in preparation for the annual cleansing and painting, as at this season of the year, in ordinary weather, most of the plants will take no harm in being left out of doors for a few days.

Vegetable and Fruit Garden.-Look to the Broccoli seedlings and plant out those which are ready. Beware of allowing them to run up in the seed-bed-it is better to transplant them temporarily.

Flower Garden.-Look to the Violas and peg down any exuberant shoots, so that the plants may present an even and regular display of flowers.

\section{JUNE 26}

Greenhouse and Frames.-Continue yesterday's work of clearing the greenhouse and of arranging the plants in a suitable position outside.

Vegetable and Fruit Garden.-Plant out the seedlings of Brussels Sprouts and Savoys, puddling them in if the weather be dry. A little soot mixed with the water is beneficial.

Flower Garden.-Remove all dead flowers and seed-pods from the Violas and continue to do so at frequent intervals-daily, if possible - as a sure method of prolonging bloom.

\section{JUNE 27}

Greenhouse and Frames.-The rest of this month may well be devoted to the annual cleansing and re-painting of the greenhouse.

Vegetable and Fruit Garden.-Continue the work of planting out Brussels Sprouts and Savoys. If space be scarce, plant them between the rows of those Peas or Beans which will shortly be done with. Firm ground, not too recently dug up, is desirable for them.

Flower Garden.-Give attention to the Sweet Peas and continue to pick the flowers regularly and frequently, never permitting any seed-pods to form. 


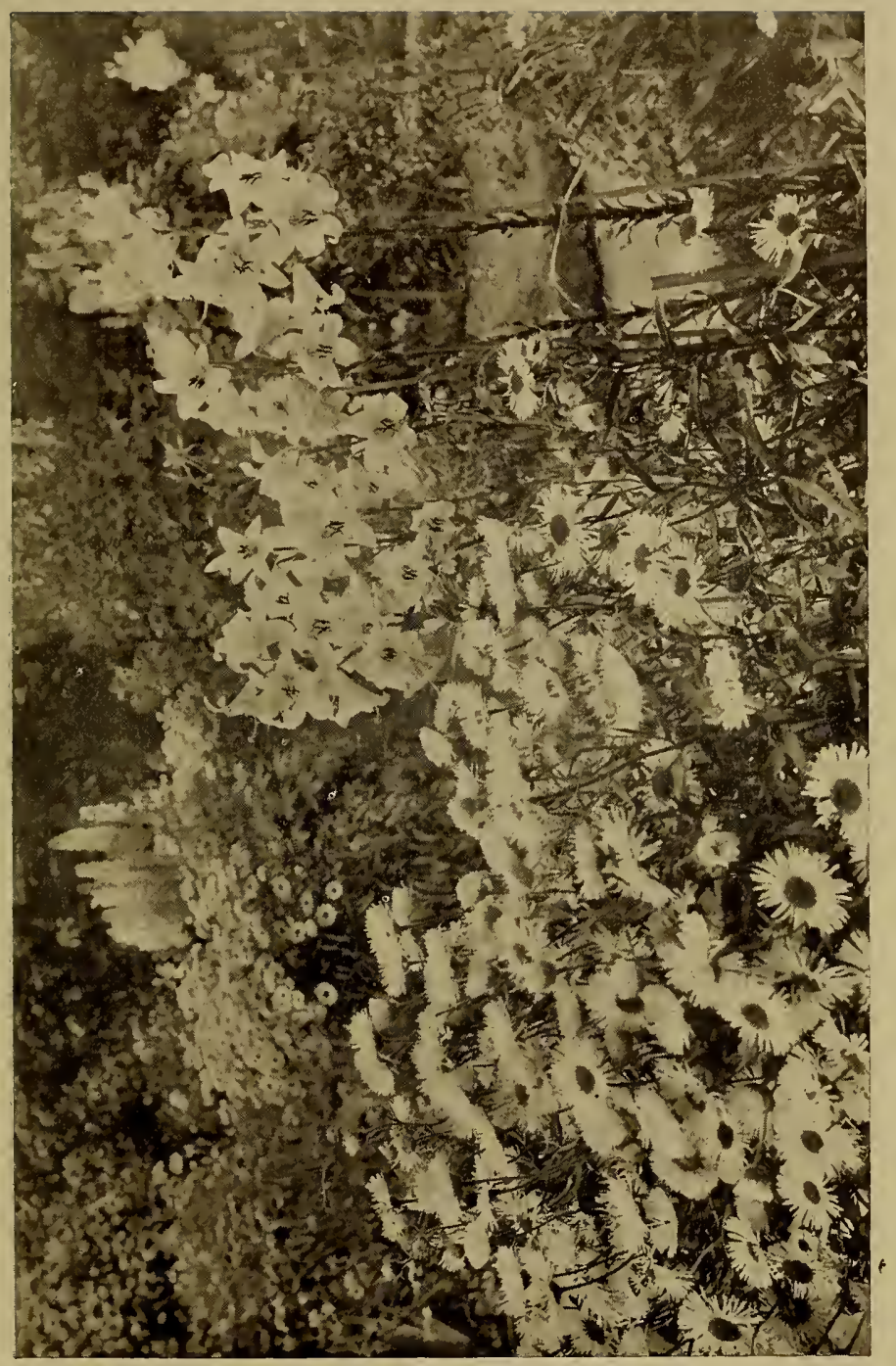





\section{A CALENDAR}

JUNE 28

Greenhouse and Frames.-Continue the annual cleansing and re-painting of the greenhouse.

Vegetable and Fruit Garden.-Plant out the young Cabbages and Cauliflowers which are ready. A proper succession is very desirable.

Flower Garden.-Look to the Gladioli and give proper support to those plants which need it. They are very liable to injury by wind.

\section{JUNE 29}

Greenhouse and Frames.-Continue the annual cleansing and re-painting of the greenhouse.

Vegetable and Fruit Garden.-Look to the young Carrots and thin out judiciously.

Flower Garden.-This is a suitable time of year for sowing Pansy seed in the open. Make a sowing to-day.

\section{JUNE 30}

Greenhouse and Frames.-Continue and complete, if possible, the re-painting of the greenhouse.

Vegetable and Fruit Garden.-Make a beginning in the final planting out of the Celery, as probably some plants are now ready to be got into their permanent quarters.

Flower Garden.-Make a sowing of Dianthus (Japan Pink, Indian Pink, etc.) in a shady situation. Sow in drills in finely sifted soil and cover very lightly.

\section{JULY I}

Greenhouse and Frames.-See that the greenhouse is thoroughly ventilated and the new paint quite hard before attempting to replace the plants.

Vegetable and Fruit Garden.-Start the month by collecting together all garden rubbish which may have accumulated.

Flower Garden.-At the present time and for two or three weeks to come the flower garden will probably be at its best. Give yourself sufficient leisure to enjoy its beauty. 


\section{A YEAR'S GARDENING}

\section{JULY 2}

Greenhouse and Frames.-Replace the plants in the greenhouse, arranging them in an orderly and suitable manner, such as will allow them to be conveniently attended to.

Vegetable and Fruit Garden.-In continuation of yesterday's work, dig a deep trench for the reception of soft decaying rubbish, such as Cabbage and Cauliflower stumps, green leaves of vegetables, pea-pods, withered flowers, etc., etc.

Flower Garden.-Though enjoying a well-earned leisure, do not neglect the light daily tasks which tend to keep the garden at its best. To-day go carefully over the Violas and remove any withered flowers or seed-pods which may have been overlooked.

\section{JULY 3}

Greenhouse and Frames.-As each pot is replaced in the greenhouse see that its soil is in proper condition and remove any moss or lichen.

Vegetable and Fruit Garden.-Complete the work of the last few days by dividing the soft from the hard wooded rubbish, laying the former in the trench you have prepared and covering it with a little soil as a deodorizer, and collecting the hard rubbish-such as tree, shrub and hedge clippings--into a heap for burning into wood-ash in the autumn.

Flower Garden.-Look over the Sweet Peas for withered flowers and seed-pods. See if the stems show signs of turning yellow at the base, and if so, give the plants a light mulching with a view to prolonging bloom.

\section{JULY 4}

Greenhouse and Frames.-Look to the exotic bulbs which have done flowering for the season and remove them to ripen in dry earth or sand in a warm place. Do not lift them if the stems are still green, but continue to water them until the foliage yellows.

Vegetable and Fruit Garden.-Complete the planting out of the main crop of Celery, a beginning in which work was made at the end of last month.

Flower Garden.-The Tropæolums and Dwarf Nasturtiums should now have daily attention. Look to them to-day and pick off all withered flowers, not permitting any seed-pods to form. 


\section{A CALENDAR}

JULY 5

Greenhouse and Frames.-Water the Hydrangeas now in flower with a weak solution of manure water so as to assist the effort of blooming.

Vegetable and Fruit Garden.-Continue the planting out of young Cabbage, Broccoli, Brussels Sprouts, etc., from time to time, and thus make useful successions of plants. Do some planting out today.

Flower Garden.-Give some special attention to the lawn to-day, considering whether the grass has been kept too short or not mown frequently enough in regard to the weather experienced. See also whether the weeds are so numerous as to need drastic measures.

\section{JULY 6}

Greenhouse and Frames.-Remove the Cinerarias into a cold frame, standing them on a layer of ashes. Shade them from the hot sun and syringe them frequently.

Vegetable and Fruit Garden.-Make a small sowing of Lettuce seed for autumn use. Do some more planting out of young greens.

Flower Garden.-Continue to give attention to the lawn, and if there are many Dandelions present, destroy them at once by cutting off the leaves with a sharp knife and then piercing the exposed rootheads with an iron skewer dipped in a phial of sulphuric acid.

\section{JULY 7}

Greenhouse and Frames.-Look to the Calceolaria seedlings which have been recently pricked off and select the strongest for potting up. Those in which yellow predominates are generally the most vigorous.

Vegetable and Fruit Garden.--Sow Radish seed in a shady spot. A rich soil and plenty of moisture are essential for the rapid growth which produces a satisfactory crop.

Flower Garden.--Continuing your examination of the lawn, be on the lookout this evening for daddy-long-legs, and if they are numerous over the grass it is doubtless infested with the grub, which comes to the surface at night and may be destroyed by late evening or early morning rolling. 


\section{A YEAR'S GARDENING}

\section{JULY 8}

Greenhouse and Frames.-Continue the potting up of the Calceolaria seedlings and bear in mind that the weakly specimens are often those from which the best colours come. Therefore pot the weaklings carefully and place them in a sheltered part of the greenhouse.

Vegetable and Fruit Garden.-Complete the planting out of young Greens but reserve the main sowing of seed until next month, any advice to the contrary notwithstanding.

Flower Garden.-Look to the Dahlias; thin out weak stems and carefully stake those which are retained. Water the plants liberally with a weak solution of liquid manure.

\section{JULY 9}

Greenhouse and Frames.-Look to the Pelargonium cuttings made in the spring. Re-pot them and nip off the flower buds and any exuberant shoots, in order that the plants may retain a dwarf and bushy growth.

Vegetable and Fruit Garden.-Look to the wall-fruit trees and remove any useless or ill-placed shoots which were overlooked or neglected last month. Do not delay-the opportunity will be lost when the fruit begins to ripen.

Flower Garden.--Look to the Hollyhocks, and if the weather be dry give them a mulching as a means of prolonging their bloom. See that the stakes hold good and that the plants are properly secured to them.

\section{JULY Io}

Greenhouse and Frames.-Remove the Chinese Primulas to a cold frame, as forcing the growth of these plants will spoil them. They are naturally hardy and should be allowed to mature slowly.

Vegetable and Fruit Garden.-Make a final thinning of the Peaches, Nectarines, etc., not only of the fruit but also of the leaves, which may shade the fruit and deter it from ripening.

Flower Garden.-See that the Evening Primroses are securely staked - they are well worthy of careful treatment. 


\section{A CALENDAR}

\section{JULY II}

Greenhouse and Frames.-Look to the Freesias and re-pot those required for early flowering in a compost of rich loam, leaf mould and sand. Care is needed in the operation, as the bulbs are small and the rootlets fragile.

Vegetable and Fruit Garden.-Give some adequate protection to the ripening fruit from the ravages of birds. Netting is the most effectual.

Flower Garden.-Now is a good time for layering Carnations. Make a beginning to-day unless the weather is very dry.

\section{JULY I2}

Greenhouse and Frames.-Give attention to the tuberous Begonias and give them some shade, lest the leaves should be scorched. Water them freely and cut out any sign of rot which may appear on the stems.

Vegetable and Fruit Garden.-Prepare a bed for a new plantation of Strawberry plants. Now is an excellent time.

Flower Garden.--Pansy and Viola seed may still be sown. Make a sowing of each to-day, choosing a shady situation and covering the seed lightly with fine earth.

\section{JULY I3}

Greenhouse and Frames.-Look to the Cyclamens and shift into larger pots those which are sufficiently advanced.

Vegetable and Fruit Garden.--Let to-day's work be to detach the Strawberry runners which have been allowed to root themselves from the store plants and to plant in as many as are required for the bed prepared yesterday.

Flower Garden.-The latter half of July often brings showery weather, which should be utilized for sowing some of the hardy annuals. Make a sowing to-day of Antirrhinum for next year's flowering. In most cases drills are preferable to broadcast sowing, giving better scope for weeding. 


\section{A YEAR'S GARDENING}

\section{JULY I4}

Greenhouse and Frames.-If the Calceolaria seedlings recently potted up have proved deficient in quantity or quality, lose no time in regrets-make another sowing to-day.

Vegetable and Fruit Garden.-Continue your work on the Strawberry plants, potting up some of the rooted runners and storing them in a frame preparatory for forcing later on.

Flower Garden.-Continue the work of sowing hardy annuals and to-day make a sowing of Sweet Alyssum.

\section{JULY I5}

Greenhouse and Frames.-Sow Mignonette seed for winter flowering. A good compost for the purpose may be made of rich loam, leaf mould and sand; fill a few small pots with this, dropping some half-dozen seeds into each pot, and keep them moist and shaded.

Vegetable and Fruit Garden.-Make to-day a sowing of Endive for winter use, and another sowing at the end of the month would be advisable.

Flower Garden.-Make a sowing of Mignonette, bearing in mind that the bed should be very firm-indeed the soil should be trodden down.

\section{JULY I6}

Greenhouse and Frames.--Sow in pots or pans some seed of the perennial Lobelia, as a provision for bedding out next year.

Vegetable and Fruit Garden.-Lift the Garlic and Shallots, unless the weather be unsuitable, and if necessary store under shelter for ripening.

Flower Garden.-Make a sowing to-day of various sorts of Candytuft. There are many colours-white, purple, crimson, carmine, etc. - and several heights in growth.

\section{JULY I7}

Greenhouse and Frames.-Make a sowing of tuberous Begonia seed, so as to give the seedlings an opportunity of becoming strong before winter and ready to flower in the spring. 


\section{A CALENDAR}

Vegetable and Fruit Garden.-Plant out the Leeks, and if the weather be unusually dry, let them be planted in trenches, with a view to securing as much moisture as possible.

Flower Garden.-If not already done, make a sowing to-day of Primrose seed on a shady border. There are now many beautiful shades of colour in this flower, from white to deep crimson, besides various tints of yellow.

\section{JULY I8}

Greenhouse and Frames.-Make another sowing of Cineraria seed, especially if last month's sowing was omitted. Few greenhouse plants can exceed the Cineraria in beauty and variety of flower.

Vegetable and Fruit Garden.--Make a main sowing of Turnips for autumn and winter use. Thin out the advancing crop and keep it clear of weeds.

Flower Garden.-Look to the Lilies (Lilium candidum) and see that they are unobtrusively but securely staked. Give them a few doses of weak manure water.

\section{JULY I9}

Greenhouse and Frames.-Look to the Cucumber beds and keep them well watered. Overhead watering may be insufficient-the soil should be kept moist.

Vegetable and Fruit Garden.-Keep a watch on the growth of the Vegetable Marrows and mulch them liberally-a method which is often better than mere watering.

Flower Garden.-Should yesterday's examination of the Lilies have shown them in bad condition, lift them, and if the bulbs have any sign of disease, dust them with flowers of sulphur and burn diseased stems and leaves. Healthy plants should not be moved.

\section{JULY 20}

Greenhouse and Frames.-Make a sowing of Cucumber seed for autumn supply.

Vegetable and Fruit Garden.-Sow a little Onion seed, with a view to providing young Onions for autumn salads. Also make a small sowing of Carrot seed, in an open spot, for use in winter and early spring. 


\section{A YEAR'S GARDENING}

Flower Garden.-The choice kinds of Polyanthus deserve special attention. Lift the plants to-day, pot them, and place them in a shaded cold frame to protect them through the winter.

\section{JULY 2 I}

Greenhouse and Frames.-Look to the Melons, and if the fruit is beginning to ripen, desist from watering, lest the fruit should crack.

Vegetable and Fruit Garden.-Prepare a bed for next month's sowing of Prickly Spinach, selecting a high and dry spot and digging it over thoroughly (twice digging is sometimes advisable) to allow the birds to destroy the Spinach moth grub. Use no manure.

Flower Garden.-Yesterday's work among the Polyanthuses may have revealed the need for division of the remaining plants. If so, divide and re-plant them to-day, especially if showery weather prevails.

\section{JULY 22}

Greenhouse and Frames.-See to the Tomato plants which have been raised in pots. Those which are in fruiting condition plunge (without removing from the pots) into the hot-bed, where the mild heat and the root constriction of the pots will assist the fruit-bearing capacity of the plants.

Vegetable and Fruit Garden.-Continue yesterday's work in the preparation of the Spinach bed.

Flower Garden.-Lift and divide the Primroses and Daisies today, unless that has already been done.

\section{JULY 23}

Greenhouse and Frames.-Look to the bulbs which have been lifted, and for storing and ripening them make use of any unused frames.

Vegetable and Fruit Garden.-Give attention to the Potato patch and see if some of the early variety are ready for lifting. It is often wise not to wait until the haulms are died down.

Flower Garden.-Cuttings of bedding Pelargoniums may be struck in the open at this time of year. Make some cuttings today and insert them in a warm border. 


\section{A CALENDAR}

\section{JULY 24}

Greenhouse and Frames.-Consider what cuttings it is desirable to make from the greenhouse plants and prepare one of the unused frames to receive them.

Vegetable and Fruit Garden.-Plant a small quantity of quickgrowing Potatoes for use as New Potatoes later in the year, when they are more than usually acceptable.

Flower Garden.--Variegated-leaved Geraniums make better foliage if the flowers are removed. Pick off the blooms from those plants you are using for foliage display.

\section{JULY 25}

Greenhouse and Frames.-Make cuttings of Hydrangeas, inserting each cutting singly in a small pot of light, loamy soil, and place them in the frame under suitable shade.

Vegetable and Fruit Garden.--Earth up the late variety Potatoes, and if the haulms show any signs of disease, bend them well over to one side, so that the disease spores may not fall upon the tubers.

Flower Garden.-Look to the Delphiniums and cut down the flower stems which have ceased to bloom.

\section{JULY 26}

Greenhouse and Frames.-Make cuttings of Geraniums, using only strong and healthy shoots, and place them in the shaded frame now allotted to cuttings.

Vegetable and Fruit Garden.-Look to the Sea-kale and let it have plenty of water, particularly the young plants. Strew soot or woodashes about them as a prevention of insect attacks.

Flower Garden.-Examine the Hollyhocks and sponge with a solution of insecticide any leaves presenting brown excrescences.

\section{JULY 27}

Greenhouse and Frames.-Make cuttings of such of the Fuchsias as you wish to increase and remove them to the appointed frame.

Vegetable and Fruit Garden.-The Sweet Herbs, such as Mint, Sage and Thyme, are probably now about to flower; if so, cut some to-day for winter use, and lay it where it will dry in the sun and be sheltered from the rain. Make another sowing of Endive. 


\section{A YEAR'S GARDENING}

Flower Garden.-Make a sowing to-day of Hollyhock seed in the open border and by the autumn the seedlings should be sufficiently advanced to be transferred to a frame for the winter. Obtain the best and cleanest seed, for the Hollyhock fungus (Puccinia malvacearum) is a virulent pest.

\section{JULY 28}

Greenhouse and Frames.-Continue to make cuttings of such greenhouse plants and shrubs as you desire to propagate.

Vegetable and Fruit Sarden.-Devote the remaining days of this month to exhaustive and thorough weeding (especially if the weather be dry), to the removal of all crops which are past bearing, and to the preparation of the ground, thus made vacant, for future crops.

Flower Garden.-Look to the Dahlias and set traps for the earwigs. A small flower-pot, half-filled with dry moss and set upside down on a stake, is effective if cleared out daily.

\section{JULY 29}

Greenhouse and Frames.-Continue, and if possible complete, the work of making summer cuttings from greenhouse plants.

Vegetable and Fruit Garden.-Continue the work of weeding, clearing and preparing the ground for new crops.

Flower Garden.-Give the Dahlias a liberal watering of weak liquid manure and repeat the dose two or three times at intervals of a few days.

\section{JULY 30}

Greenhouse and Frames.-Make cuttings of any choice Pansies, selecting young shoots from the root of the plant, and place them in the frame now devoted to cuttings.

Vegetable and Fruit Garden.-Continue the work of weeding, clearing and preparing the ground for new crops.

Flower Garden.-Make a sowing in a moist soil and in a shady situation of some varieties of Mimulus (including Musk, Mimulus moschatus) for tlowering in the following spring. 


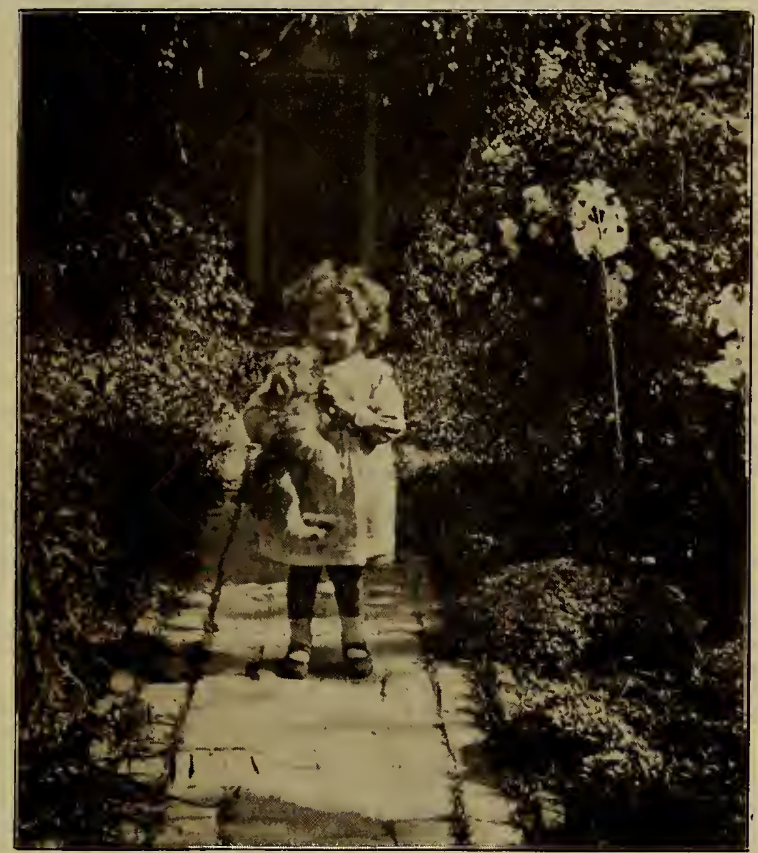

OUR WEEK-END COTTAGE.

The Path to the Front-door.

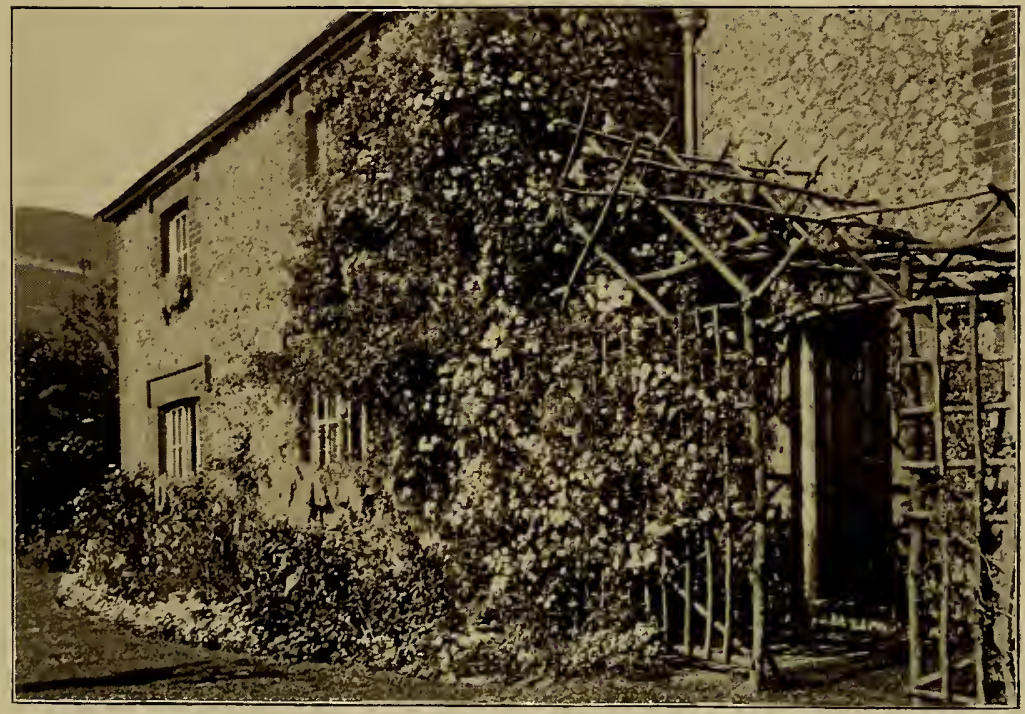

OUR WEEK-END COTTAGE.

The Porch at the Side-door. 



\section{A CALENDAR}

\section{JULY 3 I}

Greenhouse and Frames.-Make cuttings of your best Violas, choosing those shoots which are fibrous and not flowering, and place them in the appointed frame.

Vegetable and Fruit Garden.-Continue, and if possible complete, the work of weeding, clearing and preparing the ground for new crops.

Flower Garden.-Complete the layering of the Carnations, a beginning of which work was prescribed earlier in the month.

\section{AUGUST I}

Greenhouse and Frames. - Compared with the abundance of flowers in the open garden the contents of the greenhouse is now scanty, presenting a convenient opportunity for giving special attention to the climbers and other plants which are permanent in the house. Begin to-day by making a general examination of what such plants require in training, pruning, etc.

Vegetable and Fruit Garden.-Look to the Tomatoes and let those plants which are full of fruit be watered freely with liquid manure.

Flower Garden.-Begin the month by looking through the annuals and clearing away those which have flowered.

\section{AUGUST 2}

Greenhouse and Frames.-Let to-day's work be the pruning of the climbers, cutting back the strong growers to proper limits and removing the shoots which have done blooming with a view to inducing second flowering where that is probable.

Vegetable and Fruit Garden.-If yesterday's survey of the Tomato plants showed some which were dwindling and fading, do not hesitate to remove them. They are probably diseased and should be pulled up and burnt at once.

Flower Garden.-Continue the work of clearing away plants which have done flowering, not forgetting the bulbs where the foliage is withered.

AUGUST 3

Greenhouse and Frames.-Continue, and if possible complete, yesterday's work on the climbers, bearing in mind the advantage 


\section{A YEAR'S GARDENING}

of providing more ingress for light now that the days are decreasing in length.

Vegetable and Fruit Garden.-Attend to the Gooseberry and Currant bushes, picking the fruit as it ripens and seeing that, meanwhile, it is duly protected from the birds. Black Currants, especially, should be picked as soon as ripe-they quickly shrivel when left on the bush.

Flower Garden.--If the layering of the Carnations was not completed last month, let it be done to-day-it is not too late.

\section{AUGUST 4}

Greenhouse and Frames.-Give attention to the foliage plants in the house, such as Palms, Indiarubber Plants, Aspidistras, etc., sponging the leaves (a little milk added to the water is recommended), giving unobtrusive support to stems which require it and removing all traces of decay.

Vegetable and Fruit Garden.-Keep a keen watch over the wallfruit - on Peaches, Nectarines, Apricots, etc.-and do all you can to protect it from the attacks of wasps and flies. Set traps for them to-day, by hanging on the wall or branches wide-mouthed, steepshouldered bottles containing syrup.

Flower Garden.-Look to those Carnations which were layered early and take off and pot any which are rooted.

\section{AUGUST 5}

Greenhouse and Frames.--Look to the winter-flowering Begonias and consider whether you should begin to give them an occasional watering of weak liquid manure. See that they are so placed that no injury is being done to their handsome, fleshy leaves.

Vegetable and Fruit Garden.-Look out, also, for snails, which often attack and spoil the wall-fruit. Search for them at evening or early morning and destroy them.

Flower Garden.-Continue the work on the rooted layers of Carnations. Two or three rootlets may be placed in one pot, and the pots should then be allowed to stand in a shady situation, so that the plants may be well established before winter. 


\section{A CALENDAR}

\section{AUGUST 6}

Greenhouse and Frames.-Look to the Caladiums, Crotons, Dracœna, and such like plants of ornamental foliage, and do what is necessary to keep them in good condition. Caladiums should now have but little water and be gradually dried off.

Vegetable and Fruit Garden.-Look to the standard fruit treesApples, Pears, etc.-and thin out where the fruit is crowded. A rough-and-ready method is to shake the trees, by which means the blighted and useless fruit is brought down.

Flower Garden.-Look to the young Asters and lift from the borders those which are intended for indoor plants. Pot them with care and with the least possible disturbance to the roots.

\section{AUGUST 7}

Greenhouse and Frames.-Continue to give attention to the plants which remain in the greenhouse, such as the Arum Lilies, the Asparagus Fern, the Bouvardia, the Balsams, the various Heaths and Cacti, etc., etc.

Vegetable and Fruit Garden.-Continue to give attention to the standard fruit trees and give suitable support to any boughs which are heavily laden with fruit.

Flower Garden.-Look to the Dianthus (Pink) seedlings and transfer those which are sufficiently grown to their flowering quarters. They will do best in a porous soil and a sunny situation.

\section{AUGUST 8}

Greenhouse and Frames.-Look to the Gloxinias and refrain from watering those which are ceasing to bloom. The Achimenes should be treated in the same way.

Vegetable and Fruit Garden.-Make a sowing of Prickly Spinach, in the bed prepared for it last month, as a provision for the early spring.

Flower Garden.-Plant out the young Pansies which have been made from cuttings or raised from seed, or at least such of them as are sturdy enough, taking care to have a ball of earth to each plant and to leave the other plants undisturbed. 


\section{A YEAR'S GARDENING}

\section{AUGUST 9}

Greenhouse and Frames.-Pot up the Tobacco plant (Nicotiana affinis) seedlings in preparation for their flowering in winter.

Vegetable and Fruit Garden.-Make a main sowing of Cabbage seed. It is certainly advantageous to sow two distinct varieties, thus ensuring a difference in the crop, which will be appreciated at table.

Flower Garden.-Make up a bed for planting out the Brompton Stock seedlings, choosing a site which is protected by trees or shrubs. The soil should be rich and good.

\section{AUGUST Io}

Greenhouse and Frames.-The small, pure white Roman Hyacinths are imported into this country at this season. Plant a few in pots to-day and they will be flowering in November and December.

Vegetable and Fruit Garden.-Make a small sowing of Brussels Sprouts. Sow thinly and allow some of the plants to stand the winter in the seed-bed.

Flower Garden.-Complete yesterday's work by planting out the Brompton Stock seedlings in the prepared bed.

\section{AUGUST II}

Greenhouse and Frames.-Make cuttings from such of the Cacti as you wish to propagate. The slips should be 2 or 3 inches long, or more, according to size of plant, and should be put to dry in the sun for a day or two, until the sap has ceased to ooze from the incised end, before being inserted in soil.

Vegetable and Fruit Garden.-Earth up such of the Celery plants as are ready for the process, bearing in mind that the earthing stops the growth and therefore should not be done before it is necessary.

Flower Garden.-Take a comprehensive view of the various Saxifrages you have and take off sets from the sides of those plants you wish to propagate.

\section{AUGUST I2}

Greenhouse and Frames.--Look to the frames, and begin to-day the work of cleansing, repairing and painting those which are not now in use. 


\section{A CALENDAR}

Vegetable and Fruit Garden.-Cut down the Globe Artichokes of which the heads have already been used, and those (if any) which you have selected for making Chards should be kept well supplied with water.

Flower Garden.-Now is a good time for the main sowing of annuals. Prepare a seed-bed to-day, choosing a position not exposed to the full glare of the sun and pulverizing the soil thoroughly with a rake. Sow in drills rather than broadcast.

\section{AUGUST 13}

Greenhouse and Frames.-Continue the work begun yesterday on the frames now out of use, in order that they may be ready when wanted. Look out for insect pests and destroy them.

Vegetable and Fruit Garden.-If you care for Corn Salad (otherwise Lamb's Lettuce), make a sowing to-day. It is valuable for use in early spring.

Flower Garden.-Make a sowing to-day of Calandrinia on the bed prepared yesterday. Both the grandiflora and the umbellata are useful, the latter being a trailing plant. Sow also two or three varieties of Calendula-the double-flowered officinalis is excellent.

\section{AUGUST I4}

Greenhouse and Frames.-Continue and complete the work of the last two days on the frames. See that the glass is clean.

Vegetable and Fruit Garden.-Make a sowing of Lettuce seed of some hardy kind (Winter White Cos is good) that will stand the winter.

Flower Garden.-Continue the work of sowing annuals-say, the dwarf Calliopsis, an annual of compact habit and abundant bloom of several colours, and also some of the double-flowered Clarkias.

\section{AUGUST I5}

Greenhouse and Frames.-See to the Cacti cuttings recently made, and if they are sufficiently dry, insert them singly in small pots filled with sandy soil mixed with a little old mortar. Very little water should be given them until they are rooted. 


\section{A YEAR'S GARDENING}

Vegetable and Fruit Garden.-Look to the young Endive plants and plant out those that are large enough. Make a final sowing, if desirable.

Flower Garden.-Continue the sowing of annuals-Collinsia, for instance (the large-flowered white and the deep lilac), and the bright yellow Coreopsis.

\section{AUGUST I6}

Greenhouse and Frames.-Bulbs which are intended for early potflowering should be planted about this time. Make a small selection to-day, pot them and place them in a cold frame, covering them with ashes or cocoa-nut fibre until well rooted.

Vegetable and Fruit Garden.-Make a final sowing of Onion seed, first sprinkling the ground with a mixture of soot and salt-an excellent fertilizer and preventive of disease in the crop.

Flower Garden.-Continue the sowing of annuals, such as the Arkansas Erysimum (the Wallflower of the West) and the wellknown Eschscholtzia, of which there are many beautiful strains.

\section{AUGUST I7}

Greenhouse and Frames.-Annuals for winter and spring flowering may be easily raised in a cold frame at this season from seed sown in pots. Make a sowing to-day of, say, Mignonette and Nemophila.

Vegetable and Fruit Garden.-Make a sowing of Cauliflower seed. The young plants will require some protection during the winter.

Flower Garden.-Continue the sowing of annuals. A selection of Godetias should certainly be included. There are many named strains and the double-flowered varieties are very handsome.

\section{AUGUST I8}

Greenhouse and Frames.-Continue the work begun yesterday by making a sowing of other annuals for early flowering, in accordance with the space at disposal in the cold frame. There is a large variety to select from. Try Calvary Clover and Calendula.

Vegetable and Fruit Garden.-Look to the Runner Beans and nip off the tops of those which are running too vigorously, thus assisting them to set. 


\section{A CALENDAR}

Flower Garden.-Continue the sowing of annuals. The popular Larkspur (especially the Dwarf Rocket strain) and the dwarf Leptosiphon (both blue and white) should not be omitted.

\section{AUGUST I9}

Greenhouse and Frames.-Complete the work of sowing annuals to be raised in a cold frame.

Vegetable and Fruit Garden.-If all the Celery plants have not yet been got out into their permanent quarters, delay no longerdo it to-day.

Flower Garden.-Although the main sowing of annuals has not been completed in the last few days' work, the daily routine necessary to keep the garden in good order must not be neglected. The dead flowers should be picked off day by day, the lawn duly mown, and a watch kept lest trailing and climbing plants exceed their limits.

\section{AUGUST 20}

Greenhouse and Frames.-Look to the Chinese Primulas in the cold frame and give larger pots to those which are well rooted. Moisten the foliage, give them plenty of air, and shade them from the sun.

Vegetable and Fruit Garden.-Earth up some more of the Celery, taking care that the earth does not get into the hearts and that the plants are moist at the roots before being banked.

Flower Garden.-Give particular attention to-day to the Hollyhocks, Dahlias and other tall-growing plants, which are likely to need re-tying to their supports, especially if windy weather has prevailed.

\section{AUGUST 2I}

Greenhouse and Frames.--Go through the Violet bed and select some good healthy plants to force into early bloom. Lift them and put them in pots in a cold frame, preparatory to removal to the greenhouse before winter sets in.

Vegetable and Fruit Garden.-Plant out some of the young Cabbages as a supply of Early Coleworts. If planted out now they should be ready for cutting in November.

E

65 


\section{A YEAR'S GARDENING}

Flower Garden.--Plant out the seedling Canterbury Bells, Sweet Williams and other young perennials as the removal of annuals permits.

\section{AUGUST 22}

Greenhouse and Frames.-Keep a watch on the Cucumbers and on the first appearance of mildew sprinkle them with sulphur dust. Cover them at night if the weather be cold.

Vegetable and Fruit Garden.-Give attention to the Tomatoes; see that they have proper support and training and that the ripening fruit is well exposed to the sun.

Flower Garden.-Continue yesterday's work in the planting out of seedling perennials as space allows.

\section{AUGUST 23}

Greenhouse and Frames.-See that the Melon bed is maintained at a good heat and decrease the supply of water as the fruit ripens.

Vegetable and Fruit Garden.-Look to the Vegetable Marrows, pinching off all superfluous growth, so as to increase their fruit-bearing, and bringing the flowers well to the light and sunshine.

Flower Garden.-Resume the sowing of annuals. Shirley Poppy, German Scabious, Silene, Sweet Sultan and Virginian Stock all deserve a place.

\section{AUGUST 24}

Greenhouse and Frames.-A cold frame will be found very useful for storing pots of cuttings. Make preparation to-day to take advantage of this, and also fill a sufficient number of pots with light soil, well drained.

Vegetable and Fruit Garden.--Unless the weather be wet, lift the Shallots to-day and lay them in the open air to ripen.

Flower Garden.-Continue the sowing of annuals as suggested yesterday.

\section{AUGUST 25}

Greenhouse and Frames.-Take cuttings of such plants as you wish to propagate (say Petunias and Verbenas) and insert the cuttings in some of the pots prepared yesterday, afterwards placing them in the appointed frame. 


\section{A CALENDAR}

Vegetable and Fruit Garden.-Look to the Brussels Sprouts, Broccoli and the Winter Greens and earth them up, unless the weather be very dry.

Flower Garden.-Complete the August sowing of annuals, bearing in mind that those mentioned are merely suggestive; there are many other beautiful annuals very useful as a succession to spring flowers.

\section{AUGUST 26}

Greenhouse and Frames.-Continue the work of making cuttings for storing in a cold frame. To-day make cuttings from, say, Pelargoniums and Fuchsias, choosing firm and sound shoots for the operation.

Vegetable and Fruit Garden.-Continue to give attention to the Winter Greens and go over the ground with the hoe to clear it of all weeds. Take up by hand any groundsel or sow-thistle in flower and burn them at once, without scattering the seed.

Flower Garden.--Look to the seedling Wallfowers and transplant them some 4 or 5 inches apart so as to give them opportunity of bushy growth. Plant them firmly in the earth.

\section{AUGUST 27}

Greenhouse and Frames.-Continue and complete the work of making cuttings for a cold frame. Marguerites, Pentstemons, Ageratums, etc., may be thus propagated.

Vegetable and Fruit Garden.-See to the Raspberry canes and cut down those which have borne fruit.

Flower Garden.-Plant some of the early-flowering bulbs, such as Snowflake (Leucojum) and Snowdrops.

\section{AUGUST 28}

Greenhouse and Frames.-Make a small sowing in a cold frame of Hardy White Cos and Hardy Green Cabbage Lettuce seed, so that the seedlings may shortly be ready to be transplanted to the open ground and stand the winter. 


\section{A YEAR'S GARDENING}

Vegetable and Fruit Garden.-Continue to give attention to the Raspberry canes and see that this year's canes, which are the fruitbearers of next year, have proper room for growth. Thin out if necessary.

Flower Garden.-Look to such spreading clumps of perennials as Thrift, Pinks, Sweet Williams, etc., and divide and re-plant if desirable.

\section{AUGUST 29}

Greenhouse and Frames.-Look to the Orchids and examine carefully for any evidence of attacks of thrip, particularly in the young growths. Tobacco smoke is the accepted remedy.

Vegetable and Fruit Garden.-Go through the Strawberry beds, weeding them thoroughly and cutting off all runners.

Flower Garden.-Continue the work of dividing and re-planting suggested yesterday.

\section{AUGUST 30}

Greenhouse and Frames.-Continue to give attention to the Orchids, withholding water from those where flow ering has ceased and supplying the strong, growing plants with a weak solution of cow-manure.

Vegetable and Fruit Garden.-New plantations of Strawberry plants may yet be made, but must not be delayed. If a new Strawberry bed is desired, make it to-day.

Flower Garden.-Look to the China Asters, stirring gently the soil between them and supplying an occasional watering of liquid manure.

\section{AUGUST 3I}

Greenhouse and Frames.-Complete your special survey of the Orchids by sprinkling around them a mixture of soot and lime, as a deterrent to insects and a general purifier.

Vegetable and Fruit Garden.-Look to the out-door Vine and remove all useless growth. See that the grapes are fully exposed to the sun. Thin the bunches, if necessary.

Flower Garden.-See to the Lavender bushes; the flowers should now be ready to be cut for drying. 


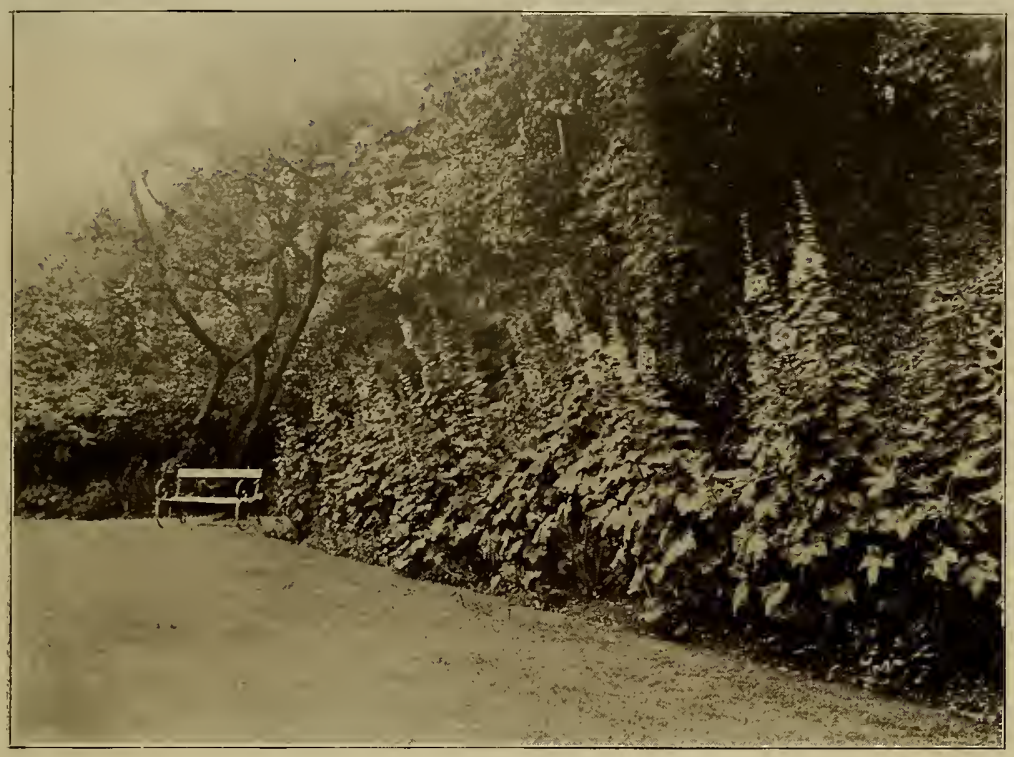

OUR WEEK-END COTTAGE.

A Border of Hollyhock.

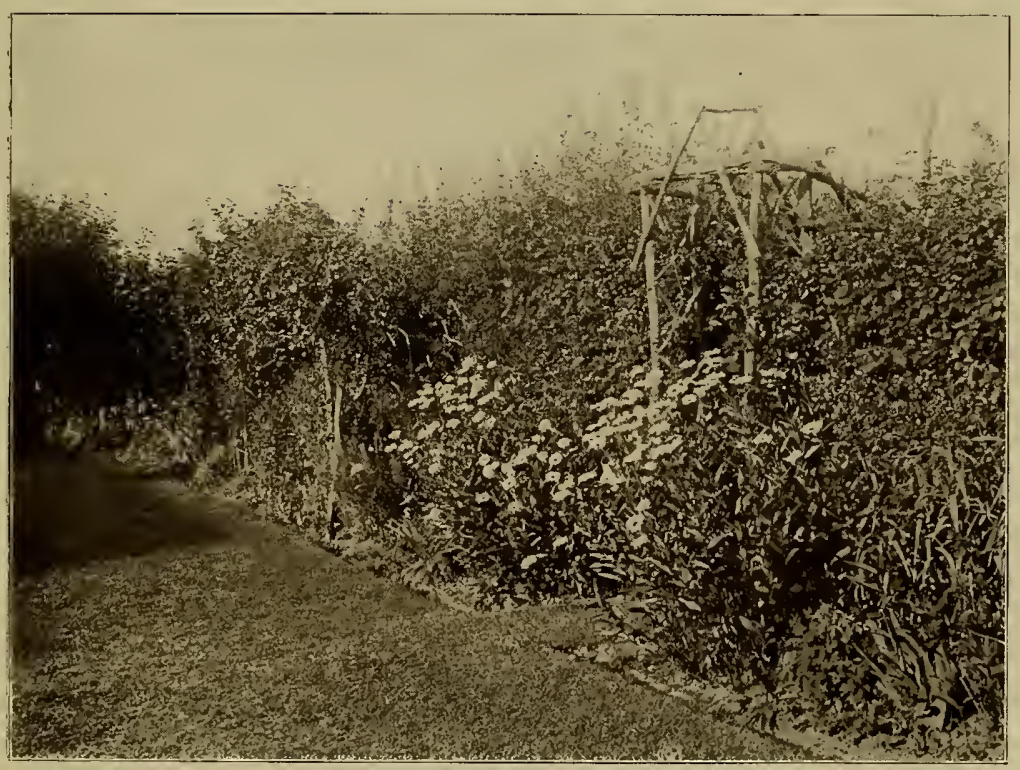

OUR WEEK-END COTTAGE,

Entrance to the Pergola. 



\section{A CALENDAR}

\section{SEPTEMBER I}

Greenhouse and Frames.-See that the summer shading of the greenhouse is partially withdrawn and that the climbers on the roof are sufficiently thinned to admit light and warmth from the sun.

Vegetable and Fruit Garden.-Take a general look round the vegetable garden and consider what arrangements have yet to be made for the winter and early spring crops, lest you discover, when too late, that something has been omitted.

Flower Garden.-Prepare a small bed, in a suitable situation, of good sandy loam for the planting of Dog's-tooth Violets-beautiful in their spring flowering and compact foliage.

\section{SEPTEMBER 2}

Greenhouse and Frames.--Look to the ventilating arrangements in the greenhouse; a well-ventilated, cool house is especially important at this time of year to enable the wood of the plants to ripen and fit them for the winter.

Vegetable and Fruit Garden.-Weeding must not be neglected; to allow the weeds to scatter their seeds brings much future labour. Begin to-day to make a thorough weeding among all the crops.

Flower Garden.-Plant the bulbs of the Dog's-tooth Violet in the bed prepared yesterday. To get the best effect plant rather closely and use both the white and red varieties.

\section{SEPTEMBER 3}

Greenhouse and Frames.-Begin to be more sparing in watering the plants in the house, as not rapid growth but continued flowering and maturing of wood are now the chief objects in view.

Vegetable and Fruit Garden.-Continue the work of weeding and hoeing, rooting up the weeds by hand where necessary (see 26th August) and stirring up the soil round the roots of the plants.

Flower Garden.-Now is a good season of the year for planting bulbs in the open. Put in some Alstrœmeria to-day, giving them a dry soil and a sunny position, and planting them some 9 inches deep. 


\section{A YEAR'S GARDENING}

\section{SEPTEMBER 4}

Greenhouse and Frames.-Look to the Chrysanthemums and transplant into larger pots those which are coming on well. Stake them carefully.

Vegetable and Fruit Garden.-Remove the crops which have finished bearing and fork over the ground deeply before planting again, manuring where necessary. Trench any ground you may intend to leave vacant for the winter, so that it may mellow in the frost.

Flower Garden.-Plant also some Ixias and Sparaxis, which need much the same treatment as the Alstrœmerias. A dry sandy border under a wall of southern aspect would suit them well.

\section{SEPTEMBER 5}

Greenhouse and Frames.-Give special attention to-day to the Cinerarias. Select those plants from which suckers can be conveniently taken for propagation. Make cuttings accordingly and pot them up.

Vegetable and Fruit Garden.--Earth up the Celery plants which have attained their full growth, taking care that the roots are moist but the tops dry.

Flower Garden.-Plant a few of both the English and Spanish varieties of the Iris. A rich soil is not requisite for them, but they should be lifted and replanted elsewhere every two or three years.

\section{SEPTEMBER 6}

Greenhouse and Frames.-Look to the Cineraria seedlings, prick them off, and pot a few of the most sturdy to push forward for early flowering.

Vegetable and Frnit Garden.-Look to the Parsley bed, cutting down some of the well-grown roots to provide a new crop before winter, and thinning out the seedlings to enable them to stand the winter.

Flower Garden.-Plant also some Fritillarias, especially the Crown Imperial, a bulb which produces a handsome spring flowering plant and which needs a rich loamy soil and an open position. Set the bulbs some 4 to 6 inches deep. 


\section{A CALENDAR}

\section{SEPTEMBER 7}

Greenhouse and Frames.-Look to the Calceolaria seedlings and re-pot those whose growth requires it. Keep them close to the glass, so as to induce a dwarf habit.

Vegetable and Fruit Garden.--Now that many of the summer crops have come to an end and are being cleared away day by day the planting of the winter crops should go on apace. Plant out a batch of Cauliflowers to-day.

Flower Garden.-Look to the Dahlias, and if you wish to obtain first-class specimens of flowers disbud and thin the shoots, tying them carefully where required.

\section{SEPTEMBER 8}

Greenhouse and Frames.-Let to-day's work be devoted to the Pelargoniums, for on their proper care in autumn their future profusion of bloom depends. Examine each plant, and any that are beginning to go off place out of doors to ripen their wood in the sun.

Vegetable and Fruit Garden.-Continue to give attention to the planting out of winter crops. Put in some Cabbages to-day, first forking over the ground thoroughly and digging in deeply manure or garden refuse. To produce good plants they must grow fast, for which a rich soil is necessary.

Flower Garden.-Continue to give attention to the Dahlias. Give them a good soaking of manure water, if the weather be dry, and protect the choice blooms from the sun's scorching heat by caps of paper. Be vigilant against earwigs, examining the traps frequently and destroying the catch.

\section{SEPTEMBER 9}

Greenhouse and Frames.-Examine the Heaths for any sign of mildew, and on the least appearance of the disease-to which Heaths are particularly liable-give the plants infected a dusting of sulphur.

Vegetable and Fruit Garden.-Continue the work of preparing the ground for winter crops, digging up and manuring each plot as it becomes vacant.

Flower Garden.--See to the Hollyhocks, thinning and tying the shoots where necessary, and supplying them with manure water as a means of prolonging their bloom. Keep a continuous watch for earwigs. 


\section{A YEAR'S GARDENING}

\section{SEPTEMBER Io}

Greenhouse and Frames.-Continue to give attention to the Heaths. Examine each plant and see that it is well drained, with no stagnant water at the roots, as a preventive of attacks of mildew.

Vegetable and Fruit Garden.--Plant out another batch of Cabbages, allowing for the larger kinds a distance of about 2 feet each way between the plants.

Flower Garden.-Plant out the young Pansy cuttings which have rooted well and prick out the seedlings which are sufficiently advanced.

\section{SEPTEMBER II}

Greenhouse and Frames.-Now is a suitable time for beginning to plant Crocuses for indoor decoration. Choose a few good named varieties and plant some to-day in pots, seed-pans or shallow boxes filled with rich light soil.

Vegetable and Fruit Garden.-Plant out another batch of Cauliflowers for the winter.

Flower Garden.-Prick out the seedlings from the open-air sowing of Polyanthuses and Auriculas, planting them into a bed of good soil and in a shady situation.

\section{SEPTEMBER I2}

Greenhouse and Frames.-Pot up a few roots of tuberous Anemones, putting them I or 2 inches deep in good soil, with the eyes upward. Place them in a frame where they are secure from frost and water them plentifully when they begin to flower.

Vegetable and Fruit Garden.-Plant out some of the Endive, choosing a dry and well-drained situation.

Flower Garden.-Continue the work of pricking out Polyanthus and Auricula seedlings.

\section{SEPTEMBER I3}

Greenhouse and Frames.-Re-pot the Agapanthuses and place them in a frame to winter. The plants are gross feeders and therefore need to be re-potted annually in well-manured loamy soil. Take care not to injure the roots. 


\section{A CALENDAR}

Vegetable and Fruit Garden.-Look to the Lettuce seedlings and plant out any that are large enough. It is well to get them out as soon as they are ready, so that they may be established before winter.

Flower Garden.-Look to the Brompton Stocks which were planted out last month, and if they are becoming at all soft and lanky lift and re-plant them, thus checking over-rapid growth to enable them to stand the winter.

\section{SEPTEMBER I4}

Greenhouse and Frames.-Plant some Ixia and Sparaxis bulbs in pots filled with good sandy soil. They will do well in a frame and need no coddling, but plenty of air.

Vegetable and Fruit Garden.-A final sowing of Lettuce seed may still be made in the open if a hardy variety be chosen, such as Bath Cos. Make a sowing to-day in well-dug but unmanured ground.

Flower Garden.-Give attention to the Lilies of the Valley. See that the bed is in proper condition and give it a top-dressing of wellrotted manure.

\section{SEPTEMBER I5}

Greenhouse and Frames.-Look to those Pelargoniums which were put out of doors a few days ago, and if the season's wood has become tinged with brown cut the plants down to within three or four eyes of the old wood, and place in a cold frame.

Vegetable and Fruit Garden.-Lift some of the main crop of Potatoes, especially if the weather be favourable.

Flower Garden.-Take a general look round the flower garden and see what arrangements are best for the further planting of springflowering bulbs. Cut down the stems of all perennials which have ceased to flower.

\section{SEPTEMBER I6}

Greenhouse and Frames.-Do not forget to attend to the remaining Pelargoniums, which need to be turned out of doors to ripen their wood in the sun. (See 8th inst.)

Vegetable and Fruit Garden.-New plantations of Asparagus may suitably be made at this season. If the present bed be insufficient, begin the preparation of a new one to-day. 


\section{A YEAR'S GARDENING}

Flower Garden.-Make a further planting of spring flowering bulbs, say Snowdrops and Scillas (Squills), the flowers of which, appearing together, make a beautiful combination of white and blue.

\section{SEPTEMBER I7}

Greenhouse and Frames.-Look to the Balsams and Cockscombs in the frames, and those which are coming into flower make use of for indoor decoration.

Vegetable and Fruit Garden.-Continue the work of making a new Asparagus bed. The soil should be rich and fairly dry.

Flower Garden.-Continue the planting of spring flowering bulbs and let to-day's planting include some more Fritillarias. Besides the Crown Imperial there are many beautiful varieties of delicate tints of colour.

\section{SEPTEMBER I8}

Greenhouse and Frames.-See to any other flowers which are coming on in the frames-such as Violets, Carnations, Pinks, etc. Pot them up and bring them into the greenhouse, giving them slight heat to ensure their blooming during the winter.

Vegetable and Fruit Garden.-Look to the Apples, and those which are ripe, as shown by their parting easily from the branch, gather at once.

Flower Garden.- In continuation of the planting of bulbs, put in the Fritillaria called Snake's-head. Unlike most of the Fritillarias it prefers a moist soil and does well in the grass.

\section{SEPTEMBER I9}

Greenhouse and Frames.-Continue yesterday's work at the frames in the potting up and removal of such plants as are ready to be brought on for winter blooming indoors.

Vegetable and Fruit Garden.-See to the early-ripening Pears and gather those which are easily detached from the bough, lest, if allowed to remain after they are ripe, they fall and are bruised.

Flower Garden.-The Bulbocodium vernum is too good to be omitted from the early-flowering bulbs. Put in some to-day planting about 2 inches deep. 


\section{A CALENDAR}

\section{SEPTEMBER 20}

Greenhouse and Frames.-Look to the various cuttings which were put to strike in the frames, either in pots or otherwise. Pot up those that have rooted in the frames and shift into single pots those which were struck in pots or pans.

Vegetable and Fruit Garden.--Such of the gathered fruit as you desire to store lay up on shelves in a dry and airy place, not allowing any of the fruits to touch each other.

Flower Garden.-Make a further clearing of the borders in preparation for the planting of spring flowers, taking up the annuals which are over and cutting down the perennials which have ceased to bloom.

\section{SEPTEMBER $2 I$}

Greenhouse and Frames.-Do not forget the Pelargoniums which were turned out of doors on the I6th inst., and cut down the plants as soon as they are ready. (See I5th inst.)

Vegetable and Fruit Garden.-Look to the wall-fruit-Peaches, Apricots, Nectarines, etc.- and make a further thinning of the fruit if necessary, and also of any leaves which may be shading the fruit from the sun.

Flower Garden.-Continue the work of clearing the borders, digging them up and manuring them where necessary.

\section{SEPTEMBER 22}

Greenhouse and Frames.-Continue the work of potting up cuttings struck in the frames. (See 2oth inst.)

Vegetable and Fruit Garden.-Continue to give attention to the wall-fruit-Peaches, Apricots, Nectarines, etc. Carefully nail in the new shoots required for future bearing and remove any not needed.

Flower Garden.-Lift the Gladioli which are dying down and store them away in a dry shed. It is a good plan to tie them in bunches and hang them from the rafters.

\section{SEPTEMBER 23}

Greenhouse and Frames.-Give attention to the seedlings raised in the frames and shift them into pots of such size as will best encourage growth. 


\section{A YEAR'S GARDENING}

Vegetable and Fruit Garden.--Look to the Cherry trees and prune away interior and cross shoots on Standard trees, but remember that the Cherry is liable to "gumming" and will not bear severe pruning.

Flower Garden.-Lift the Tigridia (Tiger-flower) bulbs and treat them in the same way as the Gladioli. (See 2and inst.)

\section{SEPTEMBER 24}

Greenhouse and Frames.-Continue yesterday's work of potting up the seedlings in the frames-such as Calceolaria, Cineraria, etc., etc.

Vegetable and Fruit Garden.-Look to the Plum trees, cutting away any shoots of gross growth, but reserving all short-jointed wood.

Flower Garden.--Lift those roots of Marvel of Peru which you have decided to store during the winter and re-plant in the spring. This method produces larger plants than can be obtained when treated as an annual or biennial.

\section{SEPTEMBER 25}

Greenhouse and Frames.-Look to the Cucumbers and remember that the frames in which they are should now be closed early. Cut the fruit immediately it is fit and promptly remove all decaying leaves.

Vegetable and Fruit Garden.-Continue to be vigilant in your efforts to defend the wall-fruit from the attacks of insects (see $4^{\text {th }}$ and 5th August) until all the fruit is picked.

Flower Garden.-Look to the Roses and cut back any of the perpetuals which seem to have a chance of a third bloom.

\section{SEPTEMBER 26}

Greenhouse and Frames.-Look to the Melons, and if the fruit is tardy in ripening give a new lining to the hot-bed. Close the frames early each day.

Vegetable and Fruit Garden.-Examine the Fruit trees for any appearance of red-spider, which at this season of the year, especially in dry weather, is often prevalent. Spray the trees with flour of sulphur as a preventive or cure. 


\section{A CALENDAR}

Flower Garden.-Give some special attention to-day to the Roses generally, cutting off each flower immediately (or even before) it comes to maturity and assisting the trees in any other way which may tend to prolong bloom.

\section{SEPTEMBER 27}

Greenhouse and Frames.-Do not forget to make provision for salads, which are always useful for the table.

Vegetable and Fruit Garden.-Lift some more of the main crop of Potatoes, not waiting for the complete dying down of the haulm if the tubers are fully grown; they will ripen as well, if not better, when lifted and stored.

Flower Garden.-Look to the Roses which have been budded early in the season and release the ties which bind the buds, so as to give freedom for growth.

\section{SEPTEMBER 28}

Greenhouse and Frames.-Look to the Roses which are in pots in the greenhouse and re-pot those which require it.

Vegetable and Fruit Garden.-Continue the work of lifting and storing the Potatoes, taking care not to bruise them.

Flower Garden.-Devote the three last days of this month to more particular attention to routine work-to the lawn, the paths, the edgings, the removal of withered stems and flowers and all weeds, the clearing away of all growth that is dead or useless, etc., etc.

\section{SEPTEMBER 29}

Greenhouse and Frames.-Bring into the greenhouse such plants as Camellias, Azaleas, etc., which may have been standing in the open during the summer.

Vegetable and Fruit Garden.-Prepare the ground from which the Potatoes have been lifted for some other crop-say Spinach.

Flower Garden.-Continue the work of general clearing up and putting in good order. 


\section{A YEAR'S GARDENING}

SEPTEMBER 30

Greenhouse and Frames.-See that the plants now coming into flower in the greenhouse are so placed that they obtain proper light and heat and are kept moderately moist.

Vegetable and Fruit Garden.-Plant out some of the Prickly Spinach recently sown, making use (if desirable) of the ground prepared yesterday.

Flower Garden.-Continue the work of general clearing up and putting in good order.

\section{OCTOBER I}

Greenhouse and Frames.-Make a beginning to-day in the removal to their winter quarters of such bedding and half-hardy plants as you wish to preserve.

Vegetable and Fruit Garden.-Go over the seed-beds and weed them thoroughly by hand so as not to disturb the seedlings.

Flower Garden.-See to the transplanting of hardy annualsan advantageous procedure where the soil is light.

\section{OCTOBER 2}

Greenhouse and Frames.-Continue the work of housing such plants as you wish to preserve throughout the winter.

Vegetable and Fruit Garden.-Lift and store the remaining Potatoes (see 27th and 28th Sept.), but if the weather be wet, postpone the work to the first dry day.

Flower Garden.-Now is a good time for the main planting of Crocuses. Make a beginning to-day.

\section{OCTOBER 3}

Greenhouse and Frames.-A good method of storing such Geraniums as you wish to keep for the next season is to take them up, cut off the tops, prune in the roots and pack them close together in some rough wooden boxes with earth that is almost dry.

Vegetable and Fruit Garden.-Weed the Asparagus bed, cutting down any remaining stems, and top-dress liberally with well-decayed manure.

Flower Garden.-Continue the work of putting in Crocuses. To be effective they should be planted liberally. 


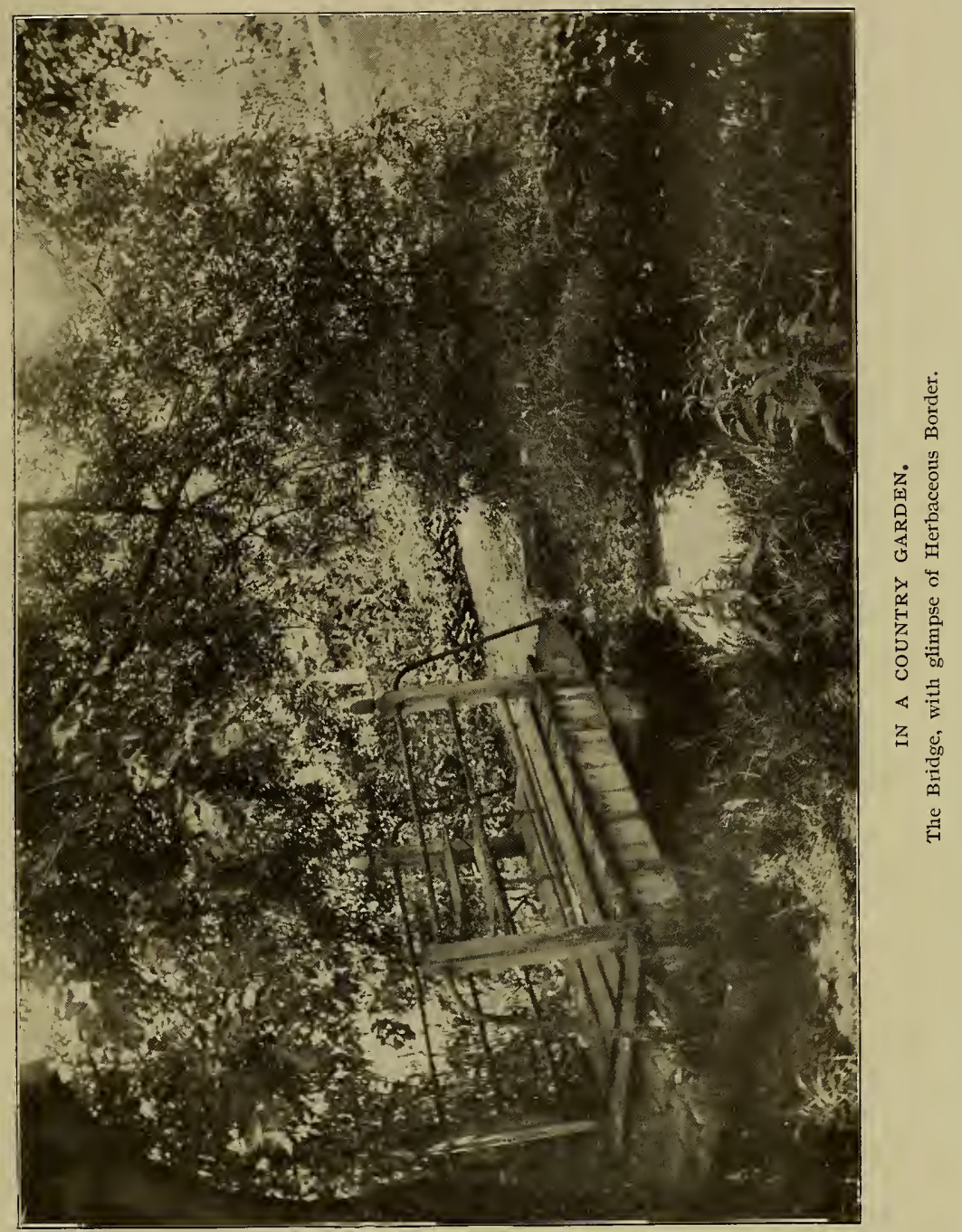





\section{A CALENDAR}

\section{OCTOBER 4}

Greenhouse and Frames.-Continue the work of storing the Geraniums, and when packed in boxes (see 3rd inst.) put them away in some shed or outhouse, or under the greenhouse staging, where there is little light and where frost will not penetrate.

Vegetable and Fruit Garden.-If you still have any young winter greens to plant out, do not delay-do it to-day.

Flower Garden.-Take advantage of any moist weather that may now occur to move evergreen shrubs and plant fresh ones.

\section{OCTOBER 5}

Greenhouse and Frames.-Look to the cuttings in the frames, such as Ageratums, Calceolarias, Cinerarias, Petunias, Verbenas, etc., and pot up and transfer to the greenhouse those which are well rooted and are ready for bringing forward.

Vegetable and Fruit Garden.-Look to the Raspberry canes, and if you wish to extend the plantation this is a suitable time for doing so.

Flower Garden.--Look to the lawn, and where any bare patches occur lay down new turf or (better still) renovate by sowing seed.

\section{OCTOBER 6}

Greenhouse and Frames.-Continue to give attention to the cuttings in the frames, potting up and transferring to the greenhouse so far as space permits.

Vegetable and Fruit Garden.-Make a general clearing of all succulent refuse, laying it in a trench (as previously advised) to rot for manure.

Flower Garden.-Plant out any young Pansies that have not yet been transferred from the seed-bed and pot up those which you destine for early flowering, placing them in the shelter of the frame or greenhouse.

\section{OCTOBER 7}

Greenhouse and Frames.-Complete, if possible, the potting up and proper arrangement of the cuttings planted in the frames. Many of them may be allowed to remain in the frames if protected from frost by mats, etc. 


\section{A YEAR'S GARDENING}

Vegetable and Fruit Garden.-Continue the gathering and storing of Apples and Pears (see I8th, Igth and 2oth Sept.), taking advantage of any fine weather for the purpose.

Flower Garden.--Prepare a bed of rich light loam, well drained, for the reception of some good Hyacinth bulbs.

\section{OCTOBER 8}

Greenhouse and Frames.-Go carefully over the plants recently brought into the greenhouse and see that they are placed in suitable positions-make, in fact, a general rearrangement.

Vegetable and Fruit Garden.-Now is the time for planting Fruit trees. Prepare the ground where they are intended to be planted by draining and making any necessary alteration in the character of the soil.

Flower Garden.-Plant specially-selected Hyacinths in the bed prepared for them. For the best effect put them in about 6 inches apart and fully 6 inches deep in the soil.

\section{OCTOBER 9}

Greenhouse and Frames.-Look carefully through all the plants in the greenhouse, especially those which have been brought in recently, re-potting where required and removing those which may be scarcely worth retaining.

Vegetable and Fruit Garden.-Continue yesterday's work in the preparation of the ground in which Fruit trees are to be planted.

Flower Garden.--Prepare a bed of good light soil for the reception of Tulips.

\section{OCTOBER IO}

Greenhouse and Frames.-Look to the frames generally, and arrange their contents to the best advantage. See that proper ventilation is provided and remove the frame-lights on fine days.

Vegetable and Fruit Garden.--Plant the Fruit trees for which the ground has been prepared, first removing all broken or bruised root-fibres. Take care that the roots are spread out evenly and that the "collar" -where the roots join the stem-is kept at the surface of the soil. 


\section{A CALENDAR}

Flower Garden.-Plant Tulips in the bed prepared for them, about 6 inches apart and 4 or 5 inches deep, selecting the varieties with due consideration to their time of blooming.

\section{OCTOBER II}

Greenhouse and Frames.-Give careful attention to the Chrysanthemums which are coming into bloom and supply them liberally with diluted manure water.

Vegetable and Fruit Garden.-Now, also, is the time to prune the roots of those Fruit trees which by their excessive foliage and lack of fruit have shown that the operation is required. Make a beginning of the work to-day.

Flower Garden.-Choose a suitable bed for planting Pheasant's Eye and other Narcissus, and double and single Daffodils. A shady border or a bed abutting on a shrubbery may be suggested-the soil is not important if well drained. Plant the bulbs 4 to 8 inches apart and 6 to 9 inches deep, according to size.

\section{OCTOBER I2}

Greenhouse and Frames.-Pot up and bring into the greenhouse some of the Chrysanthemums which have been grown for that purpose in the open. After potting, water them well and keep them in the shade for a short time.

Vegetable and Fruit Garden.-Continue the work of root-pruning the Fruit trees.

Flower Garden.-Plant in good-sized patches some bulbs of Winter Aconite. Neither soil nor situation are of importance.

\section{OCTOBER I3}

Greenhouse and Frames.--Look to the Strawberry plants which have been potted for forcing and remove to the frames any which may have been left in the open, closing the frame-lights on any suspicion of frost and as protection from heavy rain.

Vegetable and Fruit Garden.--Look to the Fruit bushes and lift and re-plant those which have been undisturbed for three years or more. 


\section{A IEAR'S GARDENING}

Flower Garden.-Attend to the winter protection of the Hollyhocks, placing any special plants under glass and covering the others with light litter.

\section{OCTOBER I4}

Greenhouse and Frames.-See that you are maintaining a sufficient supply of salading in the frames by making successional sowings from time to time.

Vegetable and Fruit Garden.-Continue the work of lifting and re-planting the Fruit bushes.

Flower Garden.-Plant out tuberous-rooted Anemones, digging deeply and manuring thoroughly.

\section{OCTOBER I5}

Greenhouse and Frames.-Look to the plants in the greenhouse that are coming into flower. The Tuberoses, for instance, should now be showing flower-spikes and should have some weak manure water.

Vegetable and Fruit Garden.-Make a final gathering of fruit (unless the weather be wet), such as late Plums, Quinces, Medlars, etc.

Flower Garden.-Make a selection from a good catalogue of such new Rose trees as you require and order them without delay.

\section{OCTOBER I6}

Greenhouse and Frames.-See to the Primulas which are beginning to show signs of bloom. Place them where they can have plenty of light and nip off the early flower-stems if the plants are small. Give weak manure water occasionally.

Vegetable and Fruit Garden.-Look to the Strawberry beds, removing any runners which may have become evident since the last nipping, digging carefully (so as not to injure the roots of the plants) between the rows and at the same time applying a light dressing of manure.

Flower Garden.-Look to the existing Rose trees and protect the roots by drawing the earth closely around them. 


\section{A CALENDAR}

\section{OCTOBER I7}

Greenhouse and Frames.-Be careful in watering, both in greenhouse and frames. Plants which have just done flowering generally need rest and should be kept fairly dry at the roots.

Vegetable and Fruit Garden.-Plant out any Lettuces that may still remain in the seed-bed and make a fresh sowing in a frame.

Flower Garden.-Take a general survey of the borders with a view to deciding what they require in the way of digging, trenching and manuring.

\section{OCTOBER I8}

Greenhouse and Frames.-Look to the pot Lilies. Those which have flowered should be removed from the greenhouse, placed in a cold frame and watered very sparingly.

Vegetable and Fruit Garden.-Look to the Fruit trees recently planted, and now that the ground has had time to settle provide the trees with suitable stakes and tie them carefully and firmly.

Flower Garden.-Make a beginning in the digging and manuring of such borders as require it, lifting the plants and putting them aside temporarily before starting to dig.

\section{OCTOBER I9}

Greenhouse and Frames.-See to the Roses in pots and select some of the strongest for forcing into early bloom.

Vegetable and Fruit Garden.-Continue the work of staking and tying the newly-planted Fruit trees.

Flower Garden.-Continue the work of digging and manuring the borders, and re-place the plants temporarily lifted.

\section{OCTOBER 20}

Greenhouse and Frames.--Prune those Roses which you selected yesterday and plunge the pots into a hot-bed of a temperature of about $45^{\circ}$.

Vegetable and Fruit Garden.--Lift the remainder of the Carrots, taking care to raise them whole, and store them in sand.

Flower Garden.--Where the summer bedding plants are finally cleared begin to put in the spring plants, such as Wallflowers, Forget-me-nots, Polyanthuses, etc. 


\section{A YEAR'S GARDENING}

\section{OCTOBER 2 I}

Greenhouse and Frames.-Look to the Azaleas which have been brought into the greenhouse for spring flowering and cut back any straggling branches. Mix some soot with the water given them.

Vegetable and Fruit Garden.-Lift the Beetroots, taking care not to bruise or break them, and put them in store.

Flower Garden.-Continue the work of putting in the spring bedding plants. Daisies, Primroses, Violas, etc., may be added to yesterday's list.

\section{OCTOBER 22}

Greenhouse and Frames.-Attend to the Camellias, sponging the leaves occasionally and supplying the plants with liquid manure as the buds develop. See that they have sufficient air, or the buds will drop.

Vegetable and Fruit Garden.-Take up the Turnips and store them. (Note.-Choose a dry day for the lifting of all root crops.)

Flower Garden.-Let the chief work of this day be the planting of the new Rose trees (see $5_{5}$ th inst.), taking care not to expose the roots to sun or wind. It may be advisable to water them thoroughly after planting.

\section{OCTOBER 23}

Greenhouse and Frames.--See to the Hyacinths which have been placed in the frames and bring into the greenhouse those which you wish to press forward for early flowering.

Vegetable and Fruit Garden.-See to the Onions; draw those which have come to maturity and spread them in a sunny situation to ripen and dry before storing.

Flower Garden.-The lifting and division of hardy perennials may still be done. Take note of any which require such treatment, and lift, divide and re-plant them to-day.

\section{OCTOBER 24}

Greenhouse and Frames.-See to the other bulbs which are to be brought forward for winter flowering and make such arrangements as will give a desirable succession of bloom. 


\section{A CALENDAR}

Vegetable and Fruit Garden.-Dig up and manure where necessary those plots of ground rendered vacant by the lifting of the root crops.

Flower Garden.-Plant out biennials-such as Canterbury Bells, Honesty, etc., etc.-in the places where they are to flower.

\section{OCTOBER 25}

Greenhouse and Frames.-Look to the Violets in the frames and see that they have proper space and air. Nip off any dead leaves and stir the surface of the soil.

Vegetable and Fruit Garden.-Continue the work of digging up the vacant plots of ground, trenching and laying up in rough ridges any which are not required for autumn planting.

Flower Garden.-Look to the perennial border edgings-such as Thrift, London Pride, Ivy, etc.- -and where they are exceeding proper limits take them up, divide and re-plant them.

\section{OCTOBER 26}

Greenhouse and Frames.-Look to the Bouvardias, and give weak liquid manure to those plants which have begun to flower.

Vegetable and Fruit Garden.-Lift the Parsnips as soon as there has been a little frost to sweeten them.

Flower Garden.-Now is a good time for planting bulbs in the turf. Consider what increase you can advantageously make to those already growing there, putting in new bulbs where desirable. Snowdrops, Snowflakes, Scilla and Crocuses are all excellent for the purpose.

\section{OCTOBER 27}

Greenhouse and Frames.-Devote the time at your disposal today to overhauling the heating apparatus and seeing that it is put in good working order.

Vegetable and Frnit Garden.-Earth up the remainder of the Celery and make the necessary preparations for covering it in case of frost. 


\section{A YEAR'S GARDENING}

Flower Garden.-Lift and re-plant Rose trees which have been established for some years; they are often much benefited by the process.

\section{OCTOBER 28}

Greenhouse and Frames.-Prepare the frames for protection against sudden frost, such as often occurs in the early days of November. Make a bank of cinder-ash round the outside of the frames and have some mats in readiness to cover the lights.

Vegetable and Fruit Garden.-Pick all the out-door Tomatoes which have not yet been gathered and put them in a sunny place in the greenhouse to ripen.

Flower Garden.-Attend to those borders which you have decided need not be dug up and give them a mulching of well-decayed manure.

\section{OCTOBER 29}

Greenhouse and Frames.-Look to the cuttings in the framesAgeratums, Petunias, Verbenas, Calceolarias, Cinerarias, etc. Keep them from frost and damp but do not force them forward. Ventilate freely, water sparingly.

Vegetable and Fruit Garden.-Look to the Sea-kale, removing all dead leaves and giving the roots a light covering of ashes.

Flower Garden.-Look to see if you have omitted to lift any bulbs which ought to be stored during the winter, and take them up to-day.

\section{OCTOBER 30}

Greenhouse and Frames.-Look to the pot plants stored in the frames, such as Lilies of the Valley, Violets, Pansies, Polyanthuses, Auriculas, etc., which are to be brought on for winter and early spring flowering, and keep their growth in check until transferred to the greenhouse.

Vegetable and Fruit Garden.-Devote to-day to hoeing and weeding among the standing crops. 


\section{A CALENDAR}

Flower Garden.-Devote the time at your disposal during the last two days of this month to clearing, weeding and general tidying up of the garden preparatory for the winter.

\section{OCTOBER 3 I}

Greenhouse and Frames.-See that your receptacles for rainwater are of sufficient capacity and suitably supplied. Soft water is far better for plants than the cold filtered water drawn from the Water Companies' mains.

Vegetable and Fruit Garden.-Gather up all decaying rubbish and dead leaves, clearing up generally as far as possible.

Flower Garden.-Continue yesterday's work of clearing, weeding and general tidying up.

\section{NOVEMBER I}

Greenhouse and Frames.-Take advantage of the fine bright weather which, after an early morning frost, so often prevails during the first few days of this month, and see that greenhouse and frames are well open to air and sunshine but closed before sunset.

Vegetable and Fruit Garden.--Look to the store of material you have on hand for protecting against frost and make suitable and plentiful provision of what you are likely to require.

Flower Garden.--Now is a suitable time for thinning out an overgrown shrubbery and for pruning shrubs generally. Make a beginning to-day.

\section{NOVEMBER 2}

Greenhouse and Frames.- -See that the plants in greenhouse and conservatory are arranged according to their needs, and bring those which are in bloom, or about to flower, into light and warmth, relegating the others to shadier and cooler positions.

Vegetable and Fruit Garden.-Make a rough plan of the garden and its crops of the past year with a view to giving a proper rotation of crops and of improving future arrangement in the light of past experience.

Flower Garden.-Continue your work on the shrubbery and remove such bushes as are not doing well. This is the season for making alterations and improvements. 


\section{A YEAR'S GARDENING}

\section{NOVEMBER 3}

Greenhouse and Frames.-Give due attention to the frames day by day, keeping them closed in cold damp weather and well protected from the inroads of frost, but bearing in mind that the plants mostly need rest, not incitement to growth.

Vegetable and Fruit Garden.-Collect all dry and non-succulent rubbish, which has not been buried in the rubbish trench, preparatory to burning. The resultant ashes will be found most useful.

Flower Garden.-On the assumption that by thinning and removal space can now be found, plant such shrubs as Aralia Japonica, Magnolia grandiflora, and some of the Spiræas.

\section{NOVEMBER 4}

Greenhouse and Frames.-Be careful in watering the greenhouse plants and see that flowers and leaves are kept dry-a most important point at this time of year.

Vegetable and Fruit Garden.-Dig up and manure any ground that needs the process, trenching into rough ridges any plots which you propose to leave vacant for the winter's frost to operate upon.

Flower Garden.--Plant also some flowering shrubs, such as the red Pyrus Japonica, Rhododendrons, Azaleas, Yellow Broom, etc.

\section{NOVEMBER 5}

Greenhouse and Frames.-Use discretion in the amount of water given, proportioning it to the need of each plant, some requiring much more than others. Water thoroughly when, but not before, the plant is dry.

Vegetable and Fruit Garden.-Make a bonfire of the dry rubbish collected on the 3rd inst. and see that it burns well until all is reduced to ashes.

Flower Garden.- Consider whether any improvement can be made in the garden by adding to the hardy creepers, and act accordingly.

\section{NOVEMBER 6}

Greenhouse and Frames.-If possible, use rain-water for all plants, and let it be slightly warmer than the temperature in which they are growing. 


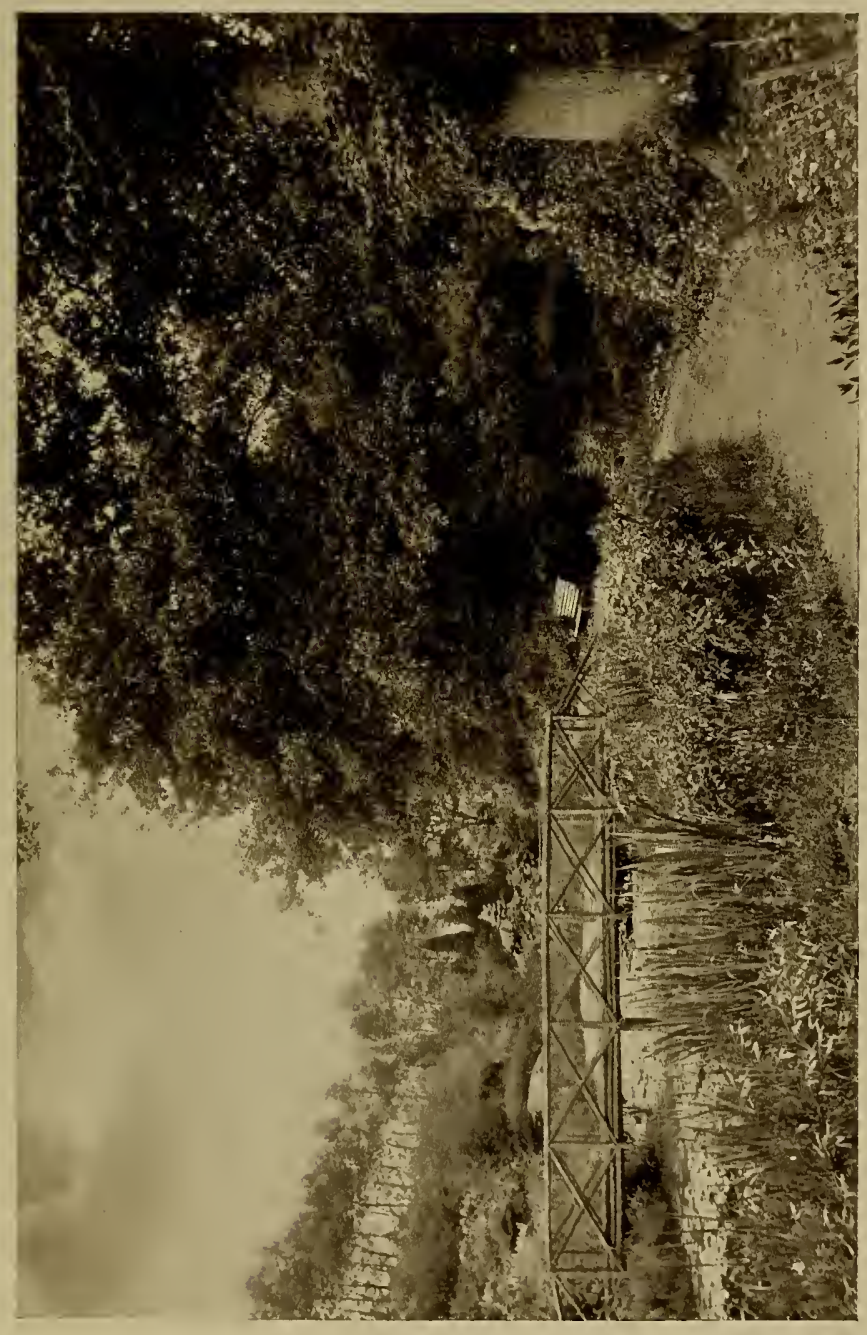

告 



\section{A CALENDAR}

Vegetable and Fruit Garden.-Carefully collect the ashes from the bonfire and store them for future use under cover from the wet.

Flower Garden.-Look to the Dahlias, and be ready at the first sign of the flowers being touched with frost to lift and store the tubers in some dry place. Label them and hang them up stalks downward.

\section{NOVEMBER 7}

Greenhouse and Frames.-Give constant attention to the temperature of the greenhouse and keep it as uniform as possible. With a dry atmosphere a comparatively low temperature (say, $40^{\circ}$ to $45^{\circ}$ ) may be permitted.

Vegetable and Fruit Garden.-If it be desirable to break up new ground for future planting let it be done at once.

Flower Garden.-Cut down the Hollyhock stems and propagate any variety you desire to increase by lifting and dividing the stools.

\section{NOVEMBER 8}

Greenhouse and Frames.-Look to the plants which are coming into flower. The Chrysanthemums, for instance, should now have close attention. Be careful that they are not crowded, lest the leaves fall. Pick off dead leaves and keep the soil loosened and free from weeds.

Vegetable and Fruit Garden.-Look to the garden paths, weeding them thoroughly and repairing them where necessary.

Flower Garden.-Look to the reserve beds of Polyanthuses. Stir the surface of the soil and give a top-dressing of well-rotted cow manure.

\section{NOVEMBER 9}

Greenhouse and Frames.-Continuing your attention to the Chrysanthemums, make a practice of watering them in the morning, so that the moisture may have gone before the cold of the night has set in. Give manure water while the flowers are expanding. 


\section{A YEAR'S GARDENING}

Vegetable and Fruit Garden.--Lift and store some of the Jerusalem Artichokes, in order that they may be at hand when inclement weather or hard frost prevents their being dug up. The rest may be lifted as required.

Flower Garden.-Put in some roots of Lilies, planting rather deep and in such a quantity as to form a good-sized clump, and choosing a site where the soil is fairly rich loam.

\section{NOVEMBER IO}

Greenhouse and Frames.-Look out for earwigs among the Chrysanthemums and set the usual traps. Be on the watch, also, for caterpillars, searching for them after dark with a lantern and destroying them.

Vegetable and Fruit Garden.-Make a small sowing of Peas in a sheltered and well-drained border, in soil that has been well dug but not quite recently manured.

Flower Garden.-If you still have any Tulip bulbs not yet planted, put them in to-day-it is not too late. Set deep and in a sunny position.

\section{NOVEMBER II}

Greenhouse and Frames.-The scarlet Salvias should now be coming into bloom. Give them due attention, treating them much in the same way as Chrysanthemums. (See 8th, gth and Ioth inst.)

Vegetable and Fruit Garden.-Make, also, a sowing of Longpod Broad Beans in a dry soil and sheltered from the north, if possible. They may be put in rather close together with a view of transplanting every other one in the early spring.

Flower Garden.-Put in one or two clumps of Galtonia (Hyacinthus candicans), a plant which shows well in isolated groups against a leafy background. Give plenty of room.

\section{NOVEMBER I2}

Greenhouse and Frames.-Look to the Chinese Primroses and try and keep them hardy and robust by such ventilation and low temperature as may be consistent with protection from frost, damp and cutting winds. 


\section{A CALENDAR}

Vegetable and Fruit Garden.-Put in a few Potatoes for an early crop, if you have at disposal a sheltered border with dry sandy soil.

Flower Garden.- Unless frost appears to be imminent (which is unlikely as yet) there is still time to put in Roses. If you have not already completed your planting order what you require to-day.

\section{NOVEMBER I3}

Greenhouse and Frames.-See to the various pots of Mignonette. They should now be coming on in succession for flowering throughout the winter.

Vegetable and Fruit Garden.-If the Asparagus bed has not yet been cleaned, see that it is done to-day, cutting down the dead grass, removing all weeds and rubbish, and giving it a good dressing of stable manure.

Flower Garden.--Earth up all Tea-rose bushes after the fashion of earthing potatoes. Also spread some light covering, such as dry bracken, over the bushes to protect them from frost.

\section{NOVEMBER I4}

Greenhouse and Frames.-Look to the Begonias (tuberousrooted), which for their foliage, as well as flower, are valuable as greenhouse plants. Keep them clean and free from damp and as warm as possible.

Vegetable and Fruit Garden.-Look to the Globe Artichokes, cutting them down to within a foot or so of the ground and heaping up some light litter against them as a protection from frost. Do not cover the hearts.

Flower Garden.-Plant Peonies (of the Chinese or Herbaceous kind) in a well-dug soil with plenty of decayed cow manure. There are many beautiful varieties, but do not omit the old-fashioned Crimson Peony.

\section{NOVEMBER I5}

Greenhouse and Frames.--Look to the Azaleas and see that they have a suitable place in the greenhouse. For the present they should be kept cool and dry. 


\section{A YEAR'S GARDENING}

Vegetable and Fruit Garden.-Lift some of the Sea-kale for forcing, removing it to a pit or shed where frost cannot reach it.

Flower Garden.-Put in any Roses you have ordered as soon as they arrive. Exposure of the roots, especially in a cold, dry wind, is most injurious to the plants.

\section{NOVEMBER $\mathrm{x} 6$}

Greenhouse and Frames.-Look to the Heaths and treat them much in the same way as the Azaleas. (See I5th inst.)

Vegetable and Fruit Garden.--Look to the Cauliflowers, and those which are showing a fair head protect from frost with a light covering. Take up those which are sufficiently matured and store them for future use out of reach of frost.

Flower Garden.-Plant any Standard Briars which you may need for future budding.

\section{NOVEMBER I7}

Greenhouse and Frames.-Let the Camellias have your special attention to-day and consider whether they have the best situation you can afford them. The buds should now be swelling and a cold draught will often cause them to drop.

Vegetable and Fruit Garden.-Trench a plot of ground for a new bed of Asparagus to be made in the spring.

Flower Garden.-Put in any Climbing Roses you have received. An old stump or a withered tree will make an effective support and good rambling space for a Crimson Rambler or a Dorothy Perkins, a Paul's Carmine or an Aimé Vibert.

\section{NOVEMBER I8}

Greenhouse and Frames.-Continuing your attention to the Camellias, see that they are kept at as uniform a temperature as possible (say, $45^{\circ}$ ) and water them sparingly. They do not need such liberal food and water as the gross-feeding Chrysanthemum.

Vegetable and Fruit Garden.-Look to the Gooseberry and Currant bushes, removing any dead wood but deferring final pruning until spring. 


\section{A CALENDAR}

Flower Garden.-Loosen the soil in the borders as much as possible before the frost hardens it, so that when the frost comes its beneficial action may penetrate the ground.

\section{NOVEMBER I9}

Greenhouse and Frames.-Look to the Cinerarias. Trim them up into a good shape and shift into larger pots those which require it. Bring them forward with occasional doses of manure water and destroy with tobacco smoke any aphis which may appear.

Vegetable and Fruit Garden.--Loosen the earth round the Gooseberry and Currant bushes, taking care not to lacerate the roots, and give them a liberal mulching of manure. A dressing of lime may also be useful.

Flower Garden.--Give to-day's time at your disposal to preserving the good appearance of the garden. Cut down dead stems, remove all that is withered and unsightly, and tidy up the borders generally.

\section{NOVEMBER 20}

Greenhouse and Frames.-Look to the Calceolarias and adopt the same treatment as that recommended for the Cinerarias. (See Igth inst.)

Vegetable and Fruit Garden.-Look to the Standard Fruit trees, especially the older ones, and scrape off any lichen or moss which may have appeared.

Flower Garden.-Continue the work of tidying up generally. Sweep the lawn gently but thoroughly and roll it well in two directions. Sweep the paths and collect all rubbish, depositing decaying matter in the rubbish trench and reserving the remainder for future burning.

\section{NOVEMBER 2I}

Greenhouse and Frames.-Go through the Pansies which have been potted up for early flowering. Trim them up generally and select the most vigorous plants for placing in a warm position where they may be brought into bloom as soon as possible.

Vegetable and Fruit Garden.--Continue your work on the Standard Fruit trees and wash over the trunks and branches with warm limewater. 


\section{A YEAR'S GARDENING}

Flower Garden.-Bear in mind when tidying up the garden and collecting the rubbish that dead leaves are particularly valuable for making composts of leaf mould and may advantageously be kept in a separate heap. Oak and Beech leaves are especially useful as heat producers during fermentation.

\section{NOVEMBER 22}

Greenhouse and Frames.-Look to the Pelargoniums and try and keep them at a temperature of about $45^{\circ}$. Thin out and train them, shifting into larger pots if necessary. If the soil is infested with worms, apply clear lime-water three or four times daily for two or three days.

Vegetable and Fruit Garden.-Give a top-dressing of manure to the Apple trees-especially the old trees. Pear trees seldom need it.

Flower Garden.-Add to your collection of garden rubbish any odd pieces of old turf or lumps of soil, exhausted manure from old hot-beds, sand and gravel sweepings, etc., etc., and allow them to decompose together, turning over the heap occasionally. No garden rubbish should be wasted.

\section{NOVEMBER 23}

Greenhouse and Frames.-Look to the plants stored in the frames and guard against excessive moisture as well as frost, frost being much more injurious when the plants are damp.

Vegetable and Fruit Garden.--Look to the Raspberry canes and gently fork up the ground between the stools, afterwards giving them a mulching of manure.

Flower Garden.-Such a heap of rubbish as that referred to under yesterday's daily work will be found very useful, with an addition of cow manure, in planting Roses where a light soil prevails.

\section{NOVEMBER 24}

Greenhouse and Frames.-See to the bulbs which have been placed in the frames to germinate. Beware of damp, and keep them dry until you move them forward into the greenhouse for bringing into flower. 


\section{A CALENDAR}

Vegetable and Fruit Garden.-Look over the newly-planted Strawberry bed and draw up the earth around each plant, afterwards spreading a slight covering of manure as a further nourishment and protection to the roots.

Flower Garden.-A really ornamental hedge may be made from the Japanese Fruiting Rose (Rosa Rugosa), and a delightfully fragrant one from the Sweet Briar. Give the matter your consideration to-day and act without delay. Now is a favourable time.

\section{NOVEMBER 25}

Greenhouse and Frames.-Keep up a sufficient supply of salading by making successional sowings in the frames, bearing in mind that the seed will be slow in germinating during cold weather.

Vegetable and Fruit Garden.-Lift some of the Broccoli plants and re-plant them in a trench as a means of protecting them from frost. This method may retard their growth but often prevents them from being killed by frost.

Flower Garden.-If you decide on planting a hedge such as that suggested yesterday, dig the ground deeply and incorporate with the soil a mixture of manure, burnt garden refuse and a little old mortar, if procurable.

\section{NOVEMBER 26}

Greenhouse and Frames.-See that the Cauliflowers in the frames are in satisfactory condition. Remove any decaying leaves and look for and destroy all vermin. Give the soil a sprinkling of a mixture of soot and wood ashes.

Vegetable and Fruit Garden.-Take up the Horseradish roots and store them in a dry place ready for use. Make new plantations.

Flower Garden.--Look to the Ferraria (or Tigridia) bulbs and lift them for the winter unless they are in a dry soil and a sunny situation; they are apt to decay in cold moisture.

\section{NOVEMBER 27}

Greenhouse and Frames.-Look to the welfare of all the vegetables in the frames, such as Carrots, Onions, Lettuces, Radishes, etc. Let them have as much air and exposure as may be consistent with protection from frost, and water sparingly, lest mould ensue. 


\section{A YEAR'S GARDENING}

Vegetable and Fruit Garden.-Look to the Celery bed, and if it appears over-saturated with rain, cut a trench for an outlet of the water. Excessive moisture, especially when followed by frost, will certainly damage the crop.

Flower Garden.-If you still have any bulbs on hand, get them in without delay to fill up odd spaces.

\section{NOVEMBER 28}

Greenhouse and Frames.-See to the renewal of the hot-beds and make an adequate provision of fermenting material for use, as required, in the way of re-making and re-lining the hot-beds and as protection for the frames.

Vegetable and Fritit Garden.-Look to the wall-trained Fruit trees and do such autumn pruning as may be necessary. Gently loosen the soil around the roots and give a light mulching of manure for some distance from the main stem.

Flower Garden.-Look to the beds in which the spring-flowering bulbs are planted, and if, through mild weather, the growth is unusually forward, protect the beds with loose litter of some sort.

\section{NOVEMBER 29}

Greenhouse and Frames.-Continue the work of re-making and preparing material for the hot-beds and frames.

Vegetable and Fruit Garden.-Give attention to the beds where crops are standing, such as Turnips, Spinach, Cauliflowers, Broccoli, Cabbages, etc. Keep the plots clean and well hoed.

Flower Garden.-Give particular attention to the lawn with a view to deciding whether some worm-killer is required. If the grass is soft and sticky and disfigured with a multitude of worm-casts apply Carter's Worm Killer.

\section{NOVEMBER 30}

Greenhouse and Frames.-Look to your supply of compost and make such addition as may be necessary. An adequate and securelystored supply may make the difference between success and failure when pressed for time in potting up seedlings. 


\section{A CALENDAR}

Vegetable and Fruit Garden.-Continue the work of keeping the standing crops clean and well hoed. Look out for (and destroy) slugs and snails, especially among the Lettuces and Cauliflowers. Soot and wood-ashes are a good protection.

Flower Garden.-Choose a mild, muggy day, if possible, for spreading the worm-killer on the lawn, watering it in if necessary.

\section{DECEMBER I}

Greenhouse and Frames.-Look to the labelling of all plants you are storing for the winter and give new labels where necessary.

Vegetable and Fruit Garden.-Make preparations for the manuring of the ground and wheel the manure to the various spots where it will be wanted.

Flower Garden.-Look over the bulbs which have been lifted and stored for the winter, removing those which are unsound, lest they infect the others. (See 27 th and 28 th Dec.)

\section{DECEMBER 2}

Greenhouse and Frames.-See that the plants stored in the frames are in good order and arrange those in the greenhouse to the best advantage, bringing into light and warmth those which are coming into flower.

Vegetable and Fruit Garden.-Continue the work of manuring, forking the manure over the ground and digging it in.

Flower Garden.-Attend to the lawn. Weed it carefully, rake . off any moss that may be present, and sweep it thoroughly.

\section{DECEMBER 3}

Greenhouse and Frames.-Pot any Lilies which you may still have on hand-it is not too late. Place the pots in a cold frame and protect them with ashes.

Vegetable and Fruit Garden.-Continue, and if possible complete, the work of manuring the plots of ground which require it. 


\section{A YEAR'S GARDENING}

Flower Garden.-In continuation of your work on the lawn, rake over any bare or poor patches, loosening the soil thoroughly, and scatter in a little grass seed, patting it down with the back of a spade. Then give the whole lawn a top-dressing of some good grass-manure, such as Carter's or Sutton's.

\section{DECEMBER 4}

Greenhouse and Frames.-Keep a watch on the Camellias; now that the buds are swelling they need constant attention. (See I7th and I8th Nov.)

Vegetable and Fruit Garden.-Take precautions for scaring the birds from the Gooseberry and Currant bushes. The swelling buds are tempting morsels to the birds, especially when frost prevails.

Flower Garden.-Look over the beds, borders and edgings, and note where they have become out of shape and are exceeding their prescribed limits. Now is a good opportunity to reform them.

\section{DECEMBER 5}

Greenhouse and Frames.-Examine the Pelargoniums and Fuchsias, loosen the soil gently and see that they are not very moist; they are better kept rather dry.

Vegetable and Fruit Garden.-Complete the work begun yesterday for protecting the fruit bushes from the depredations of birds. Black cotton, wound from twig to twig upon each bush, is an excellent method.

Flower Garden.-Complete the work begun yesterday of reshaping and re-forming the borders and edgings.

\section{DECEMBER 6}

Greenhouse and Frames.--Start some Strawberry plants for an early crop, giving them a moderate bottom heat. Use small pots.

Vegetable and Fruit Garden.-Look over the fruit you have stored-apples especially. See that none of them touch each other, and remove any which have begun to decay.

Flower Garden.-As in the vegetable garden (see 8th Dec.) consider whether the system of drainage is adequate and improve it where necessary. 


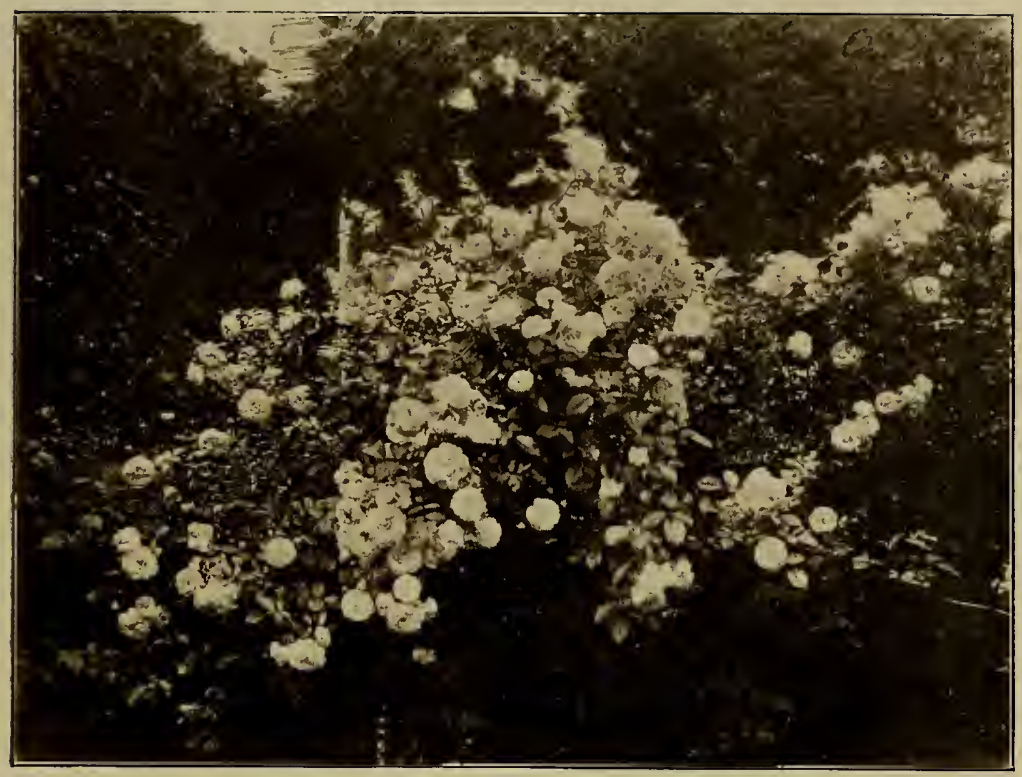

IN THE WILD GARDEN.

A Rose left to its own sweet will.

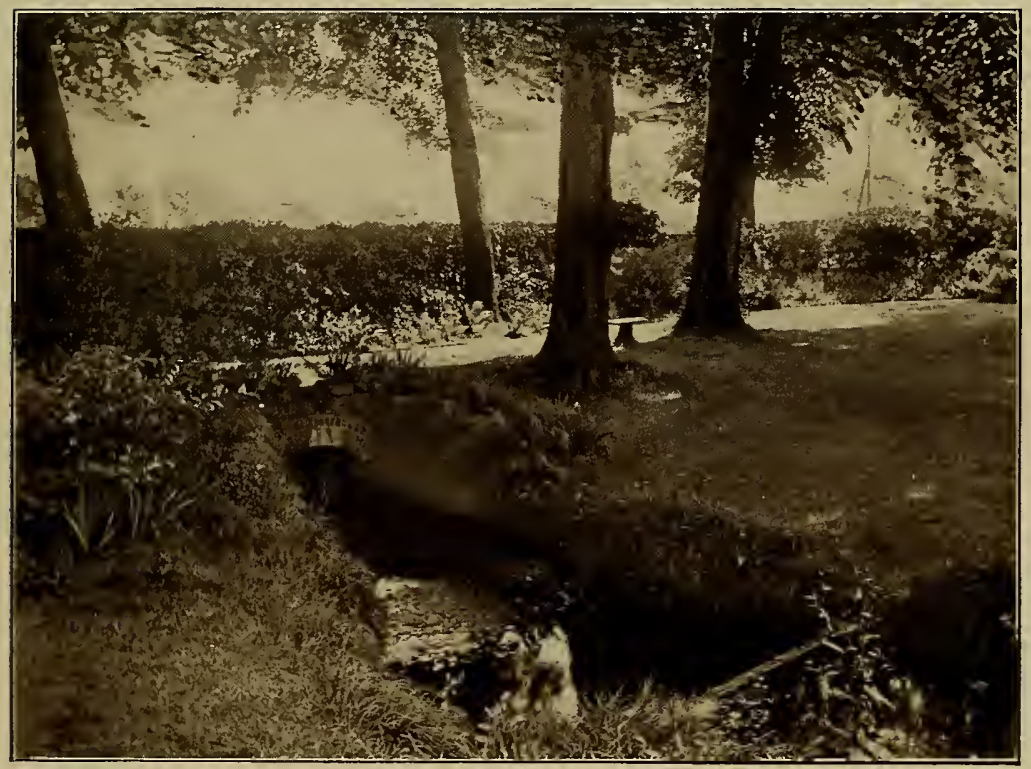

IN A COUNTRY GARDEN.

A glimpse of Stream, Beech-trees, and Drive 



\section{A CALENDAR}

\section{DECEMBER 7}

Greenhouse and Frames.-If you wish to start some young Grape Vines now is a good time to do it. Pot the roots carefully in leaf mould.

Vegetable and Fruit Garden.--Look over the garden tools with a view to replenishing them and having any defects repaired.

Flower Garden.-Look to the garden paths and remove all moss and weeds. Fork up the gravel gently and roll thoroughly.

\section{DECEMBER 8}

Greenhouse and Frames.-Look to the Azaleas now coming into bloom and beware of allowing them to stand in a draught. Be on the lookout for thrips-often induced by too dry an atmosphereand take measures to eradicate without delay.

Vegetable and Fruit Garden.-Now is a good time for making alterations in the garden. Consider whether any are desirable, especially in regard to drainage, and act accordingly.

Flower Garden.- - Unless the time must be given to the drainage of the garden now is a good opportunity for pruning and training the outdoor creepers.

\section{DECEMBER 9}

Greenhouse and Frames.-Look to the Rhododendrons-they need watching when they are beginning to flower. Treat them in the same way as Azaleas. (See 8th Dec.)

Vegetable and Fruit Garden.--If any Celery has not yet been earthed up, do it without delay and make arrangements for protecting it from the frost with some light litter.

Flower Garden.-Dig (trench, if necessary) and manure any vacant borders.

\section{DECEMBER Io}

Greenhouse and Frames.-Look to the Heaths and the Epácrises now coming forward for bloom, and beware of giving them too much water. Free drainage is essential. 


\section{A YEAR'S GARDENING}

Vegetable and Fruit Garden.-Give the Rhubarb bed a liberal mulching, thus preserving the plants from frost, increasing their productiveness and inducing an early crop.

Flower Garden.--Cut down any remaining stems of herbaceous perennials (such as Michaelmas Daisies, etc.) and gently loosen the earth in the borders, taking care not to up-turn any bulbs.

\section{DECEMBER II}

Greenhouse and Frames.-Look to the foliage plants, such as Palms, Aspidistras, Indiarubber Plant, etc., and cleanse the leaves thoroughly with a wet sponge. A little milk added to the water is recommended.

Vegetable and Fruit Garden.-Hoe the surface of the ground around the standing crops and earth up the roots as a protection against frost.

Flower Garden.-Put light litter, or leaves weighted with soil, round the roots of Roses and perennials generally, as a protection from frost.

\section{DECEMBER I2}

Greenhouse and Frames.-Keep a strict watch on the Cinerarias for any attack of green-fly, to which they are peculiarly liable in all stages of their growth.

Vegetable and Fruit Garden.-Consider what trenching and digging still remain to be done and make every effort to complete such work as soon as possible, before severe frost occurs.

Flower Garden.-In the absence of any indication of frost occurring, new turf for edgings, or to repair bare patches in the lawn, may still be laid, but do not delay.

\section{DECEMBER I3}

Greenhouse and Frames.-Look to the Roses in pots which you are bringing forward for early flowering. See that they are not crowded and are kept free from green-fly. 


\section{A CALENDAR}

Vegetable and Fruit Garden.-If the weather still remains open (as is probable) sow a few Peas of an early variety in a well-dug (but not recently manured) border with a southern aspect.

Flower Garden.--Look to the evergreen shrubs, cutting away all weak and decaying wood and trimming them into proper shape.

\section{DECEMBER I4}

Greenhouse and Frames.-See to the climbing plants, tying them carefully and pruning where necessary.

Vegetable and Fruit Garden.-Sow, also, some early Long-pod Broad Beans, choosing a warm and sheltered position.

Flower Garden.-Prune and train the outdoor creepers which, as yet, you have been unable to attend to. Nail in each stem carefully and judiciously-they will well repay such labour.

\section{DECEMBER I5}

Greenhouse and Frames.-Make cuttings of early flowering Japanese Chrysanthemums. Unless quantity is aimed at insert the cuttings singly in thumb-pots and place them in a cold frame.

Vegetable and Fruit Garden.-Do not delay to lift any Beet, Carrots, etc., which may have been left in the ground. Lift them to-day, if possible, lest the frost catch them, and store them where they will be protected from frost.

Flower Garden.-Make sure that the Tea-roses are protected at the roots during hard weather, but during a spell of moist, mild weather you will do wisely to remove the litter.

\section{DECEMBER 16}

Greenhouse and Frames.-Look to the condition of the frames. See that they are well protected with manure and stable litter at the sides and that a supply of matting is at hand to cover the lights in case of frost.

Vegetable and Fruit Garden.-Attend to the Sea-kale; cover each root with a suitable pot and heap it over with manure and litter.

Flower Garden.-Plant such hedges as_Privet and Hawthorn. IOI 


\section{A YEAR'S GARDENING}

\section{DECEMBER I7}

Greenhouse and Frames.-See that the frames are well ventilated, removing the lights entirely on mild sunny mornings but closing them early in the afternoon.

Vegetable and Fruit Garden.-Look to the Winter Greens and sprinkle soot or lime around them as a protection against slugs, especially if the weather be mild and moist.

Flower Garden.--Look to the Christmas Roses and protect the blooms from inclement weather by covering them with hand-lights.

\section{DECEMBER I8}

Greenhouse and Frames.-Look over your store of pots and sowing-pans and replenish them, if necessary. Those which are dirty, wash now, in readiness for the busy season.

Vegetable and Fruit Garden.--Look to the beds where your seedlings are growing and examine for any appearance of ravages by slugs. Sprinkle liberally with soot, as a preventive.

Flower Garden.--Examine the flower-beds for any appearance of slugs and destroy them when found. Sprinkle soot as a protection from their ravages. Be on the watch, also, for the depredations of rats and mice among the bulbs.

\section{DECEMBER I9}

Greenhouse and Frames.-Do not forget to keep up your supply of small salading. Sow Mustard and Cress from time to time in slight heat.

Vegetable and Fruit Garden.-See to the Endive and begin the blanching process by covering it with pots heaped over with litter.

Flower Garden.- Keep an eye on the reserve bed of annuals, defending them against the attacks of slugs in mild weather and giving them suitable protection when frost occurs.

IO2 


\section{A CALENDAR}

\section{DECEMBER 20}

Greenhouse and Frames.-Look to the Carnations and be on the watch against damp. Give them as much light and air as possible in fine, dry weather.

Vegetable and Fruit Garden.-Give a covering of light litter to any Parsnips which have been left in the ground for the frost to sweeten and take care to lift them before the ground is hardened.

Flower Garden.-Look to the Anemones and other choice plants wintering out of doors, and give them due protection.

\section{DECEMBER $2 \mathrm{I}$}

Greenhouse and Frames.-Look to the Auriculas and Polyanthuses and avoid all tendency to coddling them. Protection from frost and damp, not heat, is what they require.

Vegetable and Fruit Garden.-See to the Globe Artichokes and cover the crowns with small heaps of fine ashes.

Flower Garden.-Make use of all fallen leaves, either collecting them into heaps for future use or digging them in at once.

\section{DECEMBER 22}

Greenhouse and Frames.-Do not neglect the bulbs in the frames. $\mathrm{Be}$ on the lookout for those that are coming forward and transfer them to the greenhouse to flower.

Vegetable and Fruit Garden.-Prepare the Asparagus bed for the coming season-weed it and clean it thoroughly to-day.

Flower Garden.-Some hardy perennials may still be planted if the weather be mild; Solomon's Seal and Periwinkle, for instance, for the shady border and the rockery respectively.

\section{DECEMBER 23}

Greenhouse and Frames.-Look to the Violets in the frames and pot up some plants for flowering in the greenhouse. 


\section{A YEAR'S GARDENING}

Vegetable and Fruit Garden.-Continue your work on the Asparagus bed and give it a new surface soil of old compost mixed with bone-meal.

Flower Garden.-Cut Holly and Evergreens for Christmas decorations.

\section{DECEMBER 24}

Greenhouse and Frames.-Prepare stakes and sticks which will be required later on for supporting plants.

Vegetable and Fruit Garden.-Give an eye to the Broccoli, and rather than risk losing it, if frost appears imminent, cut all that is ready and hang it up in an outhouse or cellar for use when required.

Flower Garden.- Sweep the lawn, roll the paths and tidy up the garden generally.

\section{DECEMBER 25 (Christmas DAY)}

Greenhouse and Frames.-Take a holiday from actual work, but see that the temperature in the greenhouse is properly maintained. Day.

Vegetable and Fruit Garden.-Take a holiday, being Christmas

Flower Garden.--Take a holiday, being Christmas Day.

\section{DECEMBER 26}

Greenhouse and Frames.-Get some pieces of old cloth and cut it into shreds for nailing up Fruit trees and climbers. The cloth should be clean, and the shreds may vary in size from a half to one inch in width and from three to six inches in length.

Vegetable and Fruit Garden.-Look to the Fruit trees, and if there still remains any pruning not yet done, do it now, provided the weather be open and no cutting wind prevails.

Flower Garden.-Devote the time at your disposal to-day to the shrubbery, loosening the earth gently, forking in the fallen leaves and clearing away all useless rubbish. 


\section{A CALENDAR}

\section{DECEMBER 27}

Greenhouse and Frames.-Look over the bulbs which have been lifted for winter storing, such as Dahlias, Gladioli, Begonias, etc., and remove any which are unsound.

Vegetable and Fruit Garden. - Examine the Fruit trees for American blight and spray any affected tree with insecticide, first pruning it well back.

Flower Garden.- Shrubs and creepers may still be planted if the weather be open and the rainfall not excessive.

\section{DECEMBER 28}

Greenhouse and Frames.-Continue yesterday's work, examining each bulb and testing its soundness by its weight and firmness. By rejecting those which are unsound future disappointment may be avoided and the contamination of those which are good prevented.

Vegetable and Fruit Garden.-Attend to the Standard Apple trees, more particularly to those which are old, and where meagre fruiting and poor growth indicate exhaustion of soil, cut a trench round the tree and put in some fresh soil mixed with well-rotted manure.

Flower Garden.-Put in some sprigs of Ivy against any bare wall, especially one which has a northerly aspect. A little lime added to the soil when planting will be beneficial.

\section{DECEMBER 29}

Greenhouse and Frames.-Look to your compost heaps, turn them over from time to time and see that they are kept in good condition.

Vegetable and Fruit Garden.-Collect and look over the prunings of all sorts which have recently been made and make up into bundles those which may be suitable for pea-sticks, etc., storing them away in a dry outhouse.

Flower Garden.-Briars for the future budding of Roses may still be planted. 


\section{A YEAR'S GARDENING}

\section{DECEMBER 30}

Greenhouse and Frames.-Devote the time at your disposal today to a general tidying-up of the greenhouse, removing all dead leaves and litter, and seeing that the plants are arranged to the best advantage.

Vegetable and Fruit Garden.-Look to any crops, such as Lettuce, Radishes, etc., which you may have under hand-lights, and be prepared to cover them with loose litter in case of frost.

Flower Garden.-Make a rough diagram of the garden with a view to improving last season's scheme of colour and arrangement of plants. Weigh carefully all causes of failure and success, so that you may retrieve the one and maintain the other.

\section{DECEMBER 3I}

Greenhouse and Frames.-Consider if there are any arrears of work which can be done to-day, so as to start fair with the New Year.

Vegetable and Fruit Garden.-Bring up all arrears of work, so as to start fair with the New Year.

Flower Garden.-Do what you can towards making up arrears of work, so as to start fair with the New Year. 


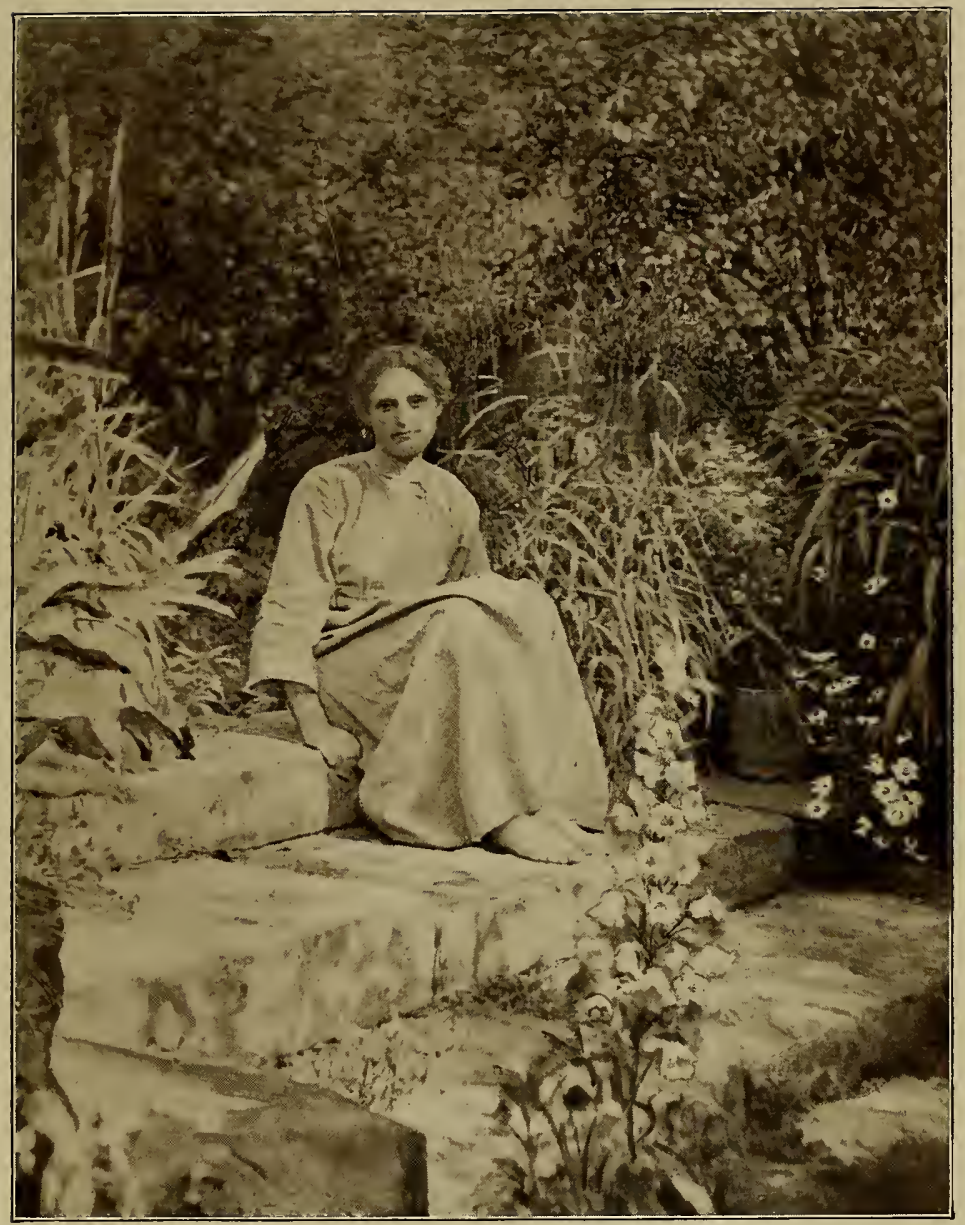

STEPS TO THE ROCK GARDEN.

" Sicily in England." 



\section{ALPINE, ROCK AND WALL GARDENS}

\section{THE ALPINE GARDEN}

AT one time it was commonly supposed that the Alpine plants, which, with their exquisite flowers, so delicately enhance the beauty of mountain scenery, could not be grown in lowland regions. The knowledge that they were only found at a considerable altitude, and the conditions to which they were thus subject-covered throughout the winter with a deep

Natural

Conditions bed of snow, under which they rested secure from frost and biting wind until the moist and spring-like days appeared-seemed to confirm this supposition. The conclusion, however, was found by experience to be erroneous, and many a beautiful garden now testifies to the fact that most of the Alpine plants can be cultivated successfully in this country. For although the conditions of their natural habitat cannot usually be had here, such conditions are not essential to the growth of the plants,

Not Essential and the principal reason for their abounding in high regions is because no taller vegetation can exist at such an altitude. Upon the plains or on the lower slopes of the mountains many of the Alpine plants, especially the smaller species, would be over-run by other and more vigorous growth, or would be destroyed by the overshadowing of bushes and trees. Hence it is that as, with the increase of elevation, the more rampant lowland growth fails, the lovely Alpine flowers gradually find their opportunity in the struggle for existence and finally prevail, unique in their ability to flourish in such an environment.

But though they are so well fitted to grace the habitat in which they abound-another instance of the survival of the fittest-it by no means follows, as already stated, that they cannot be cultivated elsewhere, while a due con-

Essential Requirements sideration of their natural mode of growth is extremely useful in determining the essential requirements for what is commonly called an Alpine Garden. 


\section{A YEAR'S GARDENING}

The first and perhaps the most important of these requirements Light and Air is light and air, for bearing in mind the natural environment of Alpine plants it is evident that they must not be subjected to any overshadowing by trees or plants of large growth. The site chosen for the Alpine Garden should be well open to the sun; exposed to the four winds of heaven, if need be, but free from cutting draughts and not under the shadow of a wall, and such a position may usually be found even in a comparatively small garden.

The next requirement is that the site shall be properly prepared for the plants. It may be that the ground already so lends itself to what is necessary that nothing need be done beyond Preparation clearing the place and adding here and there a few loads of good soil, at the same time making use of the of Site natural rock wherever it crops out by planting its crevices and crests. But whatever means may have to be taken to embellish the site, the golden rule is to avoid all appearance of artificiality. The stone Use of what that is used should be that of the neighbourhood, not is there only as being the easiest to obtain but as the most suitable-almost any kind will do, though such as are slaty and liable to crumble away should be avoided. Every endeavour should be made to take advantage of the opportunities the site may afford-a bank of chalk, for instance, may be most useful, as many plants, such as the Dwarf Harebells and Rock Roses, would do well there.

But even assuming that the ground is devoid of any of these natural advantages, the case is not hopeless. Elevations may be

Artificial ElevationsRight and Wrong made artificially, though there is a right and a wrong way of making them. The wrong way is to pile up an ugly mass of stones, burrs, clinkers and vitrified bricks-giving the appearance of a rubbish heap shot on the ground at random-and then to strew them with soil and make "pockets" for the plants. The right way, as might be expected, is more laborious, but its result is permanent and satisfactory. The elevations should be made by masses of soil, into which the rocks should have their bases buried, and wherever a seam occurs it should be crammed with earth and the plants put in with the earth, thus gradually building up together earth, rocks and plants into a consolidated whole. No space should be permitted beneath the surface of the soil, lest the roots of the plants become exposed in their crevices to draughts of dry air, and broken stone and grit should be used to fill up any hollows which may appear. In this I08 


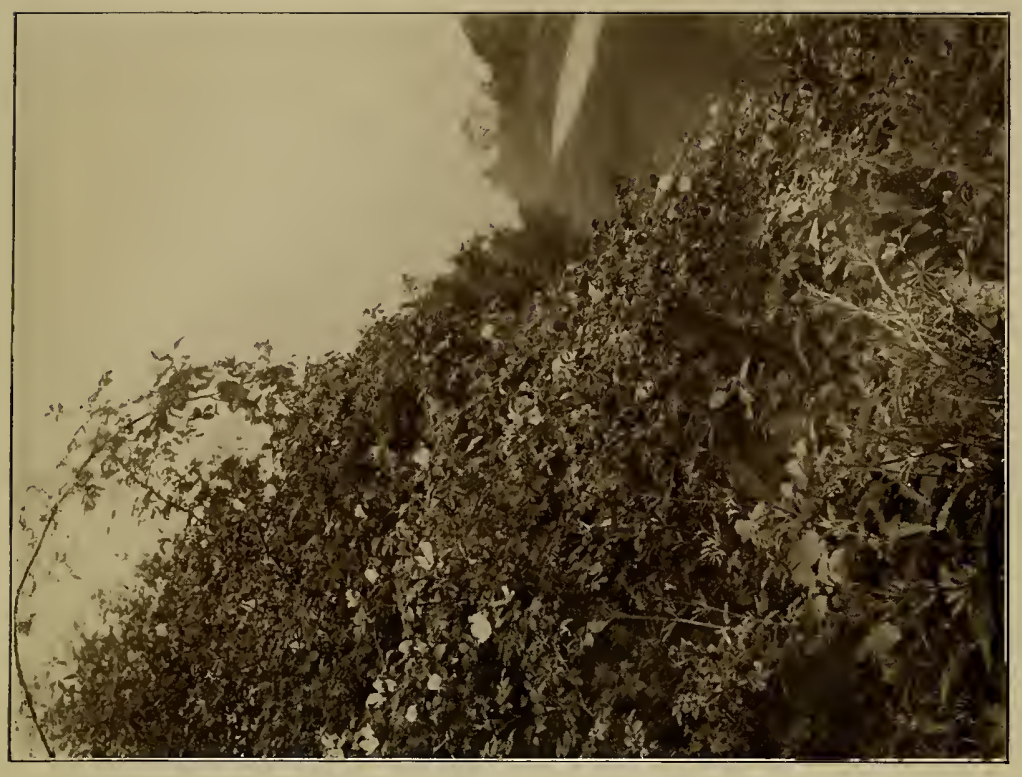

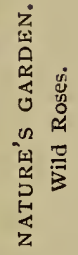

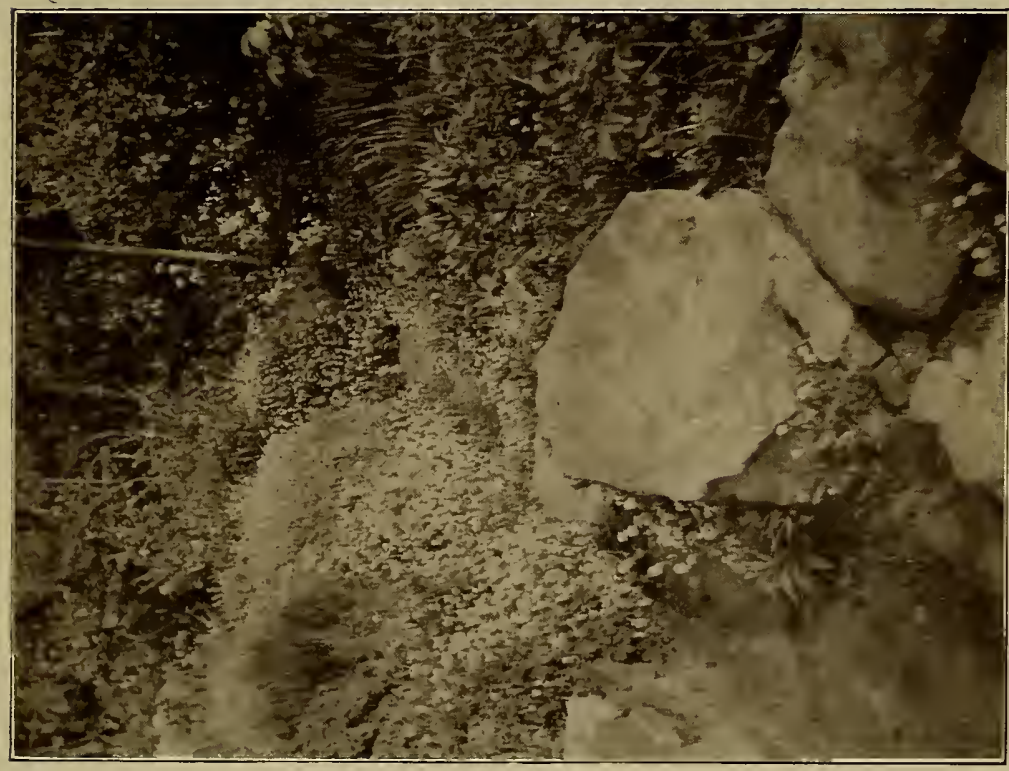

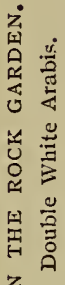

z 



\section{ALPINE, ROCK AND WALL GARDENS}

building process, of course, no cement should be used, the essential object being to provide suitable crevices in which the plants may firmly root themselves, for many a plant not more than an inch high will send out roots a yard long, perhaps radiating in all directions against a flat rock. The whole surface of the Alpine Garden should be covered with plants as far as possible, and a good effect may be obtained by the formation of irregular steps with Violets and Stonecrop jutting out from the crevices.

Another important consideration in forming an Alpine Garden is the quality of the soil. Most Alpine plants require a deep soil-some three feet, at least, should be Soil allowed-for their natural disposition is to root deeply, and unless they have provision made for this they will quickly perish in any drought. Ordinary loam, mixed with broken sandstone and grit, will suit most species, but peat is desirable for some-such as Trillium, Cypripedium and Spigelia-and hence it is good to include a few patches of peat for the benefit of such plants. Some calcareous soil may also be introduced with advantage, as certain plants, among which may be mentioned the Milkworts and Bee Orchis, thrive best in chalky formations.

There can be no doubt that an Alpine Garden, such as here indicated, may be a source of much pleasure and interest to the amateur gardener, and when once established it requires but little labour. Alpine plants have a peculiar charm of their own, embracing such a wide variety of beauty both in form and colour-in their delicate fairy-like ferns, their creeping mosses, their tiny orchids, their dwarf evergreen shrubs - so small yet so perfect in foliage and blossom-that they can scarcely fail to engender a passionate enthusiasm.

\section{THE ROCK GARDEN}

Although an Alpine Garden, in its best form, becomes essentially a Rock Garden, it is not only with Alpine plants that a Rock Garden can be made. There are many creeping mosses and low-growing plants which will do well on a properly-formed " rockery," thriving better in such a position and displaying their characteristics to greater advantage than in an ordinary border. Among such are the various kinds of Sedum (Stonecrop) and Saxifrage (Rockfoil), while the common. Wild Thyme and its white variety quickly spread into living cushions of

Suitable Plants scented beauty. These, with Yellow Alyssum, White Arabis and 


\section{A YEAR'S GARDENING}

Purple Aubretia, will form a lovely carpet of vegetation, and among them may be interspersed the trailing variety of Veronica (Speedwell), with its blue and white flowers, the common Violet and the wild Primrose. Of course these are only a few among the many that might be named and are only mentioned to show that the commonest and hardiest plants may be used with good effect if they are given a position which exhibits the beauty of their natural mode of growth.

Where space is limited, as in a suburban garden, there is no need to despise the smallest of Rock Gardens, which may "Suburban " become a feast for the eye of the jaded City man, "Rockery" especially in spring-time, if it be properly constructed and made in a suitable position. Such a place may be found even in a strip of garden, if it is fairly well enclosed and happens to run down to a railway cutting and embankment. The raised bank at the end of the garden may easily be made into a good " rockery" if simplicity be rigidly adhered to and the monstrosities of artificial stone, overhanging structures of cement, and dry and dusty recesses, be as rigidly avoided.

One sound and general principle is applicable to all Rock Gardens, from the smallest to the largest, viz., that the rocks Universal from the smallest to the largest, viz., that the rocks
Rule the soil by the rocks and stones. By a neglect of this simple rule are produced many of the ugly mounds and disfiguring structures mis-named "Rock Gardens," which are apparently formed with the erroneous idea that the "rocks," and not the plants, must be the chief consideration. But it cannot be stated too emphatically that the "rocks" must take a subsidiary place. Their bases should be firmly embedded in the earth-so laid that their most attractive sides protrude from the soil-while the smaller stones should be used on the slope of the bank to prevent any excessive draining away of the moisture. And let it not be forgotten that, as the result to be attained is a garden and not an exhibition of rocks, the rocks should be used sparingly, allowing ample room for the grouping and massing of the plants and for their sustenance by the soil.

\section{THE WALL GARDEN}

In connection with Alpine and Rock Gardens a few words on the so-called "Wall Garden" must not be omitted. Probably all of us have noticed what charming plants may spring from a mere IIO 


\section{ALPINE, ROCK AND WALL GARDENS}

chink in an old wall; dwarfed and small they may be, but none the less beautiful for that, and often sturdier and stronger and longerlived than when growing upon the ground. The Cheddar-pink, the Wallflower, the Toad-flax (Linaria), the Wall-erinus, and the dwarf Valerians (though these last have an unpleasant odour), will all do well in such a position, as well as many small ferns, such as the evergreen Polypodiums.

Of course the rough stone walls, constructed without cement, as seen in the Isle of Wight, in Wales and in the Lake District, lend themselves most readily to this embellishment; their cracks and crannies, their broad and

Suitable Walls spacious irregularities, provide just what the plants require. But even a brick wall when it is old and decaying, the mortar dropping out and a brick here and there worn away, may be made beautiful to look upon by a covering of plant growth; nor will such a growth hasten the destruction of the wall, but rather retard it.

Where there are sloping banks in a garden, or where portions of it are at different levels, it is often worth the trouble to build a rough stone wall-especially if stone can be easily obtained in the neighbourhood-as it not only

Practical Benefit adds the charm of variety to the garden by accentuating its irregularity, but may also serve a useful purpose in supporting the banks and in making a desirable division. With a wall to support it a bank may, of course, be cut at a much sharper slope than could otherwise be allowed, thus providing an additional space of level ground and giving an appearance of enlargement very valuable in a circumscribed area; while the wall itself, loosely built of rough stones and buttressed by a bank of sandy or calcareous soil, becomes an ideal spot for many a beautiful plant that would perish on level ground.

Here the delicate Alpines are free from that excitement to winter growth which, being foreign to their nature, tends to their exhaustion and premature decay, and in fact there is an almost limitless supply of rock and Alpine

Useful for Alpine Plants flowers-the Alpine Violas and the pretty creeping Blue Bindweed of North Africa may be mentioned-which will flourish to perfection in the "Wall Garden." 


\section{THE WILD GARDEN AND THE SPRING GARDEN}

\section{THE WILD GARDEN}

IT may be as well to state at once that, in the writer's conception, the Wild Garden is not synonymous with the Spring Garden, though doubtless, in our climate, it is generally at its best in the Spring.

Nature teaches us what the Wild Garden should be like, and who

Nature's

that has seen a mass of Bluebells in a recently-cut

Lesson copse- " the heavens upbreaking through the earth" -or a carpet of Primroses fringed with the delicate pink of Windflowers just bursting into blossom, can doubt that she is the mistress to whom we should submit ourselves to learn the art of forming a Wild Garden. And if we will go to her in a teachable and tractable spirit we may learn, with her generous help, to emulate her efforts and assist her in making beautiful the waste places of the earth.

Yet it must be admitted that the Wild Garden should not be attempted in a small plot of ground; its essential Not Adapted to characteristics are a broad massing of growth and Small Garden colours, a spacious outlook, the beauty of the whole effect rather than that of the individual flower.

Thus it will be seen that the functions of a Wild Garden do not

Special

Province clash with those of any other garden, but should be reserved for spaces where neither the Spring Garden, nor the Rock Garden, nor the groups of hardy plants in bed and border would be suitable; places such as the fringes of woodland walks and drives, the unused ground in grove and copse, the banks of streamlets, or even the coarse grass of some waste piece of pasture. And in the Wild Garden, wherever it may be planted, is the place for those flowers-and there are many of them-which may rightly be considered unworthy of cultivation in a trim garden, or which are apt to spread so rapidly as to become a nuisance where choicer plants are grown. Of such are the common Michaelmas Daisy, the Perennial Sunflower, Monkshood (Aconitum Nap.), the common Milkweed, with its fragrant flowers of deep purple, or (in moist situations) the common Reed, indigenous to this country, 


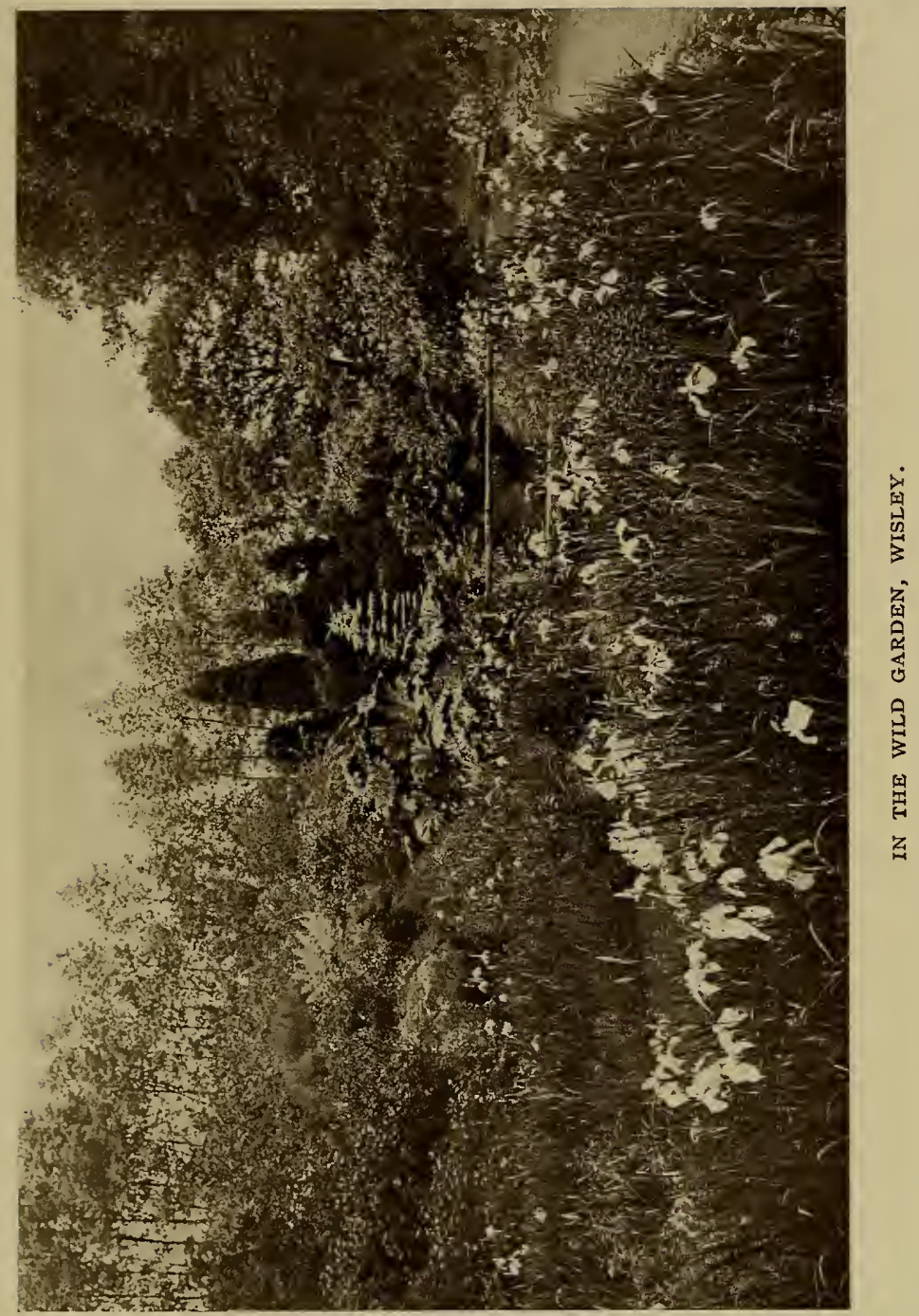





\section{WILD AND SPRING GARDENS}

tall and stately, gracefully bowing its feathery head of purplish hue. Many others there are-the Tree Lupin for sandy soil, the Loosestrife for boggy ground, Mullein (Verbuscum), Valerian, Ragged Robin, to quote but a few; while for spring flowers there are Narcissi, Daffodils, Snowdrops, Anemones, Crocuses, Primroses and Forget-me-nots.

Of course it must be understood, as already implied, that the Wild Garden is an addition to and not a substitute for any other garden, but it has advantages of its own

Advantages which can scarcely be overlooked. In its very wildness, and in its ability, when once successfully established, to increase and flourish without attention, it possesses a unique charm; while many of the hardy flowers mentioned above will undoubtedly thrive better left to themselves in the rough places of the Wild Garden than when cribbed, cabined and confined in trim borders. And as they succeed each other from season to season they relieve each other's deficiencies, as it were; the beauty of one kind will be fully in evidence while it blooms, and any ugly defects of its decay will be covered by the beauty of another kind or obliterated among more prominent plants around.

But over and above all other reasons for making a Wild Garden is its one true and special purpose-the reclaiming of ground which would otherwise be plain and bare, by embellishing it in Nature's own beautiful way, causing it to "blossom as the rose " in all the loveliness of fragrance, form and colour.

\section{THE SPRING GARDEN}

The garden that makes full provision for Spring flowers is sure to give satisfaction, for after the quiescence of winter, with the many cold and dreary days which it inevitably brings, every sign of renewed life is delightful. Moreover, the Spring flowers are in themselves a special joy; their frail beauty and delicate colouring, their seeming courage in braving the season's fitful weather-symbolical of hope maintained and faith justified-make an irresistible appeal to our best emotions.

It behoves us, therefore, to see that our gardens are so arranged that they can respond to the call of Spring, and it is a good plan to have some portion devoted to this object-to see, in fact, that our garden includes a "Spring

\section{Demands} Admittance Garden," some quiet sheltered spot where Spring may hold full $\mathrm{H}$ 


\section{A YEAR'S GARDENING}

sway and revel in its natural beauty, unmolested by the thought of the coming glory of summer.

If we are to make the best use of our " Spring Garden " we must

What to Avoid avoid any sort of "bedding-out" system and must What to Use not be over-anxious about annual culture. We have now many Spring flowers which are not dependent on rich soil and careful cultivation, and to these we may confidently look to ensure a good display.

The Yellow Alyssum, for instance, is as easy to grow as it is effective, and the White Arabis, the many varieties

Herbaceous Plants of Rock Cresses, the evergreen Candytufts and the numerous kinds of Anemone, are all most valuable; while where the soil is moist or marshy the Ranunculus (Buttercup) family-Bachelor's Buttons, Columbines in their great variety, Kingcups, and Winter Aconite (one of the earliest harbingers of Spring)-will all thrive well. And the common Primrose, the Cowslip, the Oxlip, the Polyanthus and the Auricula must not be forgotten, nor the sweet Violet, the many kinds of Violas and Pansies, and those time-honoured favourites-Forget-me-nots and Wallflowers.

Then for bulbs there are the Crocuses, the Snowdrops, the Scillas, Bulbs Tulips; while the many beautiful Irises-English, the Daffodils, the Narcissi, the Hyacinths and the Spanish and German-are a host in themselves.

To this list-which, of course, is only meant to be suggestiveShrubs there must be added the many flowering shrubs which bloom in Spring, and from which we may gain some fine effects by judicious grouping. Especially is this the case with Azaleas, of which there are several hardy kinds that will thrive well in the open garden in sheltered spots, and their flowering is not deterred by partial shade. Rhododendrons, too, are most effective when properly grouped, and they will flourish in nearly any soil where lime is absent, though sandy peat is what is best for them. As they are free growers they should not be planted too closely nor in one huge mass, as we sometimes see them, but broken up into groups of harmonious colour. The Magnolia is another beautiful flowering shrub which will be found valuable in our southern counties, though it is somewhat susceptible to frost and its flowers get nipped occasionally. Then there are the more hardy kinds of flowering shrubs, such as the Hawthorns-red, pink, double and weeping; the many sorts of Flowering Currants, the Lilac, the Laburnum, the Broom and the Furze bush; while the Deutzia, the Syringa, the 


\section{WILD AND SPRING GARDENS}

Pyrus Japonica and the Genista must not be omitted from our list.

It would, of course, be easy to extend this list of plants and bulbs and shrubs, but a mere catalogue of all that can be grown in a Spring Garden is scarcely desirable. Rather, the endeavour here made is to stimulate the enthusiasm of the lover of Spring flowers, to remind him how potent is the spell, how fair is the witchery, of Spring's sweet touch of fragrance; for when once the enthusiasm is aroused, no gardener will find much difficulty in making a Spring Garden. And who can resist the call of Spring, when- "Lo, the winter is past, the rain is over and gone, the flowers appear on the earth, and the time of the singing of birds is come "? 


\section{GARDENING}

\section{IN WINDOW-BOXES, ORNAMENTAL POTS, TUBS AND BOWLS}

IN the cottager who fills the inside ledge of her never-opened window with giant geraniums, sacrificing to them all the air of all the family, and in the wealthy owner of a riverside frontage who makes a roofgarden of his boat-house or supplements his lawn with stone vases to further brighten a bright scene with a quick succession of the most expensive bedding-out plants, the same spirit of floral decoration is expressing itself. And between these two extremes are now an increasing number who make a study of window-box gardening, of ornamental pot or tub gardening, of growing bulbs indoors in bowls, and so on-elaborating schemes of more or less successful colour and charm wherewith to brighten the outside or the inside of their homes. So that in a book on gardening some hints on the care and contrivance of these substitutes of the garden proper may be found useful.

And certainly the fascination of watching flowers grow at such close quarters, of devising harmonious effects on a miniature scale, is one that repays those who pursue it; and if, with our modern craze for quick results, we cannot hope to rival the Japanese, who will patiently produce you a forest tree of fitting dimensions for your dining-table, we can yet do a great deal in a small space that is genuinely decorative and worth while. But it must be remembered that in no branch of "gardening" is greater daily and individual care required. Where only a comparatively few handfuls of soil are being made to produce the very maximum of plant life, a week's want of water, a careless and too heavy watering-whereby the earth grows caked and sodden, and the roots decayed--the neglect of the timely administration of a sparing quantity of artificial manure in the water, or the failure to quickly sponge leaves that are choked with dust, or to remove dead leaves and blossoms and, as in the case of geraniums, even dead pellets, will cause the most disheartening II6 


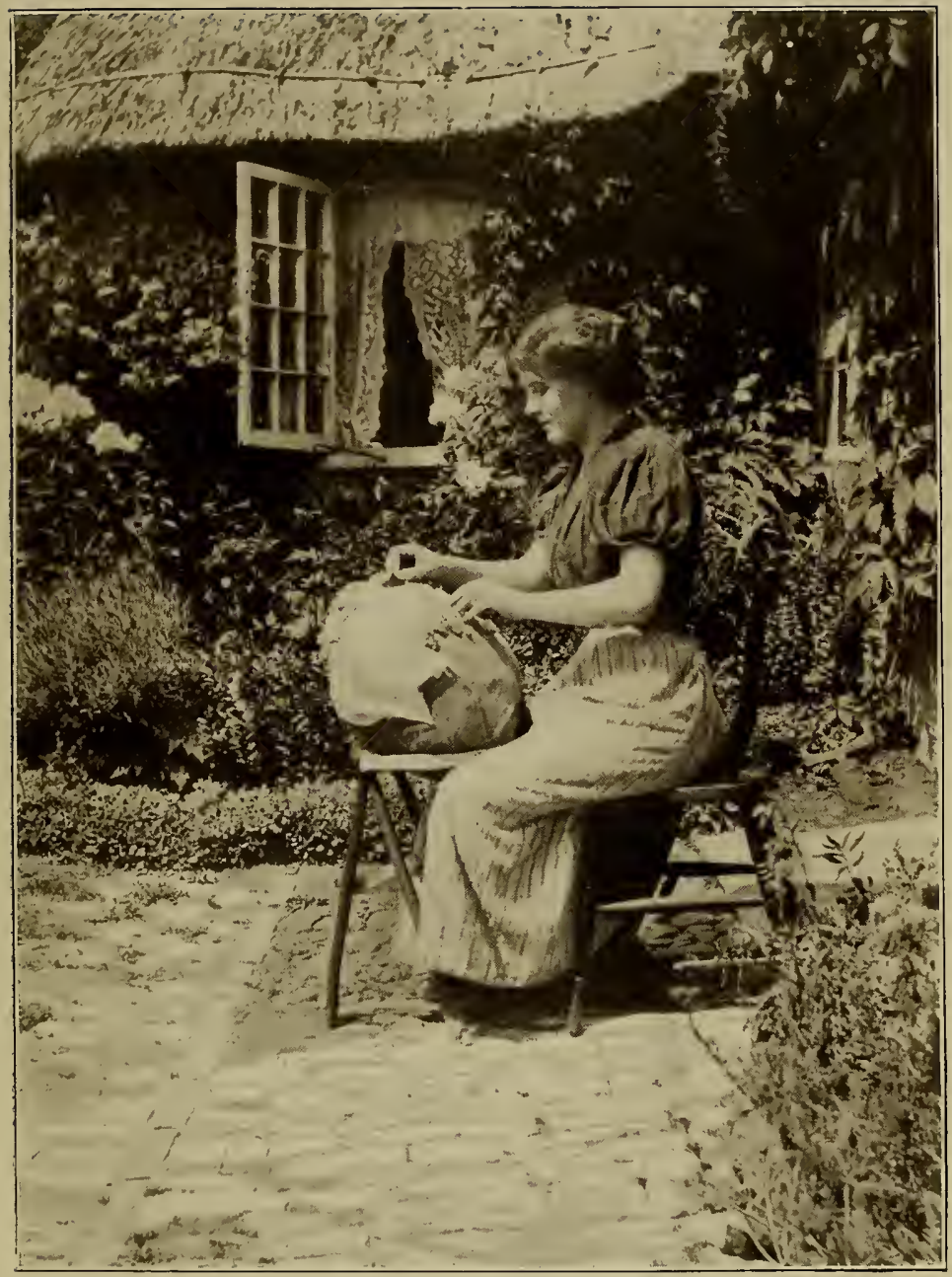

A COTTAGER'S GARDEN. 



\section{GARDENING IN WINDOW-BOXES}

results. In this class of flower-growing-if in any-an hour to-day has emphatically no power at all to replace the lost half-hour of yesterday, the ten minutes from the day before.

To begin with, the boxes themselves must vary in accordance with circumstances and individual taste, and only a few broad lines can be laid down here for following. Window A strong box of well-seasoned wood, made the re-

Boxes quired size, is the first requisite, and in this a sufficient number of holes must be pierced at the bottom, as drainage is all-important, while as a further aid to this it is advisable to have the bottom of the box raised half an inch or so from the window ledge by means of supports at the sides or corners.

The wooden box needs a couple of coats of paint, but many desire to further decorate with a facing of virgin cork or tiles. If tiles are used, unglazed red ones, or those that re- Decoration semble slightly-glazed cheap brown pottery, are recommended as more fitting backgrounds for trailing plants than the highly-glazed blue or green or yellow tiles of suburban fancy. There is something to be said for having the window-boxes painted unobtrusively to match the painted window frames, but if green boxes are liked where (say) the sashes are white or buff, few things are more simply successful than the shade of ready-mixed paint known as Middle Brunswick Green, which will be found to tone down with weather into that picturesque blue-green so satisfactory to the artistic taste.

For filling, still with an eye to proper drainage, the first thin layer should be of old broken-up flower-pots, and amongst this some lumps of charcoal is advised, to

Filling keep the drainage and the soil above it sweet. As to the best soil opinions vary, but as in any case the boxes should be emptied and refilled half-annually, personal experiment is not out of the question. A writer in the Morning Post has recently recommended that " about a third of the quantity should consist of old mushroom-bed manure and the remainder should be composed of sound fibrous loam and leaf-mould in equal proportions. With this a liberal allowance of rough grit should be incorporated." And although this mixture may not be practical for all, it may serve as a guide to the kind of soil most suitable for the purpose. Further, a little artificial manure may be added occasionally with advantage.

Window-boxes should be watered morning and evening when the weather is very dry and hot; otherwise, to water them in the evening when they require it should be Daily Care sufficient. But it is strongly advised that the leaves of the plants 


\section{A YEAR'S GARDENING}

should be syringed, or even sponged, as well as the roots watered, as they often suffer very much from dust. This attention and a few minutes spent daily in removing dead leaves and blossoms will be well repaid.

As the winter is the time when most window-boxes fail altogether Boxes in to be things of beauty, the really ambitious grower Winter will plant his boxes ready in the autumn with dwarf Shrubs, such as the Green or Golden Privet, Eunonymous (radicanus variegatus), and one or two plants having berries, such as Shimmia Japonica, or Solanum (Winter Cherry). Between the shrubs bulbs may be planted for the spring, unless indeed the excusable extravagance of two separate zinc linings to the boxes is permitted. In that case the bulbs may be set in the lining not in use for the window, and a still larger show of flowers ensured for the spring.

The choice of bulbs is a large one, and a good catalogue should b studied before planting. Winter Aconite and Snow-

Boxes in drops planted in the early autumn will be the first to Spring flower-as early as January in a sheltered, sunny window. Crocuses come next, with Narcissus, Daffodils, Hyacinths and Tulips to follow-Tulips, indeed, coming late enough to blend happily with Forget-me-nots. Nothing could be more charming, for instance, than dark purple Tulips growing amongst the Forgetme-not blue. Red-brown Wallflowers and Forget-me-nots will also serve to take the window-boxes well into May, when the summer flowers may be planted.

The end of May is the recognized time for planting boxes for the summer, and here, again, individual taste must be

Boxes in Summer exercised, as the choice is really a very wide one, though much narrowed by convention. A row of Marguerites at the back, with a second row of Scarlet Geraniums and blue and white Lobelia at the edge (there is a "Spreading Lobelia " specially suitable for hanging-baskets and window-boxes) is a combination so popular as to be almost universal, and certainly it must be owned it is effective, if unoriginal. Purple Petunias and pink Ivy Geraniums go well together and form a less hackneyed arrangement, but personal taste may better supply boxes to its own fancy from among such plants as Fuchsias, Begonias, Heliotropes, Mignonette, Stocks, Pinks, Carnations, Balsams, Calceolarias, Salvias, Nemesia, etc., etc.; while for cheapness and gaiety combined Nasturtiums and Tropæolums cannot easily be beaten. 


\section{GARDENING IN WINDOW-BOXES}

In the late summer and early autumn the Aster is a flower that can be recommended. It is now highly cultivated and well worth consideration. For later autumn any small variety of Chrysanthemum may be utilized. Boxes in
Autumn

For ornamental pots and tubs, where a variety of flowers is desired, the order of plants and procedure in filling are practically the same as for window-boxes. Outdoor flower vases are generally fairly cheap when bought direct

Ornamental

Pots \& Tubs from a pottery, and often greatly improve a garden, especially where there is much grass and few flower-beds. Only, as in the case of window-boxes, the daily care in watering, removing dead leaves and blossoms, etc., is all essential.

Butter or lard tubs - to be bought for fourpence or sixpence apiece-can also be utilized by those in search of economical ornamentation for the garden, balcony, terrace, or flat roof. Painted green (the Middle

Butter Tubs for Flowers Brunswick Green advised for flower-boxes) and well drained by means of holes drilled in the bottom, these tubs will last several seasons and always look picturesque. Where variety is not sought after and a more permanent filling desired, tubs or vases may have an effective arrangement of tall Ferns, with an undergrowth of Stonecrop, Creeping Jenny, Double Arabis, Saxifrage or Ground Ivy.

In large pots and tubs (barrels bought at a small cost at the grocer's or wine merchant's may be sawn in half and treated like the lard tubs) any of the small compact shrubs may be grown, while in our southern counties

Large Pots and Tubs and in sheltered positions Myrtles, Tree Fuchsias, Hardy Azaleas and Brooms will flourish with excellent decorative effect.

Almost every sort of bulb for spring flowering can be grown indoors in bowls, and no more charming decoration for a room can be imagined. Any sort of earthenware bowl is suitable -green, brown, or yellow-the flowers Bulbs in Bowls grown in them being selected with a view to forming an artistic whole. Snowdrops, Scillas, Crocuses, Narcissi, Daffodils, Hyacinths, Tulips, etc., will form a succession of bloom which for table decoration alone would be worth considering.

The method of growing is an extremely simple one. The bulbs should be selected in early autumn, and may be grown in pebbles, shell gravel, or damp moss, but the most popular and therefore, probably, the most successful Method of Growing medium is cocoanut fibre. This fibre, sold at the florist's for the 


\section{A YEAR'S GARDENING}

purpose, needs to be damped, and enough should be put in each bowl for the bulbs to stand in without touching-the overcrowding of bulbs is a fatal mistake. The bulbs placed firmly, with the tips just showing, more fibre should be packed round them so that the bowls are nearly full. Some small lumps of charcoal form the best drainage at the bottom of the bowls, and a few pieces amongst the fibre will keep it sweet.

After settling, the first thing to do is to give a thorough watering. Watering Afterwards water must be given occasionally and with be avoided.

A cold frame may be used to keep the bowls in while the roots Storage are forming, but a dry cellar, or even a cupboard that well. is sufficiently airy, will answer the purpose equally

The bowls should be kept in the dark until some sturdy shoots When to Move are formed, and then the transition to light, and more the Bowls plants will become weedy and the flowers poor or even non-existent. But once growth is well forward light and air are very necessary.

During the remaining growth water should be given freely until the flowers are fully out - when very little water is desirable. Where the flower stalks are tall a certain amount of support must be given to them, but it should be very carefully managed or all the natural beauty of the plant will be lost.

As they wither the flowers should be cut off, but not the leaves; they should be left to turn brown after the bulbs

The After Treatment of Bulbs flower a second time in the restricted nourishment they find in a bowl. 


\section{LAWNS}

\section{THEIR MAKING, MAINTAINING AND RENOVATION}

IT has been well said that the Lawn is the heart of a British garden, and he who has lived abroad and experienced how impossible it is to maintain there any good turf is quick to recognize, and appreciate at its true worth, the importance and charm of a well-kept grass-plat. There is about it a certain freedom and freshness, a vigour and stability, which impart a delightful sense of breadth and homeliness, so that a garden without a lawn seems not only cramped and arid but strange and alien. Most of us must have seen-and revelled in the mere sight-the beautiful, smooth-cut, velvety sward of the " backs" of Cambridge, the very perfection of cultivated turf, and perhaps have sighed at the futility of attempting to rival it in our own garden. But though lawns may doubtless be reckoned among those things that are best when old, no one, with the resources now at hand, need despair of making a good lawn in a short time.

For those who are in a hurry and must have a lawn ready-made, so to speak, the practice of putting down turves cut from a pasture has somewhat to recommend it, the chief objection being that it is very difficult to obtain Turf or Seed grass which is not full of weeds. To the casual glance, when viewed in a field, it may look suitable enough, but no sooner is it laid down and become established as a lawn than it reveals itself as mixed with an immense number of weeds, the eradication of which entails much arduous labour. Unless, therefore, it be possible to obtain really good turf for laying down, it is better, and far cheaper, to make a lawn from seed, which, if it be purchased from a seedsman of repute, such as Carter of London, or Sutton of Reading, has the double advantage of being free from weeds and obtainable in different mixtures suited to the soil and position of the intended lawn. 


\section{A YEAR'S GARDENING}

But whether the lawn be made by laying turf or by sowing seed, Preparation of Ground the proper preparation of the ground is equally important. The early autumn, during the first two weeks of September, is one of the best seasons for sowing the seed, as the soil is then warm and rain and heavy dews are generally prevalent a little later. This gives an opportunity for the seed to germinate freely and allows the young grass to become established before the winter frosts set in, enabling it, by the time spring has arrived and all growth is most vigorous, to overcome the weeds which would then begin to fructify from any weed-seeds which may have lain dormant in the soil. A word of caution against hurry may, perhaps, be necessary. The old adage, "The more haste, the Avoid Hurry less speed," is most applicable to the preparation of the ground for making a lawn, and it is certainly wise to allow a week or two for the new surface to settle and consolidate, and find its own level, before sowing the seed or laying the turf.

The first step in the preparation of the ground is to mark out the limits of the plot. Then it should be dug over to the Digging and Manuring depth of Io to I2 inches, turning the soil completely, breaking it up fine, and taking out all large stones, weeds and roots. Then the whole surface should be spread with manure, forking it in to a depth of 3 or 4 inches. This part of the preparation is one so often omitted that it is necessary to insist upon its importance; without a well-nourished soil to begin with the results are sure to be unsatisfactory. The best general manure is well-rotted stable litter, which is usually easily procured.

The next step is to find a general level, which to the amateur may Levelling seem a difficult operation, but is really fairly easy. A Levelling stout wooden peg, some 2 feet long, sharp pointed at one end but with a flat head, should be driven into the centre of the plot, allowing the top of the peg to stand up from the ground at the height required for the level of the plot. From this centre, in radiating lines at distances of some $I_{5}$ feet apart, similar pegs should be driven in, and by means of a spirit-level and a level-edged board placed from peg to peg the tops of all the pegs may be brought to an exact level.

Now comes the making of the seed-bed, which is done by careful Making Seed-bed

raking of the ground into a fine surface and to a uniform level, as judged by the projecting pegs. Then it should be trodden firmly all over (or a small roller may be used), pressing in any lump or stone so that an even as well as a level surface is obtained, until the whole is so well con- 


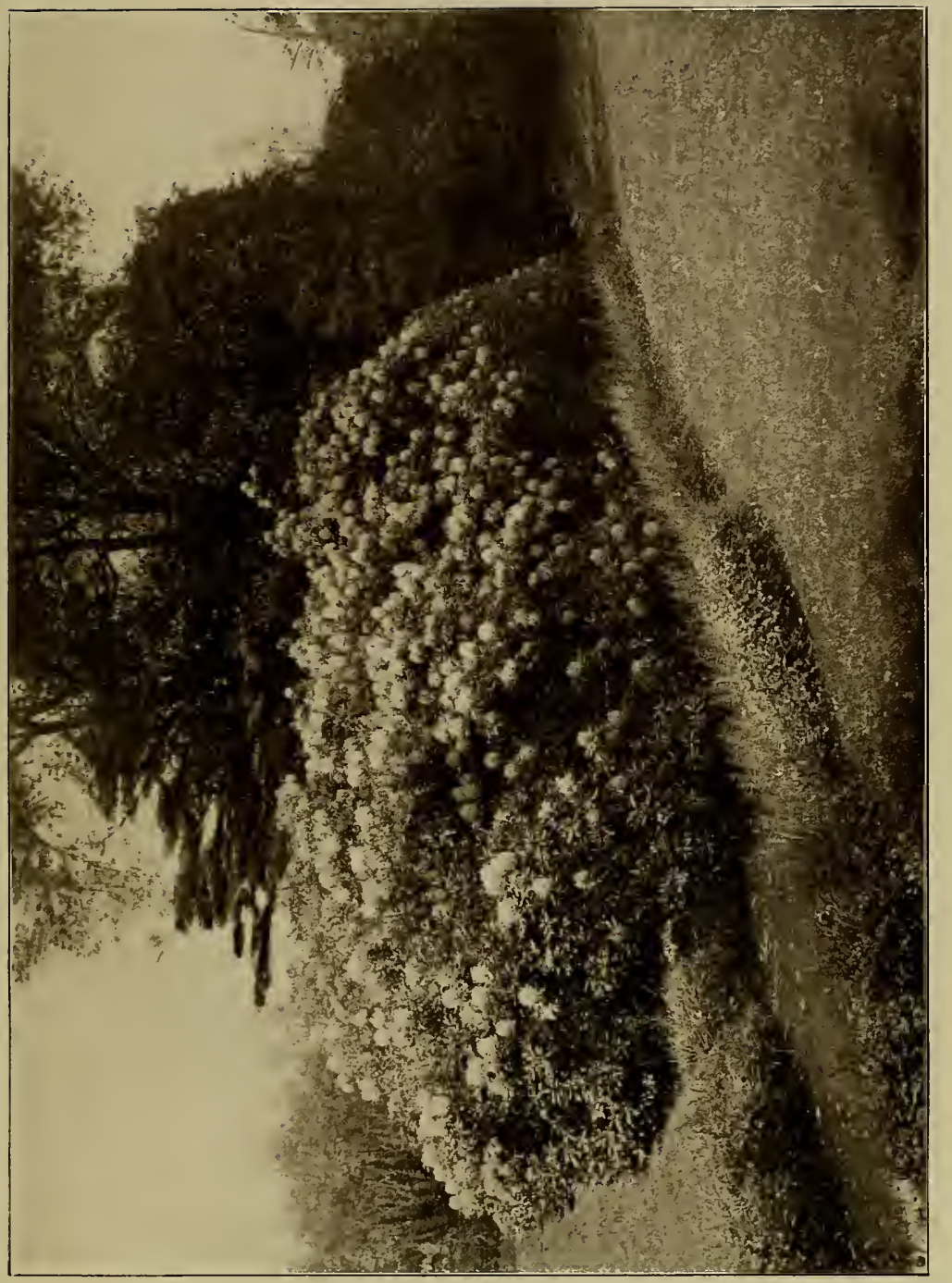

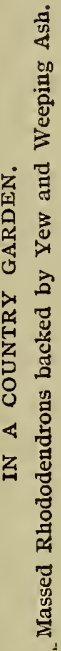





\section{LAWNS}

solidated as scarcely to show the imprints of the foot when walked upon.

The ground is now ready to be laid with the turf or to receive the seed. For sowing, a calm, dry day should be chosen, as in the wind the seed (which is very light)

Sowing may easily be blown away, while in the wet the surface of the soil would be injuriously disturbed by walking over it. It is a good plan to divide the ground into square sections by means of pegs and string, and to portion out the seed correspondingly. One pound of seed is sufficient for an area of 4 square yards. The seed should be sown as evenly as possible and be lightly covered with soil-not deeper than a quarter of an inch-by carefully raking the surface in two directions, after which the whole should be rolled and cross-rolled with a light roller.

In the course of a fortnight or three weeks, according to the weather, the young grass ought to appear above ground, and when it is about an inch high it will be greatly benefited by the application of some top-dressing

Nurture of New Growth (Carter's Fertilising Fibre is excellent for the purpose), which will supply nitrogen to assist the growth of the young grass and protect it from extremes of temperature. As soon as it has grown to the height of 2 inches it ought to be cut-preferably with a scythe, although a well-running sharp machine, set high, will do no harm. It is highly important that the young grass should be kept short from the beginning, for if allowed to become long it will be proportionately thin and fail to broaden out, and any bare places should be attended to immediately by gently loosening the soil and sowing a little seed. As grass will not thrive on a loose surface, rolling becomes an important operation in a newly-made lawn, but though careful and frequent rolling is necessary, a heavy roller is not desirable.

It may, perhaps, be well to repeat that in making a lawn by laying turf instead of by sowing seed the preparation of the ground is practically the same. In putting down the turves, which are usually cut in 3-feet lengths by I foot wide, the joints of each piece should be kept half-an-inch apart, so as to allow for expansion when beaten down and rolled.

There is one element in the preparation of the ground for making a lawn which, though it is not in accordance with the generally-accepted methods, seems to be well worth consideration. It consists in the use of chalk as a sort of sub-soil immediately below the loam on which the

Chalk

as a Sub-soil turf is to be placed or the seed sown. Undoubtedly the finest 


\section{A YEAR'S GARDENING}

natural turf is to be found on chalk formations, and the Sussex downs-the southern range running along the coast and the northern range which forms the boundary of the county-the Wiltshire downs and the Isle of Wight downs, are all examples of this fact. Chalk is conducive to good drainage, its porous nature permitting it both to absorb any excess of moisture and to retain it for the use of the soil immediately above it. It would seem, therefore, that a layer of broken chalk, some 3 or 4 inches deep, must make an excellent foundation for a lawn, and as far as the writer's recent experience goes it has fulfilled its promise admirably.

\section{MAINTENANCE AND RENOVATION}

With ordinary care and attention it is not difficult to maintain a lawn in good condition, unless it happens to be-what is certainly very beautiful-closely shaded by trees. In that case the roots of Shady Lawns the trees absorb so much of the moisture and nutriment She soil that there must ever be a fight to preserve the turf, especially if the branches of the trees extend over the grass itself and only a few feet above it. For not only is the ground impoverished by the tree roots, but in summer the foliage deprives it of light and air and rain, while in winter the continued drip of the rain from every branch and twig is destructive of all growth below. This does not imply that a shadeless lawn is desirable, but only that, if possible, the trees should be relegated to such a distance and their branches so restrained as to prevent their overhanging the grass and causing its destruction. With all shady lawns, and even under the branches of trees if they do not reach within 8 or ro feet from the ground, the turf may be kept in good order by top-dressing in spring and autumn, to which may be added, as an extra precaution if the grass be thin, an occasional spring sowing of seed, opening up the surface for that purpose by raking and cross-raking with an irontoothed rake. During dry weather any piece of turf that may be constantly in the shade should be watered liberally.

Among what may be called the common necessities of a lawn, if it is to be kept in good condition, mowing and rolling are of prime importance. The grass, whether it be young or old, should never

\section{Mowing} be allowed to grow long and ragged, though it is obvious $\begin{array}{ll}\text { Mowing } & \text { that in hot and dry weather it is unwise to keep it too } \\ \text { closely cut. As in all gardening work, discretion must be used, but }\end{array}$ as a general rule about 2 inches is the extreme length to which the 


\section{LAWNS}

grass should be allowed to attain. In hot weather it is advisable to use the machine without the collecting-box, as the cut grass provides some protection to the turf from the sun's scorching rays, while it is scarcely noticeable on the surface if the mowing has not been previously neglected. It is a good practice to sweep the lawn before mowing, thus removing stones, worm casts, or any rubbish which would be caught by the knives of the machine and so blunt them as to give them a tendency to pull and tear the grass. A free-running, sharp-bladed machine is, of course, essential to the welfare of the turf.

As to rolling, the really useful time for this work is the early spring, when the ground is moist-not wet. This is especially the case if the winter has been severe, for under frost the soil has a tendency to lift and break up, and requires, therefore, to be re-consolidated. Frequent rolling-cross-rolling, not always in one direction-is what is then required, but during frost it is positively injurious and in dry weather is, of course, useless. Speaking of frost, it may be well to put in a cautionary word against sweeping off snow from a lawn, for although no damage may be done to the turf by the Caution as to Snow actual sweeping, the removal of the snow lays the ground open to a sudden change of temperature which is decidedly injurious.

Although, as already suggested, age may be essential as an important element in the formation of a really good lawn, it does not follow that an old lawn is necessarily a good one. Unless suitable means are taken for its maintenance, the soil beneath an old lawn becomes impoverished, especially, as we have seen, when shaded by trees. When it is borne in

Impoverished Soil mind how much is annually taken out of the soil, as shown by the quantity of cut grass produced by periodical mowing, it is astonishing that so little effort is generally made to replenish the growing capacity of a lawn. For most lawns an autumn top-dressing of some manure suitable to the character of the soil, according to whether it be light, medium or stiff, is necessary, as without such occasional enrichment it is impossible to maintain them in good condition. A sure indication of impoverishment is the presence of moss, with bare or thin grass and a recurrence of weeds. Assuming that the plot is not in need of draining, and that it has a fairly level surface, its renovation is not difficult. The time selected should be early autumn, as in making a new lawn, and the first operation is to cut the grass as short as possible. Then the surface should be very thoroughly opened by means of vigor-

Method of Renewal ous raking and cross-raking, care being taken to get rid of all the moss, I25 


\section{A YEAR'S GARDENING}

and as many of the weeds as possible; so long as the roots of the existing grass are not pulled up, the more the ground is loosened the better. The surface thus prepared should then be sown with seed -thickly or thinly, according to the bareness of the turf-and covered lightly with sifted soil in which some suitable artificial manure (such as Carter's Grass Manure, No. 2) has been mixed. The whole should then be gently cross-rolled with a light roller. Of course, if there has been long-standing neglect, and the weeds have been allowed to get the upper hand of the grass, more stringent measures for their extirpation may be necessary, but even then, unless the whole plot requires readjustment in level, it is generally better to renovate rather than re-make.

Weeding by hand is not the impossible job it is sometimes supWeeds posed to be, and there may be more wisdom in submitting to a calculable expenditure of time or money on weeding an old lawn than in committing oneself to a vaguelyestimated expense in making a new one. Even on a good lawn weeding is generally a necessary precaution, and if it be done regularly each spring the labour is but small. Weeds on a lawn may be roughly divided into two classes - the shallow-rooted, such as daisies and buttercups, and the long-rooted, such as plantains and dandelions. The first are easily eradicated with a daisy-fork, but the latter require a different treatment. Merely to cut off the tops of these long-rooted weeds is worse than useless, as it induces them to ramify and send out several crowns where only one previously existed. But if, when cutting off the crown, some strong acid be immediately

\section{Acid for}

Long-rooted Weeds applied to the exposed stem, its destruction is certain. A simple plan is to have at hand a small vial of sulphuric acid, in which is immersed a stout, sharppointed iron skewer, and with the skewer thus wet with the acid the root of the weed should be pierced perpendicularly as far as possible. Of course the acid must not be allowed to drop upon one's clothes or flesh, and gloves should be used in doing the work. If the weeds are numerous, an incentive to methodical and efficient work may be found in portioning out the ground into strips of (say) a yard wide by means of pegs and string, the space thus allotted being first cleared of daisies and shallow-rooted growths and then of the deep-rooted weeds. Any bare patches which may be made by the removal of the weeds may be repaired by loosening the soil and sprinkling on it a pinch of seed. The best time for the work is the early spring, while the turf is still moist from winter rains. 


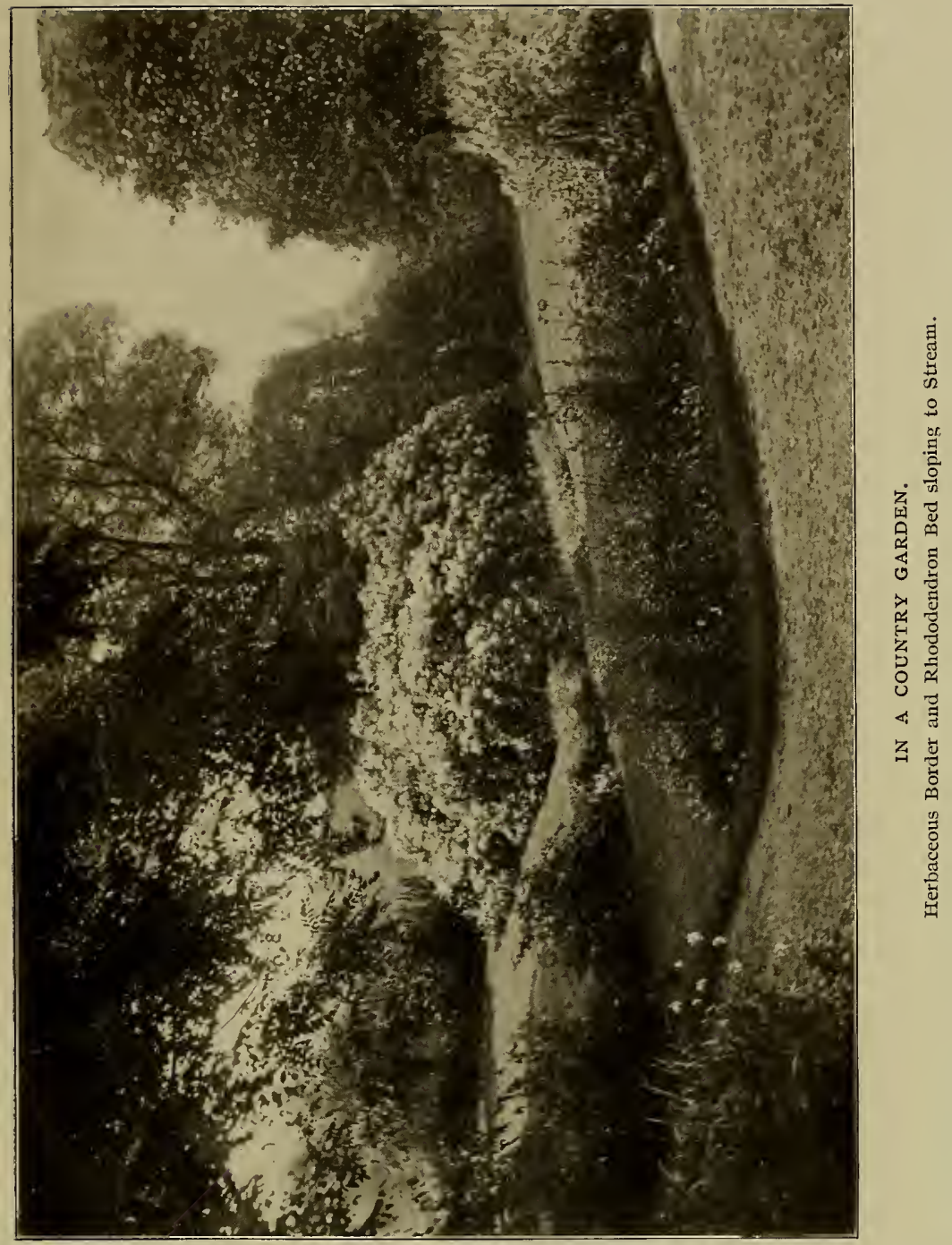





\section{LAWNS}

With all the care and attention which may be devoted to a lawn it seems impossible in some cases, at certain seasons of the year, to keep it free from worm casts. The late Worm Casts autumn, which often brings with it a spell of mild, muggy weather, is the time when this nuisance is most evident, and every morning, while these atmospheric conditions prevail, the muddy casts are renewed in spite of all previous sweeping and collecting. We are told-and we are quite ready to believe it-that worms play an important and useful part in renewing the soil, but seeing this recurring mess on our lawn we begin to think we can have too much of a good thing. Of course, the simple fact is that, beneficial as worms undoubtedly are, an excessive number in a particular area is really detrimental, and some means should be taken to diminish it. This may be done by applying a properly-compounded worm-destroyer, and Carter's "Wormkiller" (which has an excellent reputation) may safely be used for the purpose, if the directions with it are carefully adhered to. 


\section{FRUIT TREES}

\section{THEIR PLANTING, TRAINING, PRUNING AND RENOVATION}

THE pruning of fruit trees is an art that comparatively few can accomplish successfully, for its acquisition, in perfection, can only be obtained by long practice and intelligent observation. It follows that the amateur gardener, to whom gardening is but the recreation of leisure hours, is generally dependent for pruning upon the professional, who may be capable and efficient but who, on the other hand, is more Jikely to have only a slight knowledge of the rudiments of the art and be incapable of applying them intelligently.

It would be beyond the province of such a book as this to enter into a lengthy disquisition on the various methods which may be adopted in pruning and training, but a few general principles may be stated and their application in particular cases left to the wise discretion of the reader.

Probably the majority for whom this book is designed have a comparatively small garden, and in many cases, when they enter into occupation, they find it bare and empty, devoid of any fruit trees. It is deplorable how fruit culture is generally neglected, for even in a small garden, surrounded with only a low brick wall, fruit trees may be grown and trained and made productive of good crops by devoting a little care and daily attention. Naturally, much depends upon the position in which the trees are planted and the manner in which they are trained, and it is hoped that some useful hints in these respects may be found in this chapter.

\section{WALL-TRAINED FRUIT TREES}

For the peach, the nectarine, the apricot, the greengage and the plum-and, indeed, for all stone fruit-the best place 128 


\section{FRUI'T TREES}

for planting is against a brick wall with a southern aspect, and the system of training called "oblique cordon" is one which accommodates itself more than any other to a low wall and a small space. Moreover, it demands less judgment in pruning and places the tree more under control than the ordinary fan-shaped method of training.

Let us assume that it is decided to utilize the border under the low brick wall which faces south in the hitherto vacant garden by planting fruit trees, and that, among others, a one-year old peach tree is to be installed. The border itself first demands some preparation. It should be thoroughly drained and raised some 6 inches above the ground level, but there is no need for any special richness of soil-the most suitable is that which is fairly deep and of calcareous consistency. It may be mentioned here that after the trees are planted the soil should not be subjected to deep digging; an occasional loosening of the earth with a fork to the depth of 6 or 8 inches is all that is required. Much damage is often done to young fruit trees by deep digging with a spade, with the result that the roots are lacerated and bruised and suckers thrown up, thus, perhaps, destroying the tree before it has even reached maturity.

The best time for planting is October or November, while the weather is open and free from severe frost. It is necessary that the roots be kept carefully wrapped up as long as they are out of the ground, for any exposure to a dry wind or to frost might be fatal. Pre-

Season for and Method of Planting pare the station where the tree is to be planted by digging a small pit about 2 feet square and some $x 8$ inches deep, according to the size of the roots, but no deeper than will allow the crown of the root to be more than just covered. Before planting it may be necessary to prune the roots by removing any portion that is broken or bruised. For the oblique cordon system of training, such as is here advised, the stem of the young tree-which in the case of a one-year-old peach would be a single rod with budding excrescences-should be laid obliquely against the wall at an angle of forty-five degrees to the level of the ground, the roots being spread carefully in a horizontal position and then covered firmly with mould. Care should be taken that the roots are laid as far away from the wall as can be conveniently arranged, so as to give them space to ramify. The stem should then be made fast to the wall with strong nails and shreds, using caution that the nails do not come in contact with the wood and never bruising the tree with the hammer. 


\section{A YEAR'S GARDENING}

It is of the utmost importance that the training of a fruit tree be Training and Pruning attended to at the outset, as by this means may be obtained not only a well-developed fruit-bearing tree in a short time, but also one which will continue to bear for twenty or thirty years. It has been asserted that it requires seven years to produce a well-developed peach tree, but, in reality, there is no doubt that with proper care and attention a good fruit-bearing tree can be produced within four years from the planting of the maiden stem, provided it be properly trained and pruned from the beginning.

As soon as the maiden stem begins to break into bud, watch how it seems inclined to shoot. Some of the buds may be too weak and some too strong, and there will probably be too many. Therefore thin out, by rubbing off, those which are not required, retaining only those which are of even growth and at fairly equal distances from each other along the stem. When 3 or 4 inches of lateral growth have appeared, stop each lateral by nipping. There will probably succeed two other laterals, which will make equal progress and be furnished with fruit-buds by the following autumn. But it would be unwise, at this stage, to allow the tree to continue the growth of all this wood, and one of each of the double laterals should be cut back to a bud within a few inches of the stem, while the other should be shortened a little. Thus a tree capable of bearing fruit may be produced within three years, but only a very few of the fruit should be allowed to ripen on so young a tree.

It may happen that the tree is in a strong, rich soil, causing it to grow too vigorously and to make too much wood. In such a case it would be a mistake to cut it back; let it bear all the fruit it can for a season, and thus tame down its tendency to an over-growth of wood. Such a plan is excellent for checking rank growth-better even than lifting. On the other hand, if the tree be growing in poor, light soil, the buds may be weak and the laterals wanting in vigour. If so, cut all the laterals back to a bud within a few inches of the stem, and the following season there will be two laterals from each spur.

Having by these means obtained a well-developed tree of good fruit-bearing capacity, its constitution and character may be maintained by cutting back every season, as far as the first bud from the stem, one of the double laterals all through the tree, by which means a new lateral will be provided each year and the tree remain sound and productive throughout its life. 


\section{FRUI'T 'TREES}

The systematic annual cutting back described above is sometimes called winter pruning, but the best time for its performance is February or March, because not only is it then easier to see what to cut out and what to leave, Season for Pruning but also because the tree, at that season, is less likely to be exposed to, and is better able to resist, frost and dry winds. The process called summer pruning should take place as soon as the new buds appear. It consists of rubbing off with finger and thumb all buds which are not required, such as those which appear in the front of the branches of a wall-trained tree and are in such a position that they cannot be laid in on one side or the other.

With all wall-fruit it is important to thin out both fruit and leaves at an early stage. The amount of fruit retained must be a matter of judgment and depends, in some measure, upon the condition of the tree, but it is better to remove too many than too few. With peaches, for instance, 3 or 4 to the square foot is as many as should be allowed to remain if the full development of each peach is to be secured. With the same object in view the leaves should be nipped off wherever they shade the fruit and prevent its proper exposure to the sun's ripening power.

The directions already given-which, though concise, are believed to be adequate, and which have taken the peach tree as a typical example-may be applied to all walltrained fruit trees; but it is well to bear in mind that fruit trees-even those of the same kind-are not all

General

Application

of Foregoing Directions alike in habit and growth. Differences are caused by many factors, such as the particular constitution of the tree, the soil in which it is planted, and the position in which it stands. It follows that the individual needs of a tree must be met by an intelligent application of the general methods.

It remains to consider how best to renovate wall-trained fruit trees which, either through neglect or mistaken training and pruning, or from these causes combined, have deteriorated and become more or less unfruitful. The Fruit Trees old adage, "Spare the rod and spoil the child," may be paraphrased in connection with fruit trees by "Spare the knife and spoil the tree," but there is more hope of reclaiming a tree than a child. The principles of training and pruning already indicated should be applied 


\section{A YEAR'S GARDENING}

in the renovation of a tree which has got out of hand, though, of course, the "oblique cordon" system can only be applied when the tree is young. One of the great advantages of that method is that the main leader remains a permanent thing as long as the tree endures, while the laterals, as already explained, are renewed from year to year. Still, it is quite possible, by drastic and judicious cutting back, to reclaim a tree which has been allowed to run wild.

It is not uncommon to find that a fan-trained tree has become barren in fruit-bearing wood at the body of the tree, producing fruit at the extremities only. This is caused by the pruner having been afraid to use the knife in such a manner as to keep the tree within proper bounds, under the mistaken idea that it is a pity to cut off young wood. In such a case cut back without hesitation, retaining only a few good leaders. Then lift the tree and prune the rootswith a fine saw or a sharp chisel if the knife is insufficient-replant it, and lay out the leaders equally and symmetrically, making them fast to the wall by strong nails and shreds. Probably, after so ruthless a cutting back, the tree, especially if it is of a strong constitution, will make vigorous growth during the next season, in which case allow all the summer growth possible, so as to tame down its woodgrowing capacity. Then lay out each shoot carefully in a suitable direction, thinning out afterwards, as may be necessary, and cutting back the extremities from year to year, by which means the fruitbearing wood will be kept in the body of the tree.

\section{FRUIT TREES NOT WALL-TRAINED}

Hitherto our attention has been confined to wall-trained fruit trees, as from these are obtained the choicest and most prized fruits -peaches, nectarines, apricots, greengages, etc.; but there is also scope, even in a small garden, for other sorts of fruit trees, such as the apple, the pear, the cherry and the plum. All these may be grown in the dwarf or half-standard style, and the proper method of

Dwarf Standards-Their Pruning, etc.

pruning them needs a few words in this chapter. As the form of the tree is different from that of the walltrained tree, so its method of pruning must be correspondingly altered. The object of the pruning should be to form a full, round, cup-shaped head. All unproductive wood, crowded sprays and decayed branches, or any which cross each other, should be cut out, and the open, cup-like form rigorously maintained. It is possible that through neglect of timely pruning the fruit-spurs I32 


\section{FRUIT TREES}

of a tree may have become clubbed by being allowed to grow too closely together, thus hindering proper wood-growth and restricting the fruit-bearing capacity of the tree. In such a case cut away the upper part of the clubbed growth in such wise as that only two or three spurs remain, when small buds will push out and form fruiting wood the following year.

\section{SOME CHARACTERISTICS OF FRUIT TREES}

There still remains something to be said as to the particular qualities of the various kinds of fruit trees. The peach-and with it may be classed the nectarine-has purposely been taken as an example of the wall-trained fruit tree because it seems to deserve more general cultivation

Peach and Nectarine by the amateur than is usually accorded to it. It is invariably conceded that there is no more delicious fruit than a well-ripened, full-flavoured peach, and if the methods already suggested are carried out intelligently such fruit can be grown successfully and will well repay the care and attention devoted to it.

The apricot and the greengage are also, as a rule, treated as wall-trained trees, for in our humid climate, when planted as standards or dwarfs, and away from dry and warm walls, they do not fruit well. The reason assigned is that in a damp atmosphere the pollen of the flower becomes "glued" and fails to fructify.

The cherry may also be wall-trained, but it is not fond of the knife, and it does not need much thinning of the branches. Summer nipping is generally sufficient, a The Cherry method which prevents the "gumming " to which the tree is liable. Being an early flowerer, the tree is sometimes trained on a wall with a west or north-west aspect, with the object of checking its early blooming. In that case, however, it has the disadvantage of getting little or no sun at the roots, with the result that a tree of delicate constitution may sometimes be chilled to death-for the cherry loves warmth at its roots. On the other hand, the writer has a fine Morella in his present garden, trained against a wall facing due north, which is flourishing vigorously and has borne fruit abundantly for many years, though it is only fair to mention that the garden is well protected and the soil light and warm. 


\section{A YEAR'S GARDENING}

The plum (of which the greengage is, perhaps, the most delicious The Plum variety) does not do well on a cold or clay sub-soil, The Plum nor in a moist-laden climate. A poor soil really suits it best so long as it has good drainage, for it has a tendency to make a superabundance of wood if the soil be at all rich. As a consequence, frequent root pruning is generally necessary, and it should not be planted deep-a covering of 6 inches of soil is sufficient.

The pear, especially when grown as a wall-trained tree, requires The Pear root pruning or lifting more frequently, perhaps, than The Pear any other kind of fruit free, for its roots have a tendency to go deep into the ground to obtain moisture. The better the subsoil, the greater is the inducement for this rampant root growth. As a consequence, the tree becomes unfruitful, although in large standard trees the results are, of course, not so disastrous, and it is often more advisable, therefore, to adopt the dwarf-standard form rather than the wall-trained. It is said of the monks of old, who were by no means deficient in the art of horticulture, that in planting their orchards-which, as we know, were generally on moist ground, in close proximity to some stream or river-they used to lay a large slab of stone some few inches beneath each pear tree, so as to prevent the deep ramification of the roots to which this tree is particularly liable. Summer nipping is imperative in pruning the pear, as if all the wood-buds be allowed to remain they will so drain the strength of the tree that fruit-buds will not form-excessive wood growth being characteristic of the pear.

The apple, of all our fruit trees, is, perhaps, the most valuable, The Apple as its fruit accommodates itself to many purposes and The Apple can be stored for a prolonged time. Moreover, its medicinal properties are not to be despised; the old adage asserts that "An apple a day keeps the doctor away." There is no doubt that the apple is useful as a brain and nerve tonic, containing, as it does, a large percentage of phosphorus and malic acid in an easilyassimilated form. It is also claimed as a corrective for a sluggish liver (whence the time-honoured custom of serving apple-sauce with roast pork) and as a remedy for rheumatic and gouty troubles; while it is said that where cider is the common beverage the disease of stone (calculus) is practically unknown. The apple tree requires good, deep soil-a rich, sandy loam is the best-and as the tendency of its root growth is to run just below the surface it does not usually require root pruning or lifting. 


\section{FRUIT TREES}

\section{HINTS FOR THE AMATEUR PRUNER}

Speaking generally, there can be no doubt that the root pruning of fruit trees is an essential in the production of a good crop of fruit, and if the tree be too large to lift conveniently, root pruning may be effected by digging away the soil from the roots until the strong feeders are disclosed, when, if too large for the knife, they may either be severed with a sharp chisel or with a fine-toothed saw, leaving the weaker roots untouched.

In cutting away the branches of fruit trees, especially in the case of wall-trained trees, care should be taken to use a thin, sharp knife, sufficiently keen to make a clean cut.

Clean Cutting If the cut be left with a rough, fractured edge the branch is liable to split, a result which is certain to be more or less deleterious to the tree.

For cutting thick branches the fine-toothed pruning saw should be used, afterwards smoothing the saw-cut with the pruning knife and smearing it over with grafting paste, so as to prevent the decay which might ensue from Protecting water getting into the heart of the wood. This paste may be made by melting in a pipkin, over a slow fire, equal quantities of mutton fat and bees-wax with about four times the quantity of pitch. It should be applied warm, while it is sufficiently liquid to be spread with a brush. 


\section{BUSH FRUIT}

\section{GOOSEBERRIES, CURRANTS AND RASPBERRIES}

No garden where fruit is grown would seem complete without the familiar gooseberry and currant bushes and the stalwart canes of the raspberry. It may be that their familiarity has bred some contempt for their welfare, for certainly one often finds that, in an otherwise well-ordered garden, these useful producers of good fruit are left to their own devices, unkept and uncared for. A little judicious pruning, a small amount of attention at the proper season, will do much to promote the life of the bush and to ensure a reasonable crop of fruit.

\section{PROPAGATION BY CUTTINGS}

As the propagation of gooseberry and currant bushes by cuttings is a simple process, easily performed by the amateur, a few directions as to the method of making these cuttings may be desirable.

The early autumn is the best time to make them, and they should be slipped from the well-ripened wood of the previous Season for year's growth. A convenient length is from Io to I2 Slip-making inches, and all the buds on them should be cut off Disbudding except one at the base and (say) four up the stem. of Slips The importance of leaving only one bud at the base of the cutting should, perhaps, be emphasized by explaining that it is a method of guarding against the growth of suckers in the future. The cuttings should then be planted in good soil a foot or so apart, and in the following spring, when well rooted, they may be moved into the positions intended for them. Even thus early pruning may begin by cutting back, to a

Pruning and Training of Cuttings and this may often be assisted by the use of forked twigs and the judicious tying with raffia.

length of 5 or 6 inches, the shoots which have grown from the original four buds, so as to produce lateral shoots from each. The aim of the pruner should be to gradually bring the new wood into a cup-like form, I36 


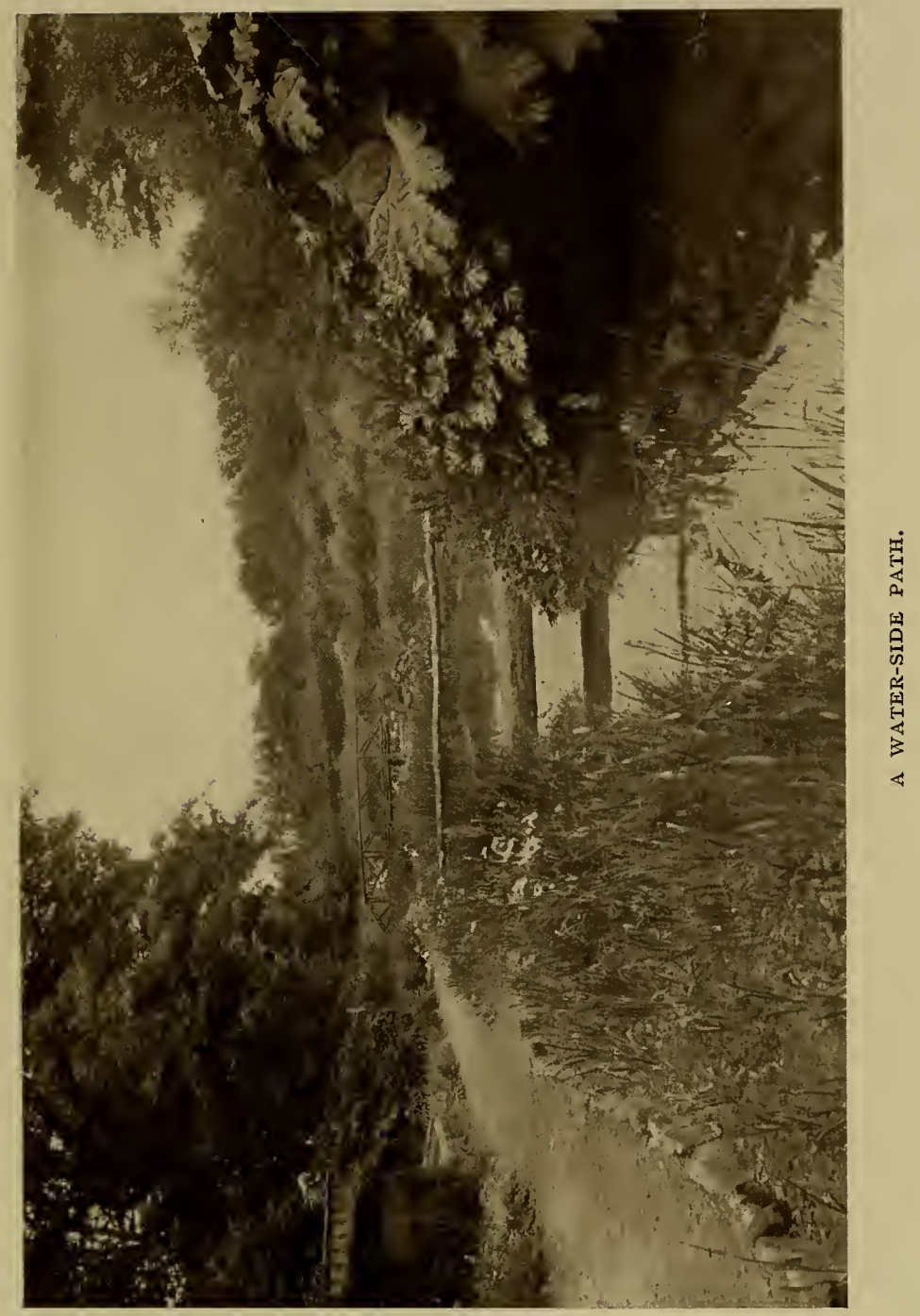





\section{BUSH FRUIT}

\section{THE GOOSEBERRY}

Perhaps one of the greatest difficulties to be contended with in maintaining the life of the gooseberry bush, and certainly in obtaining a due yield of fruit, is the depredations of the birds. Some suggestions for coping with this will be found at the end of this section, but no devices for protection will ensure a good crop of fruit if pruning be continuously neglected, while by the selection of a proper time for pruning much of the mischief wrought by birds can be provided against. Pruning should not, as a rule, be attempted before March, for until the buds begin to break it is not easy to see what is fruit-bearing wood and what is

\section{Season for \\ Pruning} not. Moreover, if it be done before the buds begin to show, those which afterwards break upon the wood which has been left for fruitbearing may be pecked out by the birds, whereas after the buds have come forward a little they are not so tempting, and the production of fruit may be more relied upon. If, on pruning thus late, it is found that the buds have already been pecked out in the young outward branches, it is best to cut back such wood to a sound bud, as a precautionary measure against a budless branch.

The best plan to adopt in pruning the gooseberry bush is to leave last season's growth at full length, though it may be shortened if it chances to extend beyond the space at command. A thinning should be made annually

Method of by cutting out old limbs which have any signs of decay and by removing any young wood which may obstruct the admission of light and air, cutting back this young wood to within a few buds from the stem.

Any suckers which may appear should be carefully eradicated from the very base and not merely cut back to the surface of the ground. These suckers are caused either by the cutting from which the bush was grown having

Removal of Suckers been badly made, or from imprudent digging around the bush having lacerated the roots and turned them up to the surface, causing them to send out shoots. If these are allowed to continue the ruin of the bush is inevitable, and for that reason the digging of the ground between gooseberry bushes should never be done with the spade. A gentle loosening of the earth with a fork, to the depth of 6 or 8 inches, and an occasional use of the dutch hoe to keep down the weeds, is quite sufficient. 


\section{A YEAR'S GARDENING}

\section{THE RED AND WHITE CURRANT}

Although the method of training and pruning into their proper form is the same for currants as for gooseberries, the Principles of future pruning for the production of fruit is not alike. Pruning

In the case of red and white currants the fruit is borne by the old wood, and as soon as the requisite form of the bush has been attained the pruning should consist in cutting away annually the young shoots, leaving only those which may be needed as new branches for extending the size of the bush or for retaining its proper form. The lateral shoots which appear from year to year on the old wood should be cut back every season to within half an Production of inch of a bud, the effect of which will be to cause large Fruit Spurs clusters of spurs to be formed in due time, and from these spurs the bunches of fruit are produced. As the bush grows old the spurs may, perhaps, become overcrowded, and it will then Thinning be necessary to thin them out, while any old mossThe pruning above described may be done at any time from November to February, but not later, and in the

Season for Pruning autumn the ground should be manured and gently forked over. In the spring, as soon as the buds begin to swell, a good dressing of soot should be given both to Soot the bushes and ground as this is a preventive of a manure. the attacks of caterpillars and also is beneficial as

\section{THE BLACK CURRANT}

With the black currant the pruning for fruit production is quite Pruning different from that of red and white currants. On the black currant the fruit comes from the young growth, the growth of the previous year. It follows, therefore, that an annual thinning out of the old wood must be made, so as to get new fruit-bearing wood for each successive season. While with red and white currants the object in view is to produce good spurs of

No Fruit Spurs wood, with the black currant no spurs must be permitted, for as the fruit is produced from the wood of the second year the growth of new wood must be encouraged and the bush kept well open in the centre to light and I38 


\section{BUSH FRUIT}

air. Finally, it should be borne in mind that the black currant bush is a strong grower and therefore requires a good soil and heavy dressings of manure to enable it to pro-

Manure duce fine fruit.

\section{THE RASPBERRY}

It is often said-though no reason is generally adduced for the truth of the statement-that raspberries will thrive well where black currants flourish, but that neither Soil raspberries nor black currants are productive where the cherry thrives. Be this as it may, there is no doubt that the soil for raspberry canes should be light and of sandy substance, while a yearly dressing of manure is necessary to induce vigorous growth. As with all ground devoted to fruit trees and

Manure bushes, the digging should not be done with a spade, lest the roots be cut or bruised, but the soil should be gently loosened with a fork, taking care not to disturb the stools of the main plants. Every autumn, before the manuring is done, the stray suckers should be removed and the pruning of the canes

Suckers attended to. If the plants are growing well and vigorously there will probably be many canes 5 or 6 feet high to each stool, in which case cut down, close to the ground, all but four; but should the canes be weak, it will be wise

Pruning and Training to leave only three, two, or even one. None of the canes, even if they be strong and vigorous, should be allowed to exceed (say) 5 feet in height, and the tops should be cut off accordingly and brought to a uniform height for each stool. A strong stake should be used for each stool, and the canes should be looped to it-with soft-finished garden string-at the top and half-way down. In pruning it is necessary to bear in mind that new wood is required each year, as those canes which have borne fruit never do so a second time. It is important, also, to remember that the stools should not be crowded too closely together, so as to prevent the Space free access of sun and air. A radius of 3 or 4 feet should be allowed to each stool. 


\section{FRUIT DESTROYERS AND GARDEN PESTS}

\section{BIRDS}

THERE is scarcely anything more vexatious to the gardener who sees his fruit on the point of coming to perfection and is beginning to congratulate himself on the result of the labour and attention he has so freely bestowed, than to find that his expectations are being falsified by the ravages of the birds, for not only are their depredations serious in their results but they seem doubly annoying from the fact that the achievement aimed at is so nearly accomplished.

\section{Provoking Mischief}

It is no uncommon occurrence, for instance, to find the last few days because of its fruit being so nearly ready to pick, has been almost denuded in a single night-or, to be more exact, during one early morning-by a flight of starlings. But the mischief done by birds is not confined to their depredations on ripe fruit; the pecking out of the fresh green buds on the gooseberry bush and the nipping of the succulent young leaves of the early pea are examples of the havoc that they can make in the spring. As regards the young fruit-buds, the finches-bullfinches, pre-eminently -are the worst offenders in country districts, but the ubiquitous sparrows are nearly as bad. Their attacks on the gooseberry bush are particularly disastrous. No sooner do the young buds appear than the birds peck out all they can conveniently reach, not only destroying the chances of fruit for the season but seriously endangering the life of the bush. Doubtless one of the best methods of

Means of Defence protection is to plant all the fruit bushes within a certain area and enclose the whole with small meshed wire-netting, but in a garden of small dimensions such a plan is unsightly and inconvenient. Fortunately there are other means of defence which, if not so absolutelyeffective, are lessexpensive 


\section{FRUIT DESTROYERS AND GARDEN PESTS}

and easier of application. A simple plan, and one which the writer has found very useful, is to run a thread of stout black cotton from branch to branch all round the bush.

Black Cotton The cotton being black, the birds do not easily see it, and alighting on a branch thus protected, their claws become entangled and they are alarmed, so that they shun the spot for the future. The same method may be usefully applied to protect the young shoots of the peas, which being succulent and tasty morsels for the birds, are often nipped off immediately they appear above ground, thus destroying the crop. It is a good rule, therefore, to run two or three lines of black cotton along the rows of peas as soon as the sowing is completed, for to delay this protection until the shoots appear is often fatal; the birds are sharp-sighted and will probably perceive the young shoots before the gardener has noticed them. Another plan for the protection of fruit-buds is to place on the ground beneath each bush a shallow pan kept filled with water-the ordinary flower-pot saucer is as good

The Water Method as anything for the purpose. These saucers of water make a convenient drinking supply for the birds, and it is asserted that if they have free access, in shallow receptacles such as these, to water which they can drink and splash about in without danger, they will refrain, in a great measure, from attacking the buds, to which they have recourse chiefly because of the moisture they contain. The same theory is applicable to the ravages made by birds on ripe fruit, and there seems no reason to reject it as mere idle fancy. Indeed, to a certain extent, it has been substantiated by the writer's personal experience, for with the use of water pans he has succeeded in gathering a full crop of cherries (of which starlings and blackbirds seem to be inordinately fond) without any serious depredations by the birds, while with a neighbour, who has a similar tree in a garden close at hand, but who disdains any such precautions, nearly all the cherries were devoured by the birds.

\section{CATS}

It may be that some lovers of cats will almost take offence at these domestic pets being included in the list of garden pests, but in the suburbs of towns, where gardens are small and adjoin each other, there can be no doubt that the gambols of cats are a serious nuisance, especially in the spring. A seed-bed, either in the vegetable or flower garden, has been carefully prepared, the seed sown, and I4I 


\section{A YEAR'S GARDENING}

the soil lightly sifted over it, but when the gardener goes on his

The Ruin of Seed-beds

morning round he finds that in the course of the previous night it has been made a playground for some of

his neighbours' cats. Its trim surface has been ruthlessly destroyed, it has been rolled upon and scratched into holes, the evenly-distributed seed is thrown into lumps and patches, and the entire work of the previous evening is spoilt and has to be done again. In dealing with a garden surrounded by other gardens it is best to

\section{Prevention} recognize and provide against this annoyance at once by raising some defence against the entry of cats, and nothing is more efficacious than to surmount the walls with wirenetting (a fine mesh is not requisite) some 2 or 3 feet high. This should be stretched from end to end of the walls, and may be supported either by iron stakes inserted into the top of the wall or by stout wooden laths firmly nailed to the side of the wall and painted some unobtrusive colour. Of course the bottom of the wire netting must itself be firmly secured, and this may be effected by means of small iron staples driven into the wall over the bottom edge of the netting at distances of not more than a foot. A wooden trellis, which is sometimes advised as being less unsightly, is really almost useless for the purpose, as a cat can climb it with ease; but a wire netting, which provides no hold for its claws and only a fine wire for the pad of its foot, a cat will not climb. For country gardens, however, such an elaborate defence is seldom needful, but it is well to be prepared against the occasional incursions of cats by covering any recentlysown seed-bed with some of the previous year's pea-sticks or similar tree-loppings.

\section{AMERICAN BLIGHT}

The apple tree and the oak are generally considered to be particularly subject to this pest. It is a woolly-looking substance of insect growth, infesting the bark of the tree and piercing the sap vessels, and ultimately destroying the branch it attacks. It lies dormant at the foot of the tree during the winter, but in the spring it renews its ravages and will spread throughout the tree if its proRemedy gress be not stopped. The best remedy is the free use of paraffin, rubbed into the crevices of the bark with a short-haired paint brush wherever the insect appears; and in the Preventive winter, to prevent a recurrence of the trouble, a lather of soft soap may be applied with a stiff brush to the base of the tree's stem. 


\section{FRUIT DES'IROYERS AND GARDEN PES'TS}

\section{ANTS}

These insects are often a great plague to the gardener, especially if their nests appear upon the turf. In such a case they should be dealt with summarily, before they have Turf attained to any considerable size, by pouring in boiling water. Ants may also become a serious pest by attacking wall-fruit just as it is ripening, when their ravages may Wall-fruit be stopped by laying a broad band of tar, mixed with a little sugar, on the bottom of the wall and around the stem of the trees. It is said that similar bands drawn in white chalk will have the same effect.

\section{APHIS (GREEN FLY)}

The rose is the chief victim of this pest, and as its attacks are often an indication that the tree is unhealthy or insufficiently nourished, steps should at once be taken to supply its needs. To remove the clusters of green fly on the young shoots or buds of the rose nothing is better than the aphis

Sign of Weakness brush, which consists of a pair of soft brushes joined together with a steel bow, so that by pressure of the hand the two brushes are brought in contact and the bud between them effectively cleared.

\section{DADDY-LONG-LEGS}

The grubs of this insect are sometimes, especially after a hot summer, very mischievous in gardens, destroying the roots of the turf on lawns and occasionally attacking choice plants, eating through the "collar" where root and stem meet. When they appear in the grass it is a good plan to roll the turf late at night and early in the morning, thus crushing them while feeding. They may also be accumulated and destroyed by careful sweeping if it be done late in the evening and early in the morning, and a thorough watering with strong liquid manure, such as a solution of guano or nitrate of soda, is a good remedy when plants are attacked by these grubs, the solution being noxious to the grub and beneficial to the plant.

\section{Rolling Sweeping \\ Liquid Manure}




\section{A YEAR'S GARDENING}

\section{EARWIGS}

Dahlias are the favourite haunt of these insects, but any flowers of sufficient size are utilized by them for shelter. The insects are so quick in movement and so anxious for concealment that even when entrapped they will escape if care be not used. Perhaps the best and simplest trap is that of a small flower-pot, stuffed with a Traps little dry moss and inverted on the top of a stake, but or better still, both morning and evening-and its catch of earwigs destroyed by plunging it into hot water.

\section{SLUGS AND SNAILS}

In moist gardens, and particularly in beds which are edged with grass or some herbaceous border, slugs and snails may do much mischief; not only in the vegetable garden but also in the flowerbeds. Among slugs the small black-and-white varieties are probably the most destructive, because they are less readily detected, whereas the larger sort can easily be caught with a pair of tongs by Large Kind hunting for them at nightfall; a warm, damp evening may be is sure to bring them abroad. Fresh lime, dusted on Caught

Lime and Wood Ashes the ground, is a common remedy, but its efficacy in rainy weather is soon exhausted, and in the writer's belief the best means of protection from slugs is the use of wood ashes and the ashes which are the result of the occasional bonfire of such garden rubbish as cannot be dug in as manure. These ashes, if kept dry and mixed with a little soot and coal ashes, are invaluable for dusting over seedlings and young vegetable crops, as in addition to warding off the attacks of slugs they enrich the soil and thereby promote a rapid growth which quickly emancipates the plant from the attacks of vermin. This method is also a protection from the ravages of snails, against whom, however, a more open warfare may be waged by searching for them at evening or early morning and destroying them. A good plan to Oil and Soot prevent snails crawling up a wall is to daub the bottom soot, thus forming a barrier over which they will not pass.

\section{WASPS}

The summer depredations of wasps may often become a serious I 44 


\section{FRUIT DESTROYERS AND GARDEN PESTS}

matter if the previous winter has been mild and fairly dry, and has therefore been favourable for preserving alive a larger number than usual of the female wasps. In such a case the gardener must look out for damage to his wall-fruit, which will probably be attacked just as it is ripening. The wasps eat away the pulp under the skin, generally making a beginning on that side of the fruit which is nearest the wall, so that at

Danger to Wall-fruit first glance the mischief is often unobserved. As soon, therefore, as any wasps are seen in a garden some means of protecting the ripening wall-fruit should be adopted without delay. A simple contrivance, and as effective as it is simple, is a high-shouldered glass jar (such as that used for pickles and jam) into which should be poured a small quantity of some kind of syrupsugar and beer mixed together is a good compound. Round the neck of the jar a piece of string should be

Simple Means of Protection fastened, leaving two free ends of string some 6 inches long on each side, by which the jar can be suspended either to nails in the wall or on a branch of the fruit tree. The syrup thus provided forms a tempting bait for the wasps, and if the jar has the usual slanted shoulders and is not too wide-mouthed, the wasps, when once in, cannot easily get out again. The number of jars required must depend, of course, upon the amount of fruit which has to be protected, but as their preparation is not difficult, it is well not to be sparing. They should be replenished with syrup from time to time, and the wasps which have been caught in the trap may be destroyed by pouring in hot water.

\section{WIRE-WORM}

If a garden, or any particular bed in it, is infested with wire-worms, drastic means of extermination should be taken, for these pests are not easy to get rid of; and as some kinds live in the larva'state for three years, they have plenty of time to do much damage. The most effective plan for destroying them is to dig in a thick sowing of quicklime and allow the ground to remain fallow for a winter, thus cutting off all means of sustenance for the grub. Traps Quicklime may also be used, with good effect, in the shape of slices of potato, carrot or turnip buried about an inch in the earth. Each piece should have a skewer stuck into it to show its position, and it must be examined, and its catch destroyed, every morn-

\section{Traps} ing. Fortunately most birds are very fond of wire-worms, and, if permitted, will materially assist the gardener in his war against them. 


\section{A YEAR'S GARDENING}

\section{WOOD-LICE}

It seems to be a prevalent notion among jobbing gardeners and florists that wood-lice are not harmful to plants, but Fallacy as a matter of fact they are terribly destructive to tender seedlings, especially in a frame, where they can secrete themselves against its sides. So early do they attack young Insidious flowers that it often appears as if the seed had failed Attack to come up, for the minute stalks which have been deprived of their leaves by the wood-lice are almost invisible. When a frame or pit is thus infected the wood-lice may Infected Frame generally be destroyed by pouring boiling water along ance recourse must be had to trapping. In common with earwigs, Traps they love darkness and a dry, snug retreat, and a thumb-sized flower-pot, with a fresh slice of potato or apple as a bait, and filled up with dry moss, will prove an alluring trap. Two or three of them should be placed in the frame or bed where the wond-lice are found to be destructive, and the next morning they will probably each contain a large number of the insects, which may be destroyed by knocking the whole contents of the pot into a pail of hot water. Of course the traps must be re-laid from day to day until the clearance is complete, but the remedy is unfailing if persevered with. The earlier in the morning the traps are cleared the better will be the catch.

\section{HOT WATER AS AN INSECTICIDE}

In a recent number of Le Jardine it has been pointed out by Mons. Boillet that the green-fly and all caterpillars are instantly killed by immersion in water heated to $45^{\circ} \mathrm{C}$. (II $3^{\circ} \mathrm{F}$.), while beetles, in spite of the greater protection their bodies possess, perish in water of $50^{\circ} \mathrm{C}$. Plants, however, will survive immersion in water of $54^{\circ} \mathrm{C}$., and accordingly, when pot-plants are attacked by insects, an easy and effective method of getting rid of the pests is to roll the pot in a cloth (so as to prevent the soil from dropping out) and plunge the plant for a few seconds into water $50^{\circ} \mathrm{C}$. (I22 $2^{\circ} \mathrm{F}$.) On fruit trees, also, caterpillars and insects may be destroyed by applying hot water either with a brush or with a syringe. In using a syringe, however, it should be borne in mind that hot water loses heat in passing through the air, and its temperature, therefore, should be raised proportionately-say, $5^{\circ}$ for every 2 yards through which it has to pass. 


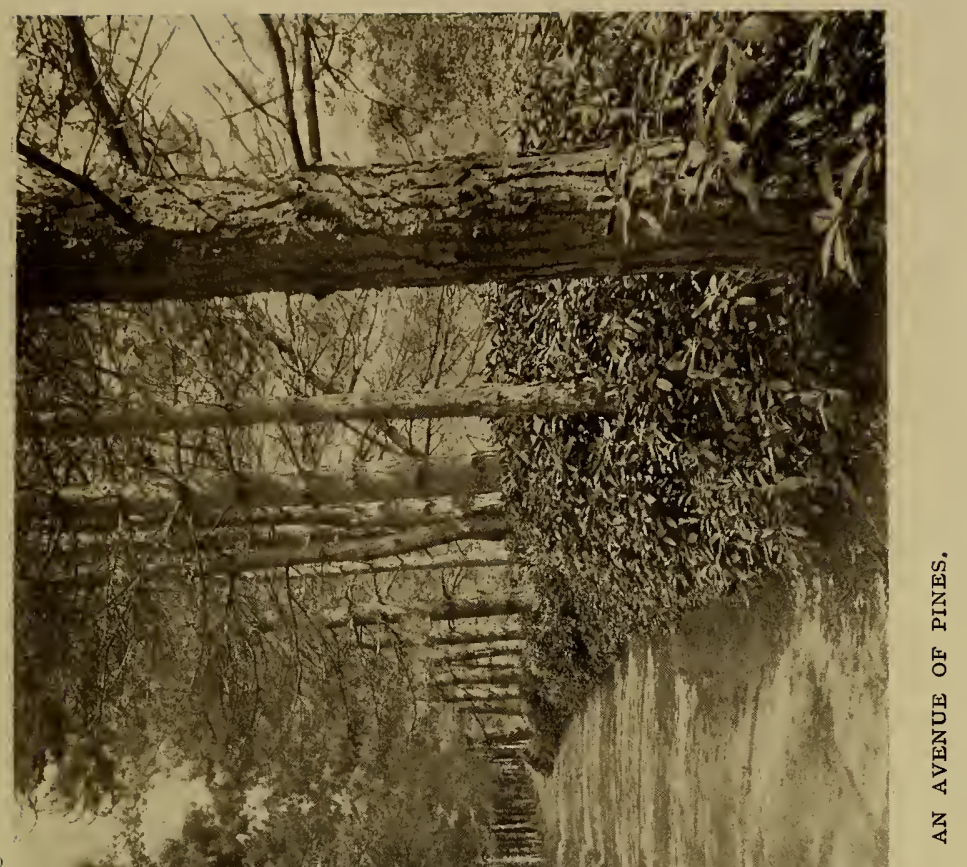





\section{THE VEGETABLE GARDEN}

\section{MONTH BY MONTH}

\section{JANUARY}

THE first month of the year is emphatically not the month for "good resolutions " with regard to the garden if success is really desired. The good resolutions must have been made, and swiftly acted on, in October and November, when the glory of the garden is newly departed and the spent land and languishing plants call for all the attention the gardener can give. January, with its uncertain weather, may indeed prove almost entirely a close time, when the procrastinator will bitterly repent not having seized earlier opportunities of trenching and pruning and numberless other pressing affairs.

In a favourable year, however, January can be made quite a busy time, and, in any case, no odd hour of good weather should be wasted, as the labours of a busy spring may be much lightened by forethought and energy now. Even a frost may be utilized to wheel out manure to where it will be wanted later on for digging in; while if, instead of being frost-bound, the land is suitably dry, plots of ground may now be manured for early crops, unless the soil is very light indeed and the rains heavy, in which case it is still rather early.

We will suppose that all fruit-tree pruning has been quite finished before this, but the shoots and twigs may be now slowly burnt to a dry ash, which forms a most valuable manure and insecticide. All such odd work, as clearing away rubbish, overlooking pea-sticks, seed potatoes and other roots, and the careful study of the seeds likely to be wanted, should be in progress. Where seeds have not been saved, but must be bought, it is none too early to do so. Tools also should be set in order and replaced where necessary.

The making of a hot-bed is another operation suitable for January when conditions permit, and its usefulness is undeniable, as early crops will well repay the pains bestowed to obtain them. Nor is the 


\section{A YEAR'S GARDENING}

usefulness of the manure employed restricted thereby; it is only maturing for use in the borders later on.

Stable manure is generally used for hot-beds. Manured straw should be heaped together, watered, beaten down, and left for a week, when it should be turned over and again watered if dry. This operation should be repeated several times until the odour has ceased to be disagreeable. Next the bed should be prepared, its size being determined by the size of the frame for use upon it. The depth of manure, however, varies according to the heat desired. For a slight hot-bed manure a foot and a half deep is sufficient, and this may be increased up to 4 feet and more where a more potent hot-bed is required. A mild but efficient bed can be made from lawn cuttings, decaying leaves, etc. Moistened and set to ferment in good time, they are very valuable in this connection, and some growers always mingle a proportion of leaf manure with stable manure in making a hot-bed. When the bed is prepared and the frame in place-but not shut-and a few days' interval allowed for the passing off of rank steam, a covering of loamy soil must be added, and the hot-bed or forcing ground will then be ready.

But forcing need not be restricted to the hot-bed proper. A sheltered and dry border, well screened, may often be used to secure early crops. Good drainage and a suitable light rich soil are essential; but given these much may be accomplished.

January is also a suitable month for draining the garden more thoroughly, should it be requisite and the weather permits it.

ASPARAGUS beds should now be well manured by laying manure on them and allowing the rain to wash it down to the roots of the plants.

BEANS (Broad) may be sown in frames, and the best method is to use 6-inch pots sunk in a hot-bed prepared as for Cucumbers. Towards the end of the month, in a sheltered part of the garden, well manured and dug, Beans may be sown in the open, and will often do very well. They should be protected with litter or branches against the frost.

CABBAGE. Plant out towards the end of the month when the weather permits.

CARROTS may be sown on a hot-bed, or on a south border under a hand-light.

CAULIFLOWERS should be started in a mild hot-bed or in a frame, and should be ready to plant out in March or April. 


\section{THE VEGETABLE GARDEN}

CRESS AND MUSTARD may be sown in pans, allowing a few days between each sowing. In this way a constant supply will be ensured. Later on sow in the open ground. It is not a bad plan to sow Cress and Mustard round other crops, such as Potatoes, where frame space is limited.

CUCUMBERS may be had all the year round if grown under glass with proper heating, and some people will even manage this with a hot-bed and frame. Three months must be allowed for growing, so that October's sowing should be ready now and seed sown to procure Cucumbers in April.

The structure of a Cucumber house must be left to the individual grower; a lean-to facing south is advised. The soil should be of turfy loam and leaf mould, if possible, and the secret of success is to let nothing check the rapid growth of the plants. Cucumber plants require a temperature of not less than $60^{\circ}$ even at night, and very careful watering with water the same temperature as the house. The roots should never be allowed to get dry.

LETTUCES may be sown in a warm border, under a hand-light, or, better still, in a frame. Protect them well, and where a constant supply is required sow small quantities at intervals of about a fortnight or three weeks.

PEAS. In favourable weather Early Peas may be sown out of doors on a sheltered border, and it is advisable to put the rows some distance apart and plant between them some other crops, such as Potatoes, Cauliflowers, etc. A still earlier picking may be secured by sowing in pots in a frame, transferring the plants later to the open ground. The heat in the frame should not be excessive.

POTATOES are extremely acceptable if ready early, and on an exhausted hot-bed a good crop may be secured. A covering of light soil must be given before putting a frame over them, and they must be carefully protected from frost. Some writers recommend a heap of leaves or a small quantity of farm-house manure as giving sufficient heat for Potatoes, and for anyone who grows Melons the pit prepared for them may well be utilized for an early crop of Potatoes first, as if started in the middle of January the Potatoes will be ready for use by the time the Melons should be planted.

RADISHES may also be grown on a partially-spent hot-bed.

SEA-KALE should now have a good covering of soil or leaves and the protection of pots to blanch it. Manure is not really necessary. The same procedure is recommended for early Rhubarb. 


\section{A YEAR'S GARDENING}

January is also the time when Sea-kale growing may be commenced in a frame that is generally heated, but which has no lights.

SPINACH should be sown in the open, but care must be taken to sow again if frost should destroy the young plants. Autumnsown Spinach may now be ready in some gardens.

STRAWBERRY plants may now be potted and put in a frame for forcing; an occasional dose of liquid manure will be found useful.

TOMATO seed may now be thinly sown in well-drained pots. Cover lightly and keep at an even temperature of not less than $60^{\circ}$. When large enough transfer the young plants to small pots and keep near the glass until well established. Almost any available glass will serve to grow Tomatoes under, and if treated after the manner of Cucumbers, but at a lower temperature, splendid crops may be secured. For outdoor growing the seed should not be sown until March or April.

\section{FEBRUARY}

"February fill-dyke" gives but scant encouragement to the gardener who sets his heart on planning his work beforehand with certainty, but for the quick seizer of opportunity it is often a month that yields a great deal of suitable weather, for the sun is fast gaining power, and spring is almost here.

Before the heaviest work of spring is started, much digging, manuring, and even weeding is the portion of this month. And almost as a first task garden paths and edgings should be put in order, for there will be little chance for merely ornamental gardening later on. Also to heap up, and even to increase, the supply of protective materials is a necessity where early sowings are practised, for frosts are still to be guarded against and may do much damage now. The gardener who has been sowing in January will have his frames to attend to daily. Water, although often very necessary, must be given with great care as long as there is a chance of frost.

ARTICHOKES (Jerusalem) may be planted now. Select a piece of garden ground that can be given up to them, as they are difficult to get rid of, and plant the tubers a good distance apart.

BEANS may be sown for a proper succession, the end of the month being the best time for sowing the principal crop. Between 


\section{THE VEGETABLE GARDEN}

rows of potatoes is a suitable place to select. Care should be taken to harden off those sown in the frame last month before planting out.

BROCCOLI may be sown in a frame and also in a sheltered spot out of doors. In a well-stocked garden there should be Broccoli ready for cutting during the month.

BRUSSELS SPROUTS. Sow now in a warm spot in the open.

CABBAGE. The plants sown in the late summer should be ready for planting out now, and should afford nice heads in the early summer. If, however, a quick-growing variety is sown now in pans in a frame they will be ready to cut almost as soon.

CARROTS. Sow thickly on a warm border and thin out later. They should be ready in May.

CAULIFLOWERS. Seed should be sown under glass to make a succession. Those plants under hand-glasses should be given a sufficiency of air and light.

GARLIC should be planted out in rows about 9 inches apart, in rich soil.

LETTUCE. Plant out (after hardening) from frames and hotbeds, and sow again both in frames and in the open for a succession. There are two sorts of Lettuce in favour-the tall variety called the cos and a short dwarf form called the cabbage. For the amateur the latter is much the easier to grow, as it does not need tying.

ONIONS and LEEKS may both be sown for salads in a warm border. For the main crops, thoroughly trench the ground now and manure it well. Sow in drills, and thin the crop at intervals.

PARSLEY. Sow in drills or between short-lived crops in the latter part of the month.

PARSNIPS. Sow as early as possible in ground that has been well dug. The rows should be $I 8$ inches apart and thinned to half the distance.

PEAS. Sow early sorts now in considerable quantities. If those already up are not promising well, dig in and sow again. Earth up those that are advancing well and stick them, as the sticks form a protection. Where sticks are scarce Dwarf Peas are advised, but the taller varieties bear more abundantly.

POTATOES. Sow a few rows of an early sort in a warm position. A light, mellow soil is advised. 


\section{A YEAR'S GARDENING}

RADISHES. Sow in the open, but in a dry, warm spot, and take care to cover with light litter to keep off the frost, removing it in all favourable weather.

RHUBARB. Divide part of the Rhubarb bed into plants having one eye apiece, and re-plant a yard apart in good soil. These new plants should be left until next season before being gathered from.

SAVOYS. Sow now in a frame, or in a very favoured position, and prick out the young plants as soon as possible, as plenty of space is a requisite.

SEA-KALE. When the plants begin to push up they should be covered with pots made for the purpose, that they may be blanched for the table. A covering of leaves to the pots will be found more effective than covering them with manure; but if the latter is used it should be well prepared and the heat allowed to pass off. Seakale may be planted now in the open ground.

SHALLOT. Sow now on good ground.

SPINACH. Sow now.

STRAWBERRIES. Some people like to make a new plantation now. In that case rumners, selected for the plump, healthy crowns, should be planted about eighteen inches apart and well mulched with manure. Plants in pots placed in heat now should bear as early as April.

TURNIPS. Sow now in a very sheltered position.

\section{MARCH}

In this month all arrears of work must be swiftly made up, and the wise gardener will leave nothing at loose ends if he can help it. As the days lengthen great industry must be used to make the most of every moment of fine weather, only taking into consideration that it is a mistake to sow seeds in damp soil if it is also heavy in character. In a light soil, however, sow as early as possible.

At this time, too, the gardener's yearly warfare with the birds must be taken up in earnest. In almost all gardens it will be found necessary to protect the seed-beds from the active marauders of the air. Netting is probably the best means of keeping off the birds, but it is also an expensive one. Branches laid lightly on the beds is of some use, but is often far from effective; a better substitute for netting is rows of black cotton fastened on sticks at either end of 


\section{THE VEGETABLE GARDEN}

the rows. White is more often used, but is not nearly so good, as the artful birds see it and apparently realize its dangers. Something which gets in their way but which they can hardly see is far more alarming to them.

Nearly every kind of vegetable seed may be sown in March; the first care is to keep up a succession of sowings on heat for the earliest crops and to plant and to sow in the open as much as time and weather will permit.

ARTICHOKES (Globe) should now be allowed to get as much sunshine as possible. The ground should also be well worked and manured, ready for suckers to be put in at the end of the month or during April. Globe Artichokes bear best in the second or third year, so that it is advisable to plant a row or two every year, clearing away a proportion of old plants at the same time. A still better way to get an early picking is to supply suckers in the spring by sowing afresh every year and protecting the seedlings during the winter.

ARTICHOKES (Jerusalem) should be planted now. A sunny spot with good soil and plenty of room will produce a crop that will well repay a little trouble in selecting and preparing it. Whole sets should be planted, if possible, a foot deep and about a yard apart. Keep the ground stirred about them when the plants are up, and when the leaves are decayed cut down the stems, but not before.

ASPARAGUS. The end of this month, or during April, sow seed in rich soil. Weed the existing beds and, if the weather is dry, water once thoroughly.

BEANS. There should be Beans to plant out from the frames now, and early sowings in the open coming forward and needing care. For the main sowing of all kinds of Beans, except the dwarf French Bean, March is the best month. The French Bean is a little less hardy, and at present should only be sown now in a favoured position-sunny and sheltered.

BEET. Sow now for an early crop, but protect from frost.

BROCCOLI. Plant out from frames; also sow twice, with about three weeks between, for an autumn and winter supply. Plants that are ready to occupy their permanent quarters in May or June may be depended on for the autumn.

BRUSSELS SPROUTS now need care and attention, and the young plants should be put into rich, well-prepared soil. Also sow 


\section{A YEAR'S GARDENING}

in the open in a sheltered border both Brussels Sprouts and other Winter Greens, such as Scotch Kale, Savoys, etc.

CABBAGES. Sow plentifully now to follow earlier crops and to make up for failures. A quick-growing seed sown now should prove very useful in July and August. When putting out young Cabbage plants mulch the roots with a compost of wet soil, to prevent dryness. Sow Red Cabbage for pickling in the autumn.

CARDOONS. Sow this month in a frame or in a very sheltered spot. When large enough plant out in well-manured soil about 8 inches apart, and finally in trenches, as for Celery, only farther apart.

CARROTS. Some seed of an early sort should be sown now, but the main crop can be deferred until next month. Ground prepared for Carrots should be manured in the previous autumn, and the admixture of sand is advised by some.

CAULIFLOWERS. Sow now in well-manured land to get young plants for putting out in May and June. Plant out from frames, etc., choosing good ground.

CELERY. Sow a little seed for early use on a mild hot-bed, and again in the middle of the month. As soon as the plants are large enough prick out to a rich soil over a heap of manure.

CUCUMBERS. The plants should now be in good condition, but sow seeds for a succession. If Cucumbers have not been previously grown, now is a good time to start.

HERBS. Sow now various kinds or divide up the existing plants. Mint may be propagated by dividing the roots. Parsley should now be sown in sufficient quantity.

HORSERADISH. Plant now.

LEEKS. Sow in very rich soil about the middle of the month, transplanting when large enough.

LETTUCE. Plant out the young plants that are ready and sow again in considerable quantity.

MELON. Sow now in small pots in a warm house, in readiness for putting into the beds next month.

ONIONS. Sow in drills about the middle of the month, and choose the best ground available. As soon as the plants are forward enough stir the ground about them and keep it free from weeds. 


\section{THE VEGETABLE GARDEN}

PARSNIPS. Sow the main crop early in the month in drills I5 to I 8 inches apart.

PEAS. Make fresh sowings, remembering to have the rows of Peas divided by rows of Cabbage, Spinach, or Potatoes. Earth up and stick the early crops as soon as possible.

POTATOES. Plant the main crop during this month.

RADISHES. Sow in small quantities. tions.

RHUBARB. This is the latest month for making fresh planta-

SEA-KALE. Sow in well-prepared beds. The existing crop will still require covering to some extent.

SPINACH. Sow the ordinary Summer Spinach in drills in the open. Also some of the Perpetual Spinach (Spinach-beet).

STRAWBERRIES. This is a good time for planting, if weather conditions are favourable.

TOMATOES. Sow early in the month to obtain plants on which to ripen fruit in the open.

TURNIPS. Sow plentifully late in the month. Also some seed for an earlier crop may be sown on a south border.

VEGETABLE MARROWS. Sow seeds in pots-three seeds in a pot is usual-and place in a cucumber frame. Later on pot singly, or at most two in a pot.

\section{APRIL}

In a month of sharp showers and warm sunshine there is much to be done in the way of watching the results of the labours of the last two months. Young plant life should abound in every direction, and every plant should be given its chance, its full meed of care and attention. Decided failures should be replaced immediately, for there is now not a moment to be lost. All plants will need watering after being transplanted, and if the weather should continue dry the watering should be repeated every day or two until the plants appear established. Thorough thinning is as important a part of the month's work as transplanting, as overcrowding is fatal to the development of any plant, and for certain crops, such as Carrots and Parsnips, thinning is the whole business, since the plants taken up will not bear transplanting. Careful weeding will also repay the gardener for the time he spends on it, as many weeds 


\section{A YEAR'S GARDENING}

flower during this month and the next, and if allowed to do so will soon have the garden under their own disastrous control. Some of the forced crops, such as Strawberries, Kidney Beans, etc., should be in good condition, and a careful lookout must be kept to make judicious pickings at the right moment, for to let any grow over-ripe on the plant is not only to lose the individual bean, or whatever it may be, but to weaken and help to destroy the plant from which it should have been taken. All forced crops must be watered carefully now, and an occasional dose of liquid manure may often be found beneficial. For a final caution, beware of insects, as they will now be awakening to activity and must be destroyed as soon as they appear.

ARTICHOKES (Globe). If beds were prepared last month, suckers should now be put in at a distance of 2 or 3 feet apart, with 4 or 5 feet between the rows.

ARTICHOKES (Jerusalem). If not already done, a planting of the tubers may still be made during the early part of this month. It should be remembered that a row of Artichokes set about I 8 inches apart make an excellent screen for an ugly fence.

ASPARAGUS. Keep the old beds quite clean, and if a new seedbed is required, prepare it now. Sow the seeds thinly and as evenly as possible; also thin out very thoroughly when the time comes. Another plan is to procure new beds by planting roots instead of seeds, and in that way an earlier cutting will be secured. The bed for roots and seeds alike requires to have had a good amount of manure well dug in and to be in a mellow condition.

BEANS (Broad). Sow a few rows for succession.

BEANS (Kidney). Sow sparingly towards the end of the month, but take great care to protect from frost.

BEET. Sow at any favourable time during this month in an open, sunny spot. The ground should be deeply dug, but not manured.

BROCCOLI. Make another sowing of some early sort.

BRUSSELS SPROUTS. Sow during this month for a late crop.

CABBAGE. Plant out from seed-beds and water in dry weather. Sow for autumn use.

CARROTS. Sow the main crop and, if desirable, continue to sow for succession until the end of July. 


\section{THE VEGE'TABLE GARDEN}

CAULIFLOWERS. Sow a small quantity now to be planted out as soon as possible. From early sowings there should be nice young plants to be put out whenever the weather is suitable, but be careful to protect them against cold.

CELERY. Sow now for a late supply in the open ground on a bed chiefly composed of manure. Plants raised earlier, in pots, should be pricked out and well protected and looked after.

CHERVIL. Sow this month and treat in the same way as parsley.

CHICORY. Sow late this month, also in May and June, in shallow drills, thinning the young plants well when they come up. The roots form a vegetable, but if the tops are required for salad the plants will need to be put into a frame later on for blanching.

CUCUMBERS. As the sun's heat increases admit more air to the growing plants and pinch off all shoots above the fruit.

ENDIVE. Sow now in moderate heat, pricking out into a rich light soil later on.

LEEKS. Sow the main crop now, and transplant later on.

LETTUCE. Sow a few seeds this and every month to keep up the succession. At this time it is best to sow where the plants are to remain, choosing a quick-growing kind and thinning freely.

MARJORAM, THYME, MINT, SAGE, etc., may be increased by dividing the roots.

MELONS. Sow again for fruit in July.

MUSHROOM BEDS may be made out of doors now and are often quite a success, although some amateurs hesitate to start before midsummer. The bed should be a firm ridge, about 4 feet high by 6 feet wide, composed of dung and loamy soil, and should be drained by a trench dug all round it. The spawn should be put into shallow holes when the bed has attained a temperature of $80^{\circ}$; it should be covered with soil and then further covered with straw kept in place by mats. It will take about 8 weeks to produce the crop, and the temperature of the bed should continue at not less than $60^{\circ}$ during that time. Moisture is important, but when watering be careful that the temperature of the water is a little above that of the bed.

ONIONS. Sow the main crop now if this has not been done already. If the plants are up, weed the bed carefully by hand. For 


\section{A YEAR'S GARDENING}

Pickling Onions, sow any time up to June, sowing the seed thickly and leaving the plants unthinned.

PARSLEY may be sown at almost any time, but this month is favourable for sowing a supply for summer and autumn. Sow broad-cast and thin out gradually.

PARSNIPS. Sow finally this month.

PEAS. Sow again for succession, choosing the tall-growing kinds and planting the rows a good distance apart.

POTATOES. If the main crop was not put in last month, there is no time to be lost now.

RADISHES. Sow for succession in the open ground.

SALSIFY. Sow during this month and next, in deep drills about I5 inches apart. The ground should have been dug and trenched, with manure at the bottom of the trench only. The roots will strike down into the manure and grow a good size.

SPINACH may still be sown, both the usual kind and the Spinach-beet.

STRAWBERRIES. Clean the old beds and give a dressing of decayed leaves and soot. Also a good watering if the weather be dry.

TURNIPS. Sow for succession, and thin out those already growing.

VEGETABLE MARROW. Sow in pots under glass, and as soon as the plants form a leaf pot singly and return to the frame to be re-established. The plants should be gradually accustomed to the open air and planted out about the end of May.

\section{MAY}

The work of May closely resembles that of April, except that the high pressure at which it has to be maintained should be increased rather than lessened. Where a crop has failed it is not too late to remedy matters, perhaps, but not a moment is to be lost. The heat of the earth is often sufficient to start seeds that a month or so earlier would have needed artificial heat, so that where a hot-bed is an impossibility, May is a month for sowing many things ordinarily set down for March or April. But whether in seed-sowing or transplanting, great care must still be exercised, for while the sun by day I58 


\section{'THE VEGE'TABLE GARDEN}

often necessitates the shading of tender plants, frosts at night are by no means uncommon, and the increased variations between heat and cold make the month a very dangerous one to the unwary gardener.

It may be safely said that during May weeding will occupy much of the time that might otherwise be called "leisure." The hoe should also be in constant use between the crops that are advancing. Insects must be fought against with soot and lime, and in every department great vigilance will be needed, as at this time of year a short period of neglect may ruin the effect of much previous hard work.

ASPARAGUS. Shoots that are as much as 6 inches long may be carefully cut now; the bed should be kept free from weeds and the ground gently stirred now and then. It is wise also to protect the beds against frost, which may destroy the sticks just as they reach perfection. New plantations of Asparagus may still be made, but they will need to be well watered if the weather be dry. If seed is sown now it should be where it is to grow, and the plants when they come up must be well thinned.

BEANS (Broad). Sow for a late crop. If the weather is very dry, soak before planting, and water the drills into which the Beans are to be placed. Pinch off the tops of the early crops if there is any sign of black fly about them.

BEANS (Kidney). Sow in considerable quantity both the dwarf and climbing sorts. Also the small seeded White Haricots, for use in winter. If the weather be dry, water the drills before sowing.

BEANS (Scarlet Runner). This useful Bean will grow in almost any soil and is well worth cultivation. It should be sown this month in open ground and must be given plenty of room.

BEET. Sow the main crop now. Thin out the crops now coming up from an earlier sowing. Also sow the White or Spinachbeet.

BROCCOLI. Sow for succession. Plant out from frames, etc.

BRUSSELS SPROUTS. Plant out now any sturdy plants to afford a picking in early autumn.

CABBAGE. Sow at the end of the month some quick-growing sorts for use in the autumn. Plant out from the seed-beds.

CAPSICUMS may be sown out of doors late in the month. 


\section{A YEAR'S GARDENING}

CARDOONS may still be sown.

CARROTS. Thin out the main crop. Sow now to obtain young Carrots in the late summer. Stir the soil frequently about those plants that are advancing well.

CAULIFLOWERS. Plant out as fast as possible those which are ready. Water well, and as Cauliflowers pay for good living, a little liquid manure is often helpful to their fine growth.

CELERY. Prick out any seedlings that are ready, giving quite 6 inches between the plants. When setting in trenches remember that plenty of manure must be used. Trenches should be about a foot and a half wide and quite 4 feet apart. Celery needs plenty of water at this season.

CHERVIL AND PARSLEY. Thin out to 9 inches apart; the thinnings should be replanted at the same distance.

CRESS. Sow in succession for salads; if it is to be eaten with Mustard, sow the Mustard when the Cress is just showing.

CUCUMBERS may be grown with success now on ridges of manure, covered with soil and sloping to the south. Until the weather is quite warm the plants must be covered with hand-lights. There is a special kind called Ridge-Cucumbers, that are suitable for outdoor culture.

ENDIVE. Sow now and treat in the same way as Lettuce.

HERBS. The different kinds of herbs, such as Balm, Mint, Marjoram and Thyme, may still be increased by slips or by the division of the roots. They will need well watering afterwards. Sweet Basil, Fennel and Dill may be sown now.

HORSERADISH. If running to seed, pinch off the tops.

INDIAN CORN. If the green cobs are liked as a vegetable, Indian corn should be sown this month on a light, rich soil.

LETTUCE. Sow for succession where the plants are to remain. Transplant with care the plants that are ready.

MELONS may still be grown in frames. The principal crop should be got out into the Melon pit.

NASTURTIUMS. The seeds are very useful for pickling and the plants should be sown now. 


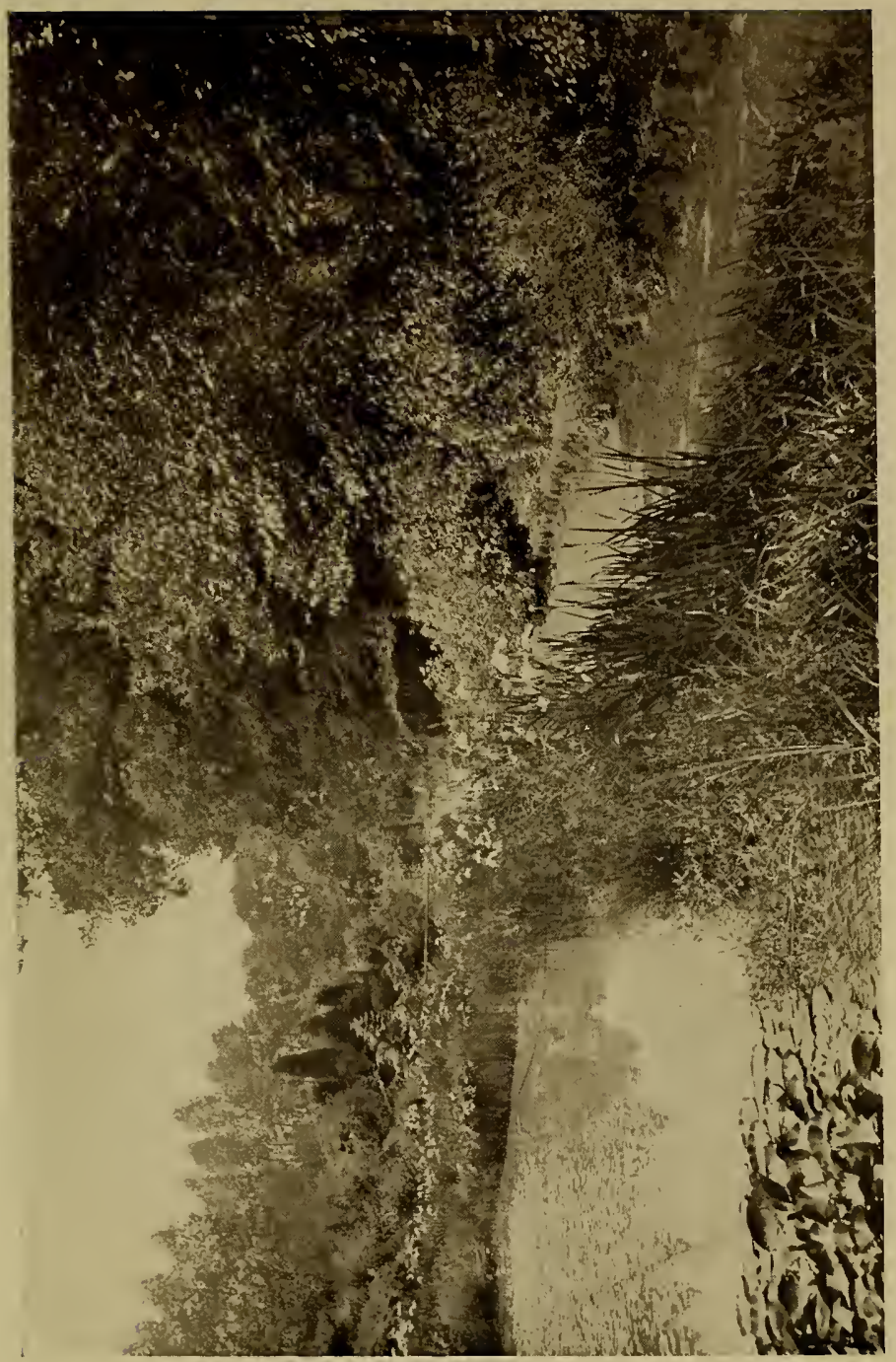

官 



\section{THE VEGETABLE GARDEN}

ONIONS. Use the hoe freely to keep the ground loosened in the Onion beds. Plant out any that are ready in rich, deeply-dug soil and water well. Also sow thickly for use in salad.

PARSNIPS. Thin out to about a foot apart.

PEAS. Sow for succession; some advise that at this time of year the sowing should be made in rather shallow trenches, likely to hold water better if the weather is very dry. Earth up and stick those ready for it.

POTATOES may still be planted if wished, and will do well. Earth up carefully those ready.

RADISHES. Sow for succession and water well.

RHUBARB may still be divided if not already done.

SAVOYS. A dwarf kind, if sown now, will be found useful in the winter.

SEA-KALE. Clear away the litter and fork the ground well between the rows. In very dry weather give one or two good waterings, otherwise leave until December.

SPINACH. Sow on a north border for succession.

TOMATOES. The plants for the open border should be hardened off and planted out late in this month, or early next. Tomato plants will need the support of sticks when they are in their final position, which should, if possible, be a sunny spot under a south wall. If grown in beds, plenty of room must be given.

TURNIPS. Sow on fresh-dug ground and in showery weather. Thin out those that are up.

VEGETABLE MARROWS. Seeds may be sown in this month in the open ground, but it is a better plan to have plants previously raised under glass to put out, when the weather is favourable, into rich, warm beds. Guard against frost and slugs. When the marrows are in readiness to be cut, remember that overgrown fruit exhausts the plant.

\section{JUNE}

This is usually a dry month, and the principal work the garden generally requires now is watering and weeding. Although in other directions the greatest activity is over for the present, there must be no slackness allowed either with the hoe or the watering-pot. Only 


\section{A YEAR'S GARDENING}

it is important to remember that too little water is sometimes worse than none at all, and that it is almost better to abstain altogether unless a good sousing can be effected.

ASPARAGUS may be cut until the middle or the end of the month, according to the district. An application of liquid manure will be found very useful now. Newly-planted beds will need watering.

BEANS (Broad). Sow for the last time.

BEANS (Kidney). Sow about the middle of the month for a late supply.

BEANS (Runner). Sow any time before midsummer as these Beans are appreciated and will soon bear, continuing until a frost cuts them down in the autumn.

BROCCOLI. A late sort may be sown this month. Plant out those ready, during showery weather if possible.

CABBAGE. A sowing of cabbage may be made now for planting out when the summer crops are cleared. Put out all plants now ready.

CAPSICUMS. Plant out in a sunny spot, if possible against a south wall.

CARROTS. Sow for succession until midsummer. Those that are up, thin to about 9 inches apart.

CAULIFLOWERS. If transplanted now from the seed-bed the plants will need plenty of water and protection from strong sunshine until they are re-established.

CELERY. Plant out towards the end of the month; this needs careful doing, as it is very important not to check the growth of celery.

CHICORY requires a deep, rich soil and should be grown in the same way as parsnips.

CUCUMBERS may still be sown on ridges.

ENDIVE. Sow broadcast this month, or in drills to be afterwards thinned. The thinnings may be re-set in a good light soil. Watering will be found necessary in dry weather.

LEEKS. Plant out in drills, if this has not been done already, and water well. 


\section{THE VEGE'TABLE GARDEN}

LETTUCE may still be sown on a north border. Plant out at every favourable opportunity.

MELONS. Sow for a final crop, growing the plants in pots until room is found for them by the removal of spent plants.

MUSHROOMS. Beds prepared now should be yielding a good supply in August, and many people think it useless to start a mushroom bed earlier. Where beds have been previously made, water them gently, if dry.

ONIONS. Sow now for salad. Thin out those needing it.

PEAS. During the early part of this month it is not too late to make a last sowing.

POTATOES. Earth up, after rain if possible.

SEA-KALE. Where there are young plants, keep them well watered.

TOMATOES. If not planted out last month, do so now, against a warm wall if possible.

TURNIPS. Sow a good quantity on well-prepared ground, after rain if possible. This crop should be very useful in the autumn.

VEGETABLE MARROWS. If not already out, there should be no delay in getting them settled as early in the month as possible. Water well in dry weather.

\section{JULY}

The work this month is difficult to define and depends very greatly on the weather. The usual order is hot weather at the beginning of the month and a good deal of rain towards the end, but if the rain is only a matter of sharp showers, barely penetrating the earth, watering may still be needed for many crops. Care must be exercised to keep plants that are bearing in good condition; to let a plant run to seed ruins its productiveness. It is also a mistake to allow such things as Vegetable Marrows to bear very large fruit, as that weakens the plant. Any crops that are over, such as Peas, Beans, etc., should be removed with as little delay as possible, and the ground prepared for Winter Greens, etc. Herbs that are in flower should be cut for drying. Vegetable refuse, which is abundant at this time, should all be put in the trenches when land is being prepared for planting, as it forms an excellent manure. 


\section{A YEAR'S GARDENING}

ARTICHOKES (Globe) should now be bearing well.

ASPARAGUS. Cease cutting early this month, as late cutting will weaken the roots. Weed the beds and dose them with liquid manure.

BEANS. Pull up any crop that is past bearing; water those that are now coming on. Sow a few Dwarf and Runner Beans for a late supply on unmanured ground.

BEET. Thin carefully, hoeing between the plants.

BROCCOLI. Plant out in drills 2 feet apart.

CABBAGE. Sow thinly at the end of the month for the following spring and summer. An open spot should be chosen and a light soil is the best. The seed-bed should be shaded and watered. Take care to select a sort advised for sowing at this particular time, as after standing the winter well some kinds are apt to " boll " in the springthat is, they will throw up seed stems without forming any heart. Cabbage sown about May should now be planted out.

CARDOONS should now be got into the trenches as soon as possible. This vegetable needs plenty of manure, water and room.

CARROTS. Sow during the month for use in winter and spring. Pull up any that are running to seed. Start a few in a frame to produce a succession of young carrots.

CAULIFLOWERS may still be sown for the late autumn. Also plant out any that are ready.

CELERY. Plant out the main crop, if this has not been done, choosing showery weather.

ENDIVE. Make two sowings, one at the beginning and one at the end of the month.

GARLIC AND SHALLOTS may both be taken up this month under favourable conditions.

LEEKS. Plant out on well-manured ground in trenches, as for celery. Water carefully.

LETTUCE. Sow now, keeping the ground shaded and well watered.

MUSHROOM BEDS may still be made but must be well protected with straw and mats.

ONIONS. Sow for autumn salads. Towards the end of the month some of the main crop may be ready to be pulled up. They 


\section{THE VEGETABLE GARDEN}

should be left on the ground in the sun for a few days before being stored.

PARSLEY. Sow now for winter use.

PEAS. Clear away those that have ceased to bear. Earth up any that require it and stick them. A few of a dwarf sort may do well if sown this month.

POTATOES. Earth up where ready. Plant quick-growing sorts to be dug as new potatoes later. Early varieties may be dug up now.

RADISHES. Sow the turnip-rooted sorts.

SEA-KALE. Well water the young plants.

SPINACH. Sow the prickly-seeded Spinach to stand the winter, or if the ground is heavy, prepare the bed for sowing in August.

TOMATOES. Train carefully.

TURNIPS. Make a good sowing early in the month for autumn and winter use. Some advise a second sowing to follow it at the end of the month. Thin out the crop now coming on.

VEGETABLE MARROWS may need to be watered, and, if so, the morning is the best time.

WINTER GREENS. Plant out in well-dug ground, and water, if necessary, until firmly established.

\section{AUGUST}

At this time of year the seasons may be said to overlap and the difficulty that the gardener experiences is to find room for all his enterprises. It becomes highly necessary to clear away all the crops that are over to make room for new ones later on, and where space is very restricted it is sometimes found necessary to sow or plant between rows of vegetables that are soon to be removed. Some ground has probably been prepared last month for the crops of winter and spring, but not all; this, therefore, comes into the work of August, and it must be remembered that the success of next year's growing greatly depends on the work done now. If the ground is too dry for the sowing of seeds it must be thoroughly soaked beforehand if it be impossible to wait for rain. Great care must be exercised to prevent the ravages of caterpillars at this time, and indeed insects and weeds are still to be fought during the whole month. 


\section{A YEAR'S GARDENING}

ARTICHOKES (Globe). As soon as the heads have been used, cut down the plant.

ASPARAGUS. Keep the bed free from weeds and do not allow any heads to run to seed.

BEANS (Runner). Stop these when they have reached to the top of the sticks. Water the roots if very dry.

BROCCOLI. Plant out as soon as possible. Plants in good condition now may be further encouraged with water and liquid manure.

BRUSSELS SPROUTS. Sow early this month.

CABBAGE. Sow two or three kinds for a full crop. It is wise to scatter lime on the ground to protect against insects and birds. Red cabbage should also be sown now, if wanted for pickling next season.

CARDOONS will probably need earthing up.

CARROTS. Sow a small quantity to stand the winter.

CAULIFLOWERS. Sow a little seed at the beginning, middle, and end of this month, to form a succession. Although sown in the open ground the young plants will need the protection of frames or hand-lights later on, unless the sowing should be in a very favoured spot that is warm and sunny, when the plants may be left uncovered as long as possible.

CELERY. Carefully earth up all that is ready, but take care to examine for slugs first. Soot or lime should remove them.

CUCUMBERS. Stop weakly shoots. Sow for succession several times between now and the end of October.

ENDIVE. Plant out all that is large enough. Sow for the last time.

LETTUCE. Sow about the middle of the month for standing through the winter.

ONIONS. Sow twice-at the beginning and end of the month. The thinnings may be used for salads. Onions that are still unripe should be spread out in the sun before being stored.

PEAS. Late crops should be supported against storms, and if the weather is dry they will need to be watered well.

SPINACH. It is not too late to sow the prickly-seeded Spinach for winter use. 


\section{THE VEGE'TABLE GARDEN}

STRAWBERRY PLANTS. Select the first runners to make new strawberry beds, when the weather is favourable.

TOMATOES. Gather when ripe, or if all chance of ripening seems improbable on account of the weather, cut the fruit and hang up in a light warm place. Remove all superfluous leaves and shoots from the plants and prevent any further onward growth.

TURNIPS. Sow early in the month.

\section{SEPTEMBER}

The principal work of this month is still the clearing out of the crops that are done with and the preparation of the land, by digging, trenching and manuring, for future crops. It must not be forgotten that all waste material-plentiful just now-such as Cabbagestumps, Bean-stalks and other spent crops, and even weeds and lawncuttings-make the most valuable manure if allowed to ferment and rot on the refuse heap, although left in the garden they form the most painful eyesores. To secure vegetables in the winter and early spring all arrangements not already made should be finished as quickly as possible, while every encouragement should be given to the plants now coming on. It is important to keep the ground round them well stirred, and in some cases an occasional dose of liquid manure may help the plants to established health before the severe frosts set in. Slugs will still be beforehand if they are given the chance and must be carefully looked for. The temperature is beginning to fall and rain may be abundant. However, in many years September is a beautiful month and gives ample scope for the improvement and general upkeep of the garden.

ASPARAGUS. New plantations may still be made.

BROCCOLI. Plant out from the beds in rows, watering the young plants until they are established. Sow seeds for a late spring crop.

BRUSSELS SPROUTS may still be planted for autumn use.

CABBAGES. Continue to plant out. Prick out, when ready, those sown last month.

CARDOONS should now be ready for use.

CARROTS. Sow in a light soil in an open spot. 


\section{A YEAR'S GARDENING}

CAULIFLOWERS. Some of the plants sown last month should now be pricked out in a favoured place, where they will be sheltered from frost. Others may soon be removed to a frame.

CELERY. Earth up where required and plant out any young plants from a summer sowing that may be ready.

ENDIVE may still be sown. Any plants that are suitable should be tied up for blanching, and if there are young plants just ready they should be planted out and well watered. Good ground should be chosen for them and it should be well manured.

LETTUCE. Plant out in sheltered spots. Sow in rich ground.

ONIONS. Those that have not already been drawn should be ready now. Seed may be sown early in the month for transplanting in the spring.

POTATOES. The perishing of the haulm will probably show that there is a crop of potatoes ripe now. They should be carefully dug, but allowed to lie on the ground for a few hours to dry. Cabbage, Spinach, Turnips are all suitable for following Potatoes, and the ground, probably a large patch, will be available now.

RADISHES. Certain kinds may now be sown for winter usethe black and white Turnip-radish in particular.

SALADS may still be procured by sowing Mustard and Cress, Radishes, etc., about once a week in a sheltered border.

SEA-KALE. Remove dead leaves, and then cover the crowns with ashes, or otherwise protect them.

SPINACH. If it has not been done already, sow now for a winter crop. Plant out the sowing made in July or August.

TOMATOES. Give liquid manure to plants that are bearing well; remove leaves that are shading the fruit, and thin the fruit if the plant is over-prolific.

TURNIPS. Seed may still be sown for autumn and winter use. Thin out earlier sowings as they are ready.

\section{OCTOBER}

By the successful gardener the gardening year is felt to be beginning now, for the work required is nearly all in the nature of preparation, and time lost during this month cannot be made up for a I68 


\section{THE VEGE'TABLE GARDEN}

whole year. Whatever has been left undone in the way of planning, clearing, planting, etc., must be hastened on with as quickly as possible. Fallen leaves, weeds, the remains of crops, must all be added to the refuse heap. Slugs and snails must be destroyed, fruit and vegetables carefully stored, young plants protected against frost, and late crops carefully watched and gathered from to prolong their productiveness. And, above all, "next year" and its requirements must be kept constantly in mind and provided for.

ASPARAGUS. As soon as the haulm turns yellow clear the beds and cover the plants with a mixture of manure and salt, finally covering them with soil.

BEANS. A small crop of Beans, if sown now, may possibly be ready in May or June, if the winter proves a mild one.

BROCCOLI. Loosen the soil round the plants and keep the beds free from weeds.

CABBAGES. Towards the end of the month plant out all those that are ready in rich soil, a foot and a half apart. Even when established they will want careful attention in the way of hoeing and weeding, and watchfulness is needed to keep them from being eaten by caterpillars.

CARDOONS. Earth up in dry weather.

CARROTS. Take up now and store. Sow sparingly in a warm border for a possible spring crop.

CAULIFLOWERS. Plant out any young seedlings, covering them with a hand-light or putting them into frames.

CELERY. Earth up in dry weather.

ENDIVE. Prick out any that are ready on to a warm, sheltered border or into a frame. Tie up any requiring it.

LETTUCE. Treat in the same manner as suggested for Endive.

ONIONS. It is important to weed the seed-beds carefully.

PARSNIPS. Lift carefully after a frost.

PEAS. Sow an early kind on a warm south border.

POTATOES. Dig up any that are left in the ground and store for the winter.

RADISHES sown now may be ready for eating in November or December. 


\section{A YEAR'S GARDENING}

SEA-KALE will probably be ready for forcing during this month and must be covered with pots and surrounded with manure, or removed to a forcing bed.

SPINACH. Weed the beds, keeping the soil loosened.

TOMATOES. Gather to ripen indoors.

\section{NOVEMBER}

As far as present crops will permit the ground should be prepared this month for spring sowing, especially if the soil is rather heavy. A very light soil should not be manured in the autumn, as with heavy rains the fertilizing ingredients are apt to be washed away. To lay the earth in ridges, exposing it to the frost's action, is in many cases highly beneficial; therefore this plan should be followed as much as possible. Beyond the preparation of the vacant spaces, the principal work of the month is comprised in pruning, planting and transplanting, of which there will be found plenty to do. If any alterations have been planned, now will be the time for effecting them; but they must be done quickly, taking advantage of any favourable spell of weather. In the frames, seeds of such things as Lettuces, Radishes, etc., may be sown, and plants of many vegetables kept in excellent condition against the early spring. The principal thing to avoid will be mould, which is sure to form if the frames are kept too close. Water must be very carefully given, especially when the weather is frosty. For the rest, to keep the garden tidy and free from dead leaves will repay the trouble taken to do so.

ARTICHOKES (Globe). Cut down and protect the crowns with straw or leaves, but do not exclude all light and air.

ASPARAGUS. Clean the beds, cut down the growth, and spread rotten manure on the ground. This is a capital time for trenching the ground preparatory to making new beds in the spring.

BEANS. On light ground and on a sheltered and sunny border a sowing of Beans may be made with great advantage. Later on, when the plants begin to appear, they must be very carefully protected from frost.

BEET. Take care to avoid waiting until frost attacks the Beetroots before digging them up, as they will be spoilt by it. 


\section{THE VEGETABLE GARDEN}

BROCCOLI. Remove all dead leaves and hoe the ground between them.

BRUSSELS SPROUTS. Remove all dead leaves.

CABBAGE. Hoe between the established plants and plant out for next summer's supply.

CARDOONS. Earth up as soon as possible.

CARROTS should be housed before any severe frost. The young plants should be carefully thinned.

CAULIFLOWERS. Give them as much air as possible, removing hand-glasses or lights whenever the weather is favourable.

CELERY. Earth up finally.

ENDIVE should be blanched in succession.

LEEKS should now be earthed up.

LETTUCE. The young plants should be kept free from slugs; it is not too late to plant out a few to stand the winter.

PEAS. A few may still be sown in a light soil, but the position must be especially favoured.

POTATOES. If any are still in the ground they should be quickly taken up and stored. In a very light soil a few may be planted still, but the position must be a favoured one.

SEA-IIALE. Cover the crowns with litter, having cleared away the old leaves.

SPINACH should be kept carefully thinned; it will then continue to grow and may be picked for eating.

TURNIPS should have the ground hoed about them.

\section{DECEMBER}

In the last month of the year the operations advised for November hold good, and the zealous gardener must still plant and transplant with diligence. When it is dry enough, trenching and digging should be continued; when the soil is very damp the surface should be hoed as often as possible to keep it loose. The birds at this time may be doing much damage to the young buds on fruit trees and bushes and should be guarded against, while the possible ravages of slugs on seedlings must not be forgotten; lime and soot are the recognized 


\section{A YEAR'S GARDENING}

weapons with which to fight these unpleasant creatures. Where the drainage of the garden is defective now is a good time to remedy it, and the sooner it is done the better. In fact, now is the best time for definitely reconsidering the garden in the light of the summer's experience, and where alteration and reform are necessary or expedient they should be executed or arranged for without delay.

BROCCOLI should now be ready for use.

CELERY should be covered with litter to protect it from frost. CHICORY may now be forced.

CUCUMBERS. In suitable weather air should be given, but especial care must be taken to close the frames and cover them with mats at night.

ENDIVE. Cover with litter and pots to blanch.

LETTUCE should now be protected with hand-lights, etc., and when the frosts are very severe litter should further protect the lights.

ONIONS. The kind known as Potato-onions may still be planted in light, rich soil.

PARSNIPS if left in the ground should now be covered with leaves or litter.

PEAS. A few may be sown on very light soil.

SEA-KALE may be covered up for forcing. 


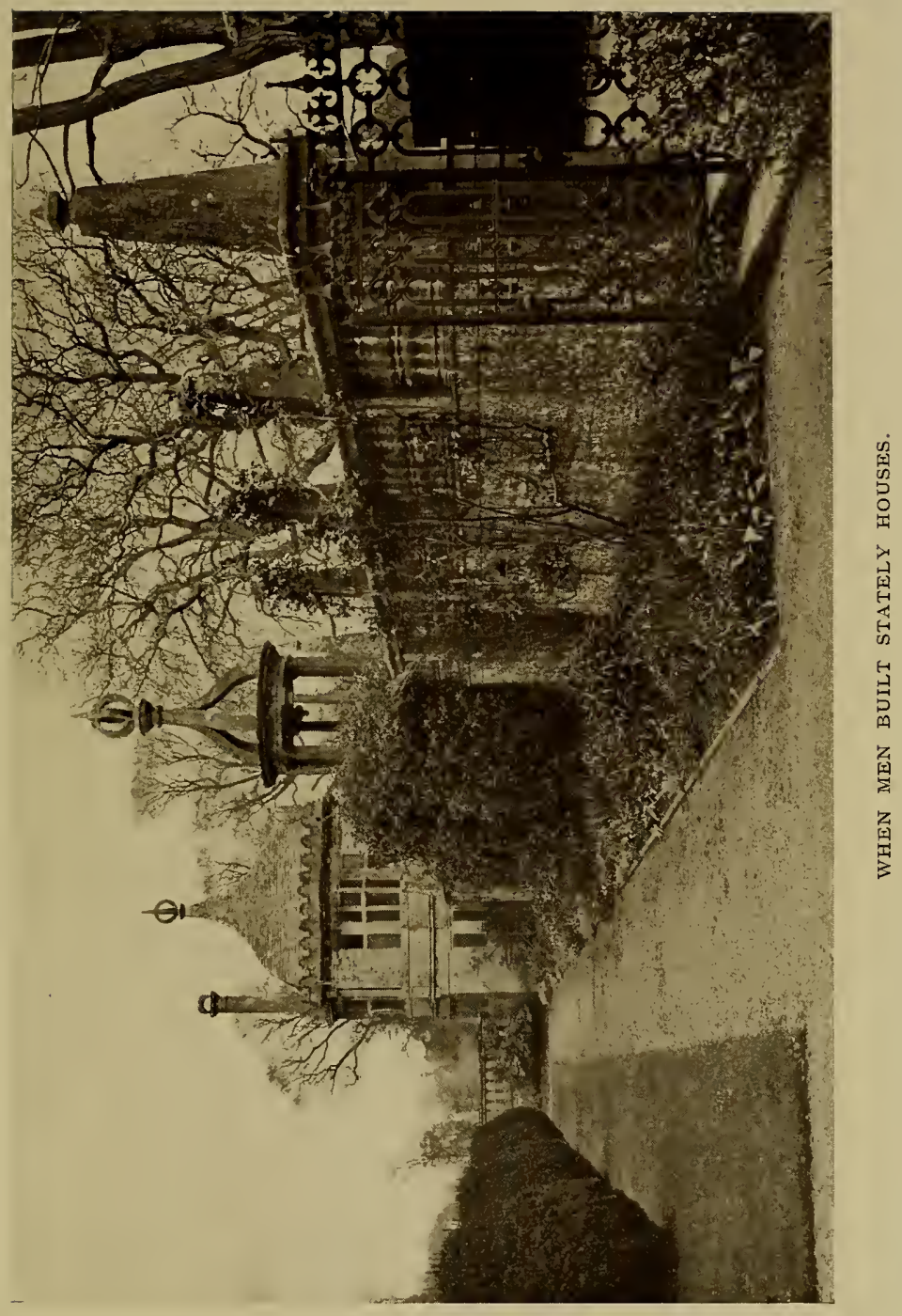





\section{AN ALPHABETICAL AND DESCRIPTIVE LIST OF FLOWERS}

\section{WITH HINTS ON THEIR CULTIVATION}

ABRONIA (Sand Verbena). Half-hardy annual. Suitable for dry soil and for rockeries. Sow early in spring, in pots, and plant out.

ABUTILON (Indian Mallow). Half-hardy greenhouse perennial. Useful for training on conservatory walls; may also be transferred to open borders for the summer. Sow in February and March in pots; re-plant when about an inch high, setting well into the earth. The plants need plenty of water and room.

ACENA. Alpine and rock plants of dwarf, carpet-like growth. Suitable for Rock Gardens and for margins of dry borders.

ACANTHOLIMON (Prickly Thrift). A hardy, dwarf, evergreen plant, good for sandy soil and in sunny situation. May be propagated by layering.

ACANTHUS. A fairly hardy perennial, remarkable for the beauty of its foliage. Thrives well in shade, but requires sun to produce good flowers. May be raised from seed but is more easily increased by division of roots.

ACHILLEA. Herbaceous perennial, of hardy habit, growing freely in most soils. Suitable for grouping in borders and in shrubberies. Among the best are A. Ptarmica (Sneezewort) and $A$. Egeratum (Sweet Maudlin).

ACHIMENES. A tuberous-rooted, greenhouse perennial, sometimes propagated by division of tubers, but more usually from seed. Sow in pots or pans in March or April, and while quite small transfer to separate pots. The seedlings require frequent watering and free drainage. 


\section{A YEAR'S GARDENING}

ACONITUM (Monkshood). A hardy, herbaceous perennial, growing from 3 to 5 feet in height, and producing long spikes of flowers -blue, white and purple. Suitable for massing in groups as a foreground to shrubberies, etc.

ACORUS (Sweet Flag). A waterside plant easy of cultivation and of abundant growth in Norfolk and Suffolk. When bruised it gives out a pleasant smell, and on that account it was formerly used with rushes for strewing floors.

ACROLINIUM. A half-hardy annual, growing about a foot high and producing rosy-pink or white "everlasting" flowers. Seeds should be sown under glass in March and the seedlings planted out in a warm border early in May. To preserve the flowers as " everlastings" they should be gathered when young.

ACTÆA (Baneberry). A perennial of vigorous growth, from 3 to 6 feet high, suitable for a Wild Garden, where, notwithstanding its somewhat coarse habit, its long spikes of white flowers and showy black berries may be very effective. (The berries are poisonous.)

ADONIS (Pheasant's Eye). An easily-cultivated and beautiful plant, perennial or biennial, with bright scarlet or yellow flowers and finely-lined leaves. Thrives in sandy loam, and may be propagated by division or by seed sown in summer.

ÆTHIONEMA. A beautiful Alpine plant, easily raised from seed and thriving in well-drained, sandy loam. It grows as a spreading bush with pink and lilac flowers, and is admirable for trailing over the face of rocks in a Rock Garden.

AFRICAN LILY. See Agapanthus.

AGAPANTHUS (African Lily). A bulbous-rooted plant with graceful foliage and large heads of blossom. The blue variety (A. umbellatus) is the best known and most successful in this country. The bulbs should be stored in winter and planted out in early spring, when they should flower in August. They may also be grown in pots or massed together in tubs, in which case they should be watered abundantly in summer with weak liquid manure.

AGAVE (American Aloe). A tropical-looking plant useful for the conservatory in winter and for placing in the garden in summer in tubs or vases. It comes to flower once in its life, after several 


\section{LIST OF FLOWERS}

years' growth, and its flowering stem may be from 20 to 40 feet high.

AGERATUM. A half-hardy annual of easy culture and among the most lasting of summer bedding plants. (The word "Ageratum " means " not growing old.") The blossoms may be light blue, lavender, or white, and they keep their colour well throughout the flowering season. The plants are usually propagated by cuttings in a gentle heat, but they may also be raised from seed.

AGROSTEMMA (Rose Campion). A. coronaria is a perennial, but more usefully treated as a biennial or annual. It is of the pink family, and thrives in dry and chalky soils, bearing rosy-white or pink flowers. A graceful plant, easily raised from seed.

ALLIUM. There are many varieties of this plant, from the field garlic and the cultivated leek to the sweet-scented $A$. neapolitanum, a handsome, white-flowered species, the blossoms of which are valuable for bouquets and vases. It is an early spring-flowering bulb, and not being very hardy it is best brought forward in a cool house, though it may be planted out of doors in a warm, sheltered position where the soil is light. A. Moly, known also as A. flavum, is a hardier kind, long established in English gardens, and its bright yellow flowers make fine masses of colour about Midsummer. It is of accommodating growth and will succeed equally well on dry banks or on moist ground.

ALONSOA (Mask-flower). Generally treated as a half-hardy annual, but may easily be grown in the open ground from seed sown in spring. There are several species, of which $A$. Warscevviczi, with its compact growth and bright scarlet flowers, and $A$. albiflora, with pure white flowers, may be mentioned.

ALOYSIA (Sweet Verbena). Usually classed as a greenhouse perennial, but in our southern counties (in the Isle of Wight, for instance) it may be left out of doors during the winter if well protected by a covering of straw. Of late years it seems to have lost favour, but it is worth cultivation if only for the fragrance of its leaves and the delicate tint of its foliage.

ALSTRCEMERIA (Peruvian Lily). With proper soil and a warm aspect these handsome plants may be treated as hardy perennials. Massed together in a suitable position they are very beautiful, every stem producing many flowers of varying colour-marking, and if kept well watered and mulched they will give no trouble in staking and 


\section{A YEAR'S GARDENING}

tying, as the stems are naturally quite sturdy. As soon as the seedheads appear they should be removed, or the plants may become exhausted, but the stems and leaves should be allowed to remain to assist the tubers in forming fresh crowns for the following season. A rich, light, well-drained soil and a wind-sheltered position are the chief requisites for their cultivation. They may be raised from seed, but it is generally wiser to obtain plants already established in pots.

ALTH王A (Hollyhock). A hardy perennial of the Mallow family, but more wisely treated as a biennial. Its bold and stately growth renders it suitable for backgrounds where large effects are required and where its somewhat coarse habit is not objectionable. Its main requirements in cultivation are deeply trenched soil, abundant manure and frequent watering.

ALYSSUM. Of the many varieties of this plant $A$. saxatile (Rock Madwort or Gold Dust) is one of the most valuable. Its hardiness and its glorious masses of yellow blossom coming early in the year have made it a well-known favourite. A. maritimum (Sweet Alyssum) is an annual which becomes a perennial by selfsowing. It bears a white flower and thrives on walls and rockeries.

AMARANTHUS (Love-lies-bleeding, Prince's Feather). These are half-hardy annuals, easily raised from seed by sowing in March in gentle heat. There are many varieties, and all owe their beauty to their richly-hued foliage or their strikingly-coloured pendant racemes. A. caudatus (Love-lies-bleeding) is a fine example when well grown, and some others are still finer, attaining a height of from 2 to 4 feet when cultivated in rich soil, and producing a fine effect if judiciously used in borders. Where the brightly-coloured pendants are a characteristic the plants should be placed in large pots or vases, in which their peculiar habit may be shown to advantage.

AMARYLLIS. Most of the varieties of this plant, being of semitropical, bulbous growth, are suited only for the greenhouse, where they become very showy and effective, producing, with a little care and management, a succession of bloom throughout the year. A congenial soil is turfy loam mixed with well-rotted manure and sand. When first potted the bulbs need only a little water and gentle bottom heat, but as soon as the leaves appear an abundance of water should be given and a vigorous growth encouraged. They are sensitive to any disturbance of their roots, and therefore should be allowed to remain in the same pots two or three years, nourishment 176 


\section{LIST OF FLOWERS}

being supplied by means of top-dressing and liquid manure. At least one variety, the $A$. belladonna, known as the Belladonna Lily, can be grown in the open air in our southern counties, and in favourable positions attains a height of from 2 to 3 feet, blooming late in summer with fine clusters of rose-tinted flowers.

AMELLUS. A dwarf, hardy annual which deserves to be better known. It may be sown in the open air in April for flowering in June, and forms a pretty, compact tuft of daisy-like, purple flowers. White, rose, scarlet and violet varieties may be had. It is often listed in catalogues under Kaulfussia amelloides.

AMERICAN ALOE. See AGAvE.

AMMOBIUM (The Winged Everlasting). Classed indifferently as a half-hardy annual, a hardy annual and a hardy perennial. As a matter of fact it is a perennial on warm sandy soils, but must be treated as an annual or biennial on wet and heavy ground. It is of easy culture and may be sown in the open. It grows to a height of some 2 or 3 feet and bears brittle-looking white flowers with yellow discs.

ANAGALIS (Pimpernel). A bright, free-growing, half-hardy annual, thriving well in dry and sunny positions. There are several varieties of various colours-blue, purple, maroon and scarlet-all flowering from July to September. The Bog Pimpernel (A. tenella), with its slender stems and little pink flowers, is very pretty when grown in a hanging pot.

ANCHUSA (Bee-plant, Cape Forget-me-not). Hardy perennials (though best treated, perhaps, as biennials), of the Forget-me-not family, and of easy culture. They should be sown in March and transplanted. The $A$. capensis is a little tender, but the $A$. sempervirens, growing some 18 inches high, with blue flowers, is hardy enough.

ANDROSACE. A family of beautiful Alpine plants whose natural habitat is at such an elevation that for months they are covered in snow, from which, as soon as it melts, they emerge in flower. They are not suited for town culture, as their leaves are apt to retain dust and soot, but planted in small fissures of the Rock Garden, in a good depth of suitable soil, such as sandy loam, where they are not clogged by too much moisture, they make a lovely addition to any collection of Alpine plants. 


\section{A YEAR'S GARDENING}

ANEMONE (Windflower). A hardy perennial common-but beautiful in all its many varieties - throughout northern and southern Europe, and of which our Wood Anemone and the purple Pasqueflower are examples. It is easily raised from seed, and many strains, both bulbous and herbaceous, are quoted in the seedsman's catalogue, the Alpine and Apennine varieties being especially delightful. For flowering in the following year the seed should be sown in the open in June or July, while from sowings made in January or February the plants should bloom in September or October of the same year. Thie seed should be covered very lightly with soil, as germination is slow, and the plants should be thinned out so as to stand 5 or 6 inches apart.

ANTHEMIS (Rock Camomile). A perennial rock plant of a hardy and vigorous type, and of which $A$. Macedonica, with its compact masses of white flowers, is a good example. The A. tinctoria and $A$. Kitaibeli, with their lärge, Marguerite-like flowers, are suitable for the mixed border, growing freely in ordinary soil and forming a good supply to draw upon for cut flowers.

ANTHERICUM (St Bruno's Lily, St Bernard's Lily). There are several varieties of this family, of which these two may be classed as hardy perennials in this country. There are two varieties of the St Bruno's Lily, the one an Alpine plant throwing up snow-white blossoms in early summer, and the other a fine border plant, growing some 3 feet high and with much larger flowers. They are usually grown by division of roots in autumn, but may be raised from seed.

ANTIRRHINUM (Snapdragon). These hardy perennials are most useful border plants, as they are easy of cultivation and thrive almost anywhere, though a free, sandy soil is that congenial to them. They are commonly divided into three classes-dwarf, medium and tall, all of which have their distinct uses in the garden. For early flowering the seed should be sown in heat in January or February, and the seedlings transplanted to the border as soon as large enough. They can also be treated as annuals, sowing the seed in the open in April and thinning out to about a foot apart. But as the Antirrhinum is quite hardy, the best way of all, perhaps, is to sow in drills in the open during summer for flowering in the following season.

AQUILEGIA (Columbine). These are usually classed as hardy perennials, but the Alpine varieties are much more delicate and should be treated as annuals or biennials. A large variety of different heights and of all colours-white, blue, scarlet, yellow, I78 


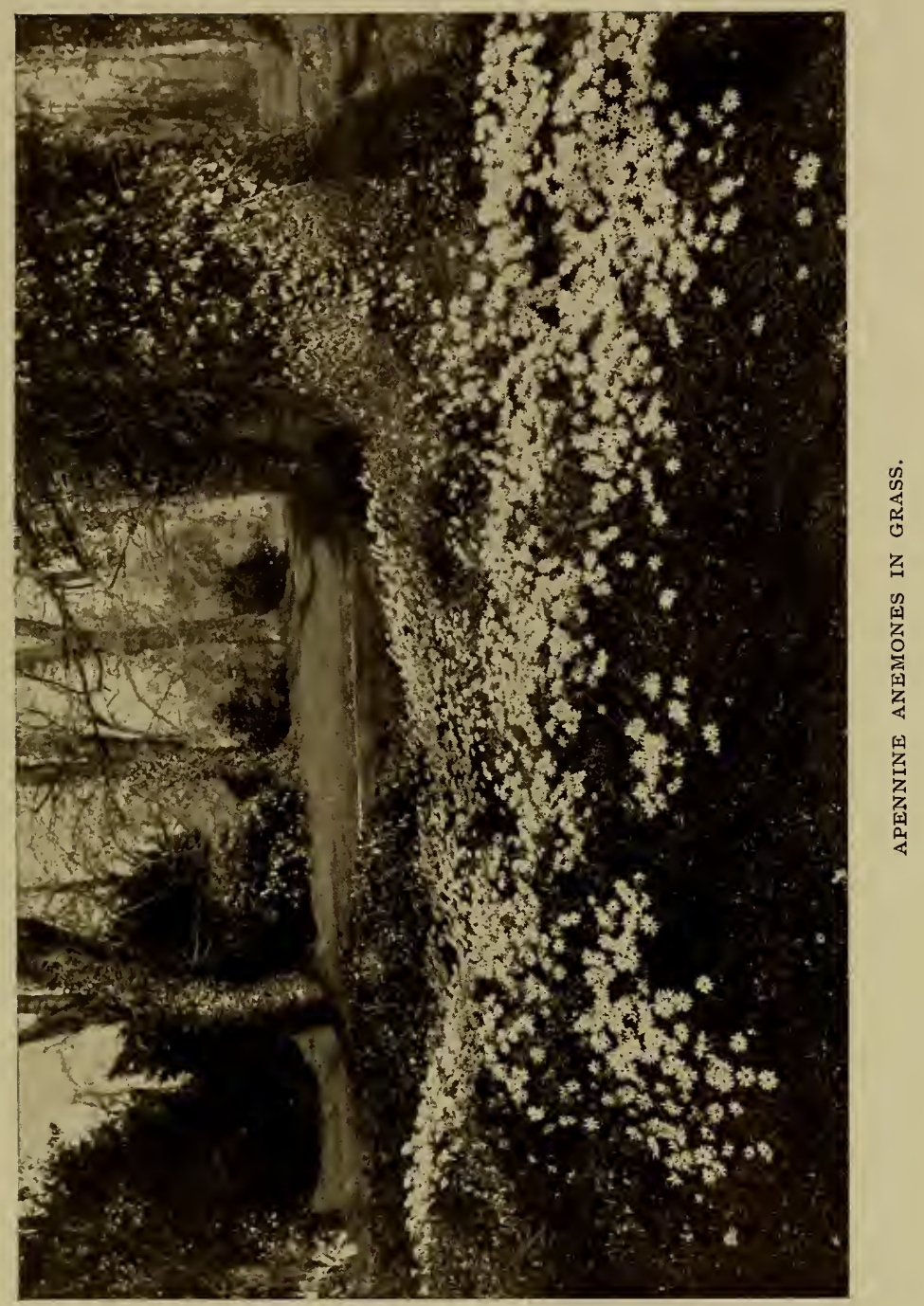





\section{LIST OF FLOWERS}

and a mixture of these colours-may be found in any good seed catalogue, and the long-spurred type has been made a speciality by some florists. For blooming in the same autumn seeds may be sown in a frame in February or March, and the seedlings transplanted as soon as their size and the weather permit. If sown in the open in summer the plants should be strong enough for transplanting by the autumn, and should flower as early as May or June in the following year. With the Alpine varieties the sowing should be made early in spring and the seedlings pricked out into pans and sheltered in a cool house or a frame until August, when they may be removed to the selected positions. A rich, well-drained loam is the proper soil for them.

ARABIS. A large family is included under this name, but the two varieties generally familiar are $A$. albida (White Rock Cress) and $A$. alpina (Bee-flower). Both are quite hardy, and the first is deservedly most popular in towns, as it will grow in any soil and presents a mass of snow-white bloom early in spring. Seed should be sown in summer for flowering in the following spring.

ARCTOTIS. Two of this species are usually included in seed catalogues and may be treated as half-hardy annuals - the $A$. grandis and the $A$. breviscapa. Both are of easy culture and bloom freely in a sunny position. A.grandis bears long-stalked daisy-like flowers of mingled white and lilac, excellent for cutting; while the A. breviscapa has an abundance of showy blossoms of a rich orange colour.

ARENARIA (Sandwort). Under this name are included a large family of rock plants, of which the two most useful in the Rock Garden are A. montana (Mountain Sandwort) and $A$. balearica (Creeping Sandwort). The first is a free and hardy grower and bears large white flowers; while the latter rapidly spreads its green growth and pretty little white flowers over rocks and stones in any ordinary soil, and is excellent for the Wall Garden. Both kinds are propagated by division.

ARGEMONE (Prickly Poppy). Although sometimes classed as a perennial, this plant is so susceptible to cold and wet that it should be treated as a half-hardy annual. Sowing should be made in a warm frame and the seedlings transplanted in moist weather to a protected border, where, in a favourable season, they will attain a height of about 2 feet, bearing large, poppy-like flowers-white with yellow stamens. 


\section{A YEAR'S GARDENING}

ARMERIA (Thrift, Sea-Pink). This is a hardy perennial which well deserves cultivation, and its pretty, grass-like cushions, covered with charming little flowers of pink, lilac or white, are admirable for the Spring Garden, or for banks, or as an edging to borders. There are several varieties to be had, among which the Laucheana, with flowers of bright pink, and the Crimson Gem may be recommended. Propagation is usually made by division of the plants in autumn, but they can be raised from seed. The miniature Alpine species, $A$. setacea, and $A$. juncea, are very beautiful and should be included in the Alpine or Rock Garden.

ARTEMISIA (Wormwood). A half-hardy annual, with a graceful growth of fresh green foliage and pretty little yellow flowers. May be raised from seed sown in gentle heat.

\section{ARUM LILY (Lily of the Nile). See RICHARDIA.}

ASPARAGUS. This is a greenhouse perennial very useful as foliage for bouquets and in table decoration. The varieties $A$. decumbens and $A$. sprengeri are of drooping habit, suitable for growing in hanging baskets. Sowings should be made in heat during February or March, pricking out the seedlings as soon as they are large enough.

ASPERULA (Woodruff). The A. odorata (Sweet Woodruff) is a hardy perennial suitable for shrubberies or the Spring Garden, as it thrives in shade and blossoms into pretty tufts of small white flowers in May. Its dried leaves and stems are extremely fragrant and were of old used to lay among linen. The A. azurea setosa is a hardy annual of rather larger growth, flowering in April with a dainty sky-blue blossom. Both may be raised from seed sown in autumn.

ASPIDIUM (Wood Fern). There are many hardy kinds-among them $A$. filix-mas (Male Fern)-which will thrive under trees or in shady parts of the garden (even in a town garden) if given plenty of water, and a long list may be found in any good florist's catalogue. The more delicate sort should be grown in leafy loam, well-drained, but many will succeed in any ordinary soil.

ASPLENIUM (Spleenrwort). A free-growing fern of deep green colour, well suited for growing in copse or on banks where it can have some shade from the sun. The smaller kinds are useful for the Wall Garden. 


\section{LIST OF FLOWERS}

ASTER. This is a large family, including in its varieties the hardy perennial Michaelmas Daisy and many named kinds of halfhardy annuals which have been greatly improved of recent years and deserve a place in every garden, as they put forth their beauty late in autumn, when the borders are beginning to lose their colour. To secure a succession of bloom there should be several sowings, and the first will need artificial heat. But often the best results are obtained by growing asters entirely in the open, in which case the sowing should be made in April on a well-prepared bed of rich soil lightened with wood ashes. The seedlings should be thinned out so as to give each plenty of room to grow into a sturdy plant before being transferred to its final quarters, and here, again, the soil should be dressed in readiness with well-rotted manure, while the plants should be assisted with weak liquid manure until they begin to flower.

AUBRETIA. A free-growing hardy perennial, excellent for Wall and Rock gardens and sloping banks, and forming beautiful cushions of foliage and flowers. There are many varieties, of which may be named the $A$. purpurea, the $A$. deltoidea, the $A$. Eyrei and the $A$. Leichtlini-all charming. Aubretias are easily grown from cuttings, or by division, or raised from seed; indeed, the seed will sow itself in the earthy chinks of a wall in autumn and bloom in the following February.

AURICULA. A hardy perennial which blooms from February to June and is deservedly a favourite with amateur gardeners. It thrives well in town gardens and does not require artificial heat, though the protection of a frame or greenhouse is needed. It may be propagated by division of the roots in February or March, or may be sown at that season in well-drained pots. The plants need plenty of water, but care must be taken not to water them when the temperature is below freezing point. The Alpine varieties are well worthy of cultivation and quite hardy; they will flourish in the open throughout the winter and flower freely in the spring.

AZALEA. Although the Chinese variety is usually considered a greenhouse plant, there are some kinds-such as $A$. indica and $A$. ledifolia - which can be grown in the open in our southern countiescertainly in Cornwall; while the Ghent variety is quite hardy in the open, especially if suitably planted in a protecting shrubbery, and few shrubs flower better in partial shade. The Azalea may be grown from seed sown under glass in spring, potting off later into a 


\section{A YEAR'S GARDENING}

compost of sandy peat and leaf mould and gradually hardening the plants in September. By December they may be settled in a warm place in the greenhouse, and by January should be growing freely. It is important to have the pots well drained, but the plant may be watered with weak manure water whenever dry.

\section{BACHELOR'S BUTTON. See RANunculus.}

BALSAM. A half-hardy annual very useful for making pot plants for summer blooming in the greenhouse or for bedding-out plants in the border. It is easy of culture and sowings may be made at any time from the middle of March to the middle of May. The earlier sowings should be made on a hot-bed or in a frame, but in May the seed may be sown in the open, on a prepared bed of light, rich soil-moist but not wet. The seedlings should be transplanted as soon as the second pair of leaves appear and kept protected until June, when they may be turned into the open border. If sown for pot plants the seedlings must be transplanted from time to time as their growth proceeds until each has its suitably-sized pot, and some authorities advise that the flowers be picked off in the early stages, with the object of giving greater vigour to the plant, but it is questionable whether this is either desirable or necessary. There are many varieties, with colours ranging through white, yellow, rose and scarlet. (See also ImpatiEns.)

BAMBUSA (Bamboo). These are such elegant and graceful plants that in all except the smallest gardens some sheltered nook should be found for one or two specimens. It is, of course, the graceful lines of their foliage which constitutes their chief beauty, and to obtain the full effect of this they should have a background of evergreens, which should be so placed as to protect the bamboos from the north and east winds; the mild, moist-laden winds from the south and west they will brave without injury. Autumn mulching, especially when first planted, is necessary to protect the roots from frost and prevent evaporation in summer.

BARTONIA. The Bartonia Aurea is that which is most in favour-a fine, showy plant, growing from I2 to I8 inches high, with a rich golden-coloured blossom. It is a hardy annual, easily grown in the open border by sowings made in spring.

BEE BALM. See MONARDA.

BEGONIA. There are two varieties in general use-the tuberous and the fibrous rooted, the tuberous being the greater favourite. I82 


\section{LIST OF FLOWERS}

It is classed as a half-hardy perennial, and from seed sown in March in gentle heat good plants may be obtained early in June. The seed is fine and should be sown very thinly, scattered on the surface of the soil, not buried. Germination is slow and apt to be irregular, and as soon as a few seedlings are large enough they should be pricked out into shallow boxes and not disturbed again until planted out. The chief requirements of the seedlings are moderate heat, moisture and shade, and when planted out they should go into a rich soil, for the Begonia is a gross feeder. For preservation for the following season the tubers should be carefully lifted (the decayed stems being gently removed) and stored in cocoa-nut fibre or sand in a cool place, where frost will not reach them. For summer bedding the Begonia produces a fine effect, the colours ranging from white to rose, pink, crimson and darkest scarlet.

\section{BELL FLOWER. See CAMPanula.}

BELLIS PERENNIS (Daisy). A hardy perennial of great service in the Spring Garden and deserving more general cultivation, as the effect when planted in large clumps is excellent. There are many kinds and various colours, of which the delicately-tinted Pink Beauty, the deep red Rob Roy, and the large-flowered White Globe may be mentioned. They may be grown from seed or by division of roots.

\section{BERGAMOT. See Monarda.}

BIGNONIA (Trumpet Flower). A handsome climber for the conservatory, producing fine scarlet or orange-coloured flowers. The variety known as $B$. radicans may be grown in the open in warm situations. Sow in early spring, in heat.

\section{BINDWEED. See Convolvulus.}

\section{BLEEDING HEART, See Dicentra.}

\section{BLUEBELL. See ScILlA.}

BLUMENBACHIA. This may be treated as a hardy annual, but should be sown in spring rather than in autumn. It has showy flowers and good foliage, and requires a warm, light soil. There are several species in cultivation.

BOCCONIA (Plume Poppy). A perennial of vigorous growth and abundant flowers, well suited for planting in bold groups. It will thrive in any ordinary soil and may be propagated by division. 


\section{A YEAR'S GARDENING}

BOG ARUM. See CAlla.

BORONIA. Usually classed as a greenhouse perennial, though it has been known to succeed in the open in $a^{5}$ moist, warm climate. The $B$. megastigma, which is the variety commonly grown, is a profuse bloomer and of delightful fragrance. It may be raised from seed.

BRACHYCOME (Swan River Daisy). Generally treated as a half-hardy annual, though it may be successfully raised from seed sown in a warm border towards the end of April or the beginning of May. It is a free bloomer and bears flowers of a bright blue with a pale centre.

BREVOORTIA. A bulbous plant of the Lily family, sometimes called Crimson Satinflower, from the vivid colour of its blossoms. It thrives best in light soil, and to obtain the best effect should be planted in groups.

BRODIÆA (Californian Hyacinth). A genus of beautiful liliaceous plants named after James Brodie, the Scottish botanist. It includes many varieties, all of which will endure the winter in the open except in unusually cold seasons, when the bulbs should be protected by a covering of straw. Among the best known and most worth cultivation are B. grandiflora and B. laxa. Autumn is the best season for planting.

\section{BROOM. See Cytisus.}

BROWALLIA. Half-hardy annuals which are useful either for decoration of the conservatory or for bedding out. The seed should be sown in March in the greenhouse and the seedlings pricked out as soon as possible, when they should be ready for transplanting to the open in May. There are at least three varieties, with flowers of violet, delicate azure blue, and white respectively.

BULBOCODIUM (Spring Meadow Saffron). A bulb of the Lily tribe, one of the earliest of spring flowers and delightful for it beautiful colour of purplish hue. It should have a place in every spring garden and may be propagated by division in summer.

BUPHTHALMUM. A free-growing, hardy perennial with fine yellow flowers, a most useful plant for the Wild Garden because of its close and vigorous growth.

BUTTERCUP. See Ranunculus. 


\section{LIST OF FLOWERS}

CACALIA. C. coccinea, sometimes called the Tassel Flower, is a hardy annual with vivid scarlet blossoms, growing from $\mathrm{I} 2$ to I8 inches high, and well suited for a mixed border.

CALAMPELIS. See ECCREMOCARPUS.

CALANDRINIA. There are several varieties but some are not of much value. C. umbellata can, however, be recommended for the Rock Garden, where it probably will maintain itself as a perennial, as it thrives in light, well-drained soil. The flower is of a brilliant crimson colour and may be easily raised from seed sown in spring in a frame, the seedlings being pricked out as soon as they will bear it and transplanted to the open in May or June.

CALCEOLARIA. The herbaceous Calceolaria is usually classed as a greenhouse perennial, but its progagation from seed will well repay the trouble involved, as by this means the best and newest varieties may be obtained. Seed should be sown in a cool house in May or June, in pots or pans filled with a rich, porous soil, care being taken to distribute it evenly, as it is very fine. It should be covered with a mere dusting of fine earth, and if water is required before the seed germinates it should be given by partially submerging the pan. As soon as it is possible to handle the seedlings they should be pricked off into other pots, and in about a month's time, when they should have four or five leaves each, they should be carefully transferred into small single pots, and by September they may be transferred into larger pots to abide the winter. Air, light, water and moderate heat are the essential requirements, and with these conditions fulfilled the plants will begin to have vigorous growth early in March. The miniature, small-flowered type is also well worth cultivation; it has a daintiness of growth and character which renders it very alluring.

CALENDULA (Garden Marigold). A familiar hardy annual of which there are many pleasing varieties. It will thrive in almost any soil and makes a showy border plant, continuing a long time in bloom if the withered flowers are at once removed. C. officinalis is the single yellow flower of the cottage garden, but the large doubleflowered variety of deep orange colour, known as Orange Cockade or Prince of Orange, and the single pure white (Plwvialis) are better worth attention.

CALIFORNIAN FUCHSIA. See ZAUSChNERIA.

CALIFORNIAN HYACINTH. See BRODIÆA.

CALIFORNIAN POPPY. See EschscholtzIA. I85 


\section{A YEAR'S GARDENING}

CALLA. A water-loving plant suitable for moist places in the Wild Garden, where, if allowed to trail over the ground at its own will, it increases rapidly in summer. It is, however, rather tender and may need renewing from year to year unless in a sheltered spot.

CALIIOPSIS (Coreopsis). A very general favourite, comprising a large variety, some of which are perennials, though it is probably wiser to treat all as annuals. The plants are among the showiest of summer flowers and are quite hardy. Seed should be sown early in April, in the place where intended to bloom, and by successive sowings the flowers may be had continuously from July to October. Any good catalogue of seeds will supply the names of various sorts, but perhaps that designated Grandiflora bears the finest and largest flowers.

CALLIRHOÉ (Poppy Mallow). This plant-really a perennial, but more often classed as a hardy annual -includes several varieties which deserve to be more generally known; such as $C$. pedata, bearing handsome dark crimson flowers, $C$. digitata, with reddish purple blossoms, and C. involucrata, which is well suited for the Rock Garden by reason of its trailing growth.

CALTHA. The Marsh Marigold (C. palustris), though abundant as a wild flower, is of sufficient beauty to warrant its introduction into the Wild Garden, especially where the soil is wet, while its double varieties are useful in any moist border and are very effective when grouped in bold masses.

CAMELLIA. Although the Camellia may be considered as essentially a greenhouse plant, it has been found by experience that it will thrive in the open in the Isle of Wight and in Cornwall, and in protected positions in our southern home counties. Its weakness consists in its inability to bear exposure to wind and in its stems and roots being susceptible to frost. But if its roots be protected by a covering of litter and its stems wrapped round with a hayband, it will endure the ordinary frosts of our climate so long as it is sheltered from the full blast of the wind. Of course some varieties are more suitable for outdoor culture than others, among which may be mentioned Duke of Devonshire, Lady Hume's Blush, and Countess of Orkney. It may be raised from seed by sowing in heat early in spring, the seedlings being pricked out as soon as they can be conveniently handled. 

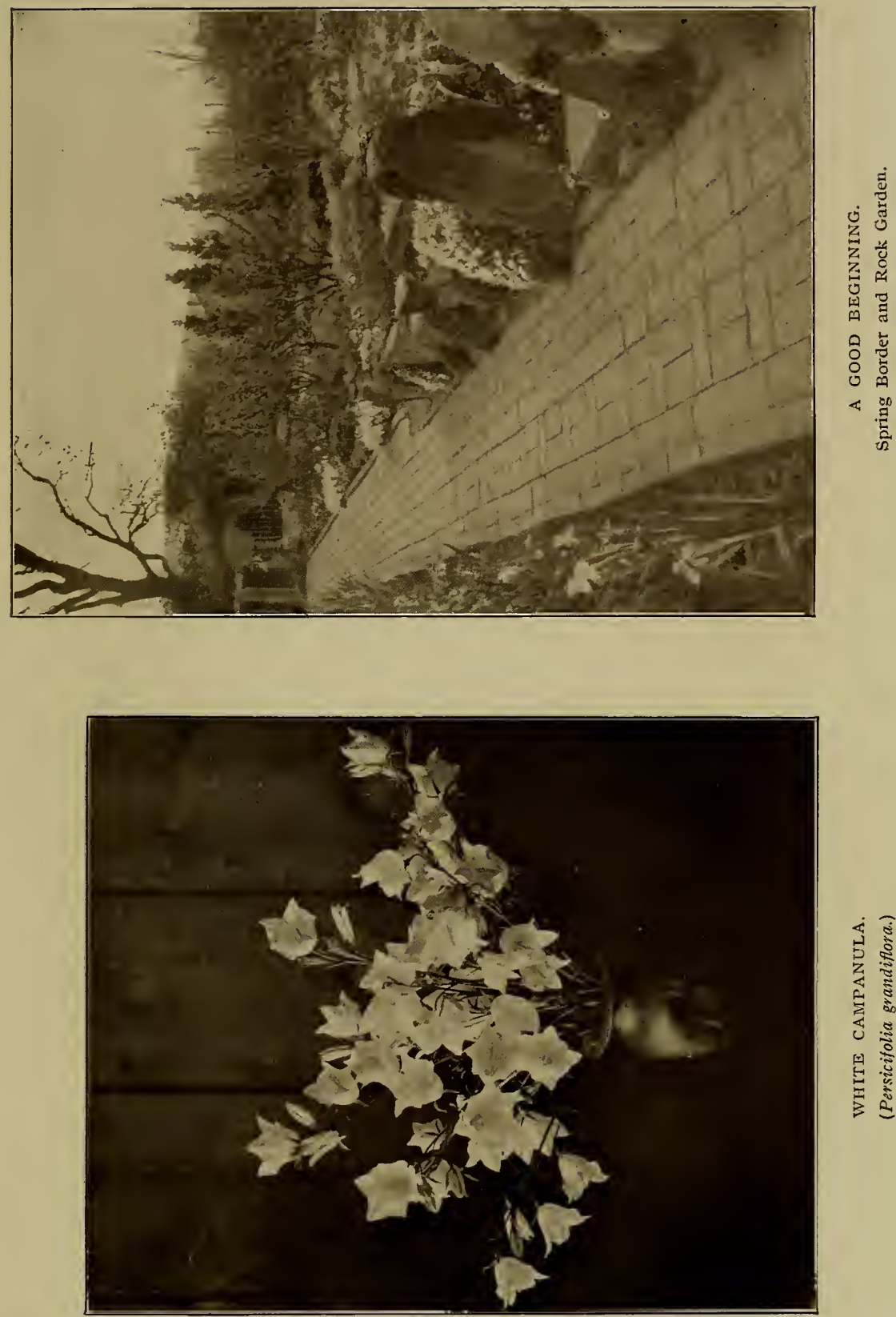

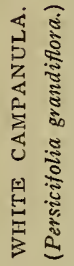





\section{LIST OF FLOWERS}

CAMPANULA (Harebell, Canterbury Bell). Among the Campanula may be found many beautiful Alpine plants, such as the Carpathian Harebell, the Mont Cenis Harebell, the Tufted Harebell and others, all of which are easy of cultivation and by their graceful growth merit a place in the Alpine Garden. The larger varieties of the Campanula-among which are the familiar Canterbury Bell, the giant white Persicifolia, the Pyramidalis (Chimney Campanula), and the Mirabilis-are most useful as border perennials, and though hardy enough to be sown in the open in summer finer specimens may be obtained by sowing the seed in March or April in a frame. As soon as these seedlings are large enough to be handled they may be pricked out into some shady place in the open, and if nurtured carefully and well watered they should be strong plants by the following October, when they may be transplanted to the flower border in confident expectation of their blooming vigorously the next year.

CAMPION. See LYCHNIS.

CANARY CREEPER. See TROPÆOLUM.

CANDYTUFT. See IBERIS.

CANNA (Indian Shot). We are indebted to M. Crozy, of Lyons, for a new and admirable type of the Canna, which has been developed into numerous varieties and has become a valuable summer bedding plant. It is classed as a half-hardy perennial, and may easily be raised from seed by sowing in steady moist heat in early spring. The integument of the seed being tough, it is usual to soak it in tepid water for twenty-four hours before sowing, and it is a good plan, also, to slit one end of the seed to allow it to germinate more easily. With these little preparations germination becomes rapid-from four to six days - and as soon as the seedlings can be handled they should be pricked out into pots or pans and gradually hardened previous to planting in the open, which may be done in May or June in a wellprepared bed of rich, light soil. Any good seedsman's catalogue will supply the names of many varieties, but their very abundance makes it desirable to select characteristic types, as some of the named sorts closely resemble each other.

CANNABIS (Indian Hemp). A hardy annual and a fine foliage plant-one which deserves attention from the fact that it will thrive in a suburban or town garden. It may be grown from seed sown in the open in April, but to obtain a large-sized plant it is advisable to sow in a frame and transplant.

CANTERBURY BELL. See Campanula. I87 


\section{A YEAR'S GARDENING}

\section{CAPE FORGET-ME-NOT. See AnchusA. \\ CAPE HYACINTH. See Galtonia. \\ CAPE MARIGOLD. See DimorphothecA. \\ CARNATION. See DiAnTHUS.}

CASSIOPE. A beautiful little Alpine heather bush, eminently suited for the Rock or Alpine Garden. It delights in a well-drained peaty soil and may be propagated either by division or by pegging down; but it is somewhat difficult of cultivation, as while needing light and moisture it must have free drainage and be shaded from any scorching sun.

CASTOR-OIL PLANT. See RICINUS.

CATANANCHE (Cupid's Dart). A hardy perennial, growing some 18 inches to 2 feet high, and an old favourite as a border plant. The $C$. corrulea, with its bright blue flowers, is that usually grown, but there is a white variety and a bi-coloured blue and white. All may easily be raised from seed and require no special soil.

CATCHFLY. See SilEnE.

CELOSIA (Cockscomb). A plant which is very useful for greenhouse decoration by reason of its graceful plumes and feathered sprays of inflorescence, and in a well-protected spot it will even flourish in the open. Seed should be sown in heat in the spring, the seedlings being pricked off as soon as possible and continued in heat until the crowns appear. They need a good rich soil and plenty of water. There are several varieties of various shades-golden, crimson and rainbow.

CELSIA. C. cretica, the Cretan Mullein, is a half-hardy biennial, but is more usefully treated as an annual. Its golden sprays of flowers and shining buds make it a pretty plant for the greenhouse, and in warm situations it will thrive in the open.

CENTAUREA. A family which includes many familiar flowers, such as the Cornflower, Sweet Sultan and Golden Knapweed. While some of the varieties are wisely treated as annuals most of them are perennial and quite hardy. C. babylonica, for instance, is a hardy perennial, and with its silvery leaves and tall shoots of yellow flowers, ranging from 8 to Io feet high, has a fine effect in a suitable position. It is easily raised from seed. C. Cyanus (Cornflower) is a native annual, sowing itself freely, and often producing the best plants in that way; there are many varieties of colour-white, sky-blue, rose and dark purple. C. moschata (Sweet Sultan) is an annual well I88 


\section{LIST OF FLOWERS}

known for its fragrance; it is not always easily grown, as it requires a calcareous soil and is very susceptible to the ravages of the greenfly. It should be sown in an open, sunny spot, not earlier than the middle of April, in the place where it is intended to flower; it does not like being transplanted. C. macrocephala (Golden Knapweed) is a sturdy plant, attaining a height of 4 feet or more, and its vigorous growth renders it suitable for the flower border edging a shrubbery. There are also other named varieties-Candidissima, with its beautiful silver foliage; Americana, bearing purple thistle-like flowers; and Depressa (King of the Bluebottles), with large rich blue flowers. All can be easily grown from seed.

CENTAURIDIUM. C. Drummondi is a showy plant with large yellow flowers, growing from 18 inches to 2 feet high. It is often classed as a hardy annual, but is more wisely treated as half-hardy, in which case the seed should be sown in a frame in April and the seedlings planted out in May.

CENTRANTHUS (Valerian). The Red Valerian (C. ruber) is a sturdy plant bearing bold clusters of dark-red flowers and blooming throughout the summer from June onwards. It is most useful as a covering for steep, stony banks where little else will grow. $C$. macrosiphon is a hardy annual of less vigorous growth and dwarfer habit, more suitable for the Rock Garden. It may be had with white, rose-coloured and bi-coloured flowers.

\section{CHEDDAR PINK. See Dianthus.}

CHEIRANTHUS (Wallflower). The Wallflower is so beloved of everyone and so well known in gardens of all sorts and sizes that little need be said as to its culture and its many varieties. It may not be amiss, however, to remark that the seed is often sown too late. May, or even April, if the weather be favourable, is none too early, and enables the plants to attain a sturdy growth, capable of withstanding the assaults of the winter, before being transplanted to their places in autumn in readiness for blooming in the early spring. If the economical practice of saving seed from one's own plants be adopted, the seed should be selected not only from the best bloom but also from the plant of the best form and habit, while it is well to bear in mind that, as its name implies, the Wallflower is not merely a border plant but flowers to perfection in the crevices of old walls-dwarfed, it may be, yet compact and full of blossom. Out of the many tints and various forms of bloom now offered in the IS9 


\section{A YEAR'S GARDENING}

seedsmen's catalogues some cannot fail to appeal to the most captious, and all seem worthy of cultivation.

CHELONE. A hardy perennial of which there are several varieties, all making handsome plants for late summer and autumn. It is easy of culture and of free growth, and may be raised from seed or increased by division or cuttings. C. barbata, bearing long racemes of bright scarlet, is a good variety.

CHENOPODIUM. The variety best known and most worth cultivation is $C$. Atriplicis, a hardy annual which may be sown in the open in April. It will thrive in any soil, growing to a height of 3 feet or more, and is chiefly valuable for its foliage and beautifullytinted stem.

CHERRY-PIE. See HELIOTROPIUM.

CHIONODOXA (Snow Glory). These bulbs are a most valuable acquisition for the Spring Garden or for embellishing stretches of grass. Hardy in growth, abundant in increase, early in bloom (often appearing the first or second week in February), lovely in their starry blossoms of snowy white graduating to pale or dark blue, they commend themselves to all lovers of flowers. They are excellent for pot culture as a table decoration and may be used with good effect as a spring edging for borders. There are several varieties to be obtained, of which $C$. lucilice is the best known and as good as any.

\section{CHRISTMAS ROSE. See HELleborus.}

CHRYSANTHEMUM. Under this name is embraced a wide variety of perennials and annuals, both hardy and half-hardy, including the pretty little Pompons and various kinds of the Marguerite or Paris Daisy. The perennial Chrysanthemum is perfectly hardy, but flowering as it does in the late autumn its bloom cannot be obtained in perfection in the open, exposed to frost and rain. It seems a pity, however, to banish it from the garden on that account, and where an ornamental hedge is desired for the separation of garden areas, or to hide an obtrusive fence or wall, it is most useful. All the annuals, of which any seed catalogue will give a large variety, may be raised from seed sown in the open in February or March. So many named varieties of the Chrysanthemum are in cultivation, and the choice must depend so much on the class required, that it would be beyond the scope of these notes to give a detailed list, but to intending purchasers any good grower (Carter, of London, for instance) will supply, gratis, a full descriptive catalogue. 


\section{LIST OF FLOWERS}

CICHORIUM (Chicory). A plant which is much in favour on the Continent as an ingredient in salads, both $C$. endivia and $C$. intybus being used for the purpose, but its value as a garden flower seems to have been overlooked. Yet $C$. intybus may be introduced with good effect into the Wild Garden, as it grows vigorously-even rampantly-and throughout the summer and autumn bears handsome blue flowers. The seed will succeed readily enough in any rough places, provided the soil be not unusually cold and heavy.

CIMICIFUGA (Bugbane). There is one variety of this plant, viz., C. racemosa (often called Black-snake-root), which might well be used for the Wild Garden, though it carries the objection of having an unpleasant odour. It is of tall, handsome growth, with long and graceful racemes of feathery white, which produce a fine effect when the plants are massed together in bold groups.

CINERARIA. A favourite plant for the greenhouse, as it blooms from Christmas to May and makes excellent table decoration either in pots or by cut flowers. The Star and Cactus varieties are especially useful for cutting because of the peculiar grace of their flowers, which preserve their freshness in water for a long time. Cinerarias are easily raised from seed, and various shades of colour in white, blue and crimson may be obtained. Their culture is by no means difficult, though they are plants which are sensitive to any neglect. The seed should be sown from April to June, in a cool frame in pans of leafy mould mixed with sand or sharp road sweepings, and as soon as the seedlings have developed their leaves they should be pricked out into small pots and transferred to larger pots as they require it, the final potting being not later than November. It is advisable to keep them in a cold frame as long as the absence of frost permits, and even when transferred to the greenhouse they are better without much heat, as every endeavour should be made to render them as hardy as possible. The more hardy they can be made the less chance there is of their being attacked by the common greenhouse pests of mildew and green-fly, to which they seem naturally susceptible. Care should also be taken that the plants are not crowded together, or thin and straggling stalks will be produced. An occasional watering with liquid manure as the time of bloom approaches will assist in preserving the leaves and give brilliancy to the colour of the flowers.

CINQUEFOIL. See Potentilla.

CISTUS (Rock Rose). A beautiful flowering shrub, and one I9I 


\section{A YEAR'S GARDENING}

which can be recommended for cultivation in a light soil and a warm situation, but without protection it will not endure a severe winter. There are several kinds, the best known of which is $C$. ladaniferus, the Gum Cistus, having leaves of a smooth and glossy upper surface and woolly-white underneath, with large white flowers blotched with red. It may be grown from seed, and in favourable situations seeds itself.

CLARKIA. A well-known hardy annual, robust, easy of culture and flowering for a long time. C. elegans is an excellent type, two varieties of which-Purple King and Salmon Queen-are especially good, and their long spikes of bloom are most useful as cut flowers. $C$. integripetala is another variety and may be had with either single or double flowers of both white and rose colour. Clarkia is much affected in its growth by the nature of the soil; a good substanced sandy loam is best and a warm position is desirable. It makes a capital winter plant for the greenhouse and for table decoration by sowing in autumn in a cool house.

CLEMATIS. A beautiful climbing plant seen in perfection in its wild state in the chalky soil of the lanes of our southern counties, embellishing the hedges in summer with its delicate white blossoms and in autumn and early winter festooning them with its long trails of feathery seed-pods. Truly it is aptly named Traveller's Joy and Virgin's Bower. It is on this original ( $C$. vitalba) that most of the hybrid and more delicate varieties are grafted; but the result is not always satisfactory, for though a vigorous growth may be obtained at first, the grafted plant often quickly perishes, and the better way is to propagate from layers or raise from seed. There are a very large number of varieties, differing greatly in habit and colour, and as colour is so important a factor in gardens it has been used as a grouping for the following list of a few of the best and hardiest sorts.

WhITE.-L Lanuginosa candida, large flowers slightly tinted with violet, blooming in spring and again late in summer.

Viticella alba, graceful growth of pure white flowers.

Viticella luxurians, vigorous growth, large flowers of greenish tint.

Jackmanni alba, large white flowers.

YELLOW.-Tangutica, fine in colour, spring blooming.

Orientalis, pale yellow, flowering in autumn.

Pink.-Viticella rosea, small flowers of lovely rose colour.

Duchess of Albany, fine shade of light pink flowers. 


\section{LIST OF FLOWERS}

RED.-Jackmanni rubra, rich crimson flowers.

Kermesina, abundant small flowers of bright red.

Countess of Onslow, crimson-purple flowers.

PURPLE.-Gipsy Queen, flowers of a velvety purple.

Jackmanni superba, fine purple flowers.

Star of India, violet with purple markings.

Purpurea elegans, violet-purple.

BuUE.-Victor Ceresole, large flowers of fine colour.

Bifrons, double-coloured-light and dark blue.

CLIANTHUS (Glory Pea). A perennial which makes an excellent greenhouse climber; the New Zealand variety, C. puniceus, being that generally used-a handsome plant, bearing large clusters of bright crimson flowers and blooming freely throughout the summer. Although too tender to stand a sharp winter it is grown successfully in the open in a warm situation in the moist and mild climate of our west country, and it seems to deserve more cultivation in that way. C. dampieri (Sturt's Pea) is an interesting variety bearing scarlet and black blossoms. Seed for both varieties should be sown in early spring, in heat, in light, well-drained soil.

CLINTONIA. A charming little half-hardy annual, of dwarf and compact habit, about 6 inches high. There are two varietiespulchella and elegans-the former being the better known. It is often used as a pot plant for the greenhouse, but it is also effective as a border edging, for which its compact habit renders it very suitable. For borders the seed may be sown in the open in April, thinning out as required, but for pot culture in the greenhouse a better show of bloom will be obtained by sowing a month or two earlier. There are three colours-white, yellow and purple.

COBEA (Cups and Saucers). A familiar half-hardy perennial, valuable as a greenhouse climber and also as an outdoor plant for trellis-work or verandah, as with a little protection it will not succumb to the ordinary winter of our climate. It is a useful plant, for in good soil and with liberal watering it will grow rapidly and flower freely during the summer. Two varieties are obtainable, the $C$. scandens, with purple bell-shaped flowers, and $C$. scandens alba, with white flowers. Seed should be sown in early spring, in gentle heat, and the seedlings potted off as soon as they will bear it.

COCKSCOMB. See Celosia.

COLCHICUM (Meadow Saffron). A family of hardy bulbs valuable because they bloom in late autumn when flowers are scarce. 


\section{A YEAR'S GARDENING}

C. autumnale, the variety best known, bears clusters of pretty flowers standing 2 or 3 inches above the ground, and may be had in several colours-white, purple, reddish lilac and bi-coloured; while there are many other varieties, of which $C$. speciosum is one of the largest and most beautiful. Care should be taken to give them a suitable position where the bloom will not be splashed with earth by the autumn rains. A sunny, well-drained spot in the Rock Garden is excellent.

COLEUS. This plant, valued for the beauty of its foliage, is usually classed as a greenhouse perennial, but in view of the difficulty of keeping it through the winter it is better to treat it as an annual and raise it from seed from year to year. Sowings should be made in March-in pots rather than in pans, so as to have depth of earth-in sandy loam with moist heat, but the seedlings must be watered judiciously, as they are liable to damp off. The varieties are not always apparent until the plants have reached a good size; the strongest are those which are simply green and black, but those with the more delicate tints of pink and yellow are best worth attention. The final pots should be of moderate size only-large pots induce free growth to the detriment of colour.

COLLINSIA. A hardy annual, very pretty in the Spring Garden if sown in autumn for early flowering, and also effective as a broad edging to a border, where, if sown early in April, it will flower in June. It is quite easy of culture and may be had in several colours -white, blue, purple and bi-coloured.

COLLOMIA. C. coccinea is a hardy annual, growing some I2 or I5 inches high, which in warm soils sows its own seed and survives the winter. It blooms well throughout the summer and its bright scarlet flowers compel attention.

COLUMBINE. See AQUilegia.

COMMELINA. A tuberous perennial which, in light soil and in a warm district, is quite hardy and grows like a weed. In cold situations and on a wet soil it must be treated as half-hardy and the roots raised and stored, or protected in the ground, during the winter. Seed should be sown in March, in a frame, and the seedlings planted out in May. C. calestis is the best known variety, with flowers of brilliant blue, but there is also a white-blooming variety.

CONVALLARIA MAJALIS (Lily-of-the-Valley). The prime necessity for the production of a good bed of Lilies-of-the-Valley is a well-manured soil, soft and loamy with plenty of sand, while a shaded I94 


\section{LIST OF FLOWERS}

south aspect, free from draughts, is the satisfactory position. The crowns should be planted in early autumn, singly and 2 or 3 inches apart, and the surface covered with a mulching of well-rotted manure. As soon as the new growth appears a weak solution of liquid manure should be applied occasionally, and for protection from spring frosts a light covering of fern litter is very useful. Of the various strains which are sold that called Fortin's may be confidently recommended. It is more robust than most and produces large flowers.

CONVOLVULUS. The plant which is generally known by this name is the Ipomcea purpurea, sometimes called Convolvulus major, or Morning Glory. It is a half-hardy perennial and is often raised in heat for a greenhouse climber, but it will do well in the open if not sown before May. There are numerous varieties of many colourswhite, blue, violet and crimson-and though it may be considered a common plant its graceful growth and brilliant bloom render it most valuable not only for trellises and arbours but also for temporary pyramids in the open border.

\section{COREOPSIS. See CALLIOPSIS.}

CORNFLOWER. See CEnTAUREA.

COSMEA (Mexican Aster). A half-hardy annual useful for autumn flowering, as it is a prolific bloomer if not caught by an early frost. There are several varieties of various colours-white, pink, mauve and purple-and that known as Bipinnata, which may be had in white and purple, is one of the best. Seed should be sown in a frame in March and the seedlings planted out in May in a warm situation. (Also known as Cosmos.)

COTONEASTER. There are several varieties of this plant, but that most useful is the well-known Wall-Cotoneaster (C.microphylla), a small-leafed, dense-growing evergreen, blossoming in spring into a mass of white bloom and afterwards crowded with bright crimson berries, which remain a beautiful sight for many weeks unless exposed to a violent wind, while its close growth renders it most useful for hiding ugly patches of wall. The trailing kinds of the Cotoneaster, commonly called Rockspray, are valuable in the Rock Garden and are quite easy of culture and propagation.

CRINUM. One of the best known of this family is $C$. capense, a fine bulbous plant, hardy of its kind, growing 2 or 3 feet high and bearing large pink blossoms. There are several varieties-white, purple, and striped pink-and-white. With a sheltered position, 


\section{A YEAR'S GARDENING}

good soil and plenty of water in summer it well repays cultivation for late summer flowering.

CROCUS. There are many species of this bulb, but only the hardy spring varieties which will thrive in any soil or situation are commonly used in our gardens. The bulbs should be planted in October or November (not later) some 3 inches deep, and to attain perfection should be grown in rich, sandy loam. To avoid the mischief often done by sparrows a few strands of black cotton should be stretched over them shortly before they begin to bloom; the cotton is inconspicuous among the flowers but is a terror to the birds. For pot culture of named varieties it is an excellent plan to grow the bulbs in well-drained, shallow boxes filled with rotted manure and leaf mould, from which they may be separately transplanted into the ornamental pot or basket as soon as they begin to bloom, thus securing a successive display of flowers in the same stage of development in each pot.

\section{CUPID'S DART. See CATANANCHE.}

CYCLAMEN. The natural habitat of the Cyclamen is in the shelter of low bushes and friendly grasses, where the plants are protected from stormy winds and biting frosts, and they thrive in a warm sheltered nook of the Rock Garden with a south-eastern aspect. Generally, however, they are treated as greenhouse perennials, for which they are well adapted, as the conditions under which they flourish best are uniform warmth, moist atmosphere with free circulation of air, absence of draught, abundant water with free drainage and shade from excessive heat. They are easily raised from seed, and seed-grown plants often yield a better supply of bloom than those grown from bulbs. Seed should be sown in October or early in November, in pans filled with good loam and leaf mould with a liberal addition of sand to ensure free drainage. The Cyclamen has many varieties and flowers of all colours-white, red, crimson and purple-and one of the hardiest sort is the round-leaved variety (C. Coum), which will bloom in the open in early spring if kept well protected with suitable litter.

CYPRIPEDIUM (Lady's Slipper). Under this name are indicated a group of Orchids, some of which are of much beauty and many perfectly hardy. Probably the Mocassin flower (C. spectabile) is the best suited for cultivation, growing from I8 inches to 2 feet high with one or two large white and rose-blotched flowers on each stem. The English Lady's Slipper (C. calceolus) is also very good I96 


\section{LIS'T OF FLOWERS}

and is useful for the Rock Garden when given a sheltered nook in chalky soil.

CYTISUS (Broom). This beautiful flowering shrub is well worth cultivation and is most useful for clothing rough banks of dry or poor ground where many other plants would soon perish. Its rich yellow blossoms give a fine effect of colour, and by using plants of various kinds of Broom a succession of bloom may be obtained from early spring to late autumn. Although yellow is predominant there are other colours of Broom to be had, such as the White Spanish Broom (C. Albus), the Purple Broom (C. purpureus), and the crimson-brown of Andre's Broom. Many kinds will grow freely from seed, even when scattered at random, but in that case it is well to give some care to the protection of the seedlings in their early growth.

\section{DAFFODIL. See NARCISSUS.}

DAHLIA. The introduction of the Single and Cactus-flowered varieties has considerably widened and strengthened the amateur gardener's interest in Dahlias, while the now prevalent custom of raising plants from seed has given a further incentive to cultivation. Seed sown in February will quickly develop into seedlings which will flower as early as plants grown from tubers, and a part from the interest in the process of raising one's own plants from seed there is always the probability of obtaining some unexpected novelty. The seed should be sown thinly in pans filled with ordinary compost and be covered with a light sprinkling of earth, and as soon as the seedlings are about an inch high they should be potted off and kept in moderate heat until they begin to grow vigorously, when they should be shifted into larger pots and gradually hardened for transfer into the open. Before planting in final position advantage should be taken of any moist and genial weather to place the pots in the open in some sheltered situation as a means of acclimatising the young plants, and the soil in which they are to be placed must be rich and good, for Dahlias are voracious feeders and the profusion of bloom depends upon their being well nourished. Dahlias are so useful as cut flowers and lend themselves so readily for indoor decoration that it is worth while to bear in mind that the early morning, while the dew is yet upon them, is the best time for cutting them, as, indeed, it is for all flowers; they maintain their freshness much longer than those cut later.

\section{DAISY. See Bellis Perennis.}

DATURA. Included in this family are several plants which are 


\section{A YEAR'S GARDENING}

worthy of cultivation, and though none are hardy they are of such rapid growth that they succeed well when treated as half-hardy annuals. Among the best are $D$. ceratocaula, growing from 2 to 3 feet high, with large trumpet-shaped flowers (often called Angels' Trumpets), coloured white and pink, or white tinged with purple, and giving out a delightful perfume. $D$. fastuosa is also very handsome and comprises two varieties, one bearing comparatively small white blossoms and the other a "double" violet flower. D. meteloides, usually known as Wright's Datura, with its spreading branches and large white flowers touched with mauve, should also be mentioned, but its leaves emit an unpleasant smell. The culture required is that usual for the half-hardy annual; seed should be sown in heat in early spring and the seedlings duly potted off and subjected to a hardening treatment before being planted in the open, where, of course, a warm and sheltered position is desirable.

DELPHINIUM (Larkspur). A most valuable plant for the garden, both for its beauty of form and fine spikes of bloom. There are many species, both annual and perennial, but the perennials, with their great range of colour and magnificent growth-from I foot high to 6 or 7 feet or more-are the most esteemed. Nearly all may be raised from seed, and this method is certainly the best where large masses of bloom are required-a most effective way of growing Delphiniums. Seed should be sown in May, the seedlings thinned out early and transferred to the border where they are to flower as soon as they will bear removal, in readiness for early bloom in the following summer. They will succeed in almost any soil or situation, but a deep friable soil, well manured, is that in which they thrive best. Every two or three seasons they should be raised, divided, and re-planted, early spring-as soon as they begin to renew their growth-being the most suitable time. A long continuance of bloom may be obtained by cutting off the spikes as soon as they have done flowering, before the seeds are formed; or, as an alternative, by cutting down the entire plant immediately it has ceased to bloom, when, in a few weeks' time, it will renew its growth and bloom again. In the latter plan, however, it is necessary to give the plant a top-dressing of manure to ensure a vigorous renewal of growth.

DIANTHUS. Under this name are included some of our most beautiful hardy flowers-the Carnation, the Pink, the Sweetwilliam -and many charming Alpine and Rock Garden plants. The Dianthus is easily raised from seed and may advantageously be treated as a I98 


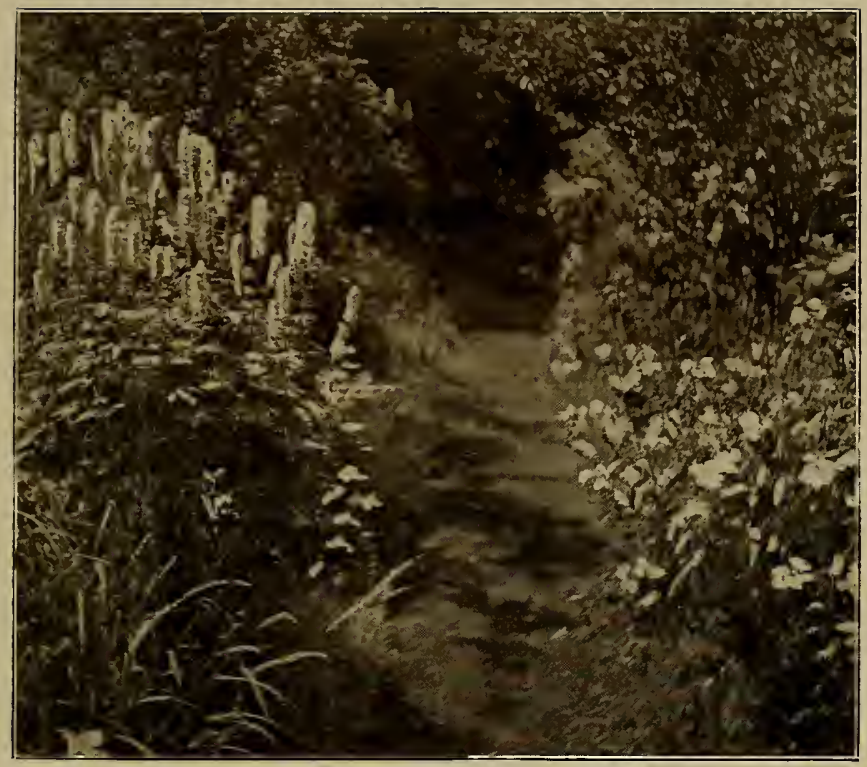

IN A COUNTRY GARDEN.

Grass Path bordered by Delphiniums.

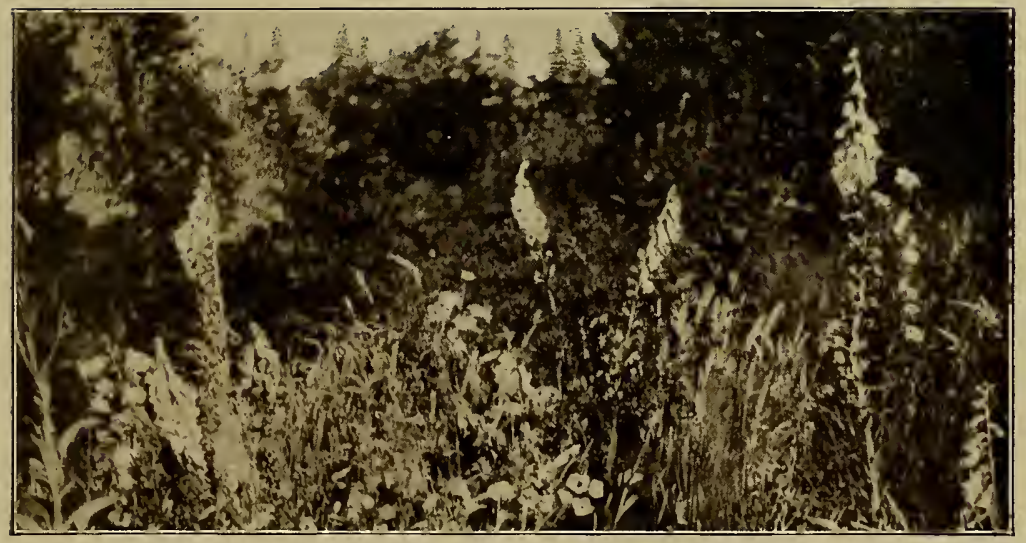

IN A COUNTRY GARDEN.

A wild border of Foxgloves. 



\section{LIST OF FLOWERS}

hardy annual, sowing in the open in June or July for flowering in the following summer. The seed should be sown in a shady spot in drills of finely-sifted soil, and covered very lightly, and the seedlings should be transferred to their final positions as soon as they will bear removal. The most suitable soil for the Dianthus is a sandy loam, and for successful flowering an open, sunshiny position is necessary. Even when subdivided under such headings as Common Pinks, Chinese Pinks, Indian Pinks, Carnations, Piccotees, Sweetwilliams, etc., there are many varieties under each class from which to choose, while those kinds best suited for the Alpine and Rock Garden embrace $D$. alpinus, $D$. casius (Cheddar Pink), D. deltoides (Maiden Pink), D. dentosus (Amoor Pink), D. neglectus (Glacier Pink) and D. petrceus (Rock Pink).

DICENTRA (Bleeding Heart). This plant (D. spectabilis) is so general a favourite and so familiar to all gardeners that it requires no recommendation here; but it may not be amiss to suggest that however useful it may be in mixed borders its more fitting place is some sheltered nook in the Rock Garden, where its slender stalks of blood-red flowers could more safely display their peculiar beauty and the plant itself rejoice in some protection against the late frosts of spring.

DIDISCUS. A pretty, half-hardy annual requiring rather careful treatment, but its beautiful clear-blue flowers, borne on erect and much-branched stems, are distinctively charming and render it well worth the trouble of cultivation. Seed should be sown in May in gentle heat and the seedlings transplanted as soon as possible into a warm, friable soil, care being taken, when watering in the early stages, to keep them free of excessive moisture.

DIGITALIS (Foxglove). A hardy perennial very valuable in borders and shrubberies, and also in the Wild Garden. The wild Foxglove, indigenous to this country, seldom varies in colour, but in the cultivated plant we have flowers of red, white, purple, rose, yellow and orange, while in many the throat-markings are of great beauty, resembling the Gloxinia. The varieties named respectively Grandiflora, Gloxinioides and Purpurea will probably be found the most useful. Any deep, moist soil is favourable to the growth of the Foxglove, and seed may be sown in the open in June or July for flowering in the following summer.

DIMORPHOTHECA (Cape Marigold). A hardy annual with pretty Marguerite-like flowers of glossy orange colour, growing some 


\section{A YEAR'S GARDENING}

I2 or I 8 inches high, a prolific flowerer and continuing to bloom until cut down by frost. It is a bold, free-growing plant and will thrive in any good soil.

DIPSACUS (Teasel). Although this is a coarse-growing plant its striking form and fine foliage render it valuable for the Wild Garden or wood plantations. It is easily raised from seed and may be treated either as an annual or a biennial, or even as a perennial, as it will often perpetuate itself. The finest kind is $D$. laciniatus, which grows to a height of 5 or 6 feet, and is proportionately sturdy, with large, deeply-cut leaves.

DODECATHEON (American Cowslip). A beautiful hardy perennial, valuable for the Spring Garden or for the early-flower border in a cool situation. It is easily raised from seed and will quickly form large patches which may be divided every three or four years. The early spring is the best time for division, when the plants begin to renew their growth after their winter rest.

DOG'S-TOOTH VIOLET. See ERYTHRONIUM.

DONDIA-EPIPACTIS. A charming little plant well suited for the Rock Garden and by no means difficult of culture. It grows some 3 or 4 inches high, and in the spring bears pretty flowers of a delicate yellow tint. It may be increased by division.

DORONICUM (Leopard's Bane). A family of showy, vigorousgrowing plants, of which $D$. plantagineum excelsum is generally considered the best. Its sturdy growth and its capability of thriving in any soil render it most useful as a covering for rough banks or for the Wild Garden, where its large, bright yellow flowers of daisy-like form are very effective in early spring. It can be easily propagated by division of the roots.

DOWNINGIA (otherwise Clintonia-which see.)

DRACOCEPHALUM (Dragon's Head). All this family is hardy and includes both perennials and annuals well suited for the Rock Garden or the mixed border. D. Ruyschianum is one of the best of the perennials and is a handsome plant with flowers of bright purple blue. Among the annuals are $D$. Moldavicum and $D$. canariensis (sometimes known as Balm of Gilead), the former being esteemed for the fragrance of its blue flowers. Perhaps the most beautiful of all, however, is $D$. grandiflorum, of dwarf habit with fine clusters of vivid blue flowers, eminently suited for the Rock Garden. All may be raised from seed and the perennials increased by division. 


\section{LIST OF FLOWERS}

DRYAS. Valuable little plants for the Alpine Garden, their natural habit of growth being to spread over the surface of limestone rocks. Both $D$. Drummondi, with its fine yellow flowers, and $D$. octopetala, with its compact tufts of white flowers, are excellent.

\section{DUSTY MILLER. See SENECIO.}

ECCREMOCARPUS (sometimes known as Calampelis). The $E$. Scaber is a useful climber for walls and trellises, and its handsome racemes of orange-scarlet bloom are very effective. It is a perennial, but its roots should be protected during the winter. It may be raised from seed sown in heat, and if sown early in the spring it will be ready to bloom out of doors the same year.

ECHINACEA (otherwise Rudbeckia). The E. purpurea, popularly called the Red Sunflower, is a hardy perennial with large flowers of a rose-purple hue often measuring some 4 inches across. It grows from 3 to 4 feet high and blooms freely during late summer and autumn. Easily raised from seed.

ECHINOPS (Globe Thistle). A fine hardy plant, growing from 3 to 5 feet high, and useful for making ornamental groups in the Wild Garden. There are several varieties, E. ritro and E. banaticus being very good, but perhaps the best is E. ruthenicus, with its roundheaded flowers of beautiful blue. It is easily increased by division or raised from seed, and it thrives in any soil.

ECHIUM (Viper's Bugloss). Of this family E. plantagineum, with its showy flowers of rich violet, is one of the handsomest, while $E$. vulgare (our native plant), with its long racemes of blue flowers, is very useful. They are best treated as annuals and are easy of culture. Seed sown in the open in spring will flower the same year, while for early summer bloom sowing should be made in autumn.

ERANTHEMUM. This plant is well suited for cultivation as a greenhouse perennial. There are many species, of which $E$. pulchellum with blue flowers, $E$. bicolor with white and red flowers, and $E$. longifolium with scarlet flowers, are the best known.

ERANTHIS (Winter Aconite). Even before the first spring flowers appear Winter Aconite gladdens us with its bright yellow blossoms, and its beautiful shining foliage is in itself an ornament. It flourishes best on a warm, chalky soil, in a half-wild state on banks or under trees, and to gain its full effect it should be planted in large, bold patches. 


\section{A YEAR'S GARDENING}

ERICA (Heath). The cultivation of hardy heaths has hitherto been much neglected in our gardens, yet with judicious planting they produce a fine effect and are eminently suited for the Wild Garden. The Cape Heaths are especially beautiful, and the writer, when visiting Cape Town, was astonished and delighted at the great variety shown at a Wild Flower Exhibition which he attended. Heaths are essentially hardy and may be raised from seed or propagated by division in autumn; among the hardiest may be reckoned the Dorset Heath ( $E$. ciliaris), the Scotch Heath $(E$. cinerea), which may be had in various colours-white, purple, rose and bi-colouredand the Alpine Forest Heath (E. carnea), which is specially valuable as one of the first to flower.

ERIGERON (Stenactis). This is a hardy perennial which will flourish in any garden soil, and its showy flowers-orange Daisies, as they are sometimes called-are very effective in a suitable position. Some of the family, however, are of a weedy growth and are best relegated to the Wild Garden. One of the most suitable for groups in borders is $E$. speciosus, of vigorous growth, reaching from 2 to $2 \frac{1}{2}$ feet high, and bearing a profusion of large purplish flowers with an orange centre; while another is $E$. Macranthus, of compact habit, growing about $I$ foot high and yielding an abundance of summer bloom. There are also some dwarf varieties, such as $E$. alpinum grandiflorum and $E$. Roylei, which are well suited for the Rock Garden.

ERINUS. An Alpine plant which will readily make itself at home in the Rock Garden or on an old wall, where, if allowed to run wild it will soon establish itself permanently. Both the blue and the white flowered varieties are charming, and that called hirsutus has a beauty of its own, its leaves (as its name implies) being covered with fine down.

ERIOGONUM. A beautiful family of Alpine plants but somewhat difficult of cultivation. E. umbellatum, however, will often thrive in the Rock Garden in sandy soil, when its many stems of bright yellow blooms present a charming appearance.

ERITRICHIUM (Fairy Forget-me-not). An Alpine plant of much beauty but not very easily acclimatized to our winters. In its natural environment it is covered with dry snow throughout the winter, and in the chilly moisture of our winter it is liable to damp off. But by planting it in fibrous peat mixed with broken limestone, and protecting it from the winter rains by means of an overhanging ledge of slate or glass, it will thrive in the Alpine Garden. 


\section{LIST OF FLOWERS}

ERODIUM (Heron's-bill). A plant of the Geranium family and a native of this country. Some of the species are well adapted for the Rock Garden and thrive in sunny situations in chalky or stony soil. The British species are E. maritimum, E. moschatum, and E. cicutarium, but the best suited for cultivation are $E$. macradenium, of dwarf growth, with flowers of delicate white tinged with purple, and $E$. Manescavi, a vigorous and showy plant bearing large purplish flowers and blooming best in a poor soil.

ERYNGIUM (Sea Holly). A hardy perennial of thistle-like appearance very valuable in the garden for decorative groups in the border, as its handsome stems with their splendid tints and brilliant steel-blue flower-heads are most effective, while in many species the finely formed leaves are an additional beauty. Among those with, specially fine foliage are $E$. bromeliafolium, $E$. pandanifolium and $E$. Lasseauxi, all quite hardy, while $E$. amethystinum and $E$. giganteum may both be recommended for their brilliant colouring. All these are easily raised from seed sown in early spring in a cold frame, the seedlings being planted out as soon as possible into a well-drained soil.

ERYSIMUM. The varieties under this name include perennials, biennials and annuals, but the hardy annual kinds are the most useful. They comprise many good sorts, of which E. Perofskianum, with its fragrant orange flowers, E. arkansanum (the Western Wallflower), and $E$. pachycarpum, a very showy plant, are excellent examples. There are also Alpine varieties suitable for the Rock Garden, such as E. pumilum (the Fairy Wallflower) and E. rhaticum, the latter being the more hardy of the two.

ERYTHRINA (Coral Tree). A useful greenhouse shrub, producing beautiful scarlet flowers and fine foliage. There are many varieties, such as Marie Belanger, Hendersoni, profusa, ruberrima, etc. But the Crista-galli is the most hardy, and in a warm situation and in a light soil it will thrive out of doors if the roots are protected during the winter. Most varieties may be raised from seed by sowing in heat in early spring and potting off in the usual manner.

ERYTHRONIUM (Dog's-tooth Violet). A hardy liliaceous bulb well suited for the Spring Garden or as a spring edging to a border, as it is elegant in leaf and flower and of neat growth. There are several varieties of colour-white, purple, rose and violet. The bulbs should be planted in autumn, and they will thrive best in peaty soil in a sunny situation. They should be planted rather deep and will bear division every two or three years. 


\section{A YEAR'S GARDENING}

ESCHSCHOLTZIA (Californian Poppy). A hardy annual which will thrive in any ordinary soil and produce a brilliant display of flowers. To obtain the best results the seed should be sown in August or September (not later), as the plants are naturally deep-rooted and need to get firm hold of the soil to bloom in perfection. The names of many varieties may be seen in any good catalogue of seeds.

EUCHARIDIUM. A hardy annual useful for either early summer or autumn flowering and continuing in bloom for a long time. For blooming early in the following summer seed should be sown in autumn, and for late summer display from April to June. One of the best varieties is $E$. Breweri, of robust growth and bearing flowers of rich red and of some fragrance.

EUPATORIUM. A perennial of somewhat coarse habit but well suited for the wild garden and for producing cut flowers for the autumn. E. purpureum is a splendid variety, growing from ro to I2 feet high and bearing fine clusters of purple flowers. Other smaller sorts are $E$. altissimum and $E$. aromaticum, producing solidlooking masses of white bloom. None are fastidious as to soil.

EUTOCA. A hardy annual which blooms freely in a sunny situation and makes a good display for a long time. It is a valuable plant for bee-keepers, as the flowers are very attractive to bees. There are several kinds and considerable variety of growth, varying from a few inches to 2 feet, with flowers of blue, purple or white. $E$. viscida is one of the larger kind, with hairy, gummy leaves and flowers of an intense blue. Of the smaller varieties $E$. Douglasii and $E$. campanularia are very good. All may be sown in the open in April.

EVENING PRIMROSE. See ENOTHERA.

EVERLASTING PEA. See Lathyrus.

EVERLASTINGS. See HELICHRYSUm.

FERRARIA (otherwise Tigridia, or Tiger-fower). A bulbous plant with very showy but short-lived flowers, requiring a dry, sunny situation and lifting and storing during the winter. A rich, sandy loam is the soil necessary to ensure vigorous growth and fine blossoms, and the bulbs should be planted about the end of April, not lifting them for the winter until the foliage has turned yellowsay in November. There are many varieties, all beautiful but rather tender. 


\section{LIST OF FLOWERS}

FEVERFEW. See Pyrethrum.

FORGET-ME-NOT. See MYosotis.

FOXGLOVE. See Digitalis.

FRANCOA (Bridal Wreath). A half-hardy perennial easy of cultivation in the greenhouse and hardy enough to be placed in the open border in a warm, sheltered position. F. ramosa, which bears long branching spikes of white or pink bloom, is an excellent variety and most useful for cut flowers. $F$. sonchifolia is short stemmed with beautiful rose-coloured flowers. From seed sown in March flowering plants may be expected in fifteen months.

FRAXINELLA (Burning Bush). A well-known hardy perennial of vigorous growth (some 2 feet high) and fragrant foliage, forming a useful plant in the herbaceous border. It may be had in two colours-purplish red and white-and may easily be raised from seed sown in spring.

FREESIA. A half-hardy bulbous plant with beautiful white or yellow flowers of delicious fragrance. It is easily raised from seed sown in a rich compost, but as the roots are very brittle care must be used in transplanting. From seed sown in February or March flowers may be obtained the same year, while a further sowing in August will supply plants for the following spring.

\section{FRENCH HONEYSUCKLE. See HedySARUM.}

FRITILLARIA (Fritillary). A bulbous plant of the Lily tribe, one species of which-F. Meleagris, the common Fritillary or Snake'shead-grows wild in the moist meadows of this country (at Oxford, for instance). The stately member of the family is $F$. imperialis (Crown Imperial), growing from 3 to 4 feet high and bearing masses of bell-like flowers. There are several varieties of this species, with flowers ranging from pale yellow to deep orange and fine red, and the aurea marginata has gold-striped foliage. Other kinds of more delicate beauty are $F$. aurea with pale yellow spotted flowers, $F$. latifolia with pendulous flowers of various shades of purple, and $F$. recurva with flowers of mixed red and yellow. All are quite hardy and will grow in almost any soil, but thrive best in good deep loam. The bulbs should be planted in autumn and may be increased by division every three or four years, lifting in autumn and re-planting immediately in fresh soil.

FUCHSIA. This is generally considered a perennial of the half-hardy class, but in our southern and western counties-par205 


\section{A YEAR'S GARDENING}

ticularly on the sea-coast-it will survive the winter in the open and grow into a fine bush abounding in masses of beautiful flowers. Too often the Fuchsia is restricted to the greenhouse, but with a little management it may be made a most useful plant for the garden. The essential point is that the plants should be kept back as much as possible while under glass and not permitted to break into leaf until they are put out of doors, which should be as early in May as the weather will allow. In fact their best place for the winter is in some dry cellar or shed, so that all their growth may be made in the open. There are many hardy kinds quite suitable for such treatment, among which may be mentioned $F$. coccinea, a graceful and freegrowing plant with beautifully-veined leaves and a profusion of crimson flowers; $F$. gracilis, a distinctly graceful plant bearing its flowers on long slender stalks; and $F$. globosa, with particularly globe-like flowers. It is quite easy to raise Fuchsias from seed, which, if sown in January or February, will produce plants ready to bloom in July or August. Of course such early sowing must be made in heat, and for the soil in which the seedlings are potted off a mixture of cow-dung is advised.

FUNKIA. A plant of the Lily order, many of the species producing fine spikes of flowers, though chiefly valued for their beautiful foliage. F. Sieboldi is, perhaps, the best in this respect, growing sometimes as much as 3 feet high and having large heart-shaped leaves with flowers of lilac hue rising above. $F$. lancifolia is a smaller species with lance-shaped leaves and has some interesting varieties in albo-marginata and undulata-variegata. All thrive best in well-drained soil and may be increased by division in autumn.

GAILLARDIA. Although among the varieties of this plant we find hardy perennials, half-hardy perennials, hardy annuals and half-hardy annuals, there is little doubt that the most convenient way, as well as the most successful, is to treat them as half-hardy annuals, sowing in a mild hot-bed early in March and planting out in May. The wonderful combination of shades of colour produced in the flowers of the Gaillardia-varying between gold and maroon, yellow and scarlet, crimson and gold, etc.- -render it a general favourite and most valuable for growing in bold groups, while as a cut flower it is highly decorative and lasts long. Among the many kinds which are good may be mentioned $G$. aristata and its varieties $G$. amblyodon and $G$. pulchella; while in the various hybrids there are $G$. grandiflora and grandiflora compacta, with others very similar. 


\section{LIST OF FLOWERS}

GALANTHUS (Snowedrop). No flower is more welcome in spring and none more valuable for its hardiness and early bloom. It will flourish in almost any soil, and is equally at home in the Rock Garden, the Spring Garden and the Wild Garden, or naturalised in the turf. There are many varieties and all are beautiful.

GALAX (Wand Plant). This is a charming little plant for the Rock Garden and will flourish without attention in moist, peaty soil. Its delicately-tinted evergreen leaf and wand-like flowers render it very attractive.

GALEGA (Goat's Rue). A hardy perennial of graceful form and bearing fine clusters of pea-shaped flowers, very effective when massed in groups for the Wild Garden. It may easily be grown from seed and will thrive in any soil, usually attaining a height of 2 feet or more. Two of the best kinds are G. officinalis, with flowers of pinky blue, of which there is also a white variety, and G. orientalis, with flowers of purplish hue.

GALTONIA (Cape Hyacinth). This flower (often catalogued under Hyacinthus candicans), with its fine spikes of white wax-like blossoms, is a valuable adjunct to the shrubbery or to a mixed border of tall plants such as Delphiniums, etc. It prefers a light soil, where it grows from 4 to 5 feet high, and flowers in late summer and autumn. The bulbs should be planted in November, and being quite hardy need not be lifted. For a succession of bloom the flowerspikes should be cut off as soon as they have faded.

GARDENIA (Cape Jessamine). A useful shrub for greenhouse cultivation and a general favourite by reason of its pure white, highlyscented flowers. G. florida is the variety that goes by the name of Cape Jessamine, and for its successful growth it requires good heat and plenty of moisture. Propagation is usually made by cuttings, but it may be raised from seed.

GAURA. The variety named Lindheimeri is that usually cultivated and may be treated as a hardy annual. It grows from 2 to 3 feet high and bears long, slender spikes of rose and white flowers.

GENISTA. See CyTisus.

GENTIANA (Gentian). For the Alpine and Rock Garden the beautiful little Gentians seem almost indispensable, and though the dwarf kinds, which are those most suitable for the Rock Garden, are less easily grown than the larger sort they need but a little care to establish them in healthy tufts. It should be borne in mind that as their natural habitat is often above the altitude where larger 


\section{A YEAR'S GARDENING}

vegetation will flourish they will not tolerate any overshadowing by taller plants; fresh air and sunlight are essential to their welfare. $G$. verna, the Vernal Gentian, is one of the most familiar, as it is one of the most beautiful of Alpine flowers. It likes a soil of sandy loam but cannot endure much drought, and will benefit, therefore, by a few pieces of broken limestone being so placed as to retard evaporation. G. Bavarica, the Bavarian Gentian, with its flowers of iridescent blue, is another lovely example. It demands a moist peaty soil-as bog-like as possible. G. acaulis and its variety alpina are both excellent for the Rock Garden, and the former will sometimes do well as a border edging. Gentians may be raised from seed by sowing in pans in spring and planting out.

GERANIUM (Cranesbill). The hardy Geranium which is a native of this country is a vigorous perennial, and some of its varieties are well worth cultivation in the garden. One of the best is $G$. armenum, growing from 2 to 3 feet high and flowering abundantly in any ordinary soil. A useful plant for the wild garden or shrubbery. $G$. ibericum, with its large, dark blossoms, and $G$. endressi, with its delicately-coloured light flowers, are also very good. Among the Alpine species $G$. cinereum and $G$. argentum are good varieties for the Rock Garden. All may be raised from seed. (See also Pelargonium.)

GERBERA. A perennial recently introduced from South Africa, and called indifferently the Transvaal or Scarlet Daisy, or the Marguerite of the Cape. In this country, except in our southern counties and in a warm situation, it is only half-hardy, but it seems well worthy of a place in our gardens. G. Jamesoni-from which, however, some beautiful hybrids have been raised-is at present the best example and is a wonderfully handsome plant with darkgreen leaves and large flowers, some 4 inches across, of brilliant scarlet, while the hybrids have flowers of more delicate colouring, such as pink, orange, yellow and almost white. They may be raised from seed.

\section{GERMANDER-SPEEDWELL. See VERONICA.}

GESNERA. A tuberous-rooted greenhouse plant with beautiful spikes of pendulous flowers. The hybrids have many shades of colour, scarlet predominating. The Gesnera may be raised from seed without difficulty, and though a perennial may, with advantage, be treated as an annual. Seeds sown in a rich soil and in moderate 208 


\section{LIST OF FLOWERS}

heat will produce flowering plants in about nine months. Even temperature and plenty of water are essential requisites for successful growth.

GEUM. A hardy perennial, of which there seem to be several named varieties of much similarity. Its brilliant scarlet flowers make it a showy plant, and it blooms freely, growing to a height of about 2 feet. It may easily be raised from seed by sowing in spring and transplanting in due course. There are some dwarf varieties, such as $G$. montanum and $G$. reptans, which are well suited for the Rock Garden.

GILIA. A hardy annual and one of the most effective of its class. It grows from I2 to I8 inches high, and its varieties include flowers of many colours-blue, lavender, purple, white, and whiteand-purple. A dwarf variety, which has been named dichotoma, is worthy of notice; it has fine foliage and a peculiar pearly-white blossom, and does not exceed 6 inches in height. For early summer flowering Gilia should be sown in autumn, while for late summer and autumn bloom the sowing should be made in April.

GLADIOLUS. In view of the attention which has lately been bestowed upon Gladioli, and all that has been written upon their cultivation for exhibition purposes, only a few remarks as to their general treatment need be made here. A light, friable loam, plentifully enriched with well-rotted manure, is the requisite soil, and the situation chosen should be fully open to the sun but sheltered from wind. The best time for planting is March and April, as the bulbs then planted produce flowers in August and September-obviously the best time for their display. But if early-flowering kinds are desired the bulbs should be set in November, and in that case they must be protected from the frost by a suitable litter. At the present time it seems unwise to dogmatise as to the best varieties, for the improvements have latterly been so rapid that many kinds which recently held a foremost place are now being superseded, and a recommendation as to the best and newest varieties can always be obtained from seedsmen of repute.

GLAUCIUM (Horned Poppy). One of the characteristics of this plant is that it will flourish on a poor soil-an undoubted recommendation when some arid bank has to be dealt with. It is of the Poppy family, sometimes classed as a hardy annual, but really a biennial, and should therefore be sown about May to provide vigorous plants for the following year. Much of its beauty is derived 


\section{A YEAR'S GARDENING}

from its handsome foliage of silvery white, and $G$. luteum has also the advantage of large orange-red flowers, while another variety called Asia Minor bears flowers of bright scarlet.

\section{GLOBE THISTLE. See ECHINOPS.}

GLOXINIA. There is little doubt that the best way of raising Gloxinias is from seed, as by this method not only can a fine strain be produced but also other new and different shades of colour, while a good selection can be made of plants with fine foliage, a feature which has now become distinctive of the Gloxinia. The best time for sowing is February and March, and a compost of fibrous loam is the most suitable soil. Seed should be sown thinly and very lightly covered with earth, and a daily sprinkling of water is desirable. Each seedling as it becomes large enough should be gently transplanted into a pot, and the process followed from day to day. A moist heat of about $60^{\circ}$ to $65^{\circ}$ will produce a rapid growth, but when the flowers begin to appear both temperature and humidity must be reduced. If it be desired to store the plants for the next season the supply of water should be gradually restricted until the leaves fall off, when the bulbs should be lifted and stored in a warm place, covered in cocoanut fibre or peat. There is an almost endless variety of shades and mixture of colours in the flower of the Gloxinia, ranging from the self-colours of crimson, rose, purple, violet, white, etc., to the tipped, ringed, shaded and spotted kinds, while in the form of the plant we have such varieties as giant, erect, drooping, etc. A single packet of seed obtained from one of our first-class seedsmen will produce an abundant variety.

GODETIA. Although this might rightly be placed under the heading of (Enothera (the Evening Primrose) it has now such an extended variety of its own that it is usually found in catalogues under the name of Godetia. It is a splendid annual, perfectly hardy, profuse in flowers of many distinct colours, and produces a fine effect when massed together in a mixed border. Seed should be sown in March or April for summer flowering, or in September for early flowering the following year. There are many varieties in the habit of the plant, from the miniature of 6 inches high with its flowers of glowing crimson (a valuable kind for border edgings) to the tall, white-flowered Duchess of Albany, growing to a height of 2 feet; while in colour the flowers range from pure pearly white to rich dark red, carmine, rose and spotted white-and-red. As the tall varieties are of robust growth it should be borne in mind, when massing them 


\section{LIST OF FLOWERS}

together for good effect, that they must be allowed proper room for development.

\section{GOLDEN ROD. See Solidago.}

GOURD. All who have seen a good collection of Gourds can scarcely fail to recognize how beautiful they are in form and tint and texture, and considering what effective use can be made of them on walls and trellises, on roofs and waste-heaps, it is surprising that they are not more generally cultivated. The varieties are very numerous and most of them can be grown in this country without difficultysuch as the Turk's Cap and its varieties, the Serpent. Hercules Club and the Giant's Punchbowel: while for miniature kinds there are the Fig, the Hen's Egg, the Bottle, the Orange, etc. Seed should be sown in a frame in April or early in May, care being taken to remove the lights whenever the weather permits as soon as the seedlings are established, lest they become thin and lank, and they should be planted out at the first favourable opportunity. A rich, moist soil will set them growing fast and vigorously, but even a poor soil, if kept well watered, will suffice for their needs.

GRAMMANTHES. A half-hardy annual of the Stonecrop family, and of which $G$. gentianoides is a useful plant for the Rock Garden. It grows in a compact tuft some 2 or 3 inches high, with a profusion of small orange-red blossom. It needs a warm, dry soil and makes a capital pot-plant for the greenhouse. From seed sown in heat early in March seedlings may be raised which may be successfully planted out in May.

GRAPE HYACINTH. See MUSCARI.

GYPSOPHILA. One of the best of this family is G. paniculata, a hardy perennial growing some 2 to 3 feet high and forming a tall bush with delicate branching stems bearing a profusion of little white flowers. G. elegans is a hardy annual, whose graceful, feathery sprays of white or mauve flowers are much used in bouquets. $G$. repens is of dwarf growth, suitable for the Rock Garden, with pretty foliage and persistent bloom.

HAWKWEED. See HiERACIUM.

HEATHS. See ERICA.

HEDYSARUM (French Honeysuckle). A free-growing hardy perennial but inclined to weedy habit. H. coronarium, which is not really a perennial though it practically becomes so by self-sowing, 


\section{A YEAR'S GARDENING}

is a showy plant growing some 3 feet high and bearing fine spikes of red or crimson or white flowers. There is also a dwarf kind- $H$. obscurum-growing about 9 or I2 inches high, a perennial with flowers of bright purple. Both may be raised from seed.

HELENIUM. A hardy autumn-flowering perennial, of vigorous growth and thriving in any ordinary soil. H. Hoopesi, with its bright orange flowers, is a variety which is generally recommended, as it blooms early; but $H$. grandiceps, with its massive head of bloom, and $H$. pumilum, a dwarfer kind, are as good as any. They may be raised from seed.

HELIANTHEMUM (Rock Cistus). A hardy perennial of dwarf evergreen character, but being compact in form and profuse in flower it is well suited for the Rock Garden. H. vulgare (the common Sun Rose), from which several varieties of similar character have sprung, is probably the most useful and varies in the colour of its flowers from white and yellow to many shades of red. It may be raised from seed.

HELIANTHUS (Sunflower). The Sunflower may be divided into two classes-the perennial (sometimes called Harpalium) and the annual, both quite hardy. The perennials are of such vigorous growth and increase so rapidly that they should not be introduced into a small garden without consideration, but in the Wild Garden, and in shrubberies and woods, they may be made very effective, being especially valuable because of their flowering in late autumn. $H$. decapetalus, a bushy plant some 4 or 5 feet high, with abundance of rich yellow flowers, $H$. giganteus, often attaining a height of ro feet, and bearing large flowers of deep yellow 2 or 3 inches in diameter, and $H$. rigidus, one of the best-known and flowering very freely, are all good examples. Of the annual sunflower there are many varieties -from the miniature kinds, both single and double, with flowers of many shades of yellow and various forms of petals, to the tall, largeflowered kind with their huge heads of bloom measuring some 18 inches across - giving abundant scope for choice.

HELICHRYSUM (Everlastings). Although this is usually classed as a hardy annual it is seldom successful when so treated, for being late in flowering it is more often than not cut down by the frost before it has attained its full colour. Treated as a half-hardy annual, however, by sowing in pans in the autumn and protecting it during the winter, it may be planted out early in spring and will mature its flowers before being nipped by the frost. $H$. arenarinm, 212 


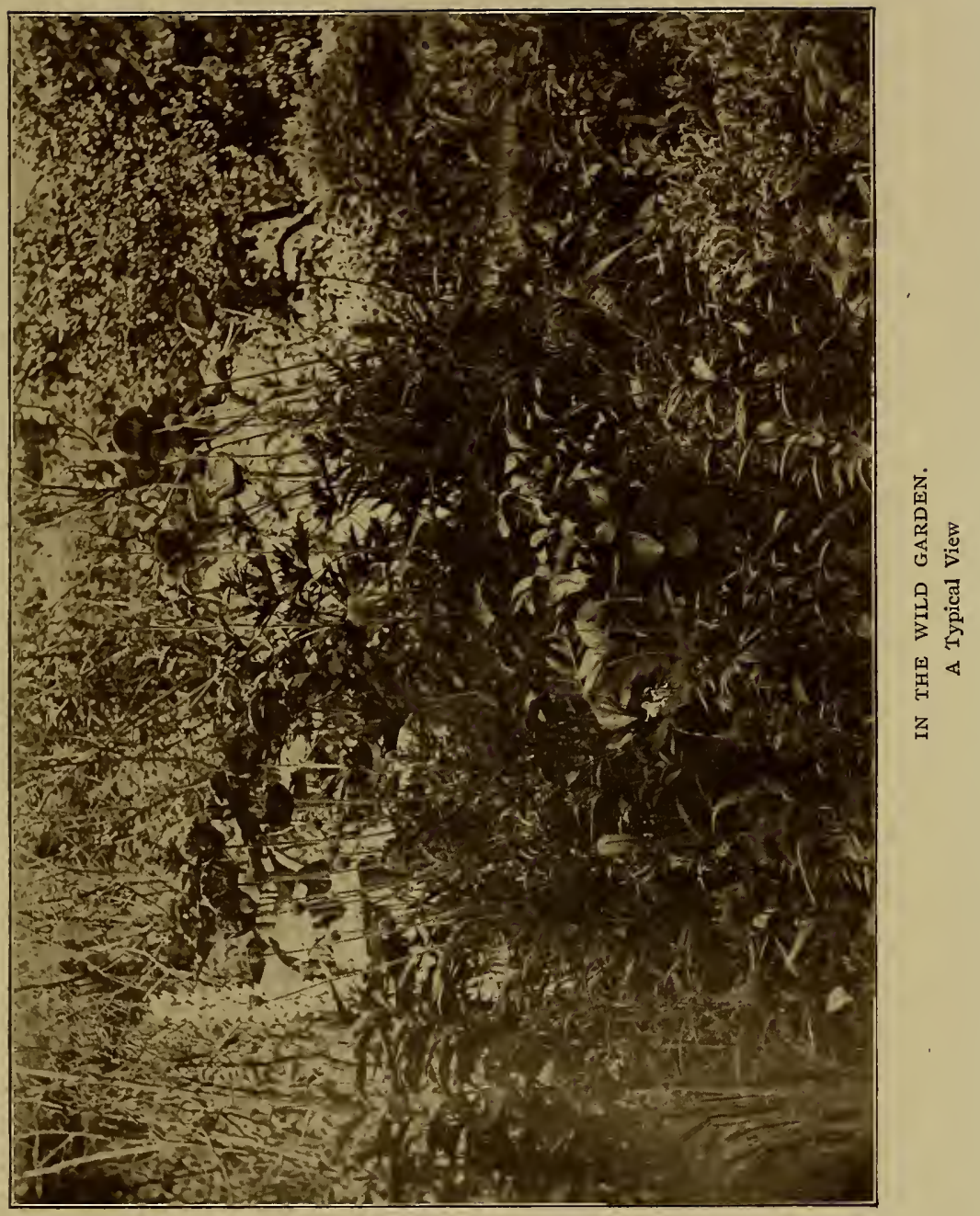





\section{LIST OF FLOWERS}

bracteatum, and macranthum are good varieties, and there are many colours-white, yellow, bronze, rose, crimson and scarlet.

HELIOTROPIUM (Cherry-pie). A half-hardy perennial, but more wisely treated as an annual, as by sowing in heat early in March the seedlings will be ready for planting out at the end of May. They need a good dry soil, and by their delightful fragrance and delicate tints of colour they are rightly highly esteemed. Many new varieties have been introduced from time to time, such as Roi des Noirs, a very dark shade, Anna Turrel, a beautiful light kind, and the White Lady, pure white; while the old-fashioned pervvianum still holds its own in the affections of most of us.

HELLEBORUS (Christmas Rose). A hardy perennial of much value in the garden, as it flowers in the open when little else is in bloom. $H$. niger is that which has for its bloom the well-known flower which bears the name of Christmas Rose, beautiful in its waxy-white and delicate blush tint; but we now have other varieties with blossoms of dark purple and ruby red, such as $H$. colchicus and $H$. abchasicus, and with foliage of marked beauty. All kinds are content with ordinary soil, but will do better in well-manured fibrous loam mixed with coarse sand, for stagnant moisture is not good for them. Propagation may be made by division, July being the best time, when the plants are in full vigour; and they may also be raised from seed sown under glass, the seedlings being pricked out into a shady border of rich soil as soon as they are large enough to bear moving. In the following year they may be transplanted to their permanent quarters, and by the third year they should bloom.

HEMEROCALLIS (Day Lily). For fragrance and beauty combined there are few flowers which compare favourably with the Day Lily. Most of the varieties can be cultivated with little trouble, while they all grow rapidly and are easily increased by division. $H$. Dumortieri is especially valuable for being perfectly hardy and blooming early; H. flava (the Yellow Day Lily) is also hardy, flowers profusely, increases rapidly, and is highly fragrant; while $H$. fulva and its many varieties, such as disticha, minor, and Kwanso (the Japanese Day Lily) are all well worth attention.

HESPERIS (Rocket). The old garden favourite known as Rocket is $H$. matronalis, a hardy perennial with sweet-scented spikes of purple or white flowers. It blooms freely and attains a height of about 18 inches, but to bring it to perfection it needs a rich moist soil, and even then is the better for division and transplanting into 


\section{A YEAR'S GARDENING}

fresh ground. Seeds should be sown in spring in a sunny situation and the seedlings transplanted in due course.

HESPEROCHIRON. A pretty little plant well suited for the Rock Garden, thriving in ordinary soil, of dwarf habit and bearing well-formed, violet-tinted white flowers.

HIBISCUS (Mallow). For most of this tribe our climate is not warm enough for open-air treatment, though $H$. coccineus is often cultivated as a flowering shrub for the conservatory, where its brilliant scarlet bloom makes a fine display. H. africanus is, however, fairly hardy when treated as an annual by sowing under glass in early spring and planting out in a warm border. It is a showy plant, growing about I8 inches high and bearing flowers of creamy yellow with purple markings. $H$. Trionum is also quite hardy as an annual and will often renew itself by self-sown seeds if the winter has been mild, while $H$. Syriacus, the well-known Rose of Sharon, grows vigorously in moist soils and has now many beautiful varieties, with flowers of every shade of colour, from white to blue, purple and crimson.

HIERACIUM (Hawkweed). A hardy annual growing some I2 to I8 inches high, with an abundance of pretty star-like flowers of white, yellow or red. One of its recommendations is that it will grow anywhere, but naturally it is rather weedy in character.

HOLIYHOCK. See AlthæA.

HONESTY. See LUNARIA.

\section{HONEYSUCKLE. See LONICERA.}

\section{HOUSELEEK. See SEMPERVIVUM.}

HUMEA. A half-hardy biennial with large, graceful leaves possessing an aromatic odour, and bearing a feathery blossom of russet hue. It makes an elegant plant for the conservatory and its sprays are useful for cutting. Seed should be sown in summer (July or August) and potted off in due course for flowering the following year. During winter the plants should be watered with liquid manure and in spring transplanted into larger pots of rich soil.

HUTCHINSIA. A pretty little rock plant well suited for the Alpine or Rock Garden. $H$. petrcea is found wild on limestone rocks in the west of England and in Wales, and H. alpina is a still smaller plant, with shining leaves and clusters of white flowers. It grows freely in sandy soil and is easily raised from seed. 


\section{LIS'T OF FLOWERS}

HYACINTH (Feather, Grape, Italian, etc.). See MuscarI.

HYACINTHUS. The Hyacinth is quite hardy, and a good display may be obtained in the open garden without any difficulty, unless the spring weather be unusually wet and boisterous; wind and rain, not frost, are the deterrents to its successful blooming. It will thrive in any ordinarily good soil, but a well-drained, rich sandy loam is what it prefers, and a cold water-logged soil is almost fatal to it. The bulbs for outdoor blooming should be planted early in the autumn with as much as 6 inches of soil to cover the crowns; for though a shallower planting may ensure an earlier bloom the flowers are stronger and fuller for deep planting. In the case of a severe frost occurring it is advisable to protect them with a covering of dry litter or half-rotten manure. After blooming the plants should be allowed to remain in position until the leaves have withered, whe. the bulbs may be lifted, dried in the sun for a short time, and, after removing the offsets, may be stored in dry sand or cocoanut fibre until the next planting time comes round. To obtain the best effect from a bed of Hyacinths they should be massed close together, and it may be wiser to plant the bulbs at 6 inches from each other, and restrict the area planted, rather than attempt to fill a larger space by planting them farther apart. Selections of distinct colours, in various shades of white, red and blue, either in the single or double form of flower, may be obtained, and in making choice it is well to bear in mind that the quality of a bulb can generally be determined by its density - a sound and prolific bulb is both hard and heavy. Finally, it may be permissible to advise that the single varieties among Hyacinths be not neglected, as in them are retained more freedom and elegance than is generally found in the double kinds.

\section{HYACINTHUS-CANDICANS. See Galtonia.}

HYDRANGEA. A handsome flowering shrub, valuable both for the garden and the greenhouse. It thrives best in a warm, moist climate, such as may be found on our southern and western coasts, while in the island of Madeira it is seen to perfection. $H$. Hortensia is the common Hydrangea of the garden and embraces many varieties, such as acuminata, a sturdy, well-formed plant with blue flowers; japonica, very like acuminata but with flowers tinged with red; communis, with pink flowers; and stellata, with rosetinted flowers turning to a greenish hue. H. paniculata should also be mentioned for its fine heads of white flowers, borne in dense panicles of about a foot long and remaining in bloom for a long time. 


\section{A YEAR'S GARDENING}

HYPERICUM (St John's Wort). A low-growing, trailing shrub which is often valuable for covering wild banks or the borders of shrubberies. $H$. calycinum (the Rose of Sharon) is one of the most useful varieties, as it will thrive in shade even when subjected to the drip of trees. H. Moserianum is a handsome hybrid, bearing large yellow flowers rich in colour and substance; while for the Rock Garden $H$. olympicum, a low-growing variety, with bright yellow flowers some 2 inches across, will be found useful, to which may be added $H$. mummularium and humifusum.

IBERIS (Candytuft). Either as a perennial or an annual, in the Rock Garden or the mixed border, this plant is well worth cultivation. Most of the varieties are quite hardy, thrive in any soil, and may easily be raised from seed. Among the perennials $I$. correcefolia is excellent, bearing fine heads of large white flowers; $I$. Gibraltarica is a beautiful plant with flowers of delicate lilac, but its hardiness is doubtful; while $I$. petraa is an Alpine species, its clusters of white flowers relieved by a tinge of red in the centre. The annuals are represented by $I$. umbellata and its varieties nana rosea and nana $a l b a$, in which there are many colours-white, crimson, lilac and purple. All are quite hardy and are therefore best sown in late summer for early flowering in the following year; with a good soil and plenty of room for development they can scarcely fail to succeed.

IMPATIENS (see also under BALSAM). In addition to the halfhardy Garden Balsam there is the hardy annual which may often be seen in cottage gardens, renewing itself from year to year by seed self-sown. It is a sturdy plant, attaining a height of 4 or 5 feet, and is apt to intrude itself where not wanted, but in the Wild Garden it is very welcome. I. glandulifera and longicormu are two good kinds, abundant in flowers varying in colour from white to rose.

INCARVILLEA (Trumpet Flower). A handsome perennial with large Gloxinia-like flowers, trumpet-shaped and borne on long stems. The plants are large-rooted and require deep, rich, welldrained soil. I. Delavayi is an excellent variety and is quite hardy in any but very cold and wet situations. It is of vigorous growth, with large, dark-green, fleshy leaves some 18 inches long, and with fine flowers of crimson-purple veined with yellow. I. grandiflora is another variety-a smaller plant with shorter leaves but larger flowers of beautiful carmine colour, relieved by blotches of white in the throat. Both varieties may be raised from seed without difficulty, the first flowering in the second year from sowing but the latter needing three, or even four, years of growth before blooming. 216 


\section{LIST OF FLOWERS}

INDIAN HEMP. See CANNABIS.

INDIAN MALLOW. See ABUTILON.

INDIAN POPPY. See MECONOPSIS.

INDIAN SHOT. See CANNA.

INULA. A hardy perennial easily raised from seed but not of much value as a border plant, though well suited for covering rough banks and for patches in the Wild Garden. I. glandulosa, bearing fine yellow flowers 4 to 5 inches in diameter, is the usual variety, but there are other kinds, such as royleana and grandiflora, which are as good or better.

IONOPSIDIUM (Violet Cress). For the Rock Garden I. acaule is a charming little plant. It is quite hardy, dwarf in its growth (about 2 inches high), and although classed as an annual its pretty tufts of lilac-coloured flowers spring up year by year from self-sown seed. It seems as if it would grow anywhere, and yet is always careful not to intrude upon its neighbours.

\section{IPOMÆA. See Convolvulus.}

IRIS. This plant may be divided into two groups, the bulbous and the non-bulbous (rhizomatous). Among the latter is $I$. Germanica, the Flag or German Iris, which in its many varieties will flourish in almost any soil, and of which the following are good examples: Black Prince, with large, fragrant flowers of light and dark purple and yellow markings; Mme. Chereau, having white flowers tinged with soft blue; and Pallida dalmatica, a fine variety, with tall stems of delicate blue flowers and splendid foliage. The bulbous kind are well represented by $I$. xiphioides, the English Flag, and by $I$. xiphium, the Spanish Iris. Both of these are handsome plants, the English Iris having many varieties of colour-white, lavender, blue, purple and striped; while the Spanish Iris includes white, blue, yellow and striped. They like a light, well-drained soil and a warm, sheltered situation, but plenty of sunlight is their chief desideratum, while their next is that they shall not be disturbed. These are also requisites for the choicer sorts of bulbs, such as $I$. reticulata, I. alata, and $I$. persica, all of which are valuable examples, especially $I$. reticulata, which produces a wealth of fragrant flowers most useful for cutting.

ISOPYRUM. The variety called thalictroides is a pretty little white-flowered plant with beautiful fern-like foliage, valuable for 


\section{A YEAR'S GARDENING}

the Rock Garden. It is easily grown from seed and will thrive in any soil.

IXIA. This is a bulb which is well worth cultivating either in the greenhouse or the open garden, for though the plants are a little tender they will often make a good display in a warm, wall-backed border of southern aspect. For early flowering the bulbs should be planted in September or the beginning of October, in a light, welldrained soil, and some protection from the frost, such as a covering of bracken-litter, should be given as soon as the new growth appears. There are several species-crateroides, ochroleuca, speciosa, viridiflora, etc.; and viridiflora should certainly not be overlooked, as its flowers are of a wonderful metallic green-very unusual.

JACOBEA. See SENECIO.

JACOB'S LADDER. See Polemonium.

JASIONE. The variety called humilis is a pretty little creeping plant well suited for the Rock Garden and bearing tufts of bell-like blue flowers. It is a perennial, but often needs a little protection in winter, and should be accorded a sheltered, well-drained spot. $J$. montana is a hardy annual variety, and both are best raised from seed.

JASMINUM. There are three kinds of Jasmine which will be found useful plants- $J$. officinale (White Jasmine), $J$. nudiflorum (Winter Jasmine), and $J$. fruticans (Shrubby Jasmine). The first is an old inhabitant of our gardens, and though a native of India is quite hardy and will thrive even in towns on a warm, sandy soil. Being a rapid grower, it makes one of the best of climbing plants, and its sweet-scented white flowers are delightful. The Winter Jasmine is also perfectly hardy, and against a good background, such as Ivy, its fragrant yellow flowers appearing in winter on its leafless stems are very charming. $J$. fruticans is a compact evergreen shrub bearing an abundance of small yellow flowers which later give place to round black berries.

JONQUIL. See NARCISSUS.

KAULFUSSIA. See Amellus.

KNIPHOFIA (Torch-flower). The brilliant colouring of the scape of this flower poised upon its upright stem makes its colloquial name of Torch-plant or Flame-flower very appropriate. $K$. aloides, or Tritoma Uvaria as it is sometimes called, is the kind which so often forms a glory in the cottage garden; it is a noble plant for the border $2 \mathrm{I} 8$ 


\section{LIST OF FLOWERS}

and will thrive in any soil, flowering late in summer and lasting for many weeks. A long-continued frost is dangerous to it, but a covering of dry litter over the crowns will generally preserve it, even in a hard winter. Some beautiful hybrids have recently been raised in which the predominating colour is yellow, ranging from that to orange and scarlet. Among them is the Obelisk, vigorous and broadleaved, with spikes of pure golden yellow; the Ophir, orange-yellow and blooming freely; and the Matador, with unusually large spikes of deep red.

LACHENALIA. These bulbs are very useful for greenhouse decoration and may be made most effective by planting them on the outside of hanging baskets, where their flower-spikes will grow upwards and their leaves hang down. They do well in a peaty soil if kept thoroughly moist, and will flourish in a cold house so long as the frost is not allowed to intrude.

\section{LADY'S SLIPPER. See CYPRIPEDIUM.}

LANTANA. A half-hardy perennial which is useful as a summer bedding plant, bearing heads of bloom something like the Verbena, but smaller. The flowers are of many colours-white, yellow, orange and crimson-and the plants bloom freely throughout the summer. Though they cannot be raised in the open they are easily propagated in the greenhouse, either from seed or cuttings, in the early spring. There are many named varieties, and among the best are Don Calmet, Eclat, La Neige and Ne Plus Ultra.

\section{LARKSPUR. See DELPHINIUM.}

LASTHENIA. A hardy annual which may be used to good effect if sown in compact patches and afterwards thinned out. Autumn sowing is the best, as it then blooms early the next year. The two varieties, L. California and L. glabrata, are both good, the first being of dwarf habit, growing about 6 inches high with bright yellow flowers, and the latter being from 9 to I2 inches high with rich orange-yellow bloom.

LATHYRUS (Everlasting Pea). This perennial is valuable as a climber, being vigorous in growth and abundant in long-lasting bloom, while its long succulent roots will provide themselves with nourishment for years without requiring attention. The gardener's care should be to let the plants grow freely and naturally, and an excellent effect may be obtained by allowing them to trail on a rough bank, untrained in any way. L. latifolius is one of the hardiest of 


\section{A YEAR'S GARDENING}

the tribe and seems able to thrive anywhere, and its white variety, L. latifolius albus, is a beautiful specimen. L. Sibthorpi, with its reddish-purple flowers, is valuable for its early blooming, while $L$. grandiflorus is a double-flowered kind, bearing large, handsome blossoms of rosy-purple. L. rotundifolius, with round-shaped leaves (as its name indicates) and fine clusters of rose-pink flowers opening early in June, is also excellent.

LATHYRUS-ODORATUS (Sweet Pea). There is little wonder that the Sweet Pea is such a universal favourite-its hardiness, its long-continued and prolific bloom, its manifold beauties in colour and form, and the readiness with which it lends itself to indoor decoration as a cut flower all combine to make it pre-eminent among annuals. Its culture requires no special knowledge, no unusual soil; it seems ever ready to do its best anywhere and under any circumstances-even in a prolonged drought. An ordinary garden soil, well dug in the autumn and enriched with a fair amount of manure, a little forking and pulverising of the ground in the spring, is all the preparation needed for sowing, and with some protection against slugs and snails and birds a bounteous crop may be relied upon; while to maintain a continuance of bloom it is only necessary (but this is imperative) to cut the flowers day by day and never permit a single seed-pod to be formed. As to the best arrangement in sowing, opinions vary; some advise clumps of three or four plants, others favour a row, and certainly a hedge of Sweet Peas is an attractive sight. But whatever the form adopted it is important to provide the young plants at an early stage with well-branched sticks of good height-say, 6 to 8 feet. For obtaining early bloom the practice of sowing in late autumn is often adopted, but its success is largely dependent upon the severity of the winter, and a more certain plan is to sow indoors about the middle of February, gradually hardening the young seedlings and planting them out as early in April as the weather permits.

LEIOPHYLLUM. For the Rock Garden L. buxifolium is very useful. It is a dainty little shrub from 4 to 6 inches high, with deepgreen leaves and clusters of small white flowers which as unopened buds are of a delicate pink hue. It likes a peaty soil and is not afraid of drought.

LEONTOPODIUM. L. (Gnaphalium) alpinum is the well-known Edelweiss, a pretty little Alpine plant with furry leaves and flowers of pale yellow encrusted with a white, woolly substance. It thrives 


\section{LIST OF FLOWERS}

well in a sandy soil in the Alpine Garden, but will not bear crowding or overshadowing.

\section{LEOPARD'S BANE. See DoRONICUM.}

LEPTOSIPHON. A hardy annual which is well worth cultivation, and of which there are some pretty dwarf varieties suitable for the Rock Garden. Thin sowing in light soil and in the early autumn is advisable for obtaining robust plants of sufficient size to endure the winter; spring sowing is not likely to succeed so well. $L$. roseus is a charming little plant with dense tufts of rosy-pink flowers, and there are several beautiful hybrids of various shades of colour. The larger kinds, such as L. densiflorus (both blue and white) and L. androsaceus (lilac), are quite attractive.

LEPTOSYNE. A useful plant for the mixed border and bearing some resemblance to the Coreopsis. $L$. Stillmanni is a showy example with bright golden-yellow flowers, blooming abundantly. It is classed in some catalogues as a hardy annual, but in common with other varieties of the Leptosyne it is more wisely treated as a half-hardy annual by sowing in heat early in spring and transplanting into the open in May. L. Douglasi is similar to L. Stillmanni, but is a smaller plant (about I foot high) with flowers rather larger, while L. maritima (a perennial, but best treated as a half-hardy annual) is still smaller-about 6 inches-and also bears bright yellow flowers.

LEUCOJUM. The most useful variety is L. astivum, sometimes called Summer Snowflake, a vigorous plant with clusters of white flowers, delicately tipped with green, gracefully hanging on stalks from I2 to I8 inches high. It blooms in early summer or late spring and will thrive in ordinary soil. As its bulbs increase rapidly it is easily propagated by division, but its flowers are certainly most effective when allowed to remain in dense groups. Another variety is L. vernum (Spring Snowflake), of dwarf growth, about 6 inches high, well suited for the Rock Garden and flowering early, but slow in establishing itself, though once it has taken good root it flowers freely.

LEWISIA. A crevice in the Rock Garden with some gravelly soil where its succulent roots can obtain moisture is just the place for $L$. rediviva, an interesting little plant only an inch or so high with large flowers varying from white to deep rose. Its moisture-retaining roots enable it to revive (as its name indicates) when apparently dead, and if, after flowering, it looks like a mere withered mass it 


\section{A YEAR'S GARDENING}

should not be thrown away. It needs plenty of sunshine to bring its blossoms out properly, and its crown should be kept dry though its roots love moisture.

LIATRIS. A perennial which may be considered hardy and which becomes very effective under good cultivation. L. elegans, when grown in rich light soil, will attain a height of about 2 feet and bear large spikes of flower a foot or more in length, of a delicate lilac or pale purple colour; while L. spicata, a somewhat smaller plant, has beautiful spikes of a carmine tint and preserves its bloom for a long time. L. pycnostachya is the tallest of its tribe, growing as much as 4 feet high, and bears handsome flower-spikes of deep purple. All may be raised from seed sown in spring or propagated by division.

LILIUM. All Lilies are beautiful but all are not adapted to the same kind of culture, and among the manifold varieties it must suffice for these notes to mention a few names representative of both outdoor and indoor culture. As a stately and graceful inhabitant of the garden none is better than $L$. candidum, the Madonna Lily of the cottage garden, where its snow-white blooms and exuberant foliage may often be seen to perfection. Capricious it may be in finding a spot to its liking, but when once established it requires no attention beyond an occasional mulching of ordinary manure, and it thrives best when left undisturbed, as many an old garden can testify. The nature of the soil in which it is placed seems of secondary importance so long as it has a sunny aspect and is sheltered from the wind. Other kinds which will do well in the garden and will thrive in ordinary soil are the Bulbiferum, about 2 feet high, with flowers of orange-red; Chalcedonicum (Scarlet Turk's Cap), about 3 feet high; Testaceum, some 5 feet high, with buff-coloured flowers; Humboldti, also about 5 feet high, with flowers of pinky-yellow spotted with dark red; and the well-known Tiger Lily, especially its variety called Splendens, which is of fine growth, often 7 feet high, and bears magnificent flowers, though blooming rather late. Among those that are suited for indoor culture in pots are Wallichianum, Lowi primulinum, Auratum and Longiflorum. For soil, good turfy loam mixed with sand (sea-sand, if possible, as it retains moisture) make an excellent compost, and the bulbs should be planted in pots about two and a half times their diameter, and covered with some 2 inches of soil. They may be left in a cold frame until well rooted, but when brought into the house they should be carefully watered, for to allow a full-rooted pot to get dry would seriously endanger the plant. 


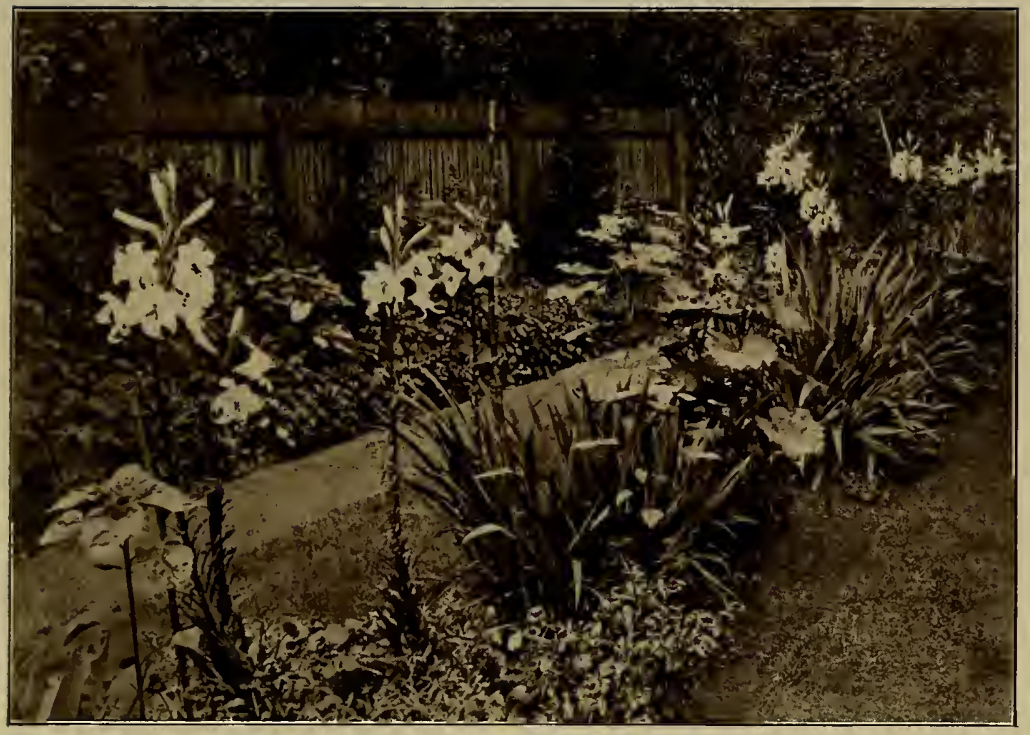

IN A SUBURBAN GARDEN.

Madonna $I_{\text {,ilies. }}$

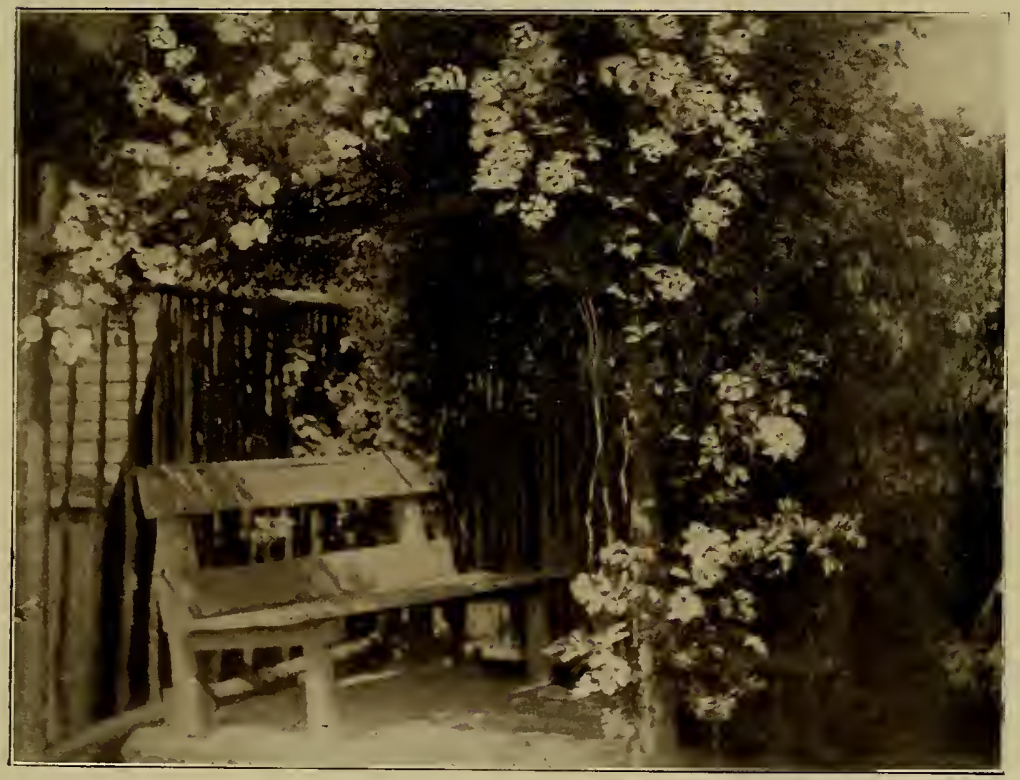

IN A SUBURBAN GARDEN.

Euphrosyne Rose over Arbour. 



\section{LIST OF FLOWERS}

After flowering the pots should be placed outside in a shady border until the foliage has quite died down, when the bulbs may be stored for the winter in a dry outhouse.

\section{LILY OF THE VALLEY. See Convallaria Majalis.}

LIMNANTHES. For a vigorous hardy annual, able to take care of itself and thrive in a poor soil, there is none better than $L$. Douglasi. It is of dwarf habit, only about 3 or 4 inches high, and if sown in autumn brings forth its white and yellow flowers (or pure white, if that variety be chosen) early in May, while it is delightfully fragrant and is a fine bee-plant. For summer flowering, seed should be sown in spring; in light soils it will generally sow itself and practically become a perennial.

LINARIA (Toad-flax). A hardy family which includes both annuals and perennials, varying from little Alpine plants of a few inches high to tall plants like giant Lobelias. Of the dwarf kinds $L$. alpina and $L$. antirrhinifolia are both very good. The alpina forms charming silvery tufts of foliage, with dark blue and deep orange flowers, and, by sowing itself, often becomes a perennial in the crevices of the Rock Garden. The antirrhinifolia does not spread so rapidly, but is prolific in a constant succession of bright purple flowers, and is also a charming plant for the Rock Garden. L. cymbalaria is that pretty little plant known by the name of Mother of Thousands, which may often be seen growing in dense and graceful pendants from the top of an old wall or falling all over its pot in a cottage window, and bearing a profusion of white or lilac flowers. L. dalmatica is a hardy perennial, a handsome, well-branched plant of 3 to 4 feet high, bearing large flowers of sulphur-yellow or orange colour.

LINUM (Flax). A family which includes several useful plants for the garden, some of them being perennial but better treated as annuals. L. grandiflorum is both hardy and showy, and by sowing in autumn as well as spring a succession of bloom may be had throughout the summer; there are two varieties, one with deep scarlet and the other with bright rose flowers. L. narbonnense is also very good and gives a copious supply of large light blue flowers, beautifully veined, if the plant is well nourished in a light soil. $L$. favum is a smaller but hardy plant with flowers of a peculiarly soft hue of yellow.

LITHOSPERMUM. Of the many varieties of this family there is but one which is of much value for the garden, viz., L. prostratum. 


\section{A YEAR'S GARDENING}

It is a pretty little evergreen, low-growing (as its name indicates) shrub, bearing a profusion of flowers of intense blue, delicately striped, and on a sandy bank or in the Rock Garden, with a little coaxing by judicious application of manure, it will soon develop into a fine spreading mass a foot or so high. It is easily propagated by cuttings.

LOBELIA. This popular plant may be roughly divided into three classes - the compact or dwarf kind, the free-growing, spreading kind, and the tall perennials. It is the dwarf kind which is chiefly used for " bedding out," being sown in winter under glass and transplanted into boxes for further growth until sufficiently established for sale when the " bedding-out " season arrives, while in the same way the spreading varieties are raised for filling hanging baskets and providing edgings for window-boxes. Various shades of blue as well as white may be had in both these kinds, catalogued under such names as Crystal Palace Compact, Emperor William, Pumila Grandiflora and Magnifica, Prima Donna (a red variety), Speciosa Alba, Speciosa Paxtonia, etc. Fine examples of the tall perennials are found in $L$. splendens, L. syphilitica, and L. cardinalis, and they are very valuable for the garden as autumn flowers. But they are only fairly hardy, and except in warm districts they need some protection during the winter, being injuriously affected by moisture in cold weather. For that reason it is generally wise to lift them after flowering and store them in a dry outhouse or frame, though they may sometimes be sufficiently protected by covering the crowns with a mound of ashes. They need a rich, free soil and plenty of water during the summer; in fact $L$. cardinalis (perhaps the least hardy of the three) is naturally a marsh-growing plant.

\section{LONDON PRIDE. See SAXIFRAGA.}

LONICERA (Honeysuckle). The Honeysuckle is chiefly useful in the garden as a climber, though there are some good bush kinds, such as L. fragrantissima and L. Standishi, in both of which the flowers, if small, are abundant and beautifully fragrant. Among the climbers $L$. sempervirens (the Trumpet Honeysuckle) may perhaps be said to bear the palm, though not quite hardy enough to endure the winter without some protection in cold districts. All through the summer it bears fine clusters of long, trumpet-shaped flowers, which are almost scarlet inside and delicate yellow within, while in addition to being a vigorous climber it will remain evergreen in a warm situation. L. japonica (Japan Honeysuckle) is perfectly hardy and retains its leaves of deep, shining green throughout the 224 


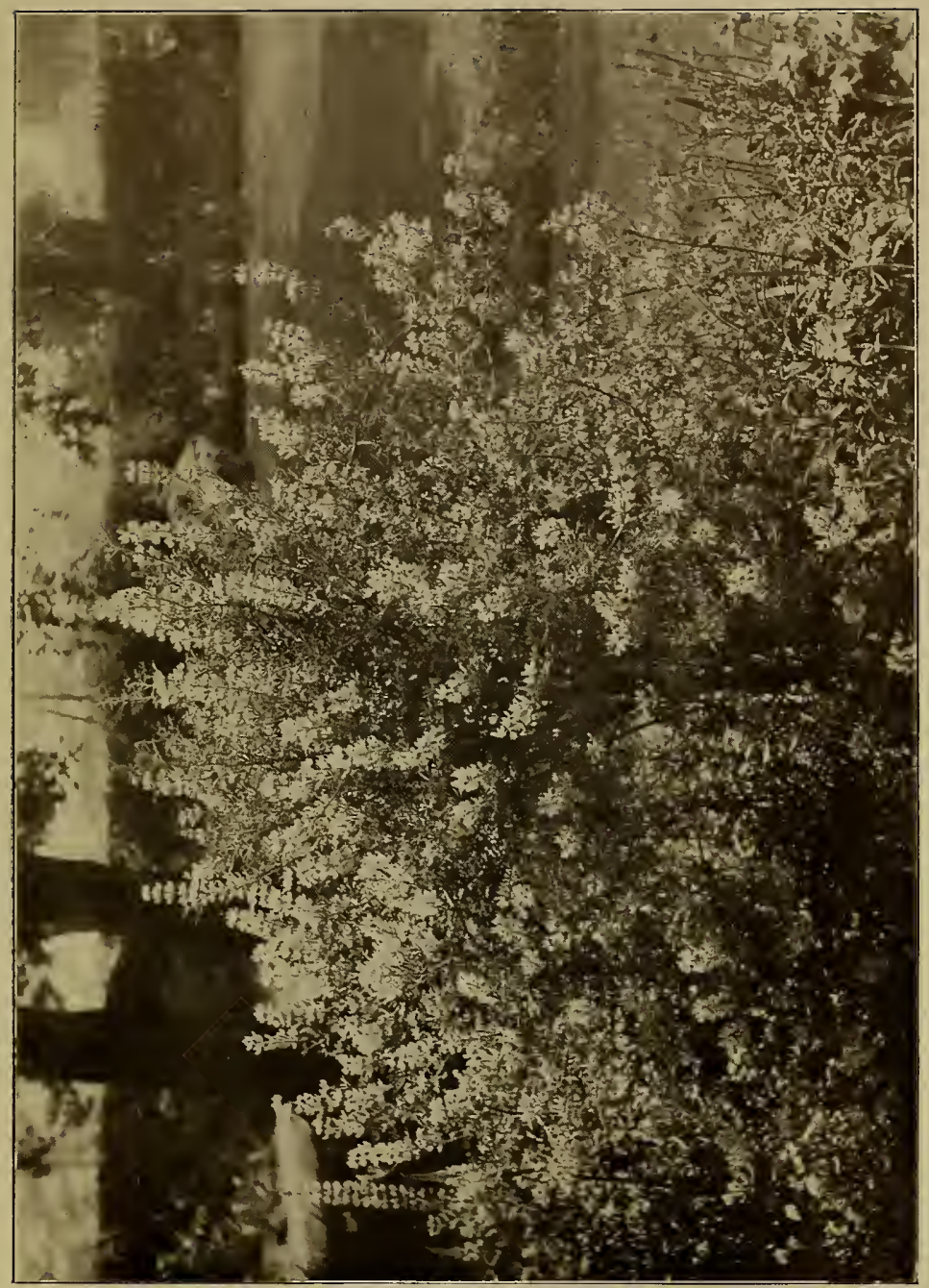

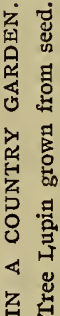





\section{LIST OF FLOWERS}

winter, while from the middle of summer to the beginning of autumn it is covered with sweet-scented slender flowers, white, tinged with red. L. periclymenum, the Woodbine, the native Honeysuckle of England, has several cultivated varieties which are valuable in the garden; such as serotina, which continues long in flower, and belgica (Dutch Honeysuckle), which is a very strong-growing plant.

\section{LOOSESTRIFE. See LYTHRUM.}

\section{LOVE-LIES-BLEEDING. See AMARANTHUS.}

LUNARIA (Honesty). A charming old-fashioned plant-a biennial-very useful for the Wild Garden or for rough banks, where its white or purple blossoms and flat silvery seed-pods may be made very effective; while if the branches bearing these seed-pods be cut at maturity and dried in the sun they form excellent indoor decoration. Seed should be sown in spring or early summer and the seedlings thinned out so as to ensure strong plants for the following year. Its natural soil is chalky ground, but it is perfectly hardy and will thrive almost anywhere.

LUPINUS (Lupine). As a hardy annual the Lupine is a most useful flower, having a large range of colour and being quite easy of culture, while the perennial and tree kind are valuable for the Wild Garden and for rough, sandy banks, as they will thrive in a poor soil. Among the annuals the hybrid $I$. atrococcineus is, perhaps, the finest, and its long spikes of bright red flowers tipped with white are both showy and graceful, while L. subcarnosus, with its flowers of beautiful blue, should not be neglected. Other kinds which have some individuality are L. luteus, mutabilis and Menziesi, while many of the smaller sorts which are named in catalogues are charming. Of the perennials $L$. arboreus (Tree Lupine) is excellent and its scent delightful; the yellow variety is the best, forming a fine bush of two or three feet high and easily raised from seed or by cuttings. $L$. polyphyllus is a handsome plant, tall and hardy, with fine spikes of flowers varying in colour from blue to purplish-red or with a mixture of purple and white, and it has several good varieties.

LYCHNIS (Campion). A family of hardy perennials, one of which-L. floscuculi-is the Ragged Robin found abundantly in our hedges and ditches, and of which there are two double varieties in cultivation. L. chalcedonica is a good border plant growing trom I8 inches to 2 feet high and bearing large dense heads of br.ght scarlet flowers; there is a white variety, but it is not so good. L. grandiflora 


\section{A YEAR'S GARDENING}

is a handsome plant (with several varieties) bearing fine clusters of large flowers with fringe-like edgings and varying in colour through many shades of red to white. All are somewhat susceptible to cold and damp, but do well in a warm situation and on a light soil. They may be raised either from seed or cuttings and are considered to be improved by occasional transplanting. In addition to the above there are several worth attention, especially L. Lagasca, a charming little plant for the Alpine garden, profuse in flowers of a bright rosecolour. Like most Alpine plants it needs plenty of sun and it thrives best in a sandy soil. It is easily raised from seed.

LYTHRUM (Purple Loosestrife). A common waterside plant, of $_{\text {shich }}$ the cultivated variety, roseum superbum, will be found useful for growing in moist or boggy ground, where its finelycoloured large spikes of flowers are very effective.

MALLOW. Under this name may be included the Malope grandiflora, a hardy annual from 2 to 3 feet high, and of which there are some showy varieties with white, crimson or rose-coloured flowers; and also the Musk Mallow of the Malva tribe, of which the white variety is the best, being a hardy perennial thriving in any soil and growing into a well-branched bush with flowers giving out a faint odour of musk.

MARGUERITE. The name which is commonly applied to the Chrysanthemum frutescens, a half-hardy bushy perennial (with large white flowers and yellow centre) from which an enormous number of varieties have been derived, most of which may be treated as annuals by sowing in spring-under cover for early flowering or in the open for later bloom. Sowings may also be made in the greenhouse in September for flowering in the spring. Among the annual kind some of the single varieties are very charming, such as that called Morning Star, with flowers of a delicate sulphur-yellow; Purple Queen, with distinctive flowers of dark purple; and Sultan, with flowers which are almost crimson; while for the double-blossomed variety there is none better than the Dumnetti strain.

MARIGOLD (Cottage, French and African, Marsh). See CalenDULA, TAGETES and CALTHA respectively.

MARTYNIA. A half-hardy annual, of which $M$. lutea, with its handsome foliage and large clusters of yellow flowers, is useful for border groups; while $M$. fragrans, with fine purple blossoms sweetly scented, is another good variety. Both may be raised from seed 226 


\section{LIST OF FLOWERS}

sown in heat in spring, the seedlings being duly pottcd off and planted out in rich soil.

\section{MARVEL OF PERU. See Mirabilis.}

MATHIOLA. In most gardening books this name is confined to the Night-Scented Stock, and though from the Mathiola all the Ten-Week, Intermediate and Brompton Stocks (not the Virginian Stock) have been derived, they are referred to in these notes under the name of Stock. $M$. dicornis or odoratissima is that which is commonly named the Night-Scented Stock, and is a hardy annual, easy of culture and sending out a delightful perfume which permeates the still evening air for a long distance. It is, however, an insignificant-looking plant and comparatively scentless during the day.

MECONOPSIS (Indian Poppy). The common Welsh Poppy $(M$. cambrica) is a member of this family and is a hardy perennial, but the kinds most useful for the garden are biennials-hardy, but requiring two years to bring them to good flowering plants. Seed should be sown about March in a frame, and the young plants kept well watered, with the frame-lights removed, throughout the summer. By the following May or earlier they should have become fair-sized plants and should then be transplanted, with as much soil as possible, to the border where they are intended to flower. A good welldrained soil is essential to their welfare as any cold moisture is injurious to them, though they need plenty of water during the summer. There are many varieties well suited for the Rock Garden, such as $M$. Wallichi, a fine plant between 4 and 5 feet high, of erect growth and bearing dainty blossoms of pale blue, peculiarly graceful in the manner in which they hang from their slender stems. Another beautiful kind is $M$. aculeata, with large purple flowers and bright yellow stamens poised on stems some 2 feet high; while for the Wild Garden $M$. cambrica, the Welsh Poppy above referred to, is most useful, as it needs no special care and will hold its own in almost any situation.

MERTENSIA. The handsomest of this family is $M$. virginica, the Virginian Cowslip, which comes into bloom in April or early in May and bears charming clusters of lavender-blue flowers drooping from stems I2 or I8 inches high. But it is a little difficult of culture and needs a moist, peaty soil and a sheltered position. $M$. sibirica, though generally classed as a hardy perennial that will grow in ordinary soil, also thrives best in moist peaty soil, but it is well worth cultivating for its beautiful clusters of small bell-like flowers, the 


\section{A YEAR'S GARDENING}

colour of which is at first a delicate pink, deepening into blue as the bloom matures. $M$. maritima is a native of our sea-coasts, and with a suitable soil-light and sandy-and a sunny situation it ought to do well in cultivation and display its pretty blue flowers from year to year. Besides these there is a dwarf kind, $M$. alpina, suitable for the Alpine Garden, growing from 6 to 8 inches high and blossoming in early summer into clusters of light blue flowers.

MICHAELMAS DAISY. Under this name is commonly known the perennial Aster or Starwort, a hardy, bush-like plant which may well find a place in our gardens, not only because of the beauty of form and colour which the many varieties display, but also because of their blooming so late into the autumn. The best effect of the plants is often lost through the mistake of tying them up in bundles against a stake, instead of allowing them to grow in masses and support each other. The following are a few of the best kinds: Aster acris, amellus, cordifolius, turbinellus, umbellatus and grandiflorus; besides which there are many beautiful varieties in the Novi Belgi and Nove Anglia types. All may be raised from seed by sowing in pots or pans in autumn; the seedlings should be ready for planting out in the spring and flower the following autumn.

MICHAUXIA. The $M$. campanuloides is usually classed as a hardy biennial, but it does not thrive well except in a warm and sheltered position, though in a suitable situation it will often continue to flower for the third or fourth year; more wisely, however, it should be sown every year. It is a tall and stately plant with flowers not unlike the Passion Flower, white tinged with purple, and if well grown is very effective in a mixed border or among evergreen shrubs.

MIGNONETTE. The delightful fragrance of this plant (Reseda odorata) ensures its welcome. There are several varieties, such as grandiflora and pyramidalis, while Machet, with its bold spikes of reddish-brown flowers, is a general favourite, especially as a potplant. For winter flowering indoors the seed should be sown about August in a compost of sandy loam and leaf-manure, taking care to sow thinly.

MIMULUS (Monkey-Flower, Musk). The cultivated forms of this plant make showy border flowers and are interesting from their curious markings, while the $M$. moschatus (the common Musk) is acceptable for its perfume. All the varieties love moisture, and in sowing seed, which should be merely sprinkled on the surface and not covered with soil, it is often advantageous to lay over it lightly 228 


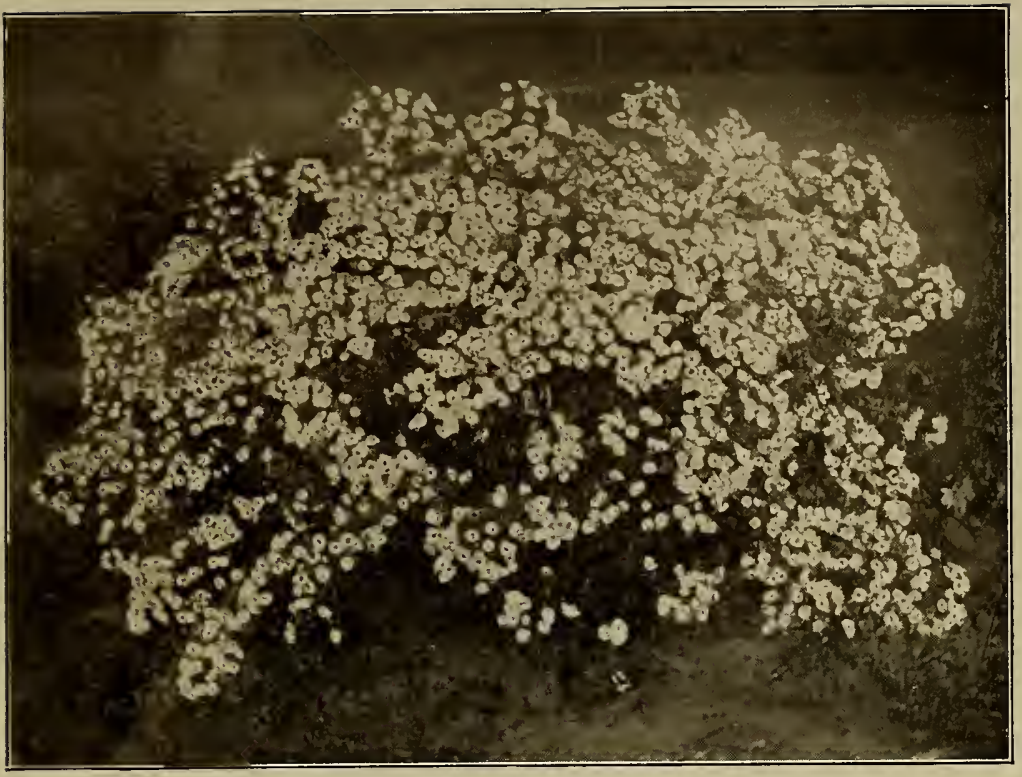

IN A SUBURBAN GARDEN.

Bush of White Michaelmas Daisies.

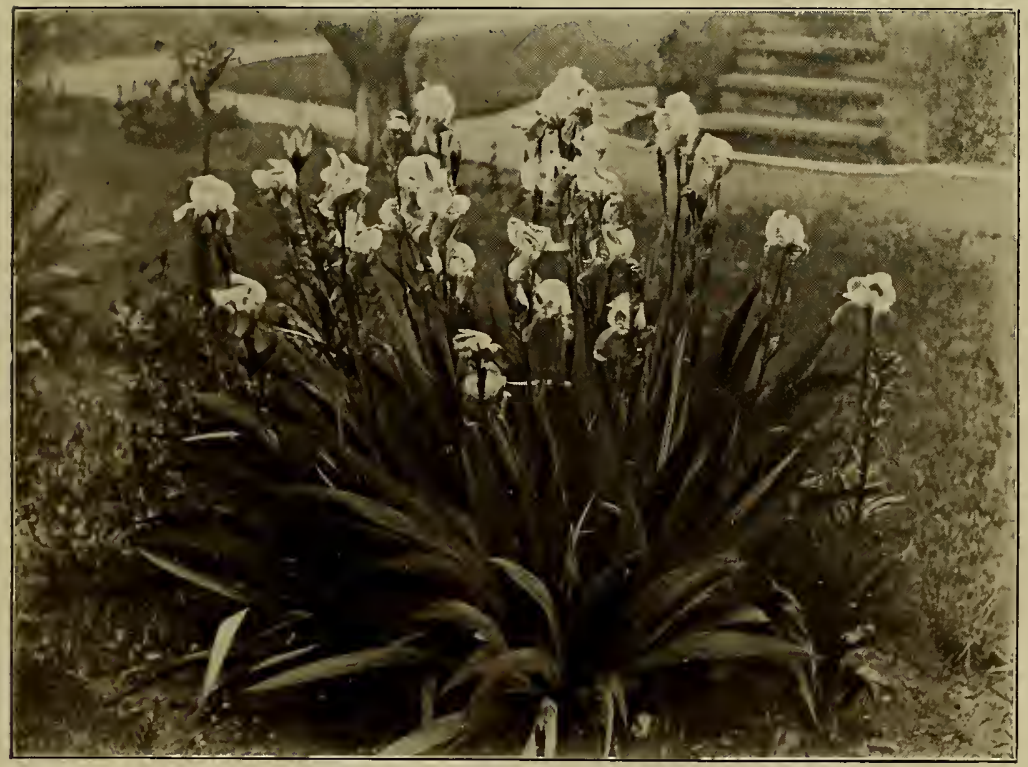

IN A SUBURBAN GARDEN.

A fine clump of Iris. 



\section{LIST OF FLOWERS}

some damp moss, removing it as soon as the seeds begin to germinate. Among the many kinds may be mentioned $M$. cardinalis, an old favourite, of which there are several varieties, and $M$. luteus, which includes many beautiful hybrids, dwarf in habit and bearing richlyblotched large flowers.

MIRABILIS (Marvel of Peru). A half-hardy tuberous perennial which may be treated as a half-hardy annual and raised from seed by sowing early in the year in heat, pricking off the seedlings to harden in a cold frame and planting out in June into a warm soil where they can get plenty of sun. $M$. jalapa is the variety usually grown, a handsome plant some 2 or 3 feet high and developing into a dense bush covered with flowers varying in colour from white to yellow, red and purple in many shades. $M$. multiflora is a smaller plant with fine clusters of bright reddish-purple flowers, while $M$. longiflora is remarkable (as its name indicates) for its long tubular flowers, which are enriched with centres of brilliant red.

MONARDA (Bee Balm). A hardy perennial thriving in any soil and well suited for the Wild Garden. $M$. didyma (known as Oswego Tea) is a fine variety bearing whorls of deep red flowers which last a long time and attaining a height of nearly 3 feet; while $M$. kalmiana is a still larger and more showy plant with flowers of brilliant crimson. In both cases the best effect is obtained by massing the plants together in bold groups.

\section{MONKSHOOD. See ACONITUM.}

MONTBRETIA. A beautiful summer and autumn flowering tuberous plant, of which there are many charming varieties easily grown in the open border. In clay or badly-drained soils they are, doubtless, apt to fail, but in rich, light soil they will flourish without trouble, while by a little judicious management as to time of planting they can be made to flower successively from spring to late autumn. In good well-drained soil they may be planted in autumn for spring flowering, though to avoid all risk of loss it is wiser to be content with summer and autumn flowering by planting from January to March and lifting and storing them during the winter. Many excellent hybrids have been derived from $M$. Pottsi, and the following list contains some of the best and hardiest for open-air culture: Bonquet Parfait, yellow and vermilion; Gerbe d'Or, golden; Etoile de Feu, yellow and fiery-red; Phare, bright red; Rayon d'Or, rich yellow; 


\section{A YEAR'S GARDENING}

Figaro, dark red and orange; Germania, vivid scarlet; Solfaterre, pale yellow; and Aurove, with large orange-coloured flowers.

MORINA (Whorl Flower). M. longifolia is a hardy perennial remarkable for its beautiful thistle-like foliage, and in a deep, moist soil it will readily attain a height of 2 or 3 feet, bearing long spikes of rose-coloured flowers. It is easily raised from seed by sowing in light, sunny soil and transplanting the seedlings to richer and moister ground.

MULLEIN. See VERBASCUM.

MUSCARI (Grape Hyacinth). A spring-flowering bulb which is eminently suited for the Rock Garden or for rough, grassy banks, being quite hardy and ready to grow in any ordinary soil; it is also useful for window-boxes, where its gracefully-poised flowers render it very attractive. M. racemosum, the most familiar kind, is valuable for its hardihood and rapid increase; it bears clusters of dark purple flowers. M. botryoides is another favourite, and its varieties-album and pallidum - are excellent, especially the latter with its clusters of delicate sky-blue flowers. $M$. moschatum is prized for its delicious scent-it is commonly known as the Musk Hyacinth-while $M$. comosum monstrosum, the Feather Hyacinth, is remarkable for its clusters of purple flowers, having some resemblance to waving feathers. $M$. conicum is wonderfully profuse in bloom, and its rich violet-blue flowers are charming in their fragrance. All these are hardy and may readily be increased by division of the bulbs every three or four years.

MUSK. See Mimulus.

MYOSOTIS (Forget-me-not). A hardy perennial well known in every garden, sowing itself freely, and a most useful spring flower. $M$. dissitiflora, an early-flowering kind with large clear blue flowers, is that generally seen in gardens and is an excellent variety. $M$. palustris, which grows wild in our ditches and on the banks of our rivulets, is also useful for garden cultivation in moist soil, while $M$. sylvatica, the Wood Forget-me-not, is valuable for the Wild Garden and in plantations or copses. M. alpestris is a dwarf variety, compact and cushion-like in habit and eminently suited for the Alpine or Rock Garden. There are varieties of white and of rose colour as well as of blue.

NARCISSUS (Daffodil). Of all hardy bulbs the Narcissi are the most valuable for the garden, and among the many beautiful flowers which we have in spring they seem indispensable. Although 230 


\section{LIST OF FLOWERS}

the family is so large, for outdoor culture we are practically restricted to three groups: the $N$. incomparabilis (Star Daffodil), the $N$. poeticus (Poet's Narcissus or Pheasant's Eye Narcissus), and the $N$. pseudo-narcissus (Common Daffodil). All these kinds may be relied upon as really hardy and suitable for growing in the open, and of each there are many varieties. Some of the best of $N$. incomparabilis are Sir Watkin, Princess Mary, Autocrat, Gloria Mundi and Mary Anderson; and of $N$. poeticus such varieties as Dante, Petrarch, etc. (introduced by Mr Engleheart), N. ornatus and grandiflorum, and $N$. recurvus, the Pheasant's Eye of the cottage garden, are all useful; while of $N$. psendo-narcissus there are three groups, the Golden, the Bi-colour and the White, in each of which there are many beautiful named kinds. The two chief requisites for the successful growth of Narcissi in the open garden are sound and healthy bulbs and early planting. Even the month of June is not too early, and September should be the latest; while to plant at a suitable depth -4 or even 5 inches of soil above the top of the bulb-is almost as imperative as to plant early. The reason advanced for the desirability of deep planting is that the bulbs are thus removed from the contraction and expansion of the soil caused by the winter's alternate frost and thaw. In congenial soil, such as well-drained loam, Narcissi increase rapidly, but it is not wise to divide them too frequently; every other year is quite often enough, and the best time is July, when the leaves have withered. For cut flowers more rare and delicate varieties may be grown in pots in the greenhouse; about five bulbs may be planted in an 8-inch pot in the summer and covered with ashes or sand until January, when it should be placed in a sunny position either in the greenhouse or in a frame. Among those suited for indoor culture are $N$. Corbularia (the Hooped Petticoat or Basket Daffodil), N. triandrus (Ganymede's Cup), with its varieties $N$. albus (Angel's Tears), $N$. calathinus and L'Ile St Nicholas, and the varieties of N. Tazetta (the Polyanthus or Bunch Narcissus), such as the Double Roman and the Paper White and the Sacred Narcissus or Joss Lily.

NASTURTIUM. See TROPFOLUM.

NEMESIA. A hardy annual-better treated, however, as halfhardy-well worthy of general culture. It may be sown in the open in May or in a frame or in boxes in the greenhouse in March; in the latter case the seedlings should be transplanted early in May. There are several varieties, one of the best being $N$. strumosa Suttonii, which may be had in many colours. $N$. floribunda is a free-growing 


\section{A YEAR'S GARDENING}

kind, attaining a height of about $I$ foot and bearing flowers of white with yellow throats, while $N$. versicolor has blossoms of blue, yellow and white. There is also a dwarf kind, named Nana Compacta Grandiflora, which is excellent.

NEMOPHILA. One of the hardiest of annuals and of much value for edgings or small beds by reason of its compact growth. Seed may be sown either in August, for spring flowering, or in April, and in the place where the plants are intended to bloom, though they will bear transplanting if it be carefully done. A light soil is desirable, in order that the seed may germinate freely and the plants be restricted from rank growth. $N$. insignis is an excellent species with sky-blue flowers and varieties of white, purple and striped; $N$. atomaria has white flowers touched with blue, and has varieties of sky-blue and black, and white and black; $N$. discoidalis has flowers of dark purple and of dark red, both edged with white; while $N$. maculata has particularly large flowers of both white and mauve.

NERTERA-DEPRESSA. A pretty little creeping plant covered with tiny scarlet berries and small round leaves, suited for level surfaces in the Rock Garden, but only hardy in the warm climates of our country. It is often used as a greenhouse pot-plant and may be propagated by division or by seed.

NICOTIANA (Tobacco Plant). A stately half-hardy annual, useful as a foliage plant in the greenhouse or for planting out in warm borders. Seed should be sown early in the year in a warm frame, and the seedlings pricked off into pots and placed in a temperature of about $60^{\circ}$, when about the end of May they ought to be well grown and ready for putting out. $N$. affinis is the most popular variety because of its fragrance, while $N$. Sandere, though not growing so tall, has many fine colours and is easy of culture.

NIEREMBERGIA. The varieties usually offered in catalogues are $N$. frutescens and $N$. gracilis, both graceful plants with elegant drooping branches and pretty white flowers touched with purple, but rather tender for our climate. The hardy variety is $N$. vivularis, with beautiful trailing foliage and large cup-like white flowers which continue in bloom throughout the summer and well into autumn. All may be raised from seed or propagated by cuttings in heat.

NIGELLA. A hardy annual which is attractive not only for its flowers but for its peculiar feathery and thorn-like growth, as indicated by its colloquial names of Love-in-a-Mist and Devil-in-a-Bush. 


\section{LIST OF FLOWERS}

The best known varieties are $N$. Damascena and $N$. Hispanica, in both of which there are several colours-white, blue and purple. Seed should be sown in March in light soil and in the place where the plants are intended to bloom, as the seedlings often do not bear transplanting.

NOLANA. A hardy annual of which the varieties $N$. atriplicifolia and $N$. prostrata are two of the best. Their trailing growth and slender stems render them well suited for the Rock Garden, and their bell-like blue or violet flowers are very showy. They like a warm, sunny situation and a light soil. Seed should be sorvn in March and the seedlings well thinned out, not transplanted.

NYCTERINIA. A pretty half-hardy annual growing in tufts some few inches high and bearing masses of white or blue blossoms in late autumn. $N$. capensis and $N$. selaginoides are both good varieties and should be sown in March in heat and planted out in May.

ENOTHERA. The common name of Evening Primrose is a misnomer in this case, for the blossoms in most kinds are well open during the day. The genus includes a great variety of perennials, biennials and annuals, and the large kinds, from their free and bold growth, are well suited for the Wild Garden, sowing themselves readily and only requiring to be confined to their own area in bold groups. Of this kind $\mathscr{E}$. fruticos $a$ and its varieties are excellent examples, growing from 2 to 3 feet high and bearing a profusion of showy yellow blossoms. $C E$. missouriensis is more suited for the herbaceous border; it has pendant stems of downy appearance and fine large flowers of bright yellow; it thrives best in a light, warm soil and opens in the evening. $E$. triloba is a hardy annual of dwarf growth, and to this class belong $\mathscr{E}$. Drummondi and Veitchiana, though the last named is better treated as half-hardy. Among the tall and vigorous kinds is $\mathscr{E}$. Lamarckiana, an erect and stately biennial growing to a height of 4 feet and bearing magnificent yellow flowers often 4 or 5 inches in diameter, while for the Rock Garden there is $C$. taraxacifolia with trailing stems and flowers of pure white which become tinted with a delicate pink as they mature.

OMPHALODES. A group of dwarf plants well suited for the Rock Garden and of which $O$. linifolia is the best known, a hardy annual with silvery leaves and pure white flowers, content with any ordinary soil and often sowing itself. O. lucilice is also hardy but must have a well-drained soil, though it delights in moisture if not 


\section{A YEAR'S GARDENING}

stagnant; it has beautiful foliage and flowers of a mauve tint. Both may be raised from seed sown in spring. In addition to the above there is $O$. verna (Creeping Forget-me-not), a hardy perennial and a charming plant for the Spring Garden. In suitable situations, such as woodland banks, and in a cool, moist soil, it quickly naturalizes itself and runs wild, its white-throated, clear-blue flowers becoming a renewed beauty every spring.

ONONIS (Rest Harrow). There are three species of this genus which grow wild in this country, and of these $O$. arvensis is well worth cultivation on rough banks or in the Wild Garden. It grows in dense tufts, bearing pretty racemes of pink flowers, and its white variety is equally or even more commendable. Other garden species are O. campestris, rotundifolia, fruticosa and viscosa. All may be raised from seed or by division.

ONOSMA. A genus which includes several species with beautiful yellow, purple or white flowers, and among which is $O$. taurica (the Golden Drop), an evergreen perennial growing from 6 to 9 inches high, bearing drooping clusters of bell-shaped yellow flowers sweetly scented. It is well suited for the Rock Garden, and should be planted so that its roots may find a firm hold between the stones in gritty loam. It may be raised from seed.

ORNITHOGALUM (Star of Bethlehem). A genus of bulbous plants of which one-O. pyrenaicum, the Spiked Star of Bethlehemis a native of this country. $O$. umbellatum and $O$. nutans have become naturalized, and together with $O$. pyramidale and $O$. latifolium are well worth a place in the garden on grassy banks, etc., or in the Wild Garden.

OROBUS. A hardy perennial of which some kinds are useful in the garden, such as $O$. aurantius, a handsome plant some $I 8$ inches high with flowers of deep yellow, O. lathyroides, with fine racemes of bright blue flowers, and $O$. vernus, which blooms in spring and bears beautiful purple or blue flowers. All may be raised from seed and will thrive in ordinary soil.

OXALIS. Under this name we have several pretty dwarf plants, both perennial and annual, which are more or less hardy in our climate, though they all like a dry sandy soil and a warm situation. O. cernua (the Bermuda Buttercup), with handsome yellow flowers, is a useful kind, while $O$. corniculata rubra is valuable as a bedding plant and luxuriates on rough chalky ground. $O$. floribunda is a 234 


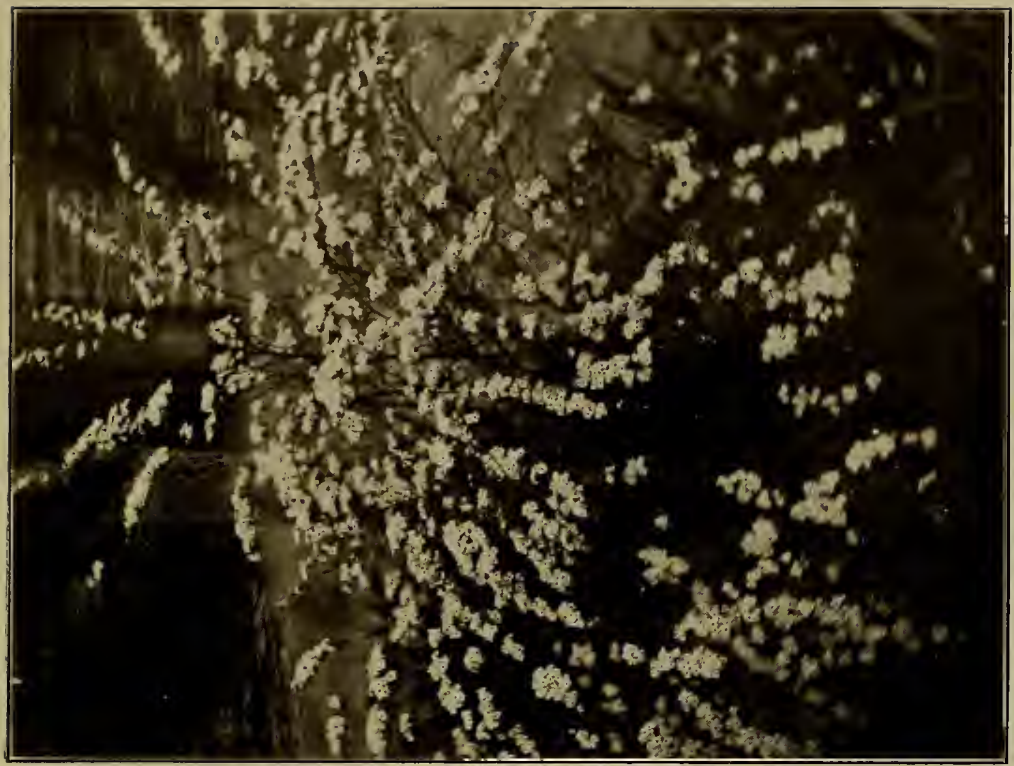

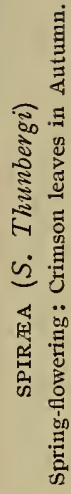

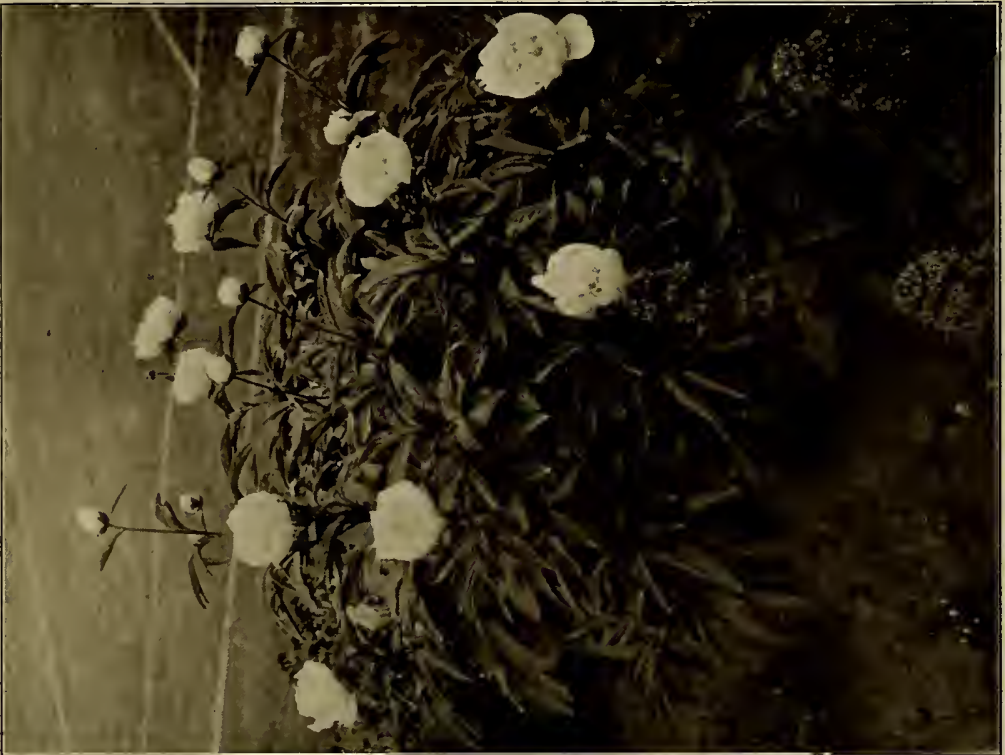

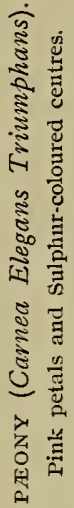





\section{LIST OF FLOWERS}

hardy and free-flowering kind, bearing a profusion of rose-tinted flowers and continuing to bloom for a long time, while $O$. Deppei, though more tender, is valuable for its beautiful reddish-purple flowers.

PEONIA (Peony). Peonies have much increased in popularity of recent years, but in spite of the well-deserved attention they have received the Tree Peony ( $P$. Moutan) is still strangely absent from many gardens. Yet it is a plant of great beauty, both in leaf and blossom, especially in early spring, and it may now be had with flowers in great variety of colour, such as white, scarlet, magenta, rose, salmon, lilac and violet. The essentials for its welfare are a well-manured soil and plenty of water during the summer, and being of slow growth it does not flower fully until the third year. September and October are the best months for planting, and the following are some of the good varieties, both single and double: Cecil Rhodes, fringed crimson; Lord Kitchener, deep red; Countess Crewe, salmon-pink; and Beatrice Kelway, white, for the single kind; while for doubles there are Eastern Prince, deep scarlet; James Kelway, rose; Reine Elizabeth, pink; Atalanta, reddish purple; and Aphrodite, white. The herbaceous or Chinese Peony, a hardy perennial, is more often seen in our gardens, and its many beautiful varieties are most valuable. Like the Tree Peony, it needs a rich soil, but while the Tree Peony requires abundance of sun the herbaceous Peony is grateful for a little shade. Planting should be done in September, and each plant should have plenty of space in which to develop. Some of the best of the older varieties are Louis Van Houtte, Gloria Patrice, and the double white Grandiflora, while among those of more recent introduction the pure white Bridesmaid, the crimson Meteor, and the rose-coloured Queen of $M$ ay are recommended for single varieties; and for the double kind the white Festiva maxima, the sulphur-coloured Salfaterre, the deep crimson Shirburnian, and the pink Lady Beresford.

PANSY. Under this name may rightly be included the oldfashioned Heart's-ease and the modern Viola, seeing that the Pansy (Pan's Eye) is the older name for the Heart's-ease (Heart's Eye), and that the Viola is a cross bet:veen the Pansy and the Viola Cormuta (the Horned Violet or Horned Pansy). Indeed the term Viola seems a misnomer and has now been superseded by that of Tufted Pansy, indicating the tufted root-growth which has been obtained by means of the crossing. The individual flowers of the Heart's-ease or Garden Pansy are often very handsome, but for general effect and masses of 


\section{A YEAR'S GARDENING}

colour the Tufted Pansy is far superior and many of the best varieties yield blooms of delicate beauty well suited for table bouquets. The Tufted Pansy is quite easy of culture and may readily be raised from seed or, if it is desired to perpetuate the particular variety, by cuttings taken early in April and kept under glass in a shady border until well rooted, when the lights may be removed. By September they ought to be ready for transplanting and should be given plenty of room for growth, so that they may bloom early in the following year. But for ordinary purposes the plants may be raised from seed by sowing in the open in a shady border in August, either pricking out the seedlings into a prepared plot in the autumn or allowing them to remain, after thinning, until the following March, when they should be transplanted into the required situation. The plants will spread rapidly, but are apt to deteriorate if permitted to remain in the same place more than two or three years, unless they receive a liberal dressing of manure, while to maintain their bloom throughout the summer it is necessary to remove immediately all faded flowers and thus prevent any seed maturing; moreover, the plants should be kept trim by nipping off any coarse or overgrown shoots, thus promoting new growth. There are so many beautiful varieties among Tufted Pansies that it is impossible to give a complete list here, but the following are fairly representative: Self-coloured (Rayless)White Beauty, pure white; Pembroke, light yellow; Rosea Pallida, pale pink; Ophelia, pale purple; and Blue Tit, bluish mauve. Selfcoloured (Rayed) - Lizzie Paul, rich yellow; Councillor W. Waters, crimson-purple; J. B. Riding, fine mauve; True Blue, deep blue; and Maggie, rose-pink. Variegated colours-Goldfinch, yellow and purple; Cottage Maid, violet and white; Hawk, white and blue; Butterfly, white and pink; and Stobhill Gem, violet and white.

PAPAVER (Poppy). Of the many beautiful annuals which grace our gardens there is none more lovely than the Shirley Poppy and none more easy to grow, fragile and delicate-looking though it is; indeed the one objection to it is that it seeds itself too readily and is apt to appear where not wanted. Although it has now spread all over the world it was not in existence before 1880 , in which year the Rev. W. Wilks, the Vicar of Shirley, (as he himself has told us) noticed among a patch of wild poppies in his garden one solitary flower which had a narrow edge of white. From this one flower, by means of selection and elimination, has sprung the whole race of Shirley Poppies, in which the shades of colour are now almost endless. The essential characteristics of the Shirley Poppy are that it 236 


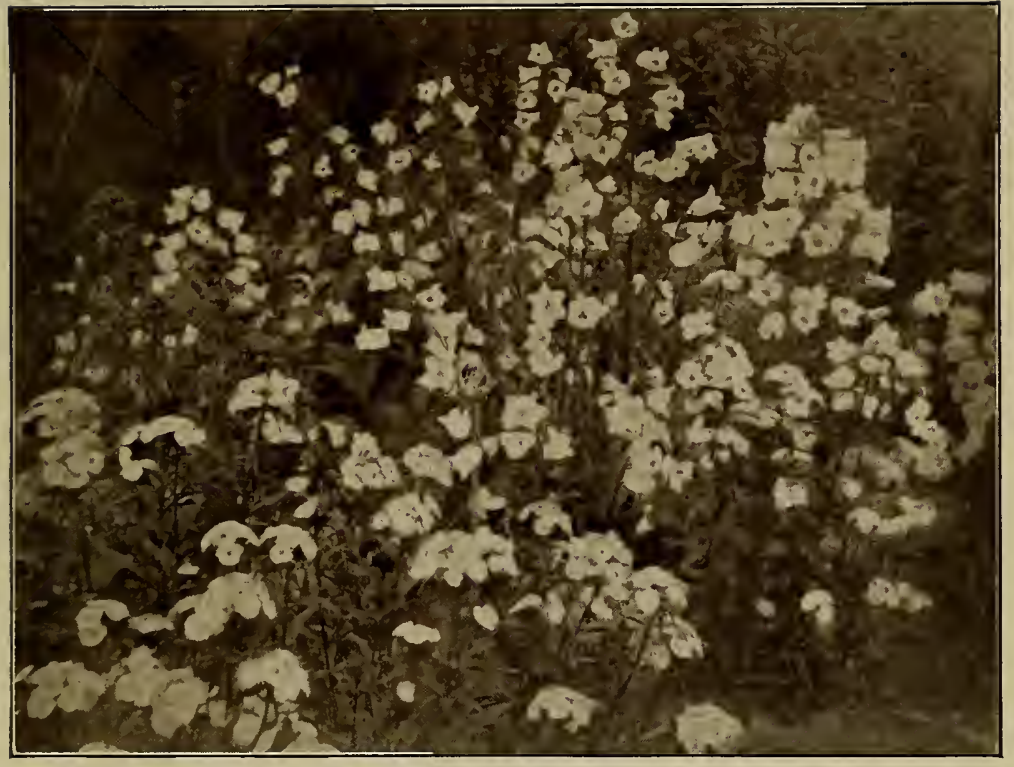

A WILD PATCH OF GARDEN.

Canterbury Bells, Campanulas, and Sweet-Williams.

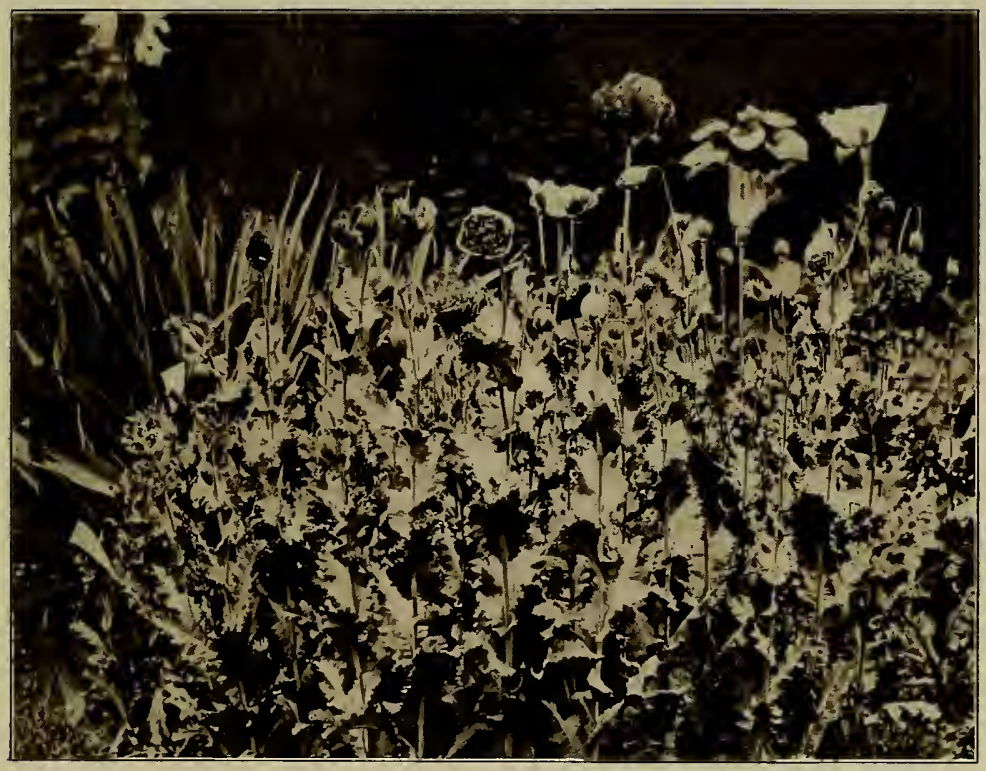

IN A SUBURBAN GARDEN.

A wild corner-Poppies. 



\section{LIST OF FLOWERS}

is single, has a white base with yellow or white stamens, and never has any black about it. Other beautiful varieties of the Single Annual Poppy are P. pavonium, or Peacock Poppy, growing in compact little tufts of about I foot high and bearing a profusion of bright crimson flowers with an inside ring of black; the Victoria Cross Poppy, with fine scarlet flowers bearing a broad white cross; and that called The Bride, with fringed flowers of pure white. The Double Annual Poppy is also well worth attention, and its fine peonyheaded bloom produces a grand effect when the plants are judiciously massed, its colours including rich scarlet, delicate pink, bright lilac, and pure white; while the annual called the Feathered Poppy makes a handsome plant some 2 feet high and bears large ball-like blossoms resembling finely-cut feathers in various shades of pink, salmon colour and white. Then there is the Oriental Poppy ( $P$. orientale), a noble and hardy perennial with splendid foliage and showy bloom, of which $P$. bracteatum is one of the best varieties, with huge blood-red flowers 6 or 7 inches across and blooming early in May; while other varieties produce flowers of orange, pink, purple, maroon, etc., in different shades. Besides these there is the beautiful little Iceland Poppy ( $P$. mudicaule), of dwarf but robust habit, bearing large flowers of rich yellow, and which, though a perennial, is better treated as an annual; while for the Rock Garden there is the Alpine Poppy ( $P$. alpinum), with various colours of scarlet, pink and yellow, sowing itself readily year by year (though a perennial, it often fails to endure) in clefts of walls or in the crevices of the Rock Garden, and thriving in poor soil and bright sunshine. All Poppies are easily raised from seed and should be sown where intended to flower, as they will not bear transplanting, and to keep them blooming it is necessary to nip off the seed-pods immediately they form.

PASSIFLORA (Passion Flower). For outdoor cultivation the Blue Passion Flower $(P$. corrulea) and its white variety, Constance Elliot, are undoubtedly the best, being fairly hardy in the southern districts of our country, especially if trained against a wall with southern aspect; a wall is better than a trellis, as it stores up heat. The Passion Flower is practically evergreen, only losing its foliage when renewing its leaves in the spring, and throughout the summer it is covered with large starry flowers which, in favourable situations, yield beautiful masses of orange-coloured fruit, but to enable it to bear fruit there must be several plants at no great distance from each other. Both the blue and the white kind are best propagated from 


\section{A YEAR'S GARDENING}

cuttings set in a cold frame in summer, but the blue may also be raised from seed sown in pots in the greenhouse or the frame, and will flower in the second year. Pruning should be done in February by cutting the young shoots to about two-thirds of their length and removing all weakly growth.

* PELARGONIUM. This genus includes the so-called Geranium, more properly termed Zonal Pelargonium, which, in its many varieties, is so useful as a " bedding-out" plant, not only because of its brilliant-coloured flowers, ranging from white to vivid scarlet, but also because of the beautiful variegated foliage it has now been made to assume. There are also a great number of double-flowered varieties which are excellent for pot culture but not so well suited for borders. Another section of the Pelargonium is the Ivy-leaved, valuable wherever a drooping habit is required (in window-boxes, for instance, or in garden vases), but they are somewhat tender and should be treated accordingly. The number of the varieties in Pelargoniums is so enormous that it is impossible to give a list here, but a few of the Zonal Pelargoniums best suited for borders are: Vesuvius, Beckwith's Pink, Queen of Whites, King of Bedders, and James Kelway.

PENTSTEMON. Both for the border and the Rock Garden the Pentstemon, in one or other of its many varieties, is admirable. For the border $P$. barbatus, a tall and handsome plant with spikes of bell-like flowers of charming pink, is one of the best, and its variety Torreyi, with flowers of deep scarlet, is equally good, but though generally described as hardy perennials they are both a little tender and thrive best in a warm soil with some protection during winter. For the Rock Garden $P$. glaber, of dwarf habit, with blue or violet flowers; $P$. Menziesii, of shrubby growth and flowers of reddish-purple; and $P$. heterophyllus, with flowers of blue deepening to purple, are all excellent. Pentstemons may be grown either from cuttings or seed, but they are a little tricky in culture and need a good friable soil, well drained.

\section{PERIWINKLE. See VINCA.}

PETUNIA. A showy half-hardy plant with large, rich blossoms embracing a great variety in shades of colour, marking and form. The single-flowered kind are useful for borders, producing a charming effect when properly massed, and may be raised from seed sown in heat in February or March, by which means good plants may be obtained for planting out by the end of May. The double-flowered 238 


\section{LIST OF FLOWERS}

kind are more suited for pot culture in the greenhouse and should be propagated by cuttings made in August in a good bottom heat and potted off in due course in ordinary compost. Some of the bestnamed double kinds are the white Juliette Lamber, the pink and white fringed-petalled Frau Stadt Schroder, and the bluish-purple Charon.

PHACELIA. A hardy annual with many varieties of size and habit, that most generally known being $P$. campanularia, growing about I foot high and producing a fine display of deep blue flowers. A larger kind is $P$. tanacetifolia, a vigorous plant some 2 or 3 feet high, with fine foliage and handsome heads of pale-blue flowers; while for the Rock Garden there is $P$. humilis, only a few inches high, with freely spreading stems bearing flowers of rich dark blue.

PHLOX. The half-hardy annual $P$. Drummondi, of which there are many varieties, is that most generally known, and is one of the most useful by reason of its brilliance and diversity in colour and its comparative indifference to bad weather. Its chief desideratum is a rich, moist soil-it cannot endure starvation. Seed should be sown early in March in a warm, moist atmosphere, and the seedlings pricked off as soon as they can be handled and kept in a temperature of $50^{\circ}$ to $55^{\circ}$ until the weather is warm enough to plant them outside. The other Phloxes, the perennial kind, may be roughly divided into two groups-the Alpine, dwarf, or creeping sort, and the tall herbaceous plants. P. subulata is a typical example of the first group, a beautiful little evergreen bearing a mass of rose-purple flowers, while its variety, $P$. nivalis, is smaller, more trailing, and more fully leaved. Then for the creeping sort we have $P$. reptans, blooming as early as the beginning of May, sending out numberless stems bearing flowers of a deep-rose tint, and thriving in a moist and shady nook; while for the tall herbaceous kind, that called Coquelicot, a fine, handsome plant with flowers of brilliant orange-scarlet, is certainly one of the best.

PHYGELIUS. $P$. capensis, the Cape Figwort, is a hardy perennial well suited for a light-soiled, dry situation, as it loves the heat and will endure drought. In a fairly good soil it will attain some 3 feet high, sending out fine flower-spikes of brilliant scarlet, which last from early summer till autumn. It may be grown from seed but is more easily grown by cuttings from the root-stock.

PHYSALIS. P. Alkekengi (the Winter Cherry), though classed as a hardy perennial, is glad of a warm situation. It is a handsome plant, growing some 18 inches high and bearing in autumn bright 


\section{A YEAR'S GARDENING}

orange-red bladder-like pods on erect stems, which, when cut and dried, make a highly decorative display in vases and last a long time. Another, and perhaps better variety, is P. Francheti (the Chinese Lantern), of much larger growth and bearing fruit-pods of brilliant coral-red; while for a third variety we have $P$. edulis (the Cape Gooseberry), which, however, is not hardy and should be treated as a greenhouse plant. All may be grown from seed, and the two first named may be sown in the open in spring.

PHYSOSTEGIA. A family of hardy perennials useful for summer flowering and thriving in any ordinary soil. $P$. virginiana is a good variety, growing about 2 feet high and bearing fine spikes of purple flowers, while the form called speciosa has larger and deepercoloured flowers. Both may be increased by division.

PHYTEUMA (Rampion). Many of these plants will be found useful for the Rock Garden. P. Sieberi, for instance, is a pretty little plant forming low tufts on which it bears stems of 4 or 5 inches long terminating in flowers of dark blue. It should have a sunny position and needs a moist soil. $P$. humile is also good, but it needs a sheltered position, being resentful of cold moisture, though it enjoys plenty of water in summer. Its blue flowers are borne on rather longer stems than those of $P$. Sieberi. Another variety often recommended is $P$. comosa, but it is very slow in growth. It has heads of purple flowers closely set on holly-like leaves, and thrives best in a cleft where it can root deeply. It is best raised from seed; the other two by division.

PINK. See Dianthus.

PLATYCODON. There are several varieties of this plant which are inclined to be troublesome in culture, but the dwarf variety, $P$. Mariesi (the Chinese Bellflower), may be treated as a hardy perennial. Its flowers may be either blue or white, and its dwarf habit prevents its beautiful foliage from breaking away as in the larger varieties. It may be raised from seed.

PLATYSTEMON. A species of Poppy, of which $P$. californicus, a hardy annual, is a useful variety, producing charming tufts of delicate foliage thickly studded with lemon-coloured flowers. It thrives in ordinary soil and should be sown in patches, where it is intended to bloom, and well thinned out. It will not bear transplanting.

PLUMBAGO. A graceful perennial, of which the two varieties, $P$. capensis and $P$. Larpenta, are of value for the greenhouse and 240 


\section{LIST OF FLOWERS}

the Rock Garden respectively. The former, with its delicate blue blossoms, makes a charming training plant for the greenhouse, while the latter is perfectly hardy and forms dense tufts of wiry stems, some 6 inches high, bearing trusses of deep blue flowers early in September, which last until the frost cuts them off. It is easily propagated by division in spring.

POLEMONIUM. A hardy perennial useful in some of its varieties for the Rock Garden. P. humile is one of the best, but though hardy on a well-drained light soil it will not endure during the winter in a damp situation. It is a pretty plant with pale blue flowers set on stems a few inches high. A larger kind, more suited for the border, is that called Richardsonii, with clusters of bell-like flowers of deep blue or of pure white. Both the white and the blue kinds are fragrant and useful for cutting. P. cceruleum (Jacob's Ladder) is a well-known variety of which there are several kinds-with blue flowers, with white flowers, or with variegated foliage.

POLIANTHES (Tuberose). The Tuberose is usually grown as a greenhouse plant, but in warm districts and in a sheltered border it will flower freely in the open. Its delightful fragrance and its pure white flowers render it a valuable plant, and in the greenhouse it is easily flowered by planting the bulbs in pots filled with a compost of loam and leaf mould and plunging the pots in a bottom heat of $60^{\circ}$ to $70^{\circ}$.

POLYANTHUS. Although this is usually considered to be a variety of Primula elatior (the Oxlip Primrose), it seems more convenient to place it under the heading of its well-known name of Polyanthus. For rich and varied colouring the Polyanthus excels, perhaps, any of our spring flowers, and though it may not yield itself so well as others for producing masses of colour, it is most effective when set in small clumps, so that the beauty of each plant may be discerned. Its cultivation is perfectly simple, for it will thrive in any garden soil, though it prefers one which is rich and moist, and flourishes best in a sheltered and somewhat shady situation. It can easily be raised from seed sown in the open during the summer months and may be increased by division in autumn or early spring. Its varieties are almost innumerable and a selection may be made without difficulty from any good seed catalogue.

POLYGALA. A family of dwarf creep ng shrubs, some of which are excellent for the Rock Garden. P. Chamabuxus purpurea is a beautiful example, with bright evergreen leaves and purplish stems, 


\section{A YEAR'S GARDENING}

compact in habit, and bearing lovely flowers of reddish-purple with yellow centres. It thrives in any well-drained soil.

POLYGONATUM (Solomon's Seal). The ordinary and most commonly grown variety is $P$. multiflorum, with graceful, drooping stems from 2 to 3 feet high, from the upper side of which spring the leaves, while from beneath hang bunches of bell-like white flowers. It is quite hardy, but flourishes best in moist soil and in some shady spot. $P$. latifolium is the old broad-leaved sort; it is of robust growth, the stems being often 3 to 4 feet high, with fine leaves and greenish-white flowers. $P$. japonicum is a distinct species, flowering early in April and growing about 2 feet high, with flowers of purplishwhite.

POLYGONUM (Knotweed). A very large and varied family, some of which are useful for the garden, especially as waterside plants. Of such are $P$. chinense, of compact habit and throwing up good sprays of white flowers, and $P$. sachalinense, a fine perennial with large leaves sometimes a foot in length, and bearing drooping racemes of greenish-white flowers. For the wild garden P. cuspidatum, with its profusion of creamy-white flowers and its persistent growth, is useful; while $P$. baldschuanicum, with its pink-hued flowers and rosy fruit, has a fine effect as a climber both in summer and autumn.

POPPY. See PAPAVER.

PORTULACA. A most valuable half-hardy annual, excelling in the brilliancy and diversity of its colour, which ranges from white through innumerable shades of red and yellow. It thrives alike in a poor, dry soil and in the well-manured border, but it must have a sunny aspect. There are both double and single kinds, and the varieties in each have become so numerous that the attempt to name them has almost been abandoned, mixed seeds being generally used. Although classed as a half-hardy annual, the seed may be sown in the open during the latter half of May; the more general plan, however, being to sow in a warm frame and prick off and plant out as soon as weather permits.

POTENTILLA (Cinquefoil). A large family in which are found some useful hardy perennials and pretty Alpine plants. The herbaceous variety includes some fine plants, notably $P$. nepolensis, growing some 18 inches high and bearing flowers of a beautiful crimson colour. P. Hopwoodiana is slightly taller, with large flowers of rose and yellow. Both these are single varieties, but the double 242 


\section{LIS'T OF FLOWERS}

kinds are more showy, and of the named sorts some of the best are: Belzebuth, dark crimson; Dr Andry, scarlet and yellow; Phoebus, rich yellow; and Fenelon, orange and scarlet. Among the dwarf Alpine species the following may be quoted: $P$. alba, with pretty white, star-like flowers; $P$. pyrenaica, with large flowers of deep yellow; and $P$. tonguei, with unusual coloured flowers, orange and terra-cotta. Potentillas are, for the most part, quite hardy and may easily be raised from seed; they thrive in a light soil and luxuriate in plenty of sunshine.

PRICKLY POPPY. See ARgEMONE.

\section{PRICKLY THRIFT. See ACANTHOLIMON.}

PRIMROSE. This hardy perennial (the Primula vulgaris) is too well known to need description here, but it may not be amiss to mention that we have now some beautiful strains which range in colour from pure white through many shades of crimson, maroon, orange and yellow. All may be raised from seed sown in the open in some shady patch of ground during June or July, and it is wise to give a protection from slugs by a sprinkling of soot or wood ashes. As soon as the seedlings are strong enough to bear removal they should be transferred to the place where they are intended to bloom, which should be a spot tempered from the fierce heat of the sun and with soil of stiff, moist loam. For the Rock Garden the Alpine Primroses are very valuable; such as Primula rosea, a Himalayan species, with compact tufts of pale-green leaves from which emerge flowerstems 6 or 7 inches high, bearing flowers of delicate pink, and of hardy and vigorous growth; while Primula denticulata is equally hardy and of more robust growth, being some 9 or Io inches high, with stout stems terminating in fine clusters of lilac blossoms. Primula viscosa, with its flowers of rosy-purple, and Primula farinosa, with flowers in shades of lilac, pink and crimson, should also be mentioned.

\section{PRIMULA-AURICULA. See AURICULA.}

PRIMULA-SINENSIS (Chinese Primrose). The genus Primula embraces many flowers which are usually called by other names, such as Auricula, Primrose, Polyanthus, etc., but the Primula of common parlance is the Primula-Sinensis in its many varieties. Under the protection of the greenhouse it is hardy enough, but though sometimes classed in seed catalogues as a perennial it is more wisely treated as an annual. Successive sowings may be made from April 


\section{A YEAR'S GARDENING}

to July in clean pots (for the Primula is nice in its requirements) filled with a compost of loam, leaf mould and a little sand; water before sowing, sow thinly, and cover lightly with soil, and place the pots in a temperature of $55^{\circ}$ to $65^{\circ}$ for germination of seed. The seedlings should be pricked off singly into pots as soon as they will bear it, and during the summer months should be freely exposed to the air, as a robust growth is essential for the production of good bloom. Care must be exercised in watering, as an excess of moisture or drought is equally fatal. The varieties are so numerous that it is impossible to give a detailed list here, but they may be had in all colours-white, blue, red, crimson, scarlet, spotted, margined, etc. The Star Primula ( $P$. stellata) is a free-flowering variety of $P$. sinensis, but taller, more slender and more elegant in growth. It is well worth cultivation, as it continues in bloom a long time and makes excellent sprays for cutting, remaining fresh in water for many days. Its culture is the same as that of $P$. sinensis and its colours are almost as various.

PRIMULA-VULGARIS. See Primrose.

PRINCE'S FEATHER. See AMARANTHUS.

PTEROCEPHALUS. The $P$. parnass $i$ is a useful addition to the Rock Garden, where its clumps of pachydermous-like leaves, surmounted with mauve flowers, are distinctly effective.

PUSCHKINIA. $P$. scilloides is a pretty bulbous plant, similar in grow th to the Scillas and a beautiful addition to the Spring Garden. It bears spikes of delicate blue flowers and needs a warm, sunny aspect and light friable soil. The bulbs should be planted in autumn, about 4 inches deep.

PYRETHRUM. A hardy perennial of vigorous growth, useful not only as a foliage plant but also for its blossoms, which are continually being improved in variety of colour and form. Though midsummer is its best time for flowering, it is valuable for autumn display, as if cut down after first blooming it will blossom again, and a succession of bloom can be obtained by periodical sowing and judicious stopping. The varieties, both single and double, are too numerous to be quoted here, but among the beautiful single kind (by many more esteemed than the double) which are recommended by Messrs Kelway the following may be mentioned: Agnes Mary Kelway, rose-coloured; Apollyon, pink; Golconde, crimson; Mrs Bateman Brown, purple; and Princess Marie, white. 


\section{LIST OF FLOWERS}

\section{RAGGED ROBIN. See Lychnis.}

RANUNCULUS (Buttercup). Among the cultivated species $R$. alpestris, the Alpine Buttercup, makes a good plant for the Rock Garden if set in a moist and porous soil. It grows in small tufts, and its large flowers of pure white, borne singly on erect stems, form an attractive contrast to its mass of shining dark-green leaves. $R$. amplexicaulis is another species well suited for the Rock Garden. It grows about I foot high, with grey-green leaves, slender stems and flowers of pure white with yellow centres. $R$. asiaticus, the Turban Ranunculus, is a garden variety of which there are many sorts and many colours, all of some value. It is less delicate than some of the named varieties of the garden Ranunculus, and in a well-worked soil and open situation it thrives well. The bulbs should be planted in the latter half of February, claw downwards, about 2 inches deep, and as soon as the leaves fade, after flowering, the bulbs should be lifted and stored in a cool place in sand, as they seldom withstand the cold rains of winter though delighting in warm moisture.

RED-HOT POKER PLANT. See KNIPHOFIA.

\section{RESEDA-ODORATA. See Mignonette.}

\section{REST HARROW. See ONONIS.}

RHODANTHE. A half-hardy annual, one of the brightest of "Everlasting" flowers and useful also for the garden border. $R$. Manglesi is the original species, and has rose-coloured blossoms with yellow centres, while $R$. maculata may be had with either white or carmine flowers. $R$. atro-sanguinea differs from the foregoing by being more branched and of dwarfer growth, and bears flowers of bright magenta, but it is somewhat tender. Seed should be sown in heat in February or March, and the seedlings pricked off as soon as possible, as they do not transplant successfully except when quite small.

RICHARDIA. There are several species of this genus, but that which is generally known and cultivated with us is $R$. athiopica, commonly called the Arum Lily or the Lily of the Nile. The latter name is certainly a misnomer, the plant not being found anywhere near the Nile, though it may be seen in profusion, growing rampantly wild, throughout the Cape. Its handsome white spathes and fine foliage make it an effective plant for the greenhouse, and it may be 


\section{A YEAR'S GARDENING}

made to vary in the time of bloom according to the treatment given. Winter and early spring are the seasons most usually chosen, for which purpose the plants should be allowed to stand out of doors during the summer and kept dry, re-potting them in a rich loam towards the end of July and keeping them moist, but allowing them to remain out of doors until frost threatens.

RICINUS (Castor-oil Plant). A half-hardy annual which is valuable in the garden for its noble ornamental foliage and which may be made a bold and effective centre for a large circular bed. Though usually raised in heat it is quite possible to obtain successful results by sowing in the open early in May. The seeds (which are large) should be put in about 3 inches deep and 2 or 3 inches apart in the place where the plants are intended to grow, and the seedlings finally thinned out till one (or more) is retained. A rich, well-drained soil is essential, as the growing season being short the seedlings must be brought on as rapidly as possible. The advantage of sowing out of doors instead of in heat arises from the fact that a plant, when raised in the house, is very apt to receive a check on its transfer to the open, from which it may fail to recover before the growing season is well advanced. Among the best varieties are Borboniensis arboreus, often growing from I2 to I5 feet high; Gibsoni, a fine dark kind; and Belot Desfougères, tall and branching.

ROCK CISTUS. See Helianthemum.

ROCKET. See HESPERIS.

ROCKFOIL. See Saxifraga.

ROMNEYA-COULTERI (Califormian Bush Poppy). A fine shrubby plant, not quite safe without some protection during the winter, except in a warm, sheltered position in our southern counties, but well worth cultivation for its large and delicate flowers of snowy white with golden stamens. The flowers are often as much as 6 inches across, and are of a peculiarly fragile, almost transparent texture, yet lasting many days and emitting a slight but delicious perfume. Care should be exercised when forking around the plant, as it will not endure any root disturbance.

ROSE. So many text-books have been written and so much valuable information recorded about the Rose, its culture has been so fully discussed and its many varieties so amply described, that it seems doubtful whether, in the compass of these brief notes, anything useful 246 


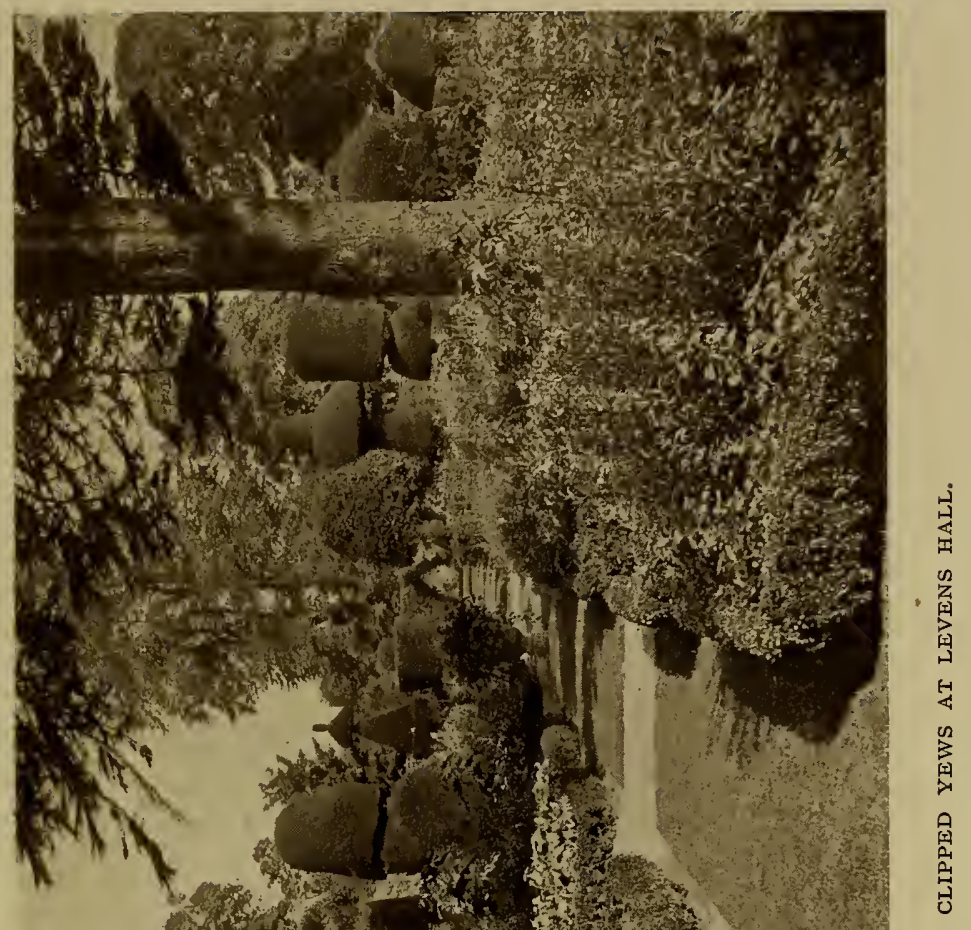





\section{LIS'T OF FLOWERS}

remains to be said. Yet a few simple hints on general treatment may not be altogether amiss.

One point worth mentioning is that the garden as a whole, and not merely a rectangular plot in it, should be beautified by this Queen of Flowers. The vast strides which have been made in recent years in the culture of the Rose have rendered it more fitted than ever to take a place in the " decorative " effect of the garden; its time of blooming is not, as formerly, confined to a few weeks' duration, but by a judicious selection of Monthly Roses, Tea Roses, Hybrid Perpetuals and Climbers we may now have the Rose in flower from early summer to late autumn.

Nor are Roses so imperious in the matter of soil as to need their being relegated to one particular plot. It is true that a rich, heavy loam, with a sub-soil of clay, is considered the best, especially for Hybrid Perpetuals, but any good soil, such as will grow vegetables successfully, will be equally satisfactory for Roses, while most Tea Roses will flourish in a light soil. Position, however, is all-important; cleanliness, sunshine and plenty of air are essential, and hence Roses are apt to flag in the dirt-laden air and close quarters of a town garden.

Probably many a young Rose-tree is spoilt in the mere planting; in both time and method there is, of course, a right and a wrong way. The early spring is a permissible time, but dangerous, for cutting winds with bright sunshine by day and a touch of frost at night are not conducive to the welfare of a newly-planted Rose. Autumn, from the middle of October to the end of November, is the best season for planting, and even then it should be done in mild, moist weather, if possible, taking care that the roots are not previously exposed for any length of time and that they do not come into direct contact with any manure which may be used.

Pruning is another important matter and one which often presents some difficulty to the amateur. But the process becomes quite simple when once the true object is grasped, viz., to induce the growth of new wood by cutting away the growths of the previous season. The best time for this is early in March, though Tea Roses may be pruned some three weeks later. It may be mentioned that with Climbing Roses it is generally advisable to cut back only a few inches of the previous summer's growth and prune to the ground the older growths. The annual pruning of Roses other than Climbers may be supplemented by thinning the shoots in May, and to obtain fine specimens of flowers disbudding is usually necessary - the picking some, or all, of the side buds of a cluster, thus allowing the centre one space and nourishment for its full development. 


\section{A YEAR'S GARDENING}

As to manuring, it is well to remember that the Rose is not naturally a gross feeder and should not be subjected to strong, crude "fertilizers." Undoubtedly the soil should be kept in good heart by the periodical incorporation of well-rotted manure, but assuming this is done the best treatment for the soil is to keep it quite loose for 5 or 6 inches from the surface. A small, thin-pronged fork is the handiest tool for the purpose and should be used constantly, especially after rainfall or watering, the object being to keep the soil in such a condition that air and warmth can penetrate easily. With the soil kept thus, artificial watering is seldom necessary; but if May should happen to be an exceptionally dry month watering may have to be resorted to during the early part of June to nourish the foliage, in which case let a liberal supply of soft water be given at intervals of not less than two days, and during the remainder of the season a mulching of stable litter will probably be sufficient to keep the ground moist.

Finally, a constant watch must be kept for caterpillars and greenfly, though the experience of the writer has been that if a Rose-tree is in good condition it seldom suffers from green-fly. But this cannot be said of the caterpillar, and nothing is really so efficacious a remedy for this pest as hand-picking. The rough-and-ready method is to pinch the leaf which is rolled up, or the leaves which are stuck together, and thus destroy the maggot within; but a better practice, perhaps, is to carry in one's waistcoat pocket a small camel's-hair brush and by its means remove the grub without destroying the leaves. In any case, constant watchfulness is the main factor; during the season not a day should be allowed to pass without making an examination of the Roses.

ROSE CAMPION. See Agrostemma.

RUDBECKIA. See EchinaCEA.

SAINTPAULIA. As a pot plant for the greenhouse or for table decoration $S$. inonantha is quite worth growing, being a pretty little perennial, some 3 or 4 inches, with fleshy leaves and clusters of bright violet-blue flowers. Seed should be sown in March in a porous compost and kept in a warm, moist air. The seedlings may be expected to flower about September and will continue in bloom throughout the winter.

SALPIGLOSSIS. A half-hardy annual which has been much improved of late, and of which there are now many beautiful strains with flowers varying in colour from delicate creamy white to orange, scarlet, crimson and purple. It has slender, erect stems from I 248 


\section{LIST OF FLOWERS}

to 2 feet high, and thrives in light rich loam. For early flowering seed should be sown in moderate heat at the beginning of March, when the plants will be ready for putting out in May; but it may also be sown in the open in April, in the place where intended to bloom, care being taken to thin out rigorously.

SALVIA (Sage). This family includes many beautiful garden plants, both perennial and annual, hardy and half-hardy. $S$. splendens, with its clear-green foliage and brilliant scarlet flowers, is one of the most useful and showy of the family, and has diverged into many valuable strains. $S$. patens, with its flowers of intense blue, is another lovely variety, while $S$. Roemeriana, with flowers of deep crimson, is of compact dwarf growth well suited for border edgings. All these may be satisfactorily treated as half-hardy annuals. There are many other varieties well worth growing, such as $S$. azurea, a perennial which will thrive in the open in mild districts, with fine spikes of pale blue flowers; and S. cacaliafolia, also perennial in warm situations, with grey-green downy foliage and erect stems bearing flowers of deep blue.

SANGUINARIA-CANADENSIS. A hardy and pretty plant well suited for the Wild Garden, where in moist soil it will readily naturalize itself, pushing forth in all directions stout creeping roots, from which appear glaucous leaves and stems of large white flowers with yellow stamens-a beautiful sight in spring. It is useful, also, for the margins of copses, or where the drip from trees prevents other vegetation.

SANVITALIA. A hardy annual thriving in any ordinary soil and easily raised from seed by sowing in autumn for spring flowering or in April for summer bloom. The double-flowered S. procumbens, with trailing stems and bright yellow flowers, is the best variety.

SAPONARIA. A hardy perennial and annual of dwarf creeping habit, and useful in the Rock Garden or as border edgings. $S$. calabrica (annual) is one of the prettiest varieties, growing about 6 inches high with slender stems of small blossoms, either pink or white; while $S$. ocymoides splendens (perennial) is particularly valuable for the Rock Garden, making an excellent drooping plant for falling over the face of the rocks and becoming a mass of rosecoloured bloom.

SAXIFRAGA. A large family which includes many species and varieties and a host of beautiful Alpine plants, most of which are quite easy to grow. Of the species most suited for the Rock Garden 


\section{A YEAR'S GARDENING}

the following may be quoted: $S$. aretioides, with stems about I inch high, bearing, in April, flowers of a beautiful golden yellow, and requiring a moist but well-drained soil, with protection from the intrusion of any coarser growth; S. burseriana, of moss-like habit, with elegantly-frilled white blossoms borne on slender red stalks, and blooming freely as early as January or February; S. ciliata, with broad, hairy leaves, and stems some 6 inches high on which are borne large flowers of pinkish hue, a handsome and very noticeable plant, but too tender to be grown in the open except in the warm districts of our country, and even then requiring a sheltered position; and S. muscoides, of which there are several kinds, one of the best being atropurpurea, with blossoms of beautiful reddish-purple borne in dense masses on stems only a few inches high. Among the larger species of Saxifraga may be mentioned $S$. cotyledon and its fine variety $S$. pyramidalis, with its pyramids of silvery-white flowers on stems growing from I2 to 20 inches high; it makes a fine pot plant and is quite hardy. S. longifolia is another beautiful species, with leaves of grey-green spotted with white, and bearing fine columns of white flowers; it is quite hardy and blooms in early summer. Last, but by no means least graceful, is $S$. umbrosa, the common London Pride, too well known to need any description here; a most useful plant for border edgings and making beautiful compact masses in the Wild Garden when grown in natural clumps.

SCABIOSA (Scabious). Although the Scabious, in most of its varieties, is either biennial or perennial, it is usually, and more conveniently, treated as a hardy annual. S. atropurpurea, the Sweet Scabious, is one of the most useful kinds, and may be had in all shades of purplish-red and yellow, and in white. When sown in the open in May it will bloom in the following year, or if sown early in April or towards the end of March it will flower in the late summer of the same year. S. caucasica is a handsome kind, a perennial, though failing to endure the winter on cool soils. It grows in dense tufts and sends out long stalks bearing large heads of blue or white flowers, very useful for cutting. Many other strains, with both double and single flowers, and in numerous shades of colour, may be selected by consulting a seedsman's catalogue.

SCHIZANTHUS. An annual of elegant growth and beautifullycoloured fairy-like blossoms bearing some fancied resemblance to a butterfly. S. pinnatus, growing from I to 2 feet high, with purple and yellow blossoms, is one of the hardy kinds, and it has 


\section{LIST OF FLOWERS}

several beautiful varieties, such as papilionaceus (purple-spotted), atropurpureus (deep purple), Priesti (white), and Tom Thumb, of compact habit. Of those suitable for greenhouse culture S. retusus, with flowers of rose and orange colour, is excellent; while $S$. Wisetonensis, of compact pyramidal form, with large flowers of white, pink and yellow, makes a fine greenhouse plant. Seed may be sown in heat in the spring for summer flowering, or in August, the plants being kept in a cool house during the winter, for planting out in the following May.

SCHIZOPETALON-WALKERI. A hardy annual growing about 6 inches high, with slender stems and fringed white flowers delicately scented. It needs a warm, rich soil and a sheltered situation, but given these advantages it may be sown in the open at the beginning of May and will bloom in the following August. It will not bear transplanting.

SCILLA (Squill). For beautiful spring flowers none is more valuable than the Scilla, and the bulbs demand only the simplest culture. Planted in early autumn in any good garden soil they will bloom in spring-from February to May, according to kind-and need no attention for years beyond a yearly top-dressing of manure. S. bifolia is one of the earliest to bloom and forms handsome tufts bearing masses of dark blue flowers, but it does not so well withstand cold rain and storm as its more vigorous variety $S$. procox. $S$. sibirica is a charming little flower of much value for the Rock Garden and is distinctive by its peculiar tint of porcelain-blue. S. hispanica, the Spanish Scilla (sometimes called $S$. campanulata), is a lateflowering kind and makes a beautiful display till nearly the end of May. It bears large, short-stalked, bell-shaped flowers of clear-blue colour. S. nutans, the common Bluebell, need not be neglected, and its varieties alba (white), rosea (rose-coloured) and carulea (pale blue) are all very pretty and include some large-flowered strains called major and grandiflora.

SCYPHANTHUS. An elegant half-hardy annual, a climber growing some 8 or to feet high, with deeply-cut leaves and cupshaped flowers of bright yellow spotted inside with red. It blooms freely from August to October in a rich, light soil.

SEA HOLLY. See ERYNGium.

SEA PINK (Thrift). See ARMERIA. $25 \mathrm{I}$ 


\section{A YEAR'S GARDENING}

SEDUM (Stonecrop). In this family there are many varieties well suited for the Rock Garden, while others are sufficiently tall and stately to serve as handsome border plants. S. spectabile, for instance, is a fine plant, with broad leaves and dense heads of reddishpurple flowers, appearing in August and continuing for two months or more; while its variety called atropurpureum is, perhaps, still more handsome, with darker blooms of rich purple. Among the dwarf kinds $S$. sempervivoides is one of the most beautiful, having leaves like those of the Houseleek, with dense heads of brilliant scarlet flowers, but it cannot withstand cold wet weather. However, it grows rapidly from seed, and by sowing in gentle heat in January good-sized plants may be obtained by the summer. $S$. stoloniferum has large flat leaves and purple flowers which appear in late summer, and is well suited for border edgings, as is $S$. ibericum, with its dainty stems and white flowers. $S$. mpestre is the native Stonecrop, too well known to need description here; and there are various forms of it well worth cultivation, such as the crested variety called monstrosum and the kind named album, with leaves of peculiar green and pinky-white flowers.

SEMPERVIVUM (Houseleek). There are several varieties of this plant, but all bearing a strong family likeness, their differences being chiefly confined to variation in the tint of leaves and the colour of flowers. They are useful additions to the contents of the Rock Garden, flourishing in chinks and crevices where few plants could find sustenance, and maintaining life and beauty in dry and sunny positions-on an old roof or the top of a wall-where nothing else could live. S. tectorum, the common Houseleek, is, of course, well known, and some of its varieties, such as rusticum and Royeni, are useful. S. calcareum is an excellent plant; quite hardy, easily grown, and suitable either for border edgings or for the Rock Garden. S. fimbriatum is justly popular for the profusion of its bloom-dark rose-coloured flowers borne on stems some six or seven inches highand for its fringed leaves tipped with purple. S. arachnoideum is a wonderful Alpine species, having leaves covered with a delicate tracery of white down which gives the appearance of the web of a spider (hence its name arachnoideum), and with which, in summer, its pretty pink flowers make a delightful contrast. Though needing plenty of root moisture it should be placed in a sunny, open spot of the Rock Garden.

SENECIO. For general usefulness in the garden there are only two of this family which are of much value, viz., S. cineraria (well $25^{2}$ 


\section{LIST OF FLOWERS}

known under the name of Dusty Miller), a perennial, quite hardy except in cold, wet soils, with silvery leaves and clusters of yellow flowers, and of which there is an excellent strain, with leaves of peculiar whiteness, called candidissima; and S. elegans, a halfhardy annual, which may be had in dwarf form, about I foot high, with fine double flowers in various colours. S. japonicus is a large, handsome plant, growing some 5 feet high and bearing, in autumn, large flowers of a fine orange colour, but it needs much moisture and is chiefly suited for growing on the banks of a stream or pond; while $S$. pulcher, though a hardy perennial, is so easily defaced by inclement weather that it requires much protection.

SIDALCEA. Though usually classed as a hardy perennial, a frequent renewal from seed is advisable, and plants grown from seed sown in the open in autumn generally do better and bloom earlier than those raised by spring sowing in heat. As a class the Sidalceas merit attention, being easy of culture, profuse in bloom and excellent for cutting. S. candida, with large white flowers on stems some 2 feet high, is a good kind, and has a variety called Rosy Gem with rose-coloured flowers. S. Listeri is equally good with its spikes of fringed pinkish flowers, while $S$. Murrayana is useful for its dwarf growth, and bears flowers of deep red colour.

SILENE (Catchfly). As a hardy annual Silene can be used very effectively for early summer display from seed sown in autumn, but it needs a light, dry soil for its successful culture. S. Armeria is a handsome variety, with good foliage and fine heads of white or pink flowers of aromatic scent. It sows itself readily in congenial soil and is well suited for the Wild Garden. S. pendula, in its many forms and colours, is valuable as a bedding plant, especially in the compacta section and double-flowered strains. S. alpestris is a hardy perennial, a compact Alpine plant which may be grown from seed sown in autumn. Quite eary in summer it is covered with glistening white flowers and may be freely used in the Rock Garden. $S$. acaulis is another Alpine plant, growing in firm tufts of beautiful light green in which appear masses of pink or crimson flowers. $S$. Schafta is a useful variety for late summer flowering-a hardy perennial spreading into tufts 5 or 6 inches high and bearing from July to September large flowers of reddish purple.

SNAPDRAGON. See ANTIRRHINUM.

SNOWDROP. See GALANTHUS.

SNOWFLAKE. See LeUCoJUm. 


\section{A YEAR'S GARDENING}

SOLANUM. Of this large family there are two or three varieties which should be mentioned here-S. capsicastrum, for instance, its bright orange-red berries rendering it a favourite plant for table or greenhouse decoration during the winter months. It can easily be raised from seed, and by sowing in heat in February and hardening the seedlings in the open during the summer good bushy potplants may be obtained for bearing berries during the winter in the greenhouse. S. jasminoides, with its pretty sprays of white flowers, is useful as a greenhouse climber, blooming throughout the greater part of the year under such protection, and in the mild climate of our southern counties thriving and blooming in the open, especially when trained against a wall with a southern aspect. But $S$. Wendlandi is, perhaps, the finest of the Solanum climbers, and planted in the greenhouse in a bed of moist, rich soil it makes a noble plant, blooming profusely, through most of the summer, in large drooping clusters of soft lilac-blue.

SOLIDAGO (Golden Rod). A hardy perennial of too coarsely vigorous a growth to be suitable for the garden border, but useful for the Wild Garden and waste places. There are many varieties of which $S$. odora, with comparatively delicate growth and fragrant flowers of deep yellow, is one of the best; while S. Buckleyi, with leaves of bluish-green and flowers of orange colour, is of value from its dwarf habit.

\section{SOLOMON'S SEAL. See Polygonatum.}

SPARAXIS. A very useful bulb for early summer flowering, and hardy enough for open-air culture in warm districts and sheltered positions. The best-known varieties are $S$. grandiflora and $S$. tricolor, growing about I foot high and bearing showy flowers in colours varying from white to several shades of red. S. pulcherrima, though a member of this family, has distinctive features-tall, slender stems several feet high, graced with pendulous bell-shaped flowers of reddish-purple, which in some strains are finely striped and verge into white. It requires a particularly sheltered position, and when once planted should not be moved.

SPECULARIA (Venus's Looking-glass). A hardy free-flowering annual, resembling a Campanula, with open bell-shaped flowers in various colours-white, blue, lilac and purple. There are some pretty dwarf forms, with both white and violet-blue flowers, well suited for the Rock Garden. Although an annual it often becomes practically a perennial by self-sown seed. 


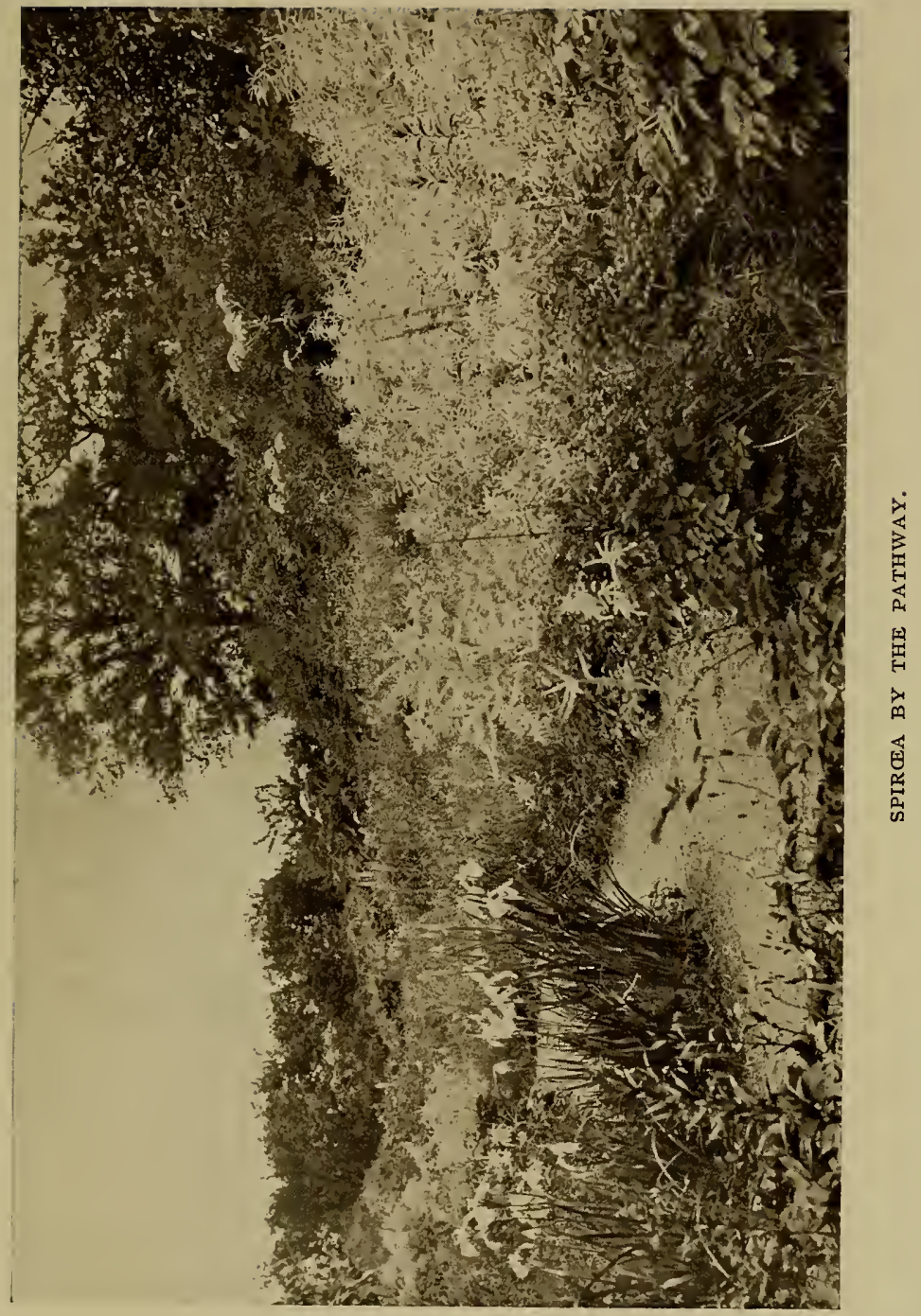





\section{LIST OF FLOWERS}

\section{SPEEDWELL. See Veronica.}

SPHENOGYNE. This is a large family, but S. speciosa is the only kind that need be mentioned here. It is usually classed as a hardy annual and will succeed when sown in the open in spring; but it is more wisely treated as half-hardy by sowing in heat in March ind transplanting in due course into light soil. It is of slender but bushy growth, after the style of a Marguerite, and bears yellow flowers with dark centres ringed with black.

SPIRAA. Either as a border perennial or as a dwarf shrub the Spiræa is valuable, being hardy, simple of culture, of good form and of pleasing variety in the colour of its flowers. Among the herbaceous varieties $S$. aruncus (Goat's-beard), a perennial of vigorous growth, 3 or 4 feet high, is useful both for its foliage and its graceful plumes of flowers. It is hardy enough to thrive in any ordinary soil but does best in deep moist loam. S. lobata is another hardy plant, growing from 2 to 3 feet high and bearing beautiful clusters of pink flowers. In the shrub kind there are many beautiful varieties, such as $S$. hypericifolia, with its tall, slender tems arching under its clusters of white flowers; $S$. discolor, with eautiful panicles of creamy-white flowers; $S$. confusa, the compact little shrub often grown in the greenhouse in pots for early spring flowering; and $S$. japonica, growing about 3 feet high with flat clusters of pinky-red flowers. Of this species there are several good forms, such as Bumalda, of dwarf growth and rose-tint flowers; splendens, with flowers of yellowish pink; and Frabeli, of value for its early flowers of fine claret colour. In cultivation of the Spiræa it should be borne in mind that it is a moisture-loving plant and needs space in which to display its full beauty.

SQUILL. See ScIllA.

STAR OF BETHLEHEM. See ORnithogalum.

STATICE (Sea Lavender). Some of the smaller kinds of this family are useful for the Rock Garden, such as S. minuta and minutiflora, and $S$. incana, of compact and dwarf habit, growing about 8 or Io inches high and with flowers in several colours. $S$. latifolia is, perhaps, the best of the larger kind-a hardy perennial some I8 inches high, with wide-spreading stems and large panicles of lavender-coloured flowers. Another good variety is $S$. Suworowi (sometimes called Candelabrum), a hardy annual growing about I foot high, with flowers of soft rose-colour, to be had, also, in crimson and white. Most of the Statices bear their flowers in 


\section{A YEAR'S GARDENING}

large sprays, which are useful as "everlastings," as they retain their colour well when cut and dried.

\section{STENACTIS. See ERIGERON.}

STEPHANOTIS. There are several species of this genus, but $S$. floribunda is the only one in general cultivation. It makes an excellent climber in the greenhouse, producing fine clusters of waxlike, sweet-scented white flowers. Planted in a well-drained bed of good loam it will thrive without much attention in a cool house, and may be propagated by cuttings made in spring from the previous year's wood.

STERNBERGIA. A hardy bulb, blooming either in autumn or spring, according to kind, and well fitted by the firm texture of its flowers to withstand the assaults of the weather. A light sandy loam is the soil best suited for it, and it should be left undisturbed, if possible, throughout the summer, so as to allow it to ripen for the next flowering. S. colchiciflora is a variety which blooms in autumn, though the leaves appear in spring. It bears flowers of pale yellow colour and sweet fragrance. S. lutea, which is supposed by some to be the Lily of the Field of the Bible, is also autumn-flowering; S. augustifolia is a more vigorous and free-flowering form of that species; while $S$. Fischeriana chiefly differs by flowering in spring instead of autumn. The handsomest of the family is S. macrantha, sending up fine broad leaves during the summer and coming into bloom in autumn with flowers of brilliant yellow.

\section{ST JOHN'S WORT. See HYPERICUM.}

STOCK. (See also Mathiola.) It may be convenient in these notes to divide Stocks into three groups-the Ten-Week Stocks, the Intermediate or East Lothian Stocks, and the Brompton and Queen Stocks. The Ten-Week Stocks are half-hardy annuals and should be sown in shallow pans or boxes under glass, during the latter half of March, in good sandy loam, and the seedlings transplanted as soon as they will bear it into light, friable soil. Care should be taken to sow thinly, and every endeavour made to give the plants a hardy constitution; and this being done they may be expected to flower continually throughout the summer and autumn. The German growers have produced an immense variety of kinds, in which there are some good distinctive colours, such as crimson, purple, and white, while the English strain, known as Pyramidal, is excellent both in form and colour and is valuable for providing autumn-flowering sorts. The Intermediate or East Lothian Stocks 256 


\section{LIST OF FLOWERS}

are half-hardy annuals of dwarf and bushy habit and very freeblooming. They are often used for indoor decoration in spring, and by sowing in pots in August or early September, and protecting the young plants in a cold frame during the winter, they will be ready to bloom indoors in March or April, if assisted by a little manure water or a top-dressing of rich soil. In this group, as in the others, there are many beautiful strains, embracing colours of crimson, scarlet, purple and white. The Brompton and Queen Stocks are characterized by their large spikes of bloom and make an effective display during May and June. In mild districts and in a warm soil they may be raised successfully by sowing in the open i July, but it is safer to sow in seed-pans and keep the seedlings under shelter until they are an inch or two high, when they may be transplanted to the border where they are to winter. This transplanting may produce a slight check which is not undesirable, as rapid growth at this season is apt to make the young plants too soft and succulent to endure the winter. The colours in both these Stocks are purple, scarlet and white, and in the Brompton variety there is also a carmine flower.

STONECROP. See SEDUM.

SUNFLOWER. See HELIANTHUS.

SWEET PEA. See LATHYRUS OdORATUS.

SWEET SULTAN. See CENTAUREA.

SWEET WILLIAM. See Dianthus.

TAGETES. Under this name come the beautiful African and French Marigolds, half-hardy annuals of much value for making a fine display of bloom in late summer. T. erecta, the African variety, produces large bushy plants with flowers of intense orange and yellow in various shades. The flowers may be either double or single, as it seems impossible to reproduce the double form with any certainty. $T$. patula, the French Marigold, has several forms, the larger sort being somewhat coarse in growth, though producing a fine display of bloom, especially in the double and striped kinds; but the dwarf form, growing about 9 inches high, is very useful as a bedding plant and remarkably profuse in flowering. $T$. signata is another variety of the French Marigold, with small flowers and elegantlycut leaves, and its strain called pumila is a dwarf form with either orange-yellow or "golden-ring" flowers. Marigolds love a sunny position, are well able to sustain drought, and will thrive in a poor 


\section{A YEAR'S GARDENING}

soil. Seed should be sown under glass in March and the seedlings planted out in the usual way.

\section{TEASEL. See Dipsacus.}

THALICTRUM. A family of hardy perennials of which some dwarf kinds are very useful for the Rock Garden, such as $T$. anemonoides, only a few inches high and bearing large white flowers in April and May; it needs a moist soil and a shady position. T. adiantifolium is valuable for its beautiful foliage, which resembles the. Maiden-hair Fern and is not only useful for cutting but also as a border edging; while $T$. aquilegifolium, and its variety purpureum, are fine tall plants, 3 or 4 feet high, with graceful fern-like foliage and ball-like flower heads. Both are quite hardy and will grow vigorously in almost any soil.

\section{THRIFT. See ARMERIA.}

THUNBERGIA. A half-hardy annual often used in greenhouses as a dwarf climber, but valuable also as an outdoor climber in summer. It grows some 4 or 5 feet high, and its slender, elegant stems are covered with bloom throughout the summer. There are various strains of colour, from white to many shades of orange and yellow. Seed should be sown in heat in March and the seedlings for outdoor culture planted out in May in rich, light soil.

TIGRIDIA. See FERRARIA.

TOAD-FLAX. See LINARIA.

TOBACCO PLANT. See Nicotiana.

TORCH-FLOWER. See KNIPHOFIA.

TORENIA. A greenhouse annual well suited for hanging baskets, etc., by which means its trailing stems and flowers are seen to the best advantage. There are no better varieties than $T$. Bailloni, with its flowers of beautiful golden yellow, and $T$. Fournieri, with its hooded flowers of pale blue spotted with indigo blue, with which may be included its white variety called White Wings. They are easily raised from seed sown in a warm temperature in March or April in ordinary compost, the seedlings being pricked out singly in due course.

TRILLIUM. A wood-lily of which there are several varieties, that called grandiflorum being the only one of much value for the garden. It grows about 9 inches high, bearing large three258 


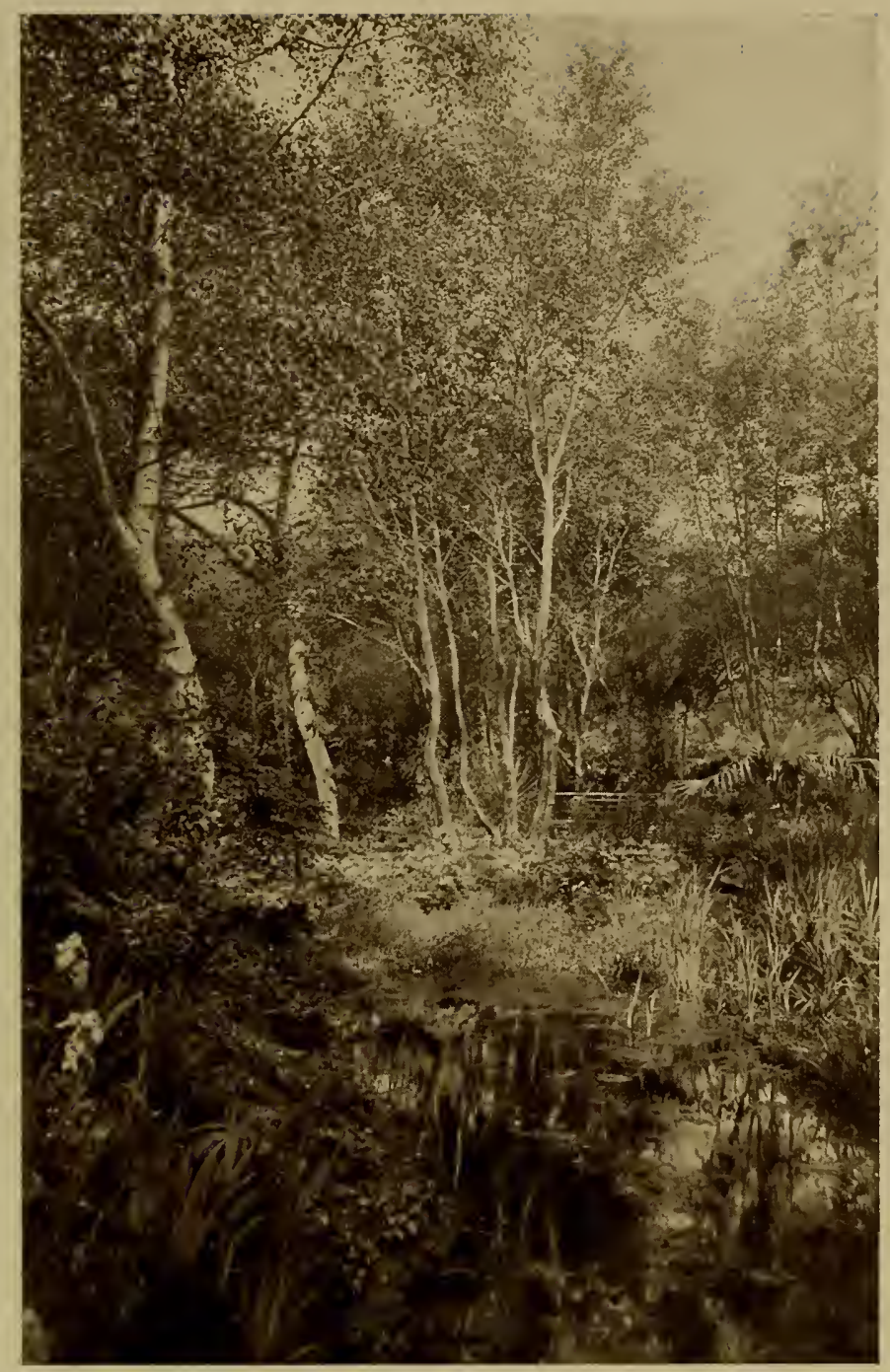

A WOODLAND BOG GARDEN. 



\section{LIST OF FLOWERS}

petalled flowers of pure white, and though a free-growing plant its beautiful foliage of soft green requires a moist and shady position.

TRITELEIA-UNIFLORA. A charming spring-flowering bulb, producing in April a profusion of violet-tinted white flowers which open only in bright sunshiny days and close in dull weather. It will thrive in almost any soil, though preferring a light one, and is well adapted for culture in pots or in the Rock Garden. The bulbs should be planted in autumn about 2 inches deep.

\section{TRITOMA. See KNIPHOFIA.}

TRITONIA. See MoNTBRETIA.

TROLLIUS (Globe-flower). A handsome, early-flowering perennial whose deep roots delight in a rich, moist soil. T.europaus, known as the Mountain Globe-flower, and under several other names, is a fine variety with many forms, of which albus, with flowers of creamy-white, and superbus, with large flowers of pale yellow, are excellent. $T$. asiacticus, the Orange Globe-flower, is particularly hardy, and has also several forms, with flowers of deep orange colour, but less globular in form than those of $T$. europaus.

TROPÆOLUM (Nasturtium). Perhaps the most important and certainly the most generally-cultivated strain is the Tom Thumb or dwarf Nasturtium, a hardy annual which will thrive in any soil -in a poor soil it makes less leaf and blooms more freely-which flowers longer and more continuously, and produces a greater variety of rich colouring, superb when seen in masses, than almost any other annual, while all the attention the plants need throughout the summer is the removal of the faded flowers so as to prevent the formation of seed-pods. Among the climbers T. speciosum, the Flame Nasturtium, with its graceful growth and brilliant vermilion flowers, stands pre-eminent; but though grown freely in the north it is seldom seen in our southern counties. Though quite a hardy perennial, it cannot endure hot sun and dry air, but if planted in a northern aspect, or, better still, in a western aspect, and shaded by trees or bushes, it will thrive and bloom freely-a suitable position, rather than any particular soil, is its chief requirement. The choice of a suitable position is important, too, for the display of its full beauty; none can be better than to allow it to trail down the sides of a rough bank or up the uneven face of a stone wall. T. Lobbianum is another fine climber - an annual-with hairy foliage and flowers in various sliades of scarlet, orange and yellow; while $T$. majus is a similar 


\section{A YEAR'S GARDENING}

variety but lacking the hairiness in foliage. $T$. perigrinum or canariense is the well-known Canary Creeper, a distinct variety and a half-hardy annual, needing a rich soil and sowing under glass. $T$. tuberosum is another distinct variety, tuberous-rooted and usually confined to the greenhouse, as in the open it flowers so late that it is often spoiled by the frost. It is a graceful trailing plant, producing showy flowers of scarlet and yellow, and in the house the tubers may be started at any time from September to March. In the open the tubers should be planted in spring and lifted in autumn for storage in a dry place. It will flourish in the poorest of soils.

\section{TUBEROSE. See Polianthes.}

TULIP. For brilliancy in colour and vivid effect in the garden the Tulip is unsurpassed, especially when a large number of the selfcoloured varieties are massed together; while by a judicious planting of different kinds, beginning with the early-flowering Duc van Thol and ending with the Gesners, a long-continued display may be obtained. Tulips thrive in any good soil, though succeeding best in that which is rich and sandy and well drained. The bulbs should be planted in October or November, about 6 inches apart and 4 or 5 inches deep, and may either be lifted as soon as the stems begin to fade and stored for the summer, or allowed to remain in the ground, unless the soil is cold and wet, for two or three years, after which they should be lifted, or they will be apt to produce small flowers. The early varieties are known collectively as "Dutch," and include many named sorts of much beauty, such as Ophir d'Or, of a beautiful yellow colour and fine globe shape; $L a$ Matelas, pink and white; Couleur de Cardinal, crimson; and Van de $M e r$, purple-all single. Among the double kinds the following are excellent-William III., orange scarlet; Voltaire, crimson; and Rose Blanche, white. The self-coloured Darwin Tulips are an important section of the late-flowering kinds, being handsome plants some 2 to 3 feet high, with massive, weather-resisting bloom and remarkably hardy and vigorous. Among the named sorts may be mentioned Negro, of dark chocolate colour; Harry Veitch, purple and black; Dorothy, rose and white; Flambeau, scarlet; and Zephyr, pinkisl-lilac and white. The Parrot Tulips are remarkable for the quaint shapes and fringed petals of their flowers, spattered with crimson and yellow and veined in various colours. Among the named kinds are Cramoisi, deep crimson with dark markings; Markgraaf, orange and scarlet; and Perfecta, golden yellow with scarlet stripe. As a pot-plant the Tulip is of 260 


\section{LIST OF FLOWERS}

great value, and the early-flowering kind, such as Duc Van Thol in all its varieties, are best adapted for this purpose, as they are of dwarf growth and take kindly to a raised temperature. But Tulips should not be given a high temperature, and plunging is generally the most satisfactory method of forcing. The wild Tulips are a distinct class from the garden varieties, and among them are many kinds well suited for the Rock Garden, such as $T$. sylvestris, the British species, useful also for planting in grass and bearing fragrant flowers of pale yellow edged with red; T. montana, only about 6 inches high, with red or yellow flowers; $T$. nitida, of elegant dwarf growth, with flowers of bright scarlet spotted black; and $T$. alberti, of low-growing, trailing habit, with red flowers splashed with yellow and edged with black. Finally it may be remarked that the enormous range of varieties in the Tulip-it has been cultivated in Europe for more than 350 years-renders it impossible to give more than a cursory description in these notes.

\section{VALERIAN. See Centranthus.}

VALLOTA-PURPUREA. A handsome bulbous plant of the Amaryllis type, with flowers of bright, deep scarlet, sufficiently hardy to be grown out of doors in mild districts and useful as a potplant in a cool greenhouse. The bulbs should be planted in good firm loam and are considered to flower more freely when pot-bound. As soon as growth begins in spring they should be watered freely and receive an occasional dose of liquid manure, and even through the winter they should not be allowed to get dry.

VENIDIUM. $V$. calendulaceum is best treated as a half-hardy annual, sowing in heat in March and planting out in May in friable soil. It is a pretty little plant of spreading habit, making a good display in summer with yellow Marigold-like flowers, and is useful for the Rock Garden or for border edgings.

\section{VENUS'S LOOKING-GLASS. See SPECUlaRIA.}

VERBASCUM (Mullein). A family of stately plants which, though biennial, are practically perennial by self-sowing and are most effective when massed in bold groups, to which their fine stems and dense flower spikes well lend themselves. $V$. phlomoides is one of the best, growing 6 to 9 feet high with splendid spikes of yellow flowers and continuing long in bloom; moreover, it will thrive in almost any soil, though a rich soil will produce a finer growth. $V$. olympicum is another sturdy variety, with flowers of $26 \mathrm{I}$ 


\section{A YEAR'S GARDENING}

rich yellow and bold woolly leaves; while $V$. cupreum, though smaller and more slender, has the peculiarity of copper-coloured flowers. There are many other named kinds, such as Pannosum, Blattaria, Boerhavi, etc.

VERBENA. A half-hardy perennial of which there are many fine varieties brilliant in colour, excellent in habit, and of long continuance in bloom. An objection to the cultivation of the Verbena is its liability to disease, but in this connection it is well to bear in mind that it will not tolerate excessive heat. Indeed, in a favourable season, the Verbena may be raised from seed sown in the open in March on a well-prepared bed, though probably the wiser method is to sow in boxes (in March) put into a frame, the seedlings being pricked out and potted as soon as large enough, and transferred to a cool house until ready for planting out towards the end of May. A well-manured, well-dug, sweet soil is essential for their welfare and will do much to preserve them from disease, to which, indeed, seedraised plants are less liable than those grown from cuttings. Moreover, there is no difficulty in obtaining seed which will come true to colour, such as white, purple, violet, rose, pink and scarlet, the last named being especially good in colour and free in growth.

VERBENA (Sweet). See Aloysia.

VERONICA (Speedwell). A very large family embracing three distinct groups, viz., large shrubby plants, vigorous perennials, and hardy dwarf plants. Most of the dwarf kind are well suited for the Rock Garden, such, for instance, as $V$. prostrata, spreading itself in tufts only a few inches high and covered with a mass of deep-blue flowers, and with varieties in either pink or white. $V$. repens is another beautiful dwarf form, with foliage of bright green and flowers of pale blue; while $V$. spicata is of somewhat bolder growth, with a profusion of dark blue flowers lasting a long time. Among the perennial kinds suitable for the garden border are $V$. longifolia-subsessilis, a handsome plant some 3 feet high with large flovier spikes of rich blue; and $V$. gentianoides, which flowers as early as May and which may be had in different forms.

VINCA (Periwinkle). A hardy trailing perennial, an evergreen vigorous in growth and indifferent as to soil. As a covering for rough banks or for patches of ground made bare by the shade and drip from trees it is very useful. $V$. major is the common Periwinkle, with glossy leaves and mauve-blue flowers; while $V$. minor is of smaller and neater growth and has varieties in the form of a white 262 


\section{LIST OF FLOWERS}

flower and variegated foliage. $V$. acutiloba is a distinct variety blooming in late autumn and producing flowers of delicate mauve.

VIOLET. The Sweet Violet (Viola odorata) thrives in any ordinary garden soil, and in ground that is very richly manured it is apt to produce more leaves than flowers, though in light sandy soil a liberal amount of decayed cow manure and leaf mould is desirable to keep the ground moist, for moisture and moderate shade are essential for successful cultivation of the Violet. For outdoor culture of Violets a sunny aspect, well shaded by deciduous trees, is excellent, the object being to gain shade for the plants during summer and as much sun as possible during the winter and early spring. Violets increase rapidly by means of runners, and a limited number of plants should be allowed thus to propagate themselves for future stock; but with the remainder the runners should be nipped off during the summer, so as to produce strong individual clumps giving abundant flowers on long stems. The plants which have been allowed to make runners should be lifted and divided in September, rejecting hard and wiry runners and retaining only those which are well fibred, the plants thus formed being transplanted into a properly-prepared bed. They should not be permitted to flower in the following spring (any buds showing should be pinched out) and during the summer leaf-growth should be encouraged by a slight mulching of manure. By the following spring, if the runners are duly picked off and the ground kept free from weeds, the plants will scarcely fail to yield a good crop of bloom. To secure the winter flowering of Violets is not difficult. The plants should be removed early in September to a frame placed in a sunny position, giving them plenty of air but guarding them from frost-heat is unnecessary-and thus treated bloom may be obtained in November and onwards throughout the winter by a succession of different varieties. The single kinds are generally considered the best for outdoor cultivation, though the double Marie Louise and the late-flowering Lady Hume Campbell will both be found useful, together with Princess of Wales, Victoria Regina, The Czar and La France. For frame culture the Neapolitan kind are still much used, though there are some better newer sorts, such, for instance, as Marie Lonise, already mentioned, while the old Double Blue is beautiful with its fine full flowers, even if its stems are rather short. Some forms of the Violet are well adapted for the Rock Garden, such as Viola pedata, the Bird's-foot Violet, of compact growth and with large handsome flowers of lilac, purple or blue; and Viola biflora, the two- 


\section{A YEAR'S GARDENING}

flowered yellow Violet, which will find its way between the chinks and crevices of the rocks and clothe them with its bright, star-like flowers.

VIRGINIAN STOCK. A hardy annual which will thrive in any soil and which by its dwarf habit is well adapted for border edgings or as a surface plant among tall flowers. Although it may be sown in spring, as other annuals, it flowers more effectively when autumn sown. There are several forms, and that called Crimson King, with flowers of rich rose-crimson, is one of the best, while in the white-flowered kind alba-nana, of very dwarf growth, is good.

VISCARIA. A hardy annual growing about $I$ foot in height, with flowers of brilliant colour ranging from crimson to pink, blue and white. It is a showy plant well suited for the border, and there is a dwarf variety which is good. The kind named oculata is remarkable for the colour of its flowers-a peculiar metallic-lilac tint.

WALLFLOWER. See Cheiranthus.

WHITLAVIA. The hardy annual $W$. grandiflora is useful in the open border, and seed may be sown either in spring or autumn. It grows about I foot high and bears fine bell-shaped flowers of dark purple.

WHORL FLOWER. See MORINA.

WIND FLOWER. See ANEMONE.

WINTER ACONITE. See ERANTHIS.

WINTER CHERRY. See PHysalis.

WOODRUFF. See AsPerula.

XERANTHEMUM. A free-growing hardy annual, one of the prettiest of the "Everlastings," growing from I2 to I8 inches high and bearing an abundance of white, purple or rosecoloured flowers, either double or single. There is a compact dwarf variety called Tom Thumb.

ZAUSCHNERIA. A perennial of graceful drooping habit with an abundance of bright vermilion or scarlet flowers, and often known by the name of Californian Fuchsia. In a warm soil and a sheltered position it will endure the winter, and even in colder places it needs only a slight protection. If planted so as to allow its drooping form to be exhibited to advantage its bright flowers are very effective 264 


\section{LIST OF FLOWERS}

during late summer and autumn. $Z$. californica (vermilion) and $Z$. splendens (scarlet) are the two best-known varieties.

ZINNIA. A half-hardy annual which has been much improved of late years and now ranks as one of the most effective of our bedding plants, especially the double varieties, which are of dwarfer and more compact growth than the singles, and with stems less liable to get damaged-an important point. The flowers have a wide range of colour, comprising many shades of scarlet, crimson, purple, orange, yellow and white, and their brilliance is little affected by inclement weather. But the plant itself is delicate and needs a sheltered, sunny situation, and should not be bedded out before June nor the seeds sown before the first week in April, even in heat, for the seedlings do not transplant very easily if they are too fully grown. Sowing may be made in the open about the middle of May, and a good display may be obtained by this method. A rich, fine soil and a sunny, sloping border (for drainage is essential) should be prepared and three or four seeds dropped in together at distances of I2 to I5 inches apart, the seedlings being eventually thinned out to one at each spot. 



\section{INDEX}

AConite (Window Boxes), I I 8

Winter (Spring Garden), I I 4

Aconitum (Wild Garden), 112

Alpine Garden, IO7

$$
\begin{gathered}
\text { (artificial elevations), } \\
\text { I08 } \\
\text { (Site, choice and pre- } \\
\text { paration of), I08 } \\
\text { (soil), log }
\end{gathered}
$$

Alpine Flants (essential needs), I07 (natural conditions), 107

Alyssum, yellow (Rock Garden), rog

American Blight, I42 (Spring Garden), II4 " Cowslip (Dodecatheotz), 200

Amoor Pink (Dianthus), 199

Anemone (Spring Garden), II 4

(Wild Garden), I 13

Ants (Destroyers and Pests), 143

Aphis (Destroyers and Pests), I43

Apple (Fruit Trees), 134

Apricot (Fruit Trees), I33

April (Vegetable Garden), I 55

Arabis, White (Rock Garden), 109

", ", (Spring Garden), I 14

" Double (for Tubs), II9

Artichokes (Globe), 156, I64, 166, I70

," (Jerusalem), I 50, I 53, I 56:

Asparagus, $148,153,156,159,162$, I64, 166, 167, 169, I 70

Aster (Window Boxes), I 19

Aubretia, Purple (Rock Garden), I Io

August (Vegetable Garden), I65

Auricula (Spring Garden), I I 4

Azaleas (for $T u b s$ ), II 9

" (Spring Garden), I I4

BACHaLOR'S ButTon (Spring Garden), I I4

Balm, 160

, of Gilead (Dracocephalum), 200
Balsams (Window Boxes), I 8

Bamboo (Bambusa), I 82

Baneberry (Actcea), 174

Beans, I48, I 50, I 53, I 56, I 59, I62, I64, I66, I69, I70

Bee Flower (Arabis), 179

" Orchids (Alpine Garden), Iog

"Plant (Anchusa), 177

Beet, I 53, I 56, I 59, I64, I 70

Begonias (Window Boxes), 1 I 8

Belladonna Lily (Amaryllis), I77

Bermuda Buttercup (Oxalis), 234

Bindweed, Blue (Wall Garden), I I I

Birds (Destroyers and Pests), I40

Black - snake - root (Cimicifuga), I9I

Blight, American (Destroyers and Pests), I42

Bog Pimpernel (Angalis), I77

Bowls for Bulbs, I 19

Bridal Wreath (Francoa), 205

Broccoli, I 51, I 53, I 56, I59, I62, I64, I66, I67, 169, I70, I72

Broom (Spring Garden), II4

Brunswick Green ( for Tubs), II9

,, (for Window Boxes),

I 7

Brussels Sprouts, I53, I 56, I 59, I66, I67, I7:

Bugbane (Cimicifuga), I9I

Bulbs (for Window Boxes), I I8

", in Bowls, I I9

", ,, (method of growing), II 9

,, (storage), I 20

", ," (watering), 20

", (Spring Garden), II4

Burning Bush (Fraxinella), 205

Bush Fruit, 136

Buttercup (Spring Garden), I I 4 


\section{INDEX}

CABBAGE, I48, I $51,154,156,159,162$, $164,166,167,169,17$ I

Calceolarias (Windozo Boxes), I 18

Californian Bush Poppy (Romneyacoulteri), 246

Candytuft (Spring Garden), I I4

Cape Figwort (Phygelizis), 239

, Gooseberry (Physalis), 240

," Jessamine (Gardenia), 207

," Marguerite (Gerbera), 208

Capsicums, I 59, I62

Cardoons, 154, 160, 164, 166, 167, 169, I7I

Carnations (Window Boxes), I I8

Carrots, I48, I5I, I56, I60, I62, I64, I66, 167, I69, I7 I

Cats (Destroyers and Pests), I4I

Cauliffowers, I48, I 5 I, I 54, I 57, I60, $162,164,166,168,169$, I7 I

Celery, I 54, 157, I60, I62, I64, I66, I68, I69, I7 I, I72

Cheddar-pink (Wall Garden), I I I

Cherry (Fruit Trees), I33

Chervil, I57, I60

Chicory, I 57, I62, I 72

Chinese Bellflower (Platycodon), 240

,L Lantern (Physalis), 240

"Primrose (Primula-Sinensis), 243

Chrysanthemums (Window Boxes), I 19

Clean Cutting (Fruit Trees), I35

Columbine (Spring Garden), I I4

Coral Tree (Erythrina), 203

Cosmos (Cosmea), 195

Cowslip (Spring Garden), I I4

Cranesbill (Geranium), 208

Creeping Forget-me-not (Omphalodes), 234

, Jenny (for $T u b s)$, I 19

Cress, I49, I60, I68

Cretan Mullein (Celsia), I 88

Crocuses (for Bowls), I 19

, (Spring Garden), II 4

", (Wild Garden), I I3

", (Window Boxes), I I8

Crown Imperial (Fritillaria), 205

Cucumbers, I49, I 54, I57, I60, I62, 166, I72

Cups and Saucers (Cobaa), I93

Currant, Black (Bush Fruit), I38

, Flowering (Spring Garden), I 4
Currant, Red and White (Bush Fruit), 138

Cuttings (Bush Fruit), 136

Cypripedium (Alpine Garden), 109

DADDY-LONG-LEGS (Destroyers and Pests), 143

Daffodils (for Bowls), I I9

, (Spring Garden), I I4

", (Wild Garden), I I3

" (Window Boxes), II 8

Day Lily (Hemerocallis), 2 I 3

December (Vegetable Garden), I7I

Deutzia (Spring Garden), $11_{4}$

Devil-in-a-Bush (Nigelia), 232

Dragon's Head (Dracocephalum), 200

Earwigs (Destroyers and Pests), I44

Edelweiss (Leontopodium), 220

Endive, I 57, 160, 162, 164, 166, 168, I69, I7 I, I72

Eunonymous (Window Boxes), I 8

Everlasting, Winged (Aimmobizım), I77

Everlastings (Acrolinium), I74

$\begin{array}{ll}, & \text { (Helichrysum), 2 I2 } \\ , & \text { (Rhodanthe), 245 } \\ , & \text { (Statice), 256 } \\ , & \text { (Xeranthemum), 264 }\end{array}$

FAIRY FORGET-ME-NOT (Eritrichium), 202

, Wallfower (Erysimum), 203

February (Vegetable Garden), 150

Ferns (for $T u b s$ ), I I9

Flag (Iris), 2 I7

Flame-flower (Kniphofia), 218

Flax (Linum), 223

Forget-me-nots (Spring Garden), I I 4

$\begin{array}{ll}., & \text { (Wild Garden), II } 3 \\ \text { (Window Boxes), I } 8\end{array}$

French Honeysuckle (Hedysarım), 2 I I

Fruit Destroyers and Garden Pests, I40

Fruit Trees (characteristics), I33

, (damage of deep digging), I 29

", (differences), I3I

, ("oblique cordon"), 129

, (planting), I29

", (pruning), 130-I3I

" (renovation), I3 I

," (soil), I29

, (Standards), I32 


\section{INDEX}

Fruit Trees (thinning), $I_{3}$ " (training), I 30 (wall trained), I 28

Fuchsias (for Tubs), I I0 (Window Boxes), I Is

Furze (Spring Garden), II4

GARLIC, I 5 I, I64

Genista (Spring Garden), II5

Gentian (Gentiana), 207

Geraniums (Window Boxes), II 8

Glacier Pink (Dianthus), 199

Globe-flower (Trollizus), 259

Glory Pea (Clianthus), I93

Goat's-beard (Spirca), 255

Goat's Rue (Galega), 207

Gold Dust (Alyssum), I 76

Golden Drop (Onosma), 234 , Knapweed (Centurea), I89

Gooseberry (Bush Fruit), I37

Green-fly (Destroyers and Pests), I43

Greengage (Fruit Trees), I33

Ground Ivy (for Tubs), I I9

HAREBELL (Campanula), I 87

Harpalium (Helianthus), 212

Hawthorn (Spring Garden), I I4

Heart's-ease (Pansy), 235

Heliotrope (Window Boxes), I 8

Herbs, I 54, I60

Heron's-bill (Erodium), 203

Horned Poppy (Glaucium), 209

Horseradish, I 54, I60

Hot Water as Insecticide (Destroyers and Pests), 146

Hyacinths (for Bowls), I 9

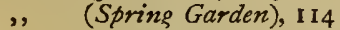

", (Window Boxes), I I8

\section{INDIAN CORN, I6O}

, Hemp (Cannabis), I87

Iris (Spring Garden), I 14

Ivy Geraniums (Window Boxes), I 8

January (Vegetable Garden), 147

July (Vegetable Garden), 163

June (Vegetable Garden), 161

KINGcups (Spring Garden), II4

Knotweed (Polygonum), 242
LABURNUM (Spring Garden), II 4

Lawns, I2I

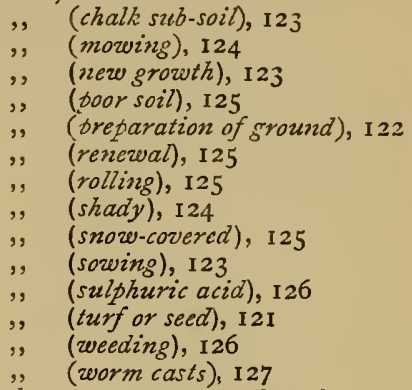

Leeks, I 5 I, I 54, I 57, I62, I64, I 7 I

Lettuce, I49, I 5 I, I 54 , I 57, I60, I63, I64, I66, I68, I69, I 7 I, I 72

Lilac (Spring Garden), I I4

Lily of the Nile (Richardia), 245

Linaria (Wall Garden), I I I

Lobelia (Windore Boxes), I 8

Loosestrife (Wild Garden), I I3

Love-in-a-Mist (Nigella), $2 \mathbf{3}^{2}$

Lupin Tree (Wild Garden), I I 3

MAGNOLIA (Spring Garden), I I4

Maiden Pink (Dianthus), I99

March (Vegetable Garden), I 52

Marguerites (Window Boxes), I I 8

Marjoram, 157,160

Mask-flower (Alonsoa), I75

May (Vegetable Garden), I58

Meadow Saffron (Colchicum), 193

$$
\text { ,, (Bulbocodium), I\$4 }
$$

Melons, I 54, I57, I60, I63

Mexican Aster (Cosmea), I95

Michaelmas Daisy (Wild Garden), II 2

Mignonette (Window Boxes), I I 8

Milkweed (Wild Garden), I 2

Milkworts (Alpine Garden), Io9

Mint, I 57, I6o

Mocassin Flower (Cypripedium), I96

Monkey Flower (Mimulus), 228

Monkshood (Wild Garden), I I2

Morning Glory (Convolvulus), I95

Mullein (Wild Garden), II 3

Mushrooms, I57, I63, I64

Mustard, I49, I 68

Myrtles (for Tubs), I I9 


\section{INDEX}

NARCISSUS (for Bozels), II 9

$\because \quad$ (Spring Garden): 114

" (Wild Garden), II 3

, (Window Boxes), i 18

Nasturtiums (Vegetable Garden), I60

$$
\text { ,, (Window Boxes), I } 18
$$

Nature's Teaching (Wild Garden), I 12

Nectarine (Fruit Trees), I33

Nemesia (Windore Boxes), I 8

November (Vegetable Garden), I 70

October (Vegetable Garden), 168

Onions, I5I, I54, I57, I6I, I63, I64, 166, 168, 169, I72

Ornamental Pots, I 19

, Tubs, I I9

Oxlip (Spring Garden), I I 4

"Primrose (Polyanthas), 24I

Paint (for $T u b s$ ), II9

,, (for Window Boxes), II7

Pansies (Spring Garden), I I4

Paris Daisy (Chrysanthemum), I90

Parsley, I 5 I, I58, 160, I65

Parsnips, I 5I, 155, I 58, I6 I, I69, I72

Pasque-flower (Anemone), I78

Passion Flower (Passiflora), 237

Peach (Fruit Trees), 128 et seq.

Pear (Fnit Trees), 134

Peas, 149, I51, 155, 158, 161, I63, 165, I66, I69, I7 I, I72

Peruvian Lily (Alstrameria), 175

Pests of the Garden, I 40

Petunias (Window Boxes), I I 8

Pheasant's Eye (Adonis), I74

Pimpernel (Angalis), 177

Pinks (Window Boxes), I 18

Plum (Fruit Trees), I34

Plume Poppy (Bocconia), 183

Polyanthus (Spring Garden), I I 4

Polypodiums (Wall Garden), I I I

Pompons (Chrysanthemum), 190

Poppy Mallow (Callirhos'), I 86

Potatoes, 149, 1 $51,155,158,161,163$, 165, I68, I69, I7 I

Pots (ornamental), II9

Primrose (Rock Garden), I Io

, (Spring Garden), I I 4

" (Wild Garden), I 13

Privet (Window Boxes), I 18

Pyrus Japonica (Spring Garden), I 15
RADISHES, I 49, I 52, I 55, I 58, I 6 I, $165,168,169$

Ragged Robin (Wild Garden), I $\mathrm{I}_{3}$

Rampion (Phyteuma), 240

Ranunculus (Spring Garden), I 14

Raspberry (Bush Fruit), 139

Rhododendrons (Spring Garden), II 4

Rhubarb, I 52, I 55, I6 I

Rock Camomile (Anthemis), I78 ,, Cress (Spring Garden), I 14

Rockfoil (Rock Garden), I09

Rock Garden, 109

," , (General Principle), I ro

", ", (Suburban), 110

" ", (Suitable Plants), 109

,Madwort (Alyssum), I76

, Pink (Dianthus), I99

, Rose (Cistus), I91

Rockspray (Cotoneaster), 195

Root Pruning (Fruit Trees), 135

SAFFRON (Bulbocodium), 184

Sage, 157

St Bernard's Lily (Anthericum), 178

St Bruno's Lily (Anthericum), 178

Salads, I68

Salsify, I 58

Salvias (Window Boxes), I 8

Sand Verbena (Abronia), i 73

Sandwort (Arenaria), 179

Savoys, I 52, I6 I

Saw-cuts (Fruit Trees), I 35

Saxifrage ( for $T u b s$ ), I 19

, (Rock Garden), 109

Scarlet Daisy (Gerbera), 208

Scillas (for Bowls), I I9 , (Spring Garden), I I4

Sea-kale, I49, I52, I55, I61, I63, 165, 168, I70, I7 I, I72

Sea Lavender (Statice), 255

Sedum (Rock Garden), Io9

September (Vegetable Garden), 167

Shallots, I 52, I64

Shimmia Japonica (Window Boxes), I 18

Shrubs, Flowering (Spring Garden), I I 4 ", (Window Boxes), 118

Slugs and Snails (Destroyers and Pests), I 44

Snake's-head (Fritillaria), 205

Sneezewort (Achillea), I 73

Snowdrops (for Bowls), i I 9 


\section{INDEX}

Snowdrops (Spring Garden), II 4 ," (Wild Garden), II 3 " (Window Boxes), I I8

Snow Glory (Chionodoxa), I90

Solanum (Window Boxes), I 8

Speedwell (Rock Garden), I Io

Spigelia (Alpine Garden), Iog

Spinach, I50, 152, 155, I58, I6I, I65, I66, I68, I70, I 7 I

Spleenwort (Asplenium), 180

Spring Garden, I 13 ,, ", (Suitable Plants), I I4

", Meadow Saffron (Bulbocodium), I 84

Star Primula (Primula-Sinensis), 244

Starwort (Michaelmas Daisy), 228

Stocks (Window Boxes), I 8

Stonecrop (for Tubs), I 19 ", (Rock Garden), 109

Strawberries, I 50, 1 52, I 55, I 58, 167

Sturt's Pea (Clianthus), I 93

Sunflower, Perennial (Wild Garden), I 2

Sun Rose (Helianthemum), 2 I 2

Swan River Daisy (Brachycome), I 84

Sweet Alyssum (Alyssum), 176

, Flag (Acorus), I74

,Maudlin (Achillea), 173

", Verbena (Aloysia), 175

Syringa (Spring Garden), I 14

Tassel Flower (Cacalia), I $\$ 5$

Thyme, I57, 160 " Wild (Rock Garden), ro9

Toad-flax (Wall Garden), I I I

Tomatoes, $150,161,163,165,167$, I68, i70

Transvaal Daisy (Gerbera), 208

Traveller's Joy (Clematis), 192

Tree Lupine (Lupinus), 225

Trillium (Alpine Garden), Io9

Tropeolums (Window Boxes), i I

Trumpet Flower (Bignonia), $\mathbf{I} \delta_{3}$

" ," (Incarvillea), 2 I6

Tubs (Omamental), II9

,. (Paint for), I I9

Tulips (for Bowls), 119

", (Spring Garden), I I4

", (Window Boxes), I 18

Turnips, 152, 155, 158, 161, I63, I65, I67, I68, I 7 I
VALERIAN (Wall Garden), I I I

(Wild Garden), I 13

Vegetable Garden (January), I47

\begin{tabular}{|c|c|c|}
\hline , & ," & (February), I 50 \\
\hline , & , & $($ March $)$, I 52 \\
\hline$\therefore$ & $"$ & (April), I 55 \\
\hline , & ", & $(M a y)$, I 58 \\
\hline , & , & (Jume), I6I \\
\hline , & , & 163 \\
\hline , & , & (August), 165 \\
\hline , & , & (September), I67 \\
\hline " & , & (October), I 68 \\
\hline$s$, & , & (November), I70 \\
\hline ", & ", & (December), I7I \\
\hline , & $\underset{I}{\text { Marr }}$ & S, I55, I58, I6I, \\
\hline
\end{tabular}

Verbascum (Wild Garden), I 13

Veronica (Rock Garden), I 10

Viola (Pansy), 235

Violas, Alpine (Wall Garden), I I I

," (Spring Garden), I I4

Violet (kiock Garden), I Io

,, (Spring Garden), I 14

", Cress (Jonopsidium), 2 I 7

Viper's Bugloss (Echizem), 201

Virginian Cowslip (Mertensia), 227

Virgin's Bower (Clematis), 192

Wall Erinus (Wall Garden), i I I

Wallflowers (Spring Garden), I I 4

," (Wall Garden), I I I

", (Window Boxes), II 8

Wall Garden, I 10

$\begin{array}{ll}, & \text { (Practical Benefit), I I I } \\ , & \text { (Suitable Plants), I I I } \\ , & \text { (Suitable Walls), I I I }\end{array}$

Wand Plant (Galax), 207

Wasps (Destroyers and Pests), I44

Welsh Poppy (Meconopsis), 227

Western Wallflower (Erysimum), 203

White Rock Cress (Arabis), I79

Wild Garden, I I 2

$\begin{array}{ll}, & \text { (Advantages), I I } 3 \\ , & \text { (Nature's Lesson), I I } 2 \\ , & \text { (Province of), I I } 2 \\ , & \text { (Suitable Plants), I I } 2\end{array}$

Window Boxes (Daily Care), I 7

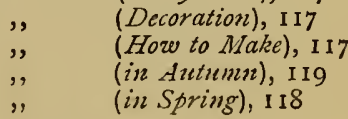




\section{INDEX}

Window Boxes (in Summer), i 18

(in Winter), II 8

(Paint for), II 7

(Soil for), I I 7

(Zinc Linings), II 8

Winged Everlasting (Ammobium), I77

Winter Aconite (Spring Garden), I I4

,, Cherry (Fhysalis), 239

, " , (Window Boxes), I 18
Winter Greens, 165

Wireworm (Destroyers and Pests), 145

Wood Anemone (Anemone), i 78

Woodbine (Lonicera), 225

Wood Fern (Aspidium), 180

Wood-lice (Destroyers and Pests), 146

Wormwood (Artemisia), 180

Zonal Pelargonium, 238 





\section{LIBRARY OF CONGRESS}

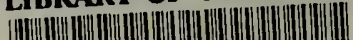

I.|. 口0009268819 